DENISE ADORNO LOPES

CARACTERIZAÇÃO MICROESTRUTURAL DE LIGAS DO SISTEMA U-Nb-Zr, NO CANTO RICO EM URÂNIO 
DENISE ADORNO LOPES

\section{CARACTERIZAÇÃO MICROESTRUTURAL DE LIGAS DO SISTEMA U-Nb-Zr, NO CANTO RICO EM URÂNIO}

Dissertação apresentada à

Escola Politécnica da Universidade de São Paulo para obtenção do título de Mestre em Engenharia

São Paulo 


\title{
DENISE ADORNO LOPES
}

\section{CARACTERIZAÇÃO MICROESTRUTURAL DE LIGAS DO SISTEMA U-Nb-Zr, NO CANTO RICO EM URÂNIO}

\author{
Dissertação apresentada à \\ Escola Politécnica da Universidade de \\ São Paulo para obtenção do título de \\ Mestre em Engenharia
}

Área de Concentração:

Engenharia Metalúrgica e de Materiais

Orientador: Prof. Dr.

Angelo Fernando Padilha

São Paulo 
Este exemplar foi revisado e alterado em relação à versão original, sob responsabilidade única do autor e com a anuência de seu orientador.

São Paulo, de janeiro de 2011.

Assinatura do autor

Assinatura do orientador

FICHA CATALOGRÁFICA

Lopes, Denise Adorno

Caracterização microestrutural de ligas do sistema U-Nb-Zr, no canto rico em urânio / D.A. Lopes. -- ed.rev. -- São Paulo, 2011.

p.

Dissertação (Mestrado) - Escola Politécnica da Universidade de São Paulo. Departamento de Engenharia Metalúrgica e de Materiais.

1. Engenharia metalúrgica 2. Engenharia nuclear 3. Materiais nucleares 4. Ligas metálicas 5. Urânio I. Universidade de São Paulo. Escola Politécnica. Departamento de Engenharia Metalúrgica e de Materiais II. t. 


\section{AGRADECIMENTOS}

Agradeço:

Ao Prof. Dr. Angelo Fernando Padilha, por me dar a oportunidade de contar com sua valiosa orientação, que despertou em mim grande interesse pela ciência dos materiais. Só tenho a agradecer por todo o apoio, ajuda e demonstração de confiança dados mesmos nos momentos mais difíceis.

Ao CTMSP (Centro Tecnológico da Marinha em São Paulo) pela oportunidade de realizar este trabalho.

Aos colegas de pesquisa (e amigos) do LABMAT (Laboratório de Materiais Nucleares), por terem me ajudado muito na parte experimental. Por todas as sugestões dadas a este trabalho e por toda paciência que demonstraram; sempre disponíveis para ensinar e responder minhas dúvidas.

À Dra. Maysa Terada, pela grande ajuda e paciência durante o processo de correção da redação deste trabalho, pela participação no meu exame de qualificação e por todas as sugestões dadas.

Ao Prof. Dr. Cláudio Geraldo Schön, pela participação no meu exame de qualificação e pelas sugestões dadas.

E a todos que direta ou indiretamente estiveram presentes nesse período do Mestrado. 


\section{RESUMO}

Foi efetuada a caracterização microestrutural de 10 ligas dos sistemas urânio-nióbio (U-10Nb; U-15Nb; U-20Nb), urânio-zircônio (U10Zr; U-15Zr, U-20Zr) e urânio-nióbio-zircônio (U-2,5Nb-2,5Zr; U-5Nb$5 Z r ; U-7,5 \mathrm{Nb}-7,5 \mathrm{Zr}$; U-10Nb-10Zr), no canto rico em urânio. As ligas estudadas são candidatas ao uso como elementos combustíveis tipo placa, utilizados tanto em reatores nucleares de pesquisa como em reatores nucleares de potência. As ligas foram preparadas por fusão a plasma em forno com eletrodo não consumível de tungstênio. Após várias fusões, as amostras sofreram tratamento térmico de homogeneização a 1000 C por 96 horas, com resfriamento em água. Em seguida, as amostras homogeneizadas foram recozidas a 700 e a $500 \stackrel{\circ}{ }$, com resfriamento em água. No total, foram estudadas 40 amostras de 10 ligas diferentes em 4 condições diferentes: bruto de fundição, homogeneizadas a $1000^{\circ} \mathrm{C}$ e envelhecidas a 700 e a $500^{\circ} \mathrm{C}$. Foram utilizadas várias técnicas complementares de caracterização microestrutural: microscopia óptica, microscopia eletrônica de varredura com auxilio de microanálise por dispersão de energia de raios $X$, difração de raios $X$ com auxílio do método de análise de Rietveld, e medidas de microdureza Vickers.

Os resultados mostraram que os elementos de liga $\mathrm{Nb}$ e $\mathrm{Zr}$ estabilizam a fase alotrópica $\gamma$ do urânio e atrasam a transformação de $\gamma$ para $\beta$. Neste aspecto, o Nb é mais eficaz que o Zr. Além disto, podem ocorrer durante o resfriamento transformações martensíticas $\quad \gamma \rightarrow \alpha$, $\beta \rightarrow \alpha^{\prime}$ e possivelmente $\gamma \rightarrow \gamma^{\circ}$. A temperatura de início de transformação martensítica $\left(M_{s}\right)$ formadora da fase $\alpha^{\prime}$ diminui com a adição dos elementos de liga estudados. $M_{s}$ intercepta a temperatura ambiente entre 
as composições $U-5 \mathrm{Nb}-5 \mathrm{Zr}$ e $U-7,5 \mathrm{Nb}-7,5 \mathrm{Zr}$. Foi verificado também que a reação peritetóide $\alpha+\gamma_{2} \rightarrow \delta$ do sistema $U$-Zr possui uma cinética lenta $e$ não pode ser detectada nos tempos e temperaturas estudados.

Em algumas ligas foi possível reter na temperatura ambiente ligas com microestrutura martensítica dúcteis, que permitem a conformação mecânica a frio, o que é de significativo interesse tecnológico. 


\section{ABSTRACT}

The microstructures of 10 uranium-rich alloys of the uraniumniobium (U-10Nb; U-15Nb; U-20Nb), uranium-zirconium (U-10Zr; $U$ $15 \mathrm{Zr} ; \mathrm{U}-20 \mathrm{Zr}$ ) and uranium-niobium-zirconium (U-2.5Nb-2.5Zr; U-5Nb-5Zr; U-7.5Nb-7.5Zr; U-10Nb-10Zr)systems have been characterized.

The studied alloys are considered for plate-type nuclear fuels fabrication used both in nuclear research reactors and in nuclear power reactors. The alloys were melted by arc plasma methods employing nonconsumable tungsten cathode. After several fusions, samples were subjected to homogenizing heat treatment at $1000^{\circ} \mathrm{C}$ for 96 hours and then quenched in water. Then the samples were annealed at 700 and 500 ${ }^{\circ} C$. The microstructural characterization encompassed 40 samples of 10 different alloys composition in four different conditions: as cast, homogenized at $1000^{\circ} \mathrm{C}$ and aged at 700 and $500{ }^{\circ} \mathrm{C}$.

Microstructural characterization was performed using several complementary techniques: optical microscopy; scanning electron microscopy with energy-dispersive $X$-ray analysis; $X$-ray diffraction with the aid of the Rietveld analysis method; and Vickers microhardness measurements.

The results showed that the $\mathrm{Nb}$ and $\mathrm{Zr}$ additions have stabilized the uranium $\gamma$-phase and delayed the $\gamma$ and $\beta$ phase transformation. In this regard, $\mathrm{Nb}$ was more effective than $\mathrm{Zr}$. However, during cooling martensitic transformations $\gamma \rightarrow \alpha^{\prime}, \beta \rightarrow \alpha^{\prime}$ and possibly $\gamma \rightarrow \gamma^{\circ}$ may occur.

The martensitic transformation start temperature $\left(M_{s}\right)$, which

produces the phase $\alpha^{\prime}$, decreased with $\mathrm{Nb}$ and $\mathrm{Zr}$ additions. $M_{S}$ intersected room temperature between the compositions $U-5 \mathrm{Nb}-5 \mathrm{Zr}$ e $U$ $7,5 \mathrm{Nb}-7,5 \mathrm{Zr}$. It was found that the peritectoid reaction $\alpha+\gamma_{2} \rightarrow \delta$ of the 
$U$-Zr system showed a very slow kinetics and could not be detected in the range of the studied times and temperatures.

An important result of the technological point of view is that in some alloys it was possible to retain at room temperature a ductile martensitic microstructure, allowing cold forming. 


\section{SUMÁRIO}

1 INTRODUÇÃ O ................................................................... 14

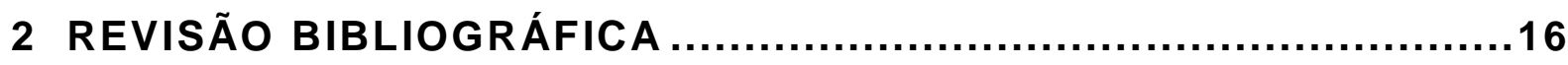

2.1 Características do urânio metálico .................................17

2.2 Diagramas binários limites .......................................21

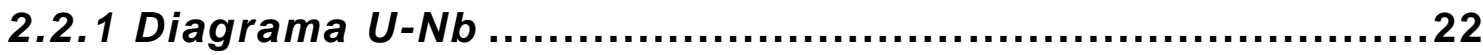

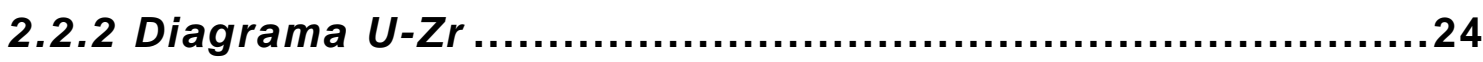

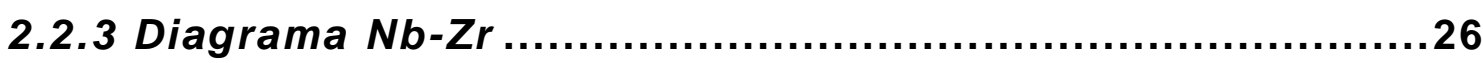

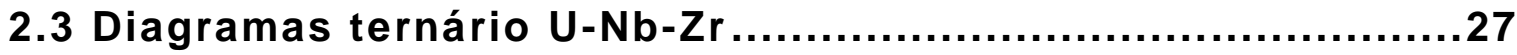

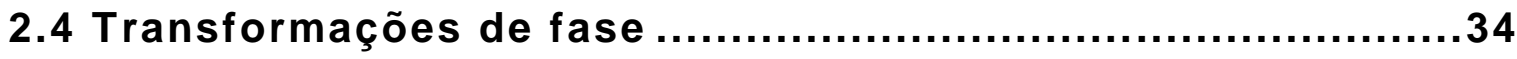

2.4.1 Transformações por nucleação e crescimento .................34

2.4.2 Transformação martensítica .......................................38

2.5 Propriedades das Ligas U-Nb-Zr ................................. 41

2.5.1 Propriedades térmicas .......................................... 42

2.5.2 Resistência à corrosão ........................................43

2.5.3 Dureza................................................................. 44

2.5.4 Influência do carbono em ligas $U$-Nb-Zr......................46

2.6 Aplicações nucleares das ligas U-Nb-Zr ..........................49

3 MATERIAIS E MÉTODOS ................................................52

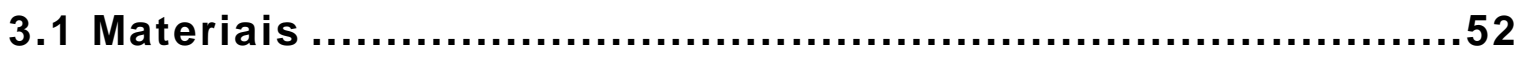

3.2 Preparação das ligas ................................................. 53

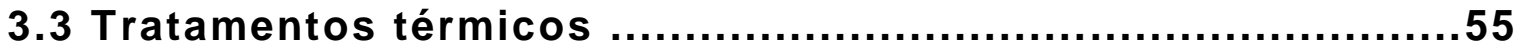

3.4 Técnicas de caracterização microestrutural ...................56

3.4.1 Preparação metalográfica ......................................57

3.4.2 Microscopia óptica (MO) .......................................58

3.4.3 Microscopia eletrônica de varredura (MEV) ................58

3.4.4 Análise por dispersão de energia (EDS) ......................59

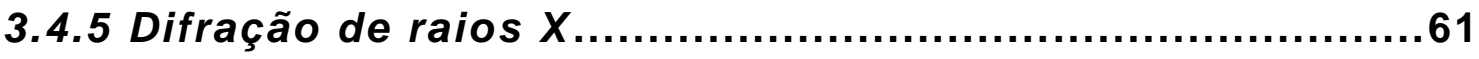

3.4.6 O Método Rietveld .................................................62

3.4.7 Medidas de dureza ...............................................64 


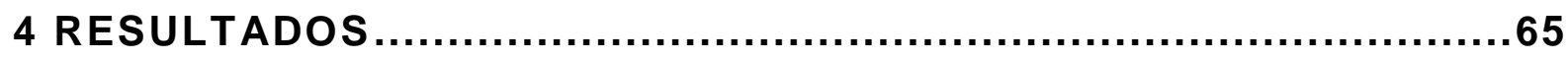

4.1 Caracterização microestrutural das ligas ........................65

4.1.1 Estado bruto de fundição ......................................65

4.1.1.1 Microscopia óptica ............................................65

4.1.1.2 Microscopia eletrônica de varredura.......................69

4.1.1.3 Análise por dispersão de energia ........................73

4.1.2 Estado solubilizado.............................................78

4.1.2.1 Microscopia eletrônica de varredura........................78

4.1.2.2 Análise por dispersão de energia ..........................81

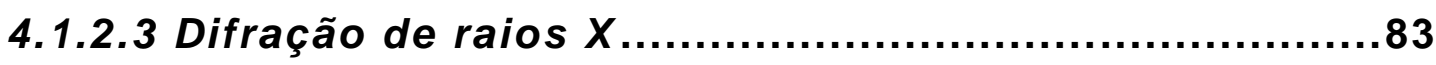

4.1.2.3 Medidas de dureza..............................................86

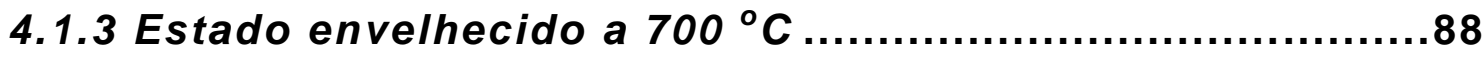

4.1.3.1 Microscopia óptica ..............................................88

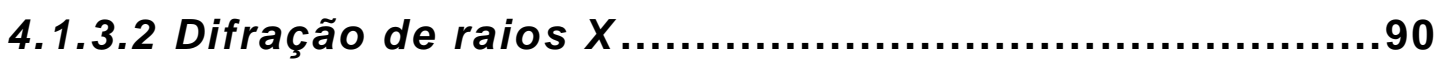

4.1.3.3 Medidas de dureza...........................................97

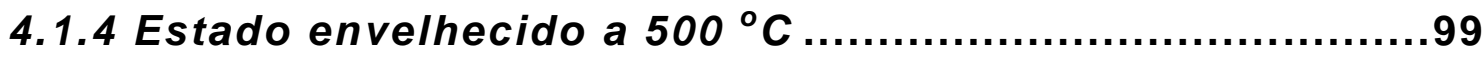

4.1.4.1 Microscopia óptica ..............................................99

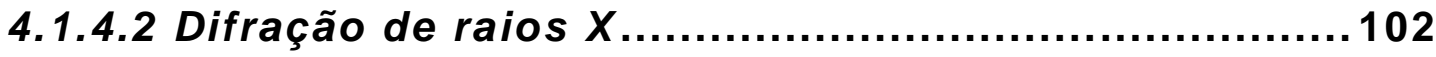

4.1.4.3 Medidas de dureza........................................... 108

4.2 Caracterização química das ligas .................................110

5 DISCUSSÃO DOS RESULTADOS .......................................113

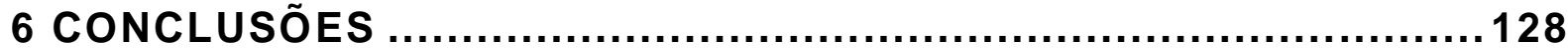

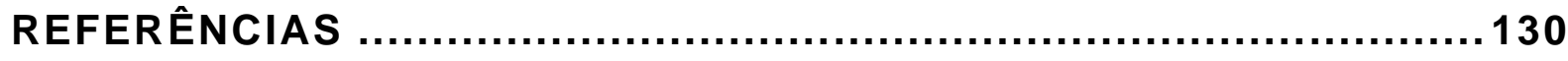




\section{LISTAS DE FIGURAS}

Figura 1: Coeficiente de dilatação térmica nas três direções da fase ortorrômbica (fase a) do urânio. 18

Figura 2: Esquema ilustrativo do reticulado cristalino da fase ortorrômbica $\alpha$ 19

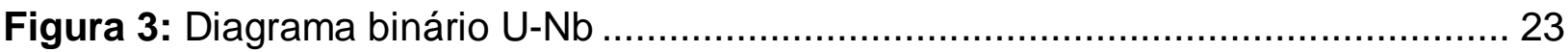

Figura 4: Diagrama binário U-Zr ................................................................ 25

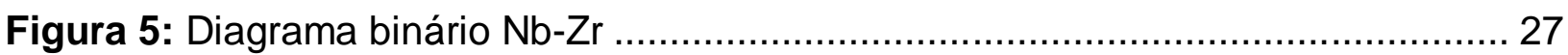

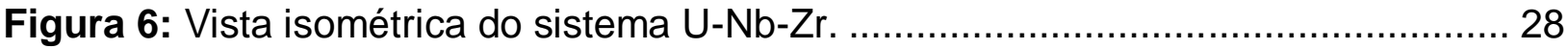

Figura 7: Corte isotérmico a $700{ }^{\circ} \mathrm{C}$ do diagrama U-Nb-Zr (\% massa) ....................... 29

Figura 8: Corte isotérmico a $630{ }^{\circ} \mathrm{C}$ do diagrama U-Nb-Zr (\% atômica) ...................... 30

Figura 9: Corte isotérmico a $500{ }^{\circ} \mathrm{C}$ do diagrama U-Nb-Zr (\% atômica) ...................... 30

Figura 10: Parâmetro de rede fase gama no sistema ternário U-Nb-Zr (\% massa) ..... 33

Figura 11: Esquema ilustrativo da parcelas da energia associada à formação de um

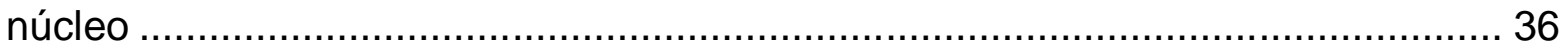

Figura 12: Regiões onde prevalecem transformações martensíticas para o sistema

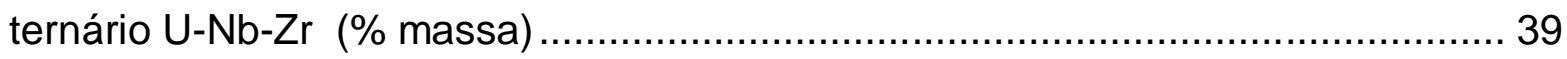

Figura 13: Esquema de transformação martensítica para tratamentos térmicos sobre

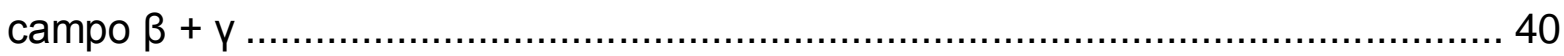

Figura 14: Dureza versus temperatura de transformação da liga U-1,5Nb-5Zr. .......... 45

Figura 15: Diagrama de fases binário U-C............................................................. 46

Figura 16: Energia livre de formação dos carbonetos para os elementos $U, \mathrm{Nb}$ e $\mathrm{Zr}$.... .

Figura 17: Desenho esquemático da montagem de um elemento combustível tipo placa; monolítico e dispersivo

Figura 18: Esquema de montagem do equipamento para realização dos tratamentos térmicos. 55

Figura 19: Esquema ilustrativo dos ciclos térmicos utilizados no presente trabalho.... 56

Figura 20: Micrografias óticas das ligas em estado bruto de fundição, fusão a plasma. Ataque imersão solução glicerina, $\mathrm{HNO}_{3}$ e $\mathrm{HF}, 5-15 \mathrm{~s}$. 66 
Figura 21: Micrografias eletrônicas das ligas em estado bruto de fundição. Regiões numeradas áreas de análise por EDS. MEV com elétrons retroespalhados. Amostras analisadas após polimento mecânico.

Figura 22: Análise por dispersão de energia (EDS) das ligas no estado bruto de fundição, regiões de análise referente às micrografias apresentadas em seção precedente na Figura 21

Figura 23: Micrografias eletrônicas das ligas em estado solubilizado a $1000 \stackrel{\circ}{\circ}$ por 96 horas. Regiões numeradas áreas de análise por EDS. MEV com elétrons retroespalhados. Amostras analisadas após polimento mecânico.

Figura 24: Análise por dispersão de energia (EDS) das ligas no solubilizado, regiões de análise referente às micrografias apresentadas em seção precedente na Figura 23.

Figura 25: Difratogramas de raios $X$ das ligas que apresentaram formação da fase matensítica $\alpha$ ' após tratamento térmico a $1000 \stackrel{\circ}{\circ}$ por 96 horas seguidas de têmpera em água.

Figura 26: Micrografias óticas das ligas após tratamento isotérmico a $700{ }^{\circ} \mathrm{C}$ por 20 horas seguidas de têmpera em água, MO. 88

Figura 27: Difratogramas de raios $X$ das ligas após tratamento isotérmico a $700 \stackrel{\circ}{\mathrm{C}}$ por 20 horas seguidas de têmpera em água. 91

Figura 28: Micrografias ópticas das ligas no após tratamento isotérmico a $500 \stackrel{\circ}{\circ} \mathrm{C}$ por 20 horas seguidas de têmpera em água, MO. 99

Figura 29: Difratogramas de raios $X$ das ligas após tratamento isotérmico a $500 \stackrel{\circ}{\mathrm{C}}$ por 20 horas seguidas de têmpera em água. 102

Figura 30: Efeitos da concentração de elementos de liga na morfologia, estrutura e propriedades para algumas ligas temperadas 118

Figura 31: Variação dos parâmetros de rede da fase martensítica $\alpha^{\prime}$ com a taxa de resfriamento da liga $\mathrm{U}-10 \mathrm{Zr}$. 119

Figura 32: Cálculo volume da célula unitária fase $\alpha^{\prime}$ para os patamares $1000{ }^{\circ} \mathrm{C}$ e $700 \stackrel{\circ}{\circ}$. 120 
Figura 33: Posicionamento das ligas com base na análise química sobre um canto do triângulo de Gibbs, juntamente com resumo esquemático das fases encontradas ara os respectivos cortes isotérmicos $700^{\circ} \mathrm{C}$ e $500^{\circ} \mathrm{C}$........................................ 124

Figura 34: Gráfico contorno de superfície dos valores de dureza para as ligas ternárias. 125

Figura 35: Gráfico contorno de superfície dos valores de dureza para as ligas binárias do sistema U-Nb. 125

Figura 36: Gráfico contorno de superfície dos valores de dureza para as ligas binárias do sistema U-Zr. 126 


\section{LISTA DE TABELAS}

Tabela 1: Fases cristalinas do urânio metálico........................................................ 17

Tabela 2: Propriedades do urânio metálico............................................................ 20

Tabela 3: Condutividade térmica e expansão térmica da liga U-5Zr-5Nb, $\cup_{2}$ e U...... 43

Tabela 4: Aspectos de resistência à corrosão ligas ternária U-Nb-Zr recozidas $1000^{\circ} \mathrm{C}$ e têmperadas em água.

Tabela 5: Secção de choque (em barns) de diversos elementos, para nêutrons térmicos.

Tabela 6: Composição química (ppm) do urânio metálico utilizado na preparação das ligas. 52

Tabela 7: Composição química (ppm) do nióbio utilizado na preparação das ligas. .... 53

Tabela 8: Composição química (\% massa) do zircônio utilizado na preparação das

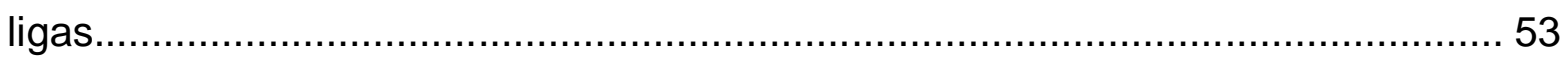

Tabela 9: Composição nominal (\% massa) das ligas produzidas............................... 54

Tabela 10: Linhas características de emissão de raios $X$ dos elementos $U$, Nb e $\mathrm{Zr}$... 61

Tabela 11: Parâmetros de rede das fases encontradas para as ligas após aplicação de 86

Tabela 12: Dureza Vickers, ligas fundidas a plasma tratadas termicamente a $1000^{\circ} \mathrm{C} \mathrm{e}$ temperadas em água

Tabela 13: Parâmetros de rede das fases encontradas para as ligas após aplicação de tratamento

Tabela 14: Dureza Vickers das ligas fundidas a plasma e tratadas termicamente a 700 ○C por 20 horas seguidas de têmpera em água. 98

Tabela 15: Parâmetros de rede das fases encontradas para as ligas após aplicação de tratamento isotérmico a $500{ }^{\circ} \mathrm{C} 20$ horas seguidas de têmpera em água............. 108

Tabela 16: Dureza Vickers, ligas fundidas a plasma tratadas termicamente a $500 \stackrel{\circ}{\mathrm{C}}$ por 20 horas e temperadas em água. 109

Tabela 17: Análise quantitativa dos elementos de liga (\% massa).......................... 110

Tabela 18: Análise quantitativa de impurezas (ppm). 


\section{INTRODUÇÃO}

Em uma sociedade em que a demanda por energia cresce de modo não sustentável, a busca por fontes alternativas de energia passou a ser uma importante linha de pesquisa. Uma dessas fontes alternativas é a geração de energia por meio da fissão nuclear em reatores, onde a energia térmica por meio de fissão nuclear é gerada na região central de um reator.

Há vários tipos de projeto de reatores de fissão, que podem ser diferenciados pelo elemento físsil utilizado no elemento combustível, pelo fluido refrigerante, ou pelo tipo de nêutrons utilizados para a fissão. Um dos modelos atualmente considerado como padrão é o Pressurized Water Reactor (PWR), que utiliza a água como refrigerante e moderador e o urânio enriquecido como elemento físsil (FROST, 1982). O elemento combustível para este tipo de reator é classificado em três tipos ou gerações (FROST, 1959):

i) Varetas, na forma de pastilha cerâmica de $\mathrm{UO}_{2}$;

ii) Placas utilizando dispersão de combustíveis metálicos (constituído de ligas ou compostos de urânio) ou cerâmicos, dispersos em liga de zircônio;

iii) Monolíticos do tipo placa, que utilizam combustíveis metálicos constituídos de liga de urânio, envolvidos por liga de zircônio.

Atualmente, os combustíveis metálicos são uma alternativa aos cerâmicos, já que se procura diminuir o enriquecimento dos combustíveis para evitar a geração de $\mathrm{Pu}$, tanto para redução na quantidade de rejeitos como também para assegurar a não proliferação de armas nucleares (SNELGROVE, 1996). As ligas metálicas possibilitam alcançar maior densidade de urânio, sendo estas muito superiores aos compostos óxido de urânio e silicetos de urânio, usualmente empregado em reatores de pesquisa de pequeno e médio porte (200 a $400 \mathrm{MWe}$ ). Essas ligas metálicas podem conter uma densidade de urânio de até $17,5 \mathrm{~g} / \mathrm{cm}^{3}$, bem mais elevada do que densidade de urânio no $\cup_{2}\left(10,5 \mathrm{~g} / \mathrm{cm}^{3}\right)$ e no $\bigcup_{3} \mathrm{Si}_{2}\left(12,1 \mathrm{~g} / \mathrm{cm}^{3}\right)$ (HOFMAN, 1996). 
Os elementos combustíveis do tipo (i) são baseados em tecnologia de fabricação já consagrada pelo uso, mas apresentam como limitação a baixa transmissão de calor causada pelo espaço vazio (gap) entre a pastilha e o tubo metálico (FROST, 1959). Esses elementos são utilizados atualmente na maioria absoluta dos reatores PWR para produção de energia e foram utilizados nos primeiros PWR para propulsão (VON HIPPEL; CHUNYAN, 2001). O primeiro submarino nuclear brasileiro utilizará este tipo de elemento combustível, provavelmente com vareta combustível constituída de tubo de aço inoxidável austenítico e pastilhas de $\mathrm{UO}_{2}$ (CTMSP, 2000).

O Centro Tecnológico da Marinha em São Paulo (CTMSP) vêm desenvolvendo o combustível nuclear avançado tipo placa para o segundo núcleo do reator protótipo de terra do Laboratório de Geração Núcleo Elétrica (LABGENE) da Marinha do Brasil (CTMSP, 2005). O LABGENE, além de servir como base para o desenvolvimento do protótipo de terra do reator nuclear a propulsão da Marinha, tem também como objetivo o desenvolvimento do reator nacional de potência para a geração núcleo-elétrica de pequeno e médio portes (200 a $400 \mathrm{MWe}$ ). Esta estratégia de desenvolvimento foi muito bem sucedida pelos americanos no seu programa nuclear naval com o desenvolvimento do reator Army Power Package Reactor (APPR), do tipo PWR, a partir da década de 1950. O reator em desenvolvimento pela Marinha é um conceito avançado do reator PWR, que emprega combustível tipo placa, em substituição ao combustível clássico de varetas de liga de zircônio contendo pastilhas de $\mathrm{UO}_{2}$.

Diversas ligas com elevados teores de urânio foram objeto de estudo no mundo, cada qual com suas vantagens e desvantagens relativas a cada tipo de reator e respectivo processo de fabricação. Dentre elas destacam-se as ligas de U-Nb-Zr, utilizadas em experimentos como o Boiling Water Reactor (EBWR) com a composição $\mathrm{U}-1,5 \% \mathrm{Nb}-5 \% \mathrm{Zr}$, onde a liga mostrou possuir boa estabilidade dimensional sob ciclos térmicos e sob radiação (IAEA-TECDOC-2374, 2003). Experimentos posteriores (IAEATECDOC-2374, 2003) indicaram que teores maiores de elementos de liga podem convergir em uma associação de resistência à corrosão e estabilidade dimensional. Além disso, análises preliminares de simulações permitem afirmar que os combustíveis de U-Nb-Zr podem estender a vida útil do reator por um período de 20 a 30 anos. 
O objetivo deste trabalho consiste no estudo experimental dos diagramas de fase $\mathrm{U}-\mathrm{Nb}-\mathrm{Zr}$, por meio da construção de dois cortes isotérmicos $\left(500{ }^{\circ} \mathrm{C}\right.$ e $\left.700{ }^{\circ} \mathrm{C}\right)$, no canto rico em urânio, já que as informações sobre o sistema são bastante incompletas e antigas, devido ao recesso no desenvolvimento tecnológico de combustíveis metálicos nos anos 1980, causado por acontecimentos políticos e estratégicos internacionais. Além disso, como objetivo tecnológico tem-se a obtenção de ligas que apresentem retenção de fase metaestáveis U- $y$ a temperatura ambiente, sendo estas passíveis a laminação. Isto tornará possível a aplicação destas ligas como combustível nuclear de alta densidade e baixo enriquecimento. $O$ estudo foi efetuado através da caracterização microestrutural de ligas obtidas via fusão a plasma. Está presente neste trabalho uma apresentação da microestrutura das ligas (composição, estrutura cristalina, distribuição de fases e respectivas morfologias), estudadas por difração de raios $\mathrm{X}$ e análise semiquantitativa de composição por dispersão de energia (EDS).

A primeira parte desta dissertação resume as propriedades do urânio metálico puro, obtidas na literatura (CAHN, et al., 1994; KUMMERER, 1980; WILKINSON, Vol. I, 1962). Em seguida, foram revisadas as informações da literatura dos sistemas binárias U-Nb, U-Zr e Nb-Zr (HARRINGTON; RUEHLE, 1959; OKAMOTO, 1992; ZEGLER; LLOYD, 1956), e do sistema ternário U-Nb-Zr (DWIGHT; MUELLER, 1956; FROST, 1959). Em seguida, será apresentada uma revisão sobre as transformações de fase possíveis neste sistema e as propriedades das ligas U-Nb-Zr. Finalmente, será feita uma apresentação sucinta sobre aplicações nucleares da liga ternária.

A segunda parte do trabalho trata dos materiais e métodos utilizados e os resultados obtidos e em sequência a discussão dos mesmos. Foram apresentados os resultados de caracterização das ligas obtidas produzidas via fusão a plasma. As características químicas, mecânicas e microestruturais das ligas foram apresentadas em conjunto com os resultados de difração de raios $X$ e análise de EDS, o que permitiu a avaliação das ligas em termos de homogeneidade de composição. Por fim foram apresentadas as conclusões do trabalho. 


\section{REVISÃO BIBLIOGRÁFICA}

\subsection{Características do urânio metálico}

O urânio foi descoberto em 1789 pelo químico alemão Klaproth e seu nome dado em homenagem ao planeta Urano, descoberto cinco anos antes (YEMELYANOV; YEVSTYUKHIN, 1969).

O urânio é um metal pesado cuja temperatura de fusão é de $1130{ }^{\circ} \mathrm{C}$ e pode ser encontrado nas formas U- $\alpha$; U- $\beta$ e U-y (WILKINSON, Vol. I, 1962). A fase cristalina $\alpha$ é estável até $661^{\circ} \mathrm{C}$ e apresenta estrutura ortorrômbica; a fase $\beta$ apresenta estabilidade entre $661{ }^{\circ} \mathrm{C}$ e $769{ }^{\circ} \mathrm{C}$ e possui uma estrutura tetragonal; a fase y é estável acima de $769{ }^{\circ} \mathrm{C}$ e apresenta uma estrutura cúbica de corpo centrado (CAHN, et al., 1994; WILKINSON, Vol. I, 1962) . A Tabela 1 apresenta detalhes da estrutura cristalina do urânio (YEMELYANOV; YEVSTYUKHIN, 1969).

Tabela 1: Fases cristalinas do urânio metálico.

\begin{tabular}{|c|c|c|c|c|c|}
\hline $\begin{array}{c}\text { Fase } \\
\text { cristalina }\end{array}$ & $\begin{array}{l}\text { Sistema de } \\
\text { cristalização }\end{array}$ & $\begin{array}{c}\text { Parâmetro } \\
\text { de rede } \\
\text { (̊̊) }\end{array}$ & $\begin{array}{c}\mathrm{N}^{\circ} \text { átomos } \\
\text { por célula } \\
\text { unitária }\end{array}$ & $\begin{array}{c}\text { Densidade } \\
\text { teórica } \\
\left(\mathrm{g} / \mathrm{cm}^{3}\right)\end{array}$ & $\begin{array}{c}\text { Temp. } \\
\left({ }^{\circ} \mathrm{C}\right)\end{array}$ \\
\hline $\begin{array}{c}\text { U- } \alpha \text {, estável até } \\
\qquad 662^{\circ} \mathrm{C}\end{array}$ & Ortorrômbica & $\begin{array}{c}a=2,852 \\
b=5,865 \\
c=4,91\end{array}$ & 4 & 19,12 & 25 \\
\hline $\begin{array}{c}\text { U- } \beta \text {, estável } \\
\text { entre } 662 \text { e } 769 \\
{ }^{\circ} \mathrm{C}\end{array}$ & Tetragonal & $\begin{array}{l}a=10,759 \\
b=5,656\end{array}$ & 30 & 18,11 & 720 \\
\hline $\begin{array}{c}\mathrm{U}-\gamma, \\
\text { estável entre } \\
769 \text { e } 1130{ }^{\circ} \mathrm{C}\end{array}$ & $\begin{array}{l}\text { Cúbica de } \\
\text { corpo } \\
\text { centrado }\end{array}$ & $a=3,52$ & 2 & 18,06 & 805 \\
\hline
\end{tabular}


A fase $\alpha$ apresenta um comportamento interessante quando submetido a um aumento de temperatura; enquanto os parâmetros de rede a e c sofrem expansão linear, o parâmetro b apresenta uma retração (HOLDEN, 1958). Na Figura 1, pode-se observar a variação dos coeficientes de expansão térmica com a temperatura nas três direções cristalográficas.

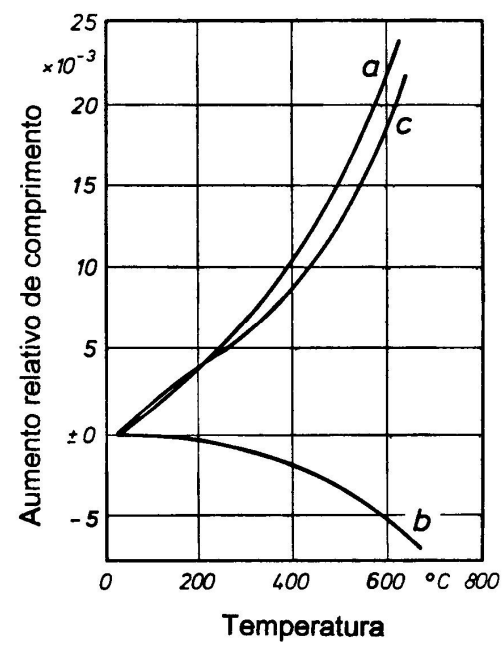

Figura 1: Coeficiente de dilatação térmica nas três direções da fase ortorrômbica (fase $\alpha$ ) do urânio (KUMMERER, 1980).

A Figura 2 apresenta o reticulado cristalino e parâmetros de rede da fase ortorrômbica (fase a) do urânio (KUMMERER, 1980). 


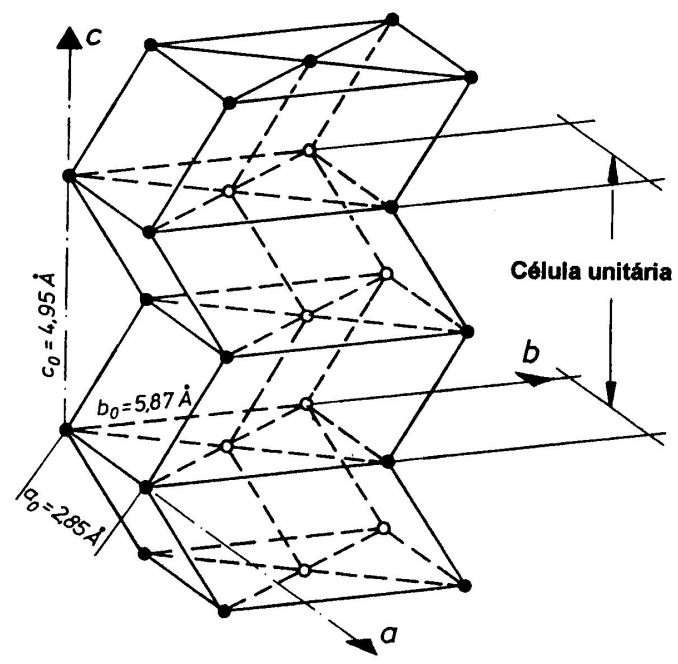

Figura 2: Esquema ilustrativo do reticulado cristalino da fase ortorrômbica a (KUMMERER, 1980).

A instabilidade dos grãos alfa do urânio mostra-se contínua para novos ciclos térmicos e é proporcional à intensidade da temperatura dos mesmos (WILKINSON, Vol. I, 1962). Obviamente, este fenômeno deve ser eliminado para utilização do componente internamente ao núcleo do reator, devido ao combustível estar sujeito à grande quantidade de ciclos de potência e consequentemente, a ciclos térmicos. A condição bruta de fusão do urânio apresenta uma microestrutura não uniforme e não homogênea, com grãos alfa preferencialmente orientados. Deste modo, para diminuir o efeito da anisotropia da fase alfa, faz-se necessária a aplicação de tratamentos térmicos e mecanotérmicos visando o refino da microestrutura e a homogeneização (CAHN, et al., 1994; WILKINSON, Vol. I, 1962).

A instabilidade do urânio metálico diante de ciclos térmicos não se restringe à fase alfa. No campo de transição de fase alfa-beta, ocorrem distorções no elemento combustível, pois a diferença de expansão volumétrica entre a fase alfa e a fase beta é de aproximadamente $1 \%$. A fase beta deforma plasticamente a fase alfa, causando fadiga na fase alfa (CAHN, et al., 1994; WILKINSON, Vol. I, 1962).

Devido à anisotropia das fases alfa e beta decorrente da assimetria do reticulado cristalino dessas fases, o coeficiente de expansão linear do urânio metálico fica dependente da direção cristalográfica (KOPELMAN, 1959). Medidas reais desse coeficiente não podem ser feitas diretamente em uma amostra policristalina, mas 
podem ser calculadas em função dos parâmetros de rede ou medidas diretamente em um monocristal (KOPELMAN, 1959).

A fase y do urânio tem a estrutura menos complexa que as outras duas, pois apresenta uma estrutura cúbica de corpo centrado, responsável por um comportamento plástico superior ao das fases $\alpha$ e $\beta$. Devido à simetria de seu reticulado cristalino, na fase $\mathrm{\gamma}$, é possível realizar medidas diretas de expansão linear térmica em amostras policristalinas (KOPELMAN, 1959).

A condutividade térmica do urânio é umas das propriedades mais importantes, tendo em vista sua aplicação como elemento combustível, já que, dentro do reator, o elemento combustível deve trocar uma grande quantidade de calor com o meio refrigerante (LAMARSH, 1982). A temperatura do núcleo do reator diminui com o aumento da condutividade térmica do elemento combustível (YEMELYANOV; YEVSTYUKHIN, 1969). Por outro lado, quanto menor for a condutividade térmica, maior será a tensão interna no combustível (YEMELYANOV; YEVSTYUKHIN, 1969). A Tabela 2 a seguir apresenta algumas propriedades do urânio metálico a serem consideradas para sua utilização como elemento combustível.

Tabela 2: Propriedades do urânio metálico (ASM Handbook, vol. 2, 1992).

\begin{tabular}{|c|c|}
\hline PROPRIEDADE & VALOR DE REFERÊNCIA \\
\hline Densidade teórica / real média $\left(\mathrm{g} / \mathrm{cm}^{3}\right.$ a $\left.25^{\circ} \mathrm{C}\right)$ & 19,12 a 19,02 \\
\hline Temperatura de fusão $\left({ }^{\circ} \mathrm{C}\right)$ & 1129 a 1132 \\
\hline Temperatura de ebulição $\left({ }^{\circ} \mathrm{C}\right)$ & 3818 a 3900 \\
\hline Calor latente de fusão $(\mathrm{kcal} /$ átomo g de $\mathrm{U})$ & 2,5 a 3,0 \\
\hline Calor latente de evaporação $(\mathrm{kcal} /$ átomo g de $\mathrm{U})$ & 93 a 106,7 \\
\hline Calor de transformação $(\mathrm{kcal} /$ átomo g de $\mathrm{U})$ & 0,674 \\
$\alpha \rightarrow \gamma\left(\Delta \mathrm{H}\right.$ a $\left.668^{\circ} \mathrm{C}\right)$ & 1131 \\
$\beta \rightarrow \gamma\left(\Delta \mathrm{H}\right.$ a $\left.774{ }^{\circ} \mathrm{C}\right)$ & \\
\hline
\end{tabular}


O urânio metálico oxida-se rapidamente em temperatura ambiente na presença de ar, oxigênio, hidrogênio, água ou vapor de água (SMITH, 1967). Mesmo amostras recém polidas podem possuir camadas de óxido extremamente finas. Com o passar dos dias, o aumento da camada de óxido faz com que a superfície polida adquira uma coloração dourada (KOLPELMAN, 1959). Aumentando-se a exposição dessa superfície à atmosfera oxidante, observa-se que ela adquire uma coloração preta devido à formação intensa de $\mathrm{UO}_{2}$ (KOLPELMAN, 1959). Após atingir certa espessura, o filme de óxido se quebra, expondo a superfície novamente à atmosfera oxidante, dando início a todo o processo de oxidação (SMITH, 1967).

Uma especial atenção à prevenção de danos à saúde deve ser dada às propriedades do urânio, como a piroforixidade, toxidade e radioatividade (EG\&G 2530, 1988; HENDERSON, 1989; Radiological Health Handbook, 1970). O urânio metálico em pó é muito pirofórico, ou seja, pode queimar espontaneamente em temperatura ambiente (ASM Handbook, vol. 2, 1992). Além disso, deve-se tomar muito cuidado ao se realizar o corte do urânio metálico, sendo necessária a utilização de fluido refrigerante durante o processo. A toxidade do urânio é muito semelhante à de outros metais pesados, como mercúrio e chumbo, sendo esse outro ponto a ser considerado para adoção de medidas de precauções contra danos à saúde (ASM Handbook, vol. 2, 1992). O fato de o urânio ser radioativo (emissor de $\alpha$ ) é outro ponto que o torna nocivo à saúde. Porém, o fato da radiação a ser extremamente ionizante, ela somente é considerada nociva ao incidir sobre tecidos internos do corpo. Fora isso, o urânio metálico natural, composto por $99,275 \%$ do isótopo $238,0,72 \%$ do isótopo 235 e 0,0058 do isótopo 233 , oferece pouco perigo do ponto de vista radiológico (ASM Handbook, vol. 2, 1992).

\subsection{Diagramas binários limites}

A possibilidade de utilização do urânio puro como elemento combustível metálico é muito limitada devido às propriedades desse material, discutidas no item 
anterior. A necessidade de melhorias nas características do urânio metálico puro, tais como estrutura cristalina, estabilidade de fase, microestrutura, textura cristalográfica, comportamento mecânico e resistência à oxidação, tornou o uso de ligas de urânio com adição de diferentes elementos, a melhor opção para o aumento da estabilidade do combustível (YEMELYANOV; YEVSTYUKHIN, 1969).

O conhecimento de diagramas de fase é essencial para o processamento do elemento combustível. As informações sobre o sistema U-Nb-Zr são muito antigas e incompletas. Entretanto, os sistemas binários U-Nb, U-Zr e Nb- Zr são bem conhecidos e possuem diagramas confiáveis (OKAMOTO, 1992). Por esta razão, foi feito um resumo da literatura para os sistemas que estabelecem as faces do prisma do digrama ternário U-Nb-Zr.

\subsubsection{Diagrama $U-N b$}

O sistema U-Nb apresenta uma vasta região de solução sólida de fase Y estabilizada e é uma das faces do diagrama ternário U-Nb-Zr. A Figura 3 apresenta 0 diagrama de fase para o sistema U-Nb. 


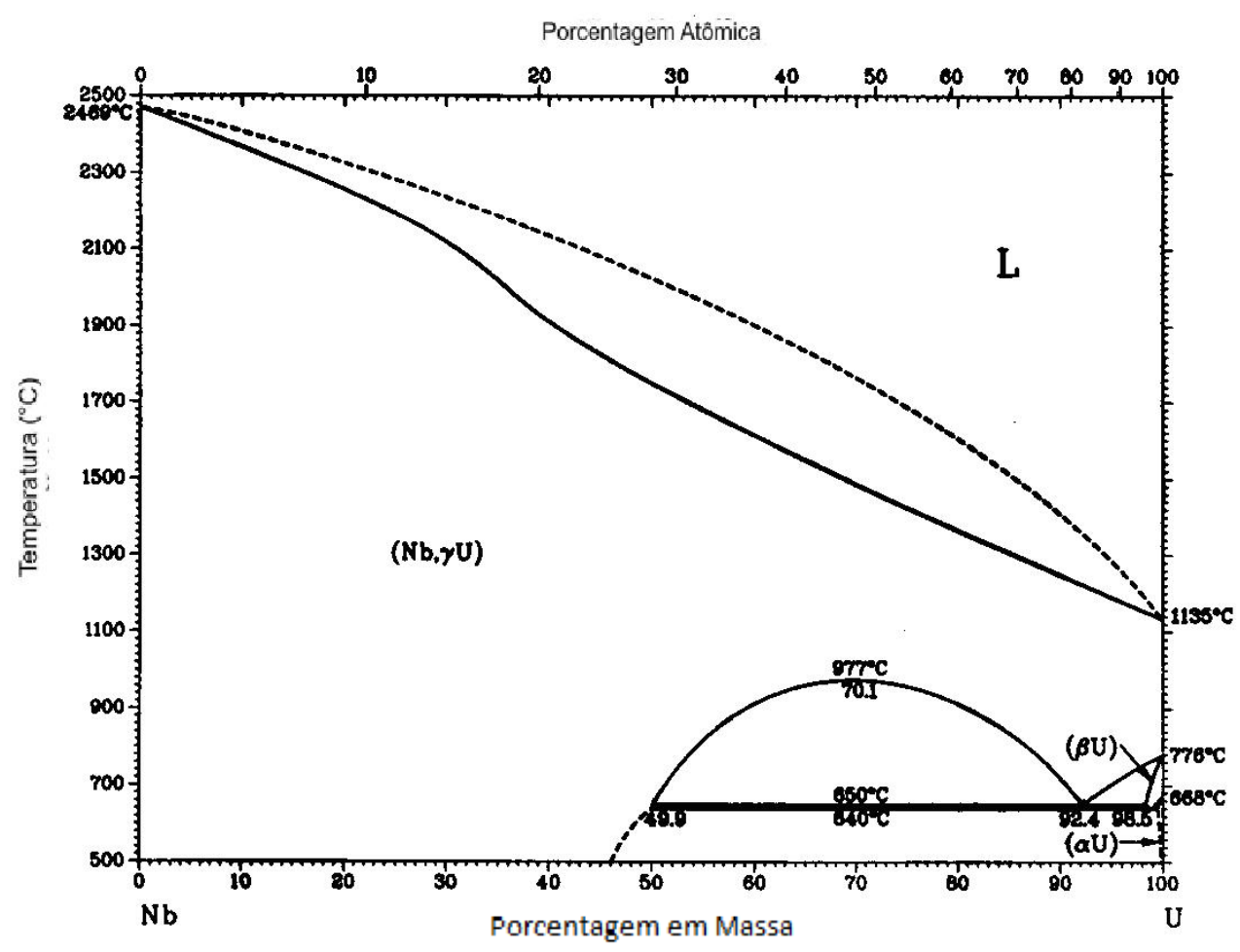

Figura 3: Diagrama binário U-Nb (ASM Handbook ,vol. 3, 1992).

A microestrutura de equilíbrio em temperaturas abaixo de $640{ }^{\circ} \mathrm{C}$ é uma mistura de duas fases, $\alpha$ e $\gamma$, sendo $y$ uma fase rica em nióbio em uma matriz quase pura de urânio $\alpha$. Neste sistema de alta miscibilidade com a fase $\gamma$, a fase $\beta$ não está presente em ligas contendo concentrações de nióbio acima de 4\% e a quantidade mínima de nióbio presente na fase de estrutura cúbica de corpo centrado varia de acordo com a taxa de resfriamento. Para taxas de resfriamento de $18^{\circ} \mathrm{C} / \mathrm{s}$, o valor mínimo é de $4,9 \%$ e para taxas de resfriamento rápido, é 4\% (DWIGHT; MUELLER ,1956). Para taxas de resfriamento lento, em condições de equilíbrio, há decomposição da fase y em a e y modificada. Os limites do domo de imiscibilidade (10 a 50\% de nióbio) não são afetados para concentrações de oxigênio de até 1000 ppm.

No diagrama, é possível verificar que o sistema possui um monotetóide em $640{ }^{\circ} \mathrm{C}$, a 7,6 \% em massa de nióbio, onde através de uma reação isotérmica, há uma redistribuição do nióbio ocorrendo a decomposição da fase y em a e em uma nova fase gama, com diferenças no parâmetro de simetria e composição de nióbio. Essa nova fase, que será aqui denominada $\gamma_{3}$, tem estrutura tetragonal de corpo centrado 
ordenada, cujos parâmetros mudam com a concentração de nióbio. Essa decomposição ocorre em uma faixa de composição de $4 \%$ a $9 \%$ em massa de nióbio. A tendência do urânio e nióbio formarem uma célula unitária tetragonal é decorrência da diferença nas valências e no diâmetro atômico desses dois elementos (WILKINSON, Vol. II, 1962).

Para reter a fase $\mathrm{y}$ em temperaturas mais baixas, pode ser aplicado um tratamento térmico de homogeneização na região de $\gamma$, seguida de têmpera à temperatura ambiente, gerando assim uma solução sólida supersaturada (TANGRI; CHAUDHURI, 1965). O aumento na porcentagem de nióbio inserido na estrutura do urânio gera um aumento na proporção de fase y retida durante a têmpera, já que a adição de nióbio no urânio estabiliza a fase gama em concentrações acima de $10 \%$ em massa de nióbio, além de propiciar uma melhora na resistência à corrosão do urânio metálico (WILKINSON, Vol. II, 1962). Posteriormente ao tratamento térmico para retenção de fase $\mathrm{\gamma}$, é possível fazer um tratamento térmico de envelhecimento de maneira a adequar as propriedades mecânicas a uma aplicação particular como, por exemplo, combustível nuclear (WILKINSON, Vol. II, 1962).

\subsubsection{Diagrama $U-Z r$}

O U-Zr é o segundo sistema binário que limita uma das faces do diagrama ternário U-Nb-Zr, onde o zircônio apresenta total solubilidade na fase $\mathrm{y}$ do urânio. $\mathrm{A}$ Figura 4 apresenta o diagrama de fases para o sistema U-Zr. Adições de oxigênio e nitrogênio alargam o domo de imiscibilidade em ambos os eixos, afetando mais intensamente o canto rico em zircônio (WILKINSON, Vol. II, 1962).

O zircônio possui várias vantagens sobre outros elementos de ligas quando utilizado como liga de urânio, pois possui uma pequena seção de captura de nêutrons (0,18 bars), possui alto ponto de fusão, é dúctil e possui alta resistência à corrosão (YEMELYANOV; YEVSTYUKHIN, 1969). 


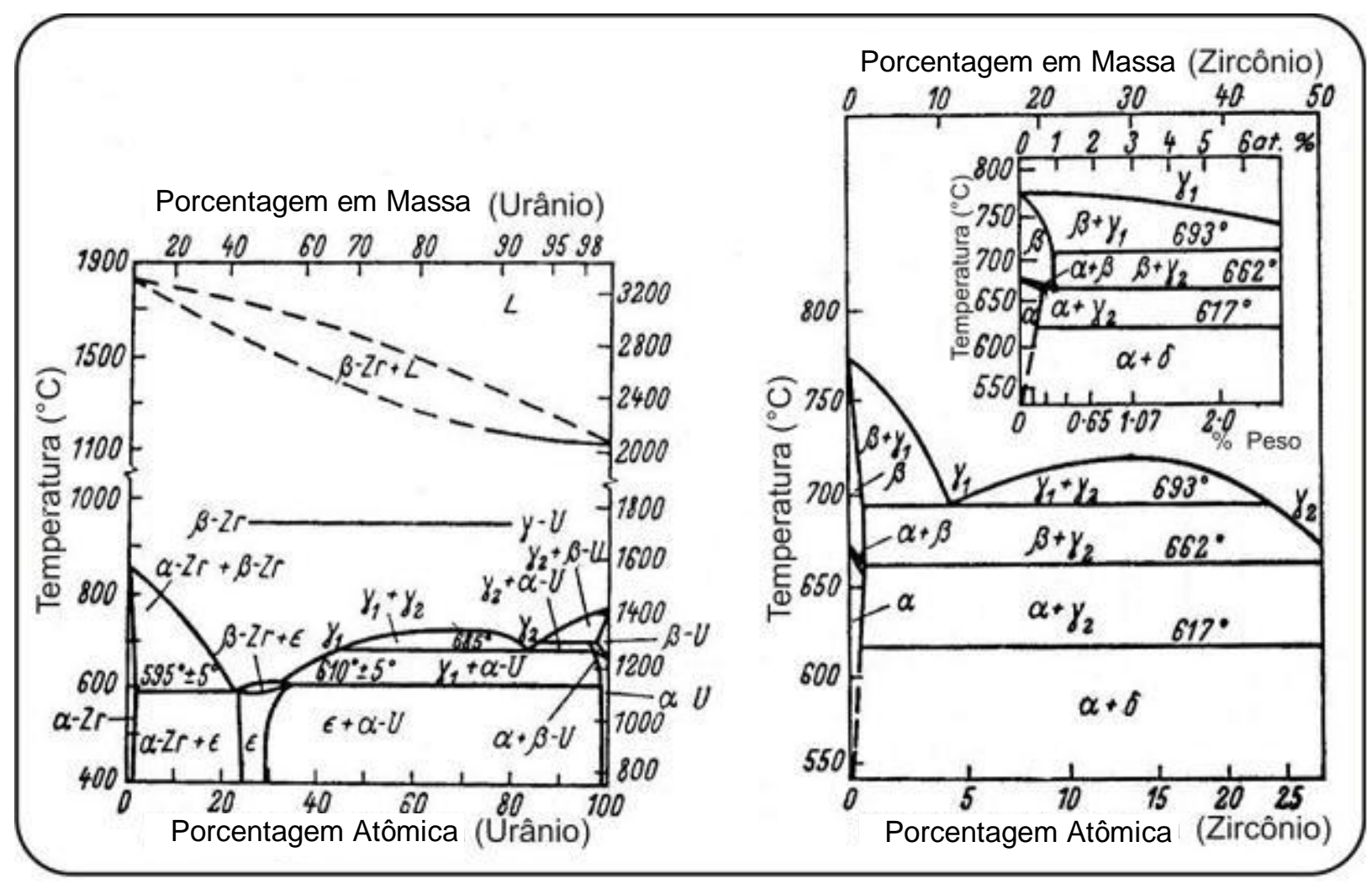

Figura 4: Diagrama binário U-Zr (YEMELYANOV; YEVSTYUKHIN, 1969).

No diagrama, é possível observar que, no sistema $U-Z r, V_{1}$ sofre uma decomposição monotetóide a $693{ }^{\circ} \mathrm{C}$ e há uma decomposição eutetóide da fase $\beta$ a $662{ }^{\circ} \mathrm{C}$. A solubilidade do zircônio nas fases $\alpha$ e $\beta$ é de, respectivamente, 0,2\% a 662 ${ }^{\circ} \mathrm{C}$ e $0,41 \%$ a $693{ }^{\circ} \mathrm{C}$. A solubilidade máxima do urânio na estrutura hexagonal do zircônio é de aproximadamente 0,8\% em massa (WILKINSON, Vol. II, 1962).

Existe somente uma fase intermetálica $\delta$ formada para temperaturas abaixo de $61{ }^{\circ} \mathrm{C}$ por uma reação peritetóide $\alpha+\mathrm{Y}_{2} \rightarrow \delta$ de composição nominal $U Z \mathrm{Zr}_{2}$. $A$ fase $\delta$ possui estrutura hexagonal de grupo espacial $P 6 / \mathrm{mmm}$, sua composição varia na faixa de $42,5 \%$ - 57,5\% $\mathrm{Zr}$ para temperaturas de $400 \stackrel{\circ}{\mathrm{C}}$, como pode ser visto no diagrama de fases.

O zircônio estabiliza a fase gama do urânio à temperatura ambiente, além de ajudar no refino de grão, no aumento da ductilidade da liga e no aumento da resistência mecânica. Apesar do zircônio estabilizar a fase gama, são necessários teores mais elevados para promover a mesma estabilização provida por uma adição menor de $\mathrm{Nb}$ ou Mo. Como comparação, uma estabilização de fase gama promovida com 10\% em 
massa de $\mathrm{Nb}$ seria obtida somente com a adição de 50\% de Zr (HARRINGTON; RUEHLE, 1959).

Destaca-se no diagrama a região acima da fase $\delta$, com composição de aproximadamente $50 \%$ em massa de zircônio. Nesta composição, a transformação de fase ocorre tão lentamente que é possível reter a fase $\mathrm{y}$ em temperatura ambiente. Esta porcentagem de elemento de liga, entretanto, não é atrativa, pois acarreta em uma maior seção de choque e consequentemente, em perda de nêutrons (HARRINGTON; RUEHLE, 1959).

\subsubsection{Diagrama $\mathrm{Nb}-\mathrm{Zr}$}

Último dos sistemas binários a compor as faces do diagrama U-Nb-Zr, o sistema $\mathrm{Nb}-\mathrm{Zr}$ apresenta temperaturas de fusão elevadas e uma vasta região de solução sólida do nióbio na fase $\beta Z$ r. A Figura 5 apresenta o diagrama de fase do sistema $\mathrm{Nb}-\mathrm{Zr}$.

A solubilidade máxima de nióbio na fase $\alpha Z r$, que apresenta estrutura hexagonal, é de $0,7 \%$ a uma temperatura de $620^{\circ} \mathrm{C}$. No diagrama, é possível observar a presença de uma decomposição monotetóide a $620{ }^{\circ} \mathrm{C}(\beta \mathrm{Zr}$, Nb). Há um domo de imiscibilidade localizado na faixa de $19 \%$ a $92,2 \%$ em massa de nióbio (ASM Handbook, vol. 3, 1992). 


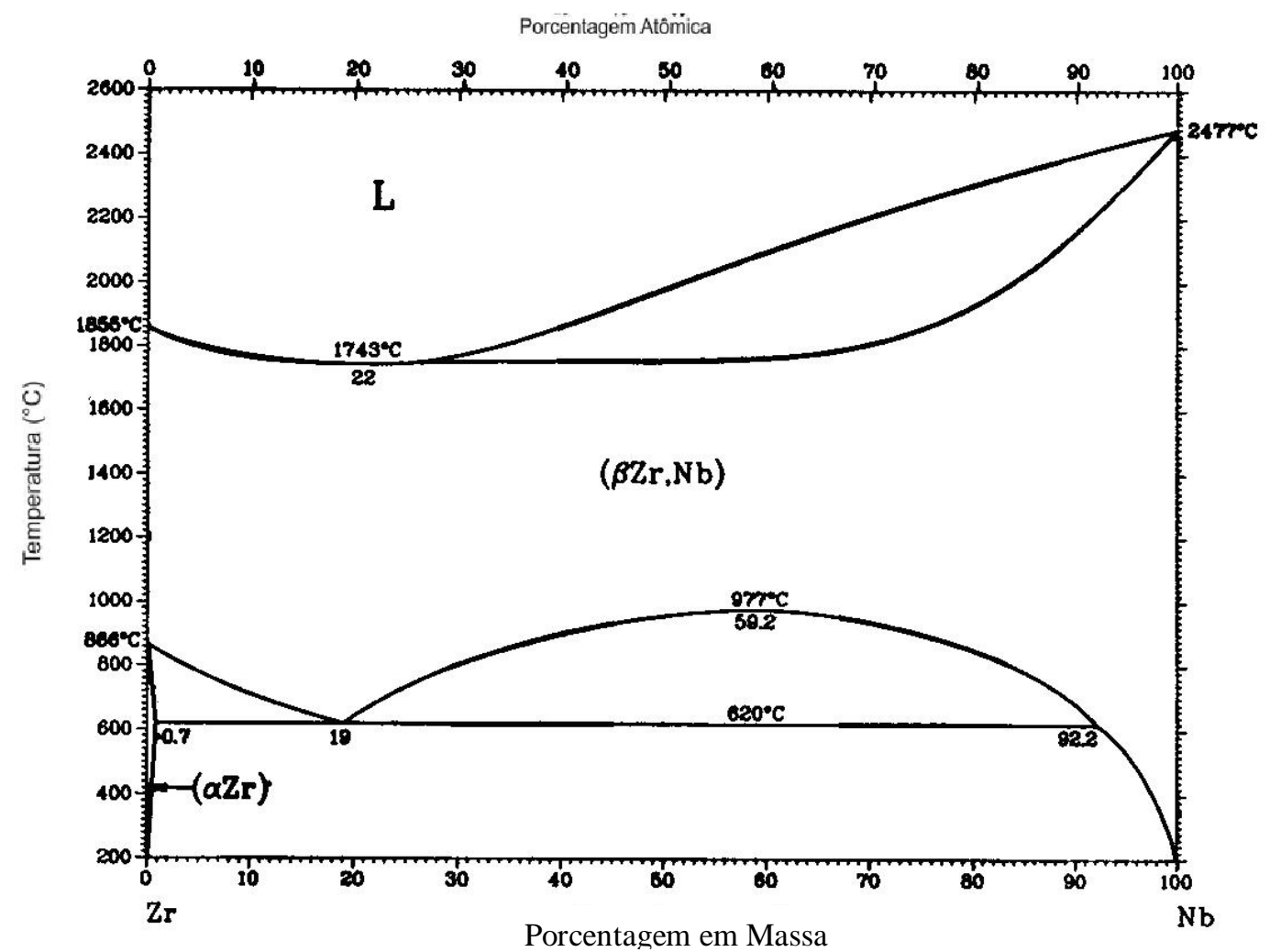

Figura 5: Diagrama binário Nb-Zr (ASM Handbook ,vol. 3, 1992).

Nota-se que os três sistemas binários que limitam o prisma do diagrama ternário $\mathrm{U}-\mathrm{Nb}-\mathrm{Zr}$ exibem completa solubilidade em altas temperaturas. Além disto, em todos os três sistemas há várias transformações de fase que resultam na decomposição da fase y do urânio em temperaturas mais baixas.

\subsection{Diagramas ternário U-Nb-Zr}

Uma vista isométrica da junção dos três diagramas binários limites é apresentada na Figura 6. 


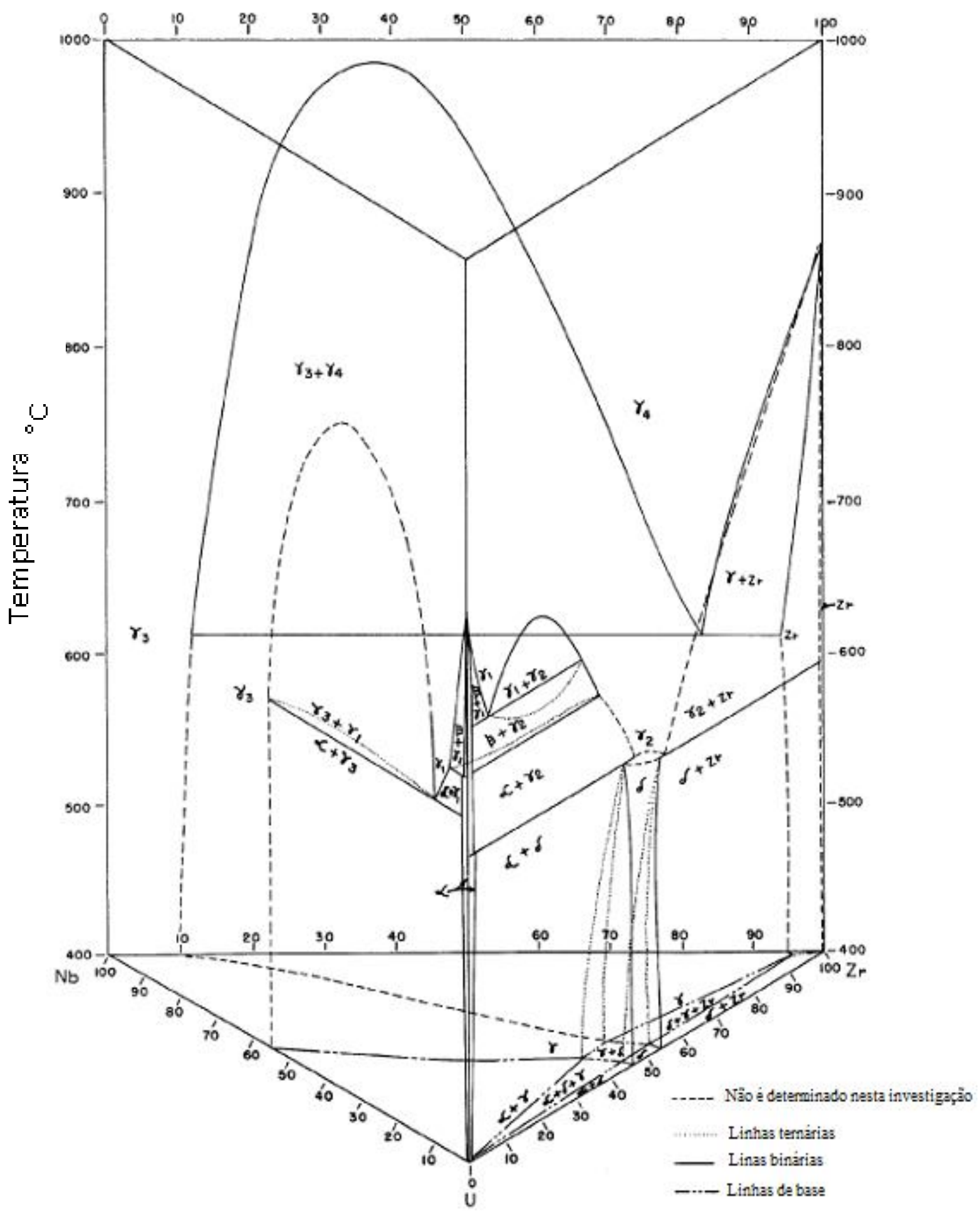

Figura 6: Vista isométrica do sistema U-Nb-Zr (DWIGHT; MUELLER, 1956). 
A sequência de transformações de fase no sistema ternário é mais facilmente visível com auxílio de séries de seções isotérmicas. Essas seções são mostradas nas Figuras 7 a 9. As concentrações do corte isotérmico apresentado na Figura 7 encontram-se em porcentagem em massa. Já as concentrações dos cortes apresentados nas Figuras 8 e 9, encontram-se em porcentagem atômica.

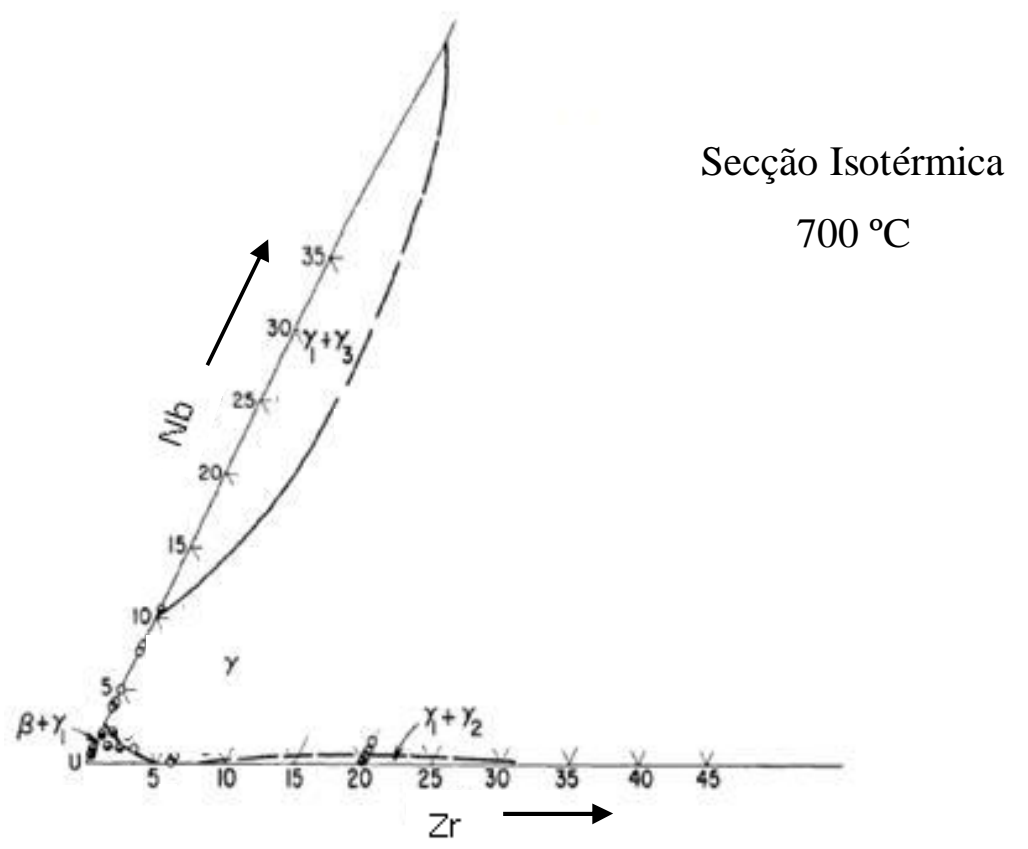

Figura 7: Corte isotérmico a $700{ }^{\circ} \mathrm{C}$ do diagrama U-Nb-Zr (\% massa) (DWIGHT; MUELLER, 1956). 


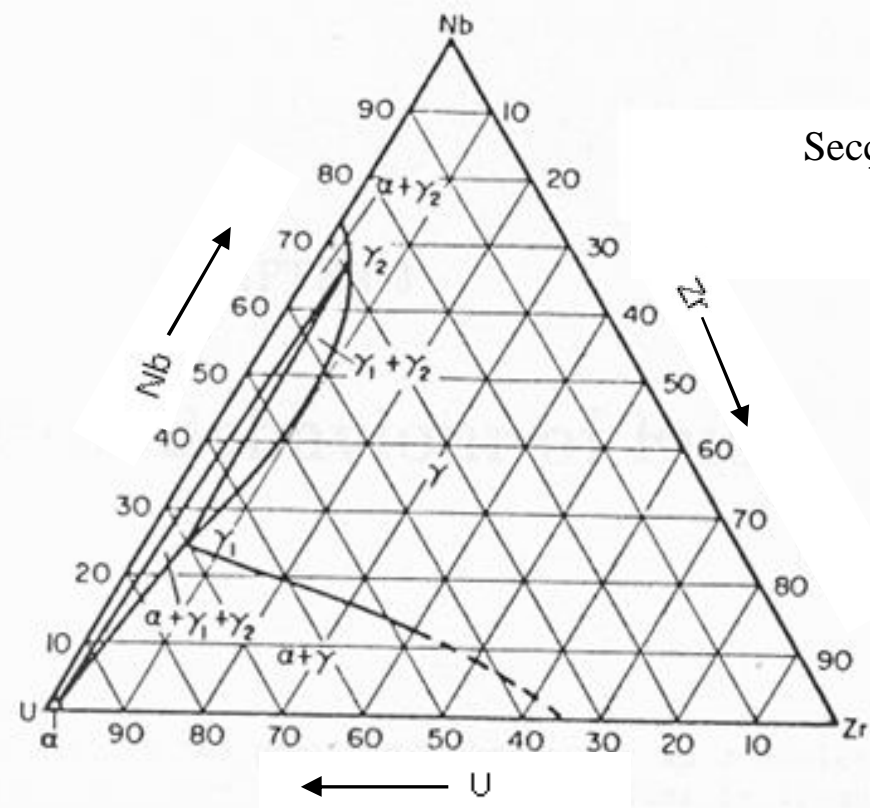

Figura 8: Corte isotérmico a $630{ }^{\circ} \mathrm{C}$ do diagrama U-Nb-Zr (\% atômica) (FROST, 1959).

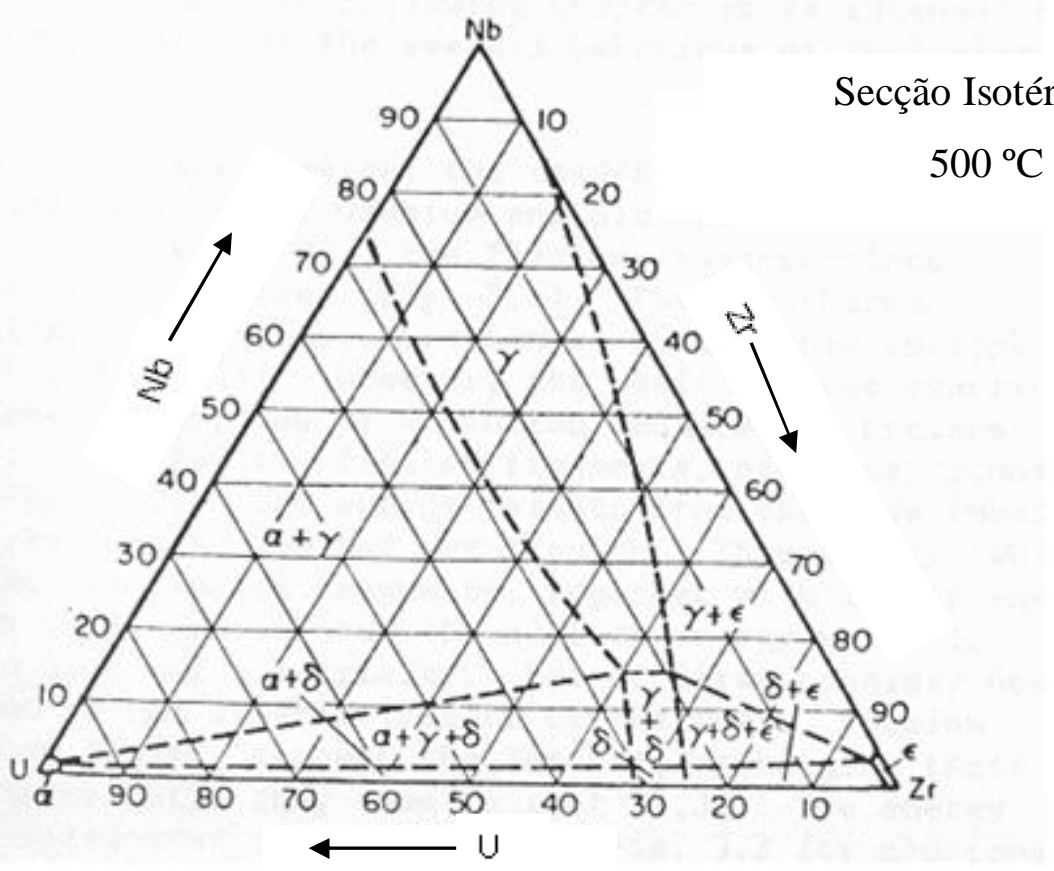

Figura 9: Corte isotérmico a $500{ }^{\circ} \mathrm{C}$ do diagrama U-Nb-Zr (\% atômica) (FROST, 1959). 
Para temperaturas acima de $970{ }^{\circ} \mathrm{C}$, apenas uma fase $\mathrm{\gamma}$, cúbica de corpo centrado, se estende por todo o diagrama do sistema U-Nb-Zr (DWIGHT; MUELLER, 1956).

A nomenclatura adotada nos diagramas ternários encontrados na literatura (DWIGHT; MUELLER, 1956; FROST, 1959) se apresenta de forma confusa, com diferentes denominações para as fases estáveis a baixa temperatura das ligas de urânio. Esta nomenclatura tem origem no fato de que os sistemas U-Nb e U-Zr possuem um domo de imiscibilidade, onde há a presença de fase $\mathrm{y}$ intermediária decorrente da decomposição da fase $y$ inicial do urânio.

A nomenclatura da Figura 7 é derivada da utilizada nos diagramas binários que limitam o sistema, onde as fases $\gamma_{1}, \gamma_{2}$ e $\gamma_{3}$ são derivadas da decomposição da fase $Y$ em temperaturas mais baixas. Sendo $\gamma_{1}$ fase rica em urânio, $\gamma_{2}$ fase rica em zircônio $e$ $\gamma_{3}$ fase rica em nióbio, todas possuem estruturas cristalinas próximas à da fase $\gamma$, com algumas distorções devido à geração de solução sólida substitucional. A nomenclatura nas Figuras 8 e 9 se diferencia um pouco da adotada na Figura 7, por serem de autores diferentes (DWIGHT; MUELLER ,1956; FROST, 1959). Nessas figuras, a fase rica em nióbio é denominada $\mathrm{Y}_{2}$ e a fase rica em zircônio, $\varepsilon$. Posteriormente houve publicação de trabalho onde foi proposta uma nomenclatura mais universal as fases (LEHMANN; HILLS, 1960). Outras fases presentes no sistema U-Nb-Zr são as fases $\alpha$ e $\beta$ do urânio e a fase correspondente a $U Z_{2}$, denominada $\delta$.

Há muitos pontos a serem destacados nos cortes isotérmicos. Primeiro, as adições simultâneas de nióbio e zircônio diminuem a temperatura na qual a fase y é estável como fase única. Segundo, adições de $4 \%$ ou mais de nióbio causam o desaparecimento da fase $\beta$. Deste modo, para essas concentrações, as transformações no resfriamento ocorrem sempre de $\mathrm{y}$ para $\alpha$. Terceiro, cada vale monotetóide apresenta-se em temperaturas inferiores àquelas dos diagramas binários, e são nessas temperaturas que as duas fases gamas convergem para uma. Quarto, uma das fases gama $\gamma_{3}$ é a fase que mais ocorre como fase de equilíbrio. Por último, a fase $\delta$, correspondente a $U \mathrm{Zr}_{2}$, é eliminada para concentrações de nióbio acima de $7 \%$ em massa. 
O fato de a fase gama y se decompor em uma série de estruturas cúbicas de corpo centrado cria um domo de imiscibilidade mesmo em altas temperaturas. O domo de imiscibilidade das fases $y_{1}$ (rica em urânio) e $\delta$ (rica em zircônio), diminui com a adição de nióbio.

Dos sistemas ternários reportados para o urânio, o que possui a maior região de fase y é o sistema U-Nb-Zr (DWIGHT; MUELLER, 1956). Quando a porcentagem atômica de $\mathrm{Zr}$ mais $\mathrm{Nb}$ está na faixa de 50 a $80 \%$, a fase gama é muito estável em temperaturas acima $500 \stackrel{\circ}{ } \mathrm{C}$.

A adição de $\mathrm{Nb}$ às ligas de U-Zr propicia um aumento de sua estabilidade mesmo após irradiação. O Zr retarda a transformação da fase y do urânio, mas precisa ser adicionado em uma quantidade considerável para estabilizar a fase $\gamma$, fazendo com que a liga fique inviável em termos de economia neutrônica. $\mathrm{A}$ adição do $\mathrm{Nb}$ às ligas de U-Zr possibilita a ocorrência desta transformação, mesmo utilizando menor quantidade de elementos de liga (YAKEL, 1969).

A inserção dos elementos $\mathrm{Nb}$ e $\mathrm{Zr}$ ao urânio geram uma solução sólida do tipo substitucional. $\mathrm{O} \mathrm{Nb}$ causa uma diminuição no parâmetro de rede da fase cúbica de corpo centrado do urânio. O Zr, por sua vez, causa um ligeiro aumento nos parâmetros de rede da fase $y$, ou seja, um soluto reduz a distorção introduzida por outro. Devido à essa compensação, a estrutura y presente no sistema ternário U-Nb-Zr pode exibir uma estrutura similar à existente nas estruturas ricas em urânio dos sistemas ternários (DWIGHT; MUELLER, 1956). As alterações no parâmetro de rede da fase U-y com relação à composição do sistema ternário $\mathrm{U}-\mathrm{Nb}-\mathrm{Zr}$ podem ser observadas na figura apresentada a seguir: 


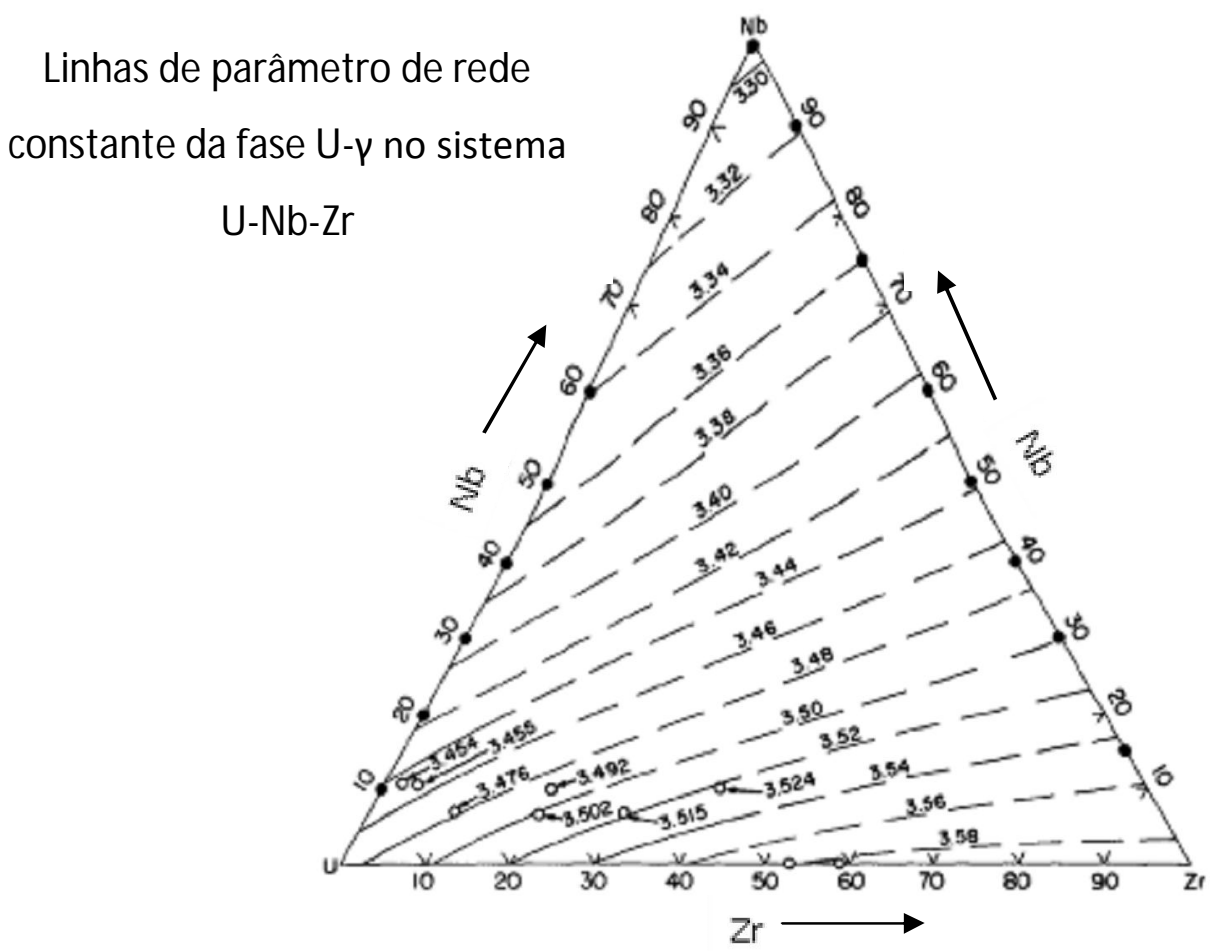

Figura 10: Parâmetro de rede fase gama no sistema ternário U-Nb-Zr (\% massa) (DWIGHT; MUELLER, 1956).

Com adições simultâneas de $\mathrm{Nb}$ e $\mathrm{Zr}$ ao $\mathrm{U}$, a fase $\mathrm{y}$ torna-se estável em temperaturas mais baixas. $\mathrm{O} \mathrm{Nb}$ e $\circ \mathrm{Zr}$ exercem conjuntamente esse efeito de estabilização da fase gama em ligas ternárias.

A presença de oxigênio não causa deslocamentos nos limites do domo de imiscibilidade, para concentrações de até 1000 ppm (DWIGHT; MUELLER, 1956). 


\subsection{Transformações de fase}

A necessidade da estabilização da fase y sob irradiação para aplicações como combustíveis em uma ampla faixa de temperaturas torna ainda mais relevante o estudo das transformações de fases e a velocidade na qual se dá a decomposição eutetóide da fase y em fases estáveis, descrita pela reação:

$$
Y \longrightarrow \alpha+\beta \quad \text { (decomposição eutetóide) }
$$

Será feita aqui uma revisão dos processos que governam a reação dada acima. Em um dos processos, a decomposição da fase gama depende do movimento dos átomos (se dá por difusão), e é denominada transformação por nucleação e crescimento. Ainda para resfriamentos rápidos, é possível verificar transformações martensíticas dos tipos $Y \rightarrow \gamma^{0}, \quad \gamma \rightarrow \alpha^{\prime}$ e $\beta \rightarrow \alpha^{\prime}$ que ocorrem por processos de cisalhamento. Ambos os processos serão abordados a seguir.

\subsubsection{Transformações por nucleação e crescimento}

A nucleação, isto é, o aparecimento de um "núcleo" de uma nova fase no interior de uma fase pré-existente, desempenha um papel importante tanto nas morfologias resultantes como na velocidade em que estas transformações ocorrem (RIOS; PADILHA, 2007).

A nucleação é um fenômeno termicamente ativado, controlado pela difusão. A movimentação aleatória dos átomos pela liga pode formar embriões, que são grupos de átomos com composição diferente da composição média da matriz. Se a fase matriz na qual o movimento está ocorrendo for aquela que apresenta a menor energia livre, os embriões representam regiões de alta energia e, portanto, têm vida curta. A fase $\alpha$ é a fase estável, ou seja, os embriões formados representam potenciais sítios de nucleação (CHRISTIAN, 1965). 
Entretanto, para que o embrião sobreviva e se torne um núcleo de uma nova fase, deve haver uma redução de energia livre do sistema para a transição embriãonúcleo. Este crescimento envolve a criação de uma nova interface entre a fase matriz e o núcleo, e no caso de reações no estado sólido, pode haver a introdução de tensões elásticas e deformações na matriz, quando as novas fases formadas apresentarem estruturas cristalinas diferentes da estrutura da matriz (CHRISTIAN, 1965). Este é o caso estudado neste trabalho, pois y é cúbica de corpo centrado, e a e $\beta$ são, respectivamente, ortorrômbica e tetragonal.

Desprezando-se os termos de tensão é possível aplicar o modelo simplificado de nucleação, onde a variação de energia livre de Gibbs G para a formação de um núcleo homogêneo esférico é descrito como:

$$
\Delta G=4 / 3 \pi r^{3} \Delta G_{v}+4 \pi r^{2} \gamma_{s}
$$

onde $Y_{s}$ é a energia de formação da interface e $G_{v}$ a energia disponível para a formação do volume do núcleo da nova fase. Ao se examinar a contribuição individual de cada termo da equação (02), observa-se que há um determinado valor de raio, determinado raio "crítico", em que um pequeno aumento no raio causa uma redução na energia livre, dada a forte dependência com o termo volumétrico, o que favorece a nucleação (RIOS; PADILHA, 2007). A Figura 11 apresentada a seguir, mostra o comportamento de cada parcela da equação (02), assim como a soma de suas partes. 


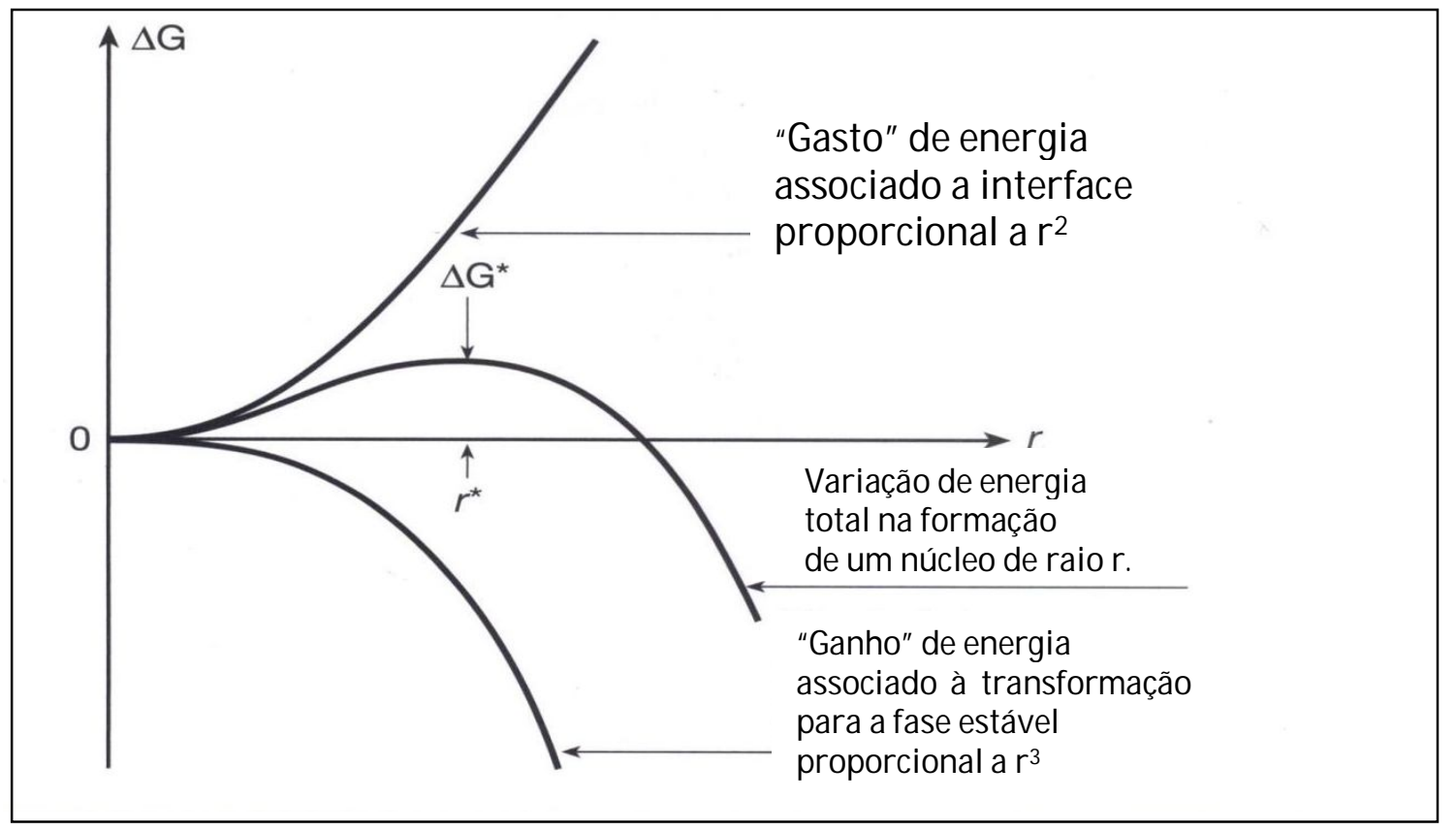

Figura 11: Esquema ilustrativo da parcelas da energia associada à formação de um núcleo (COLPAERT, 2008).

O mecanismo de difusão do Nb e do Zr no urânio ocorre de modo não anômalo, sendo o coeficiente de difusão D expresso pela equação de Arrhenius (BROPHY; ROSE; WULFF, 1964). É essa equação que influenciará o quão rápido irá ocorrer o crescimento de novas fases após a nucleação. A seguir são apresentadas as equações do coeficiente de difusão $\mathrm{D}$, que expressam a mobilidade do Nb (GALER; TOTEMEIER, 2004) e do Zr (MASH; DISSELHORST, 1955) no urânio, válidas para algumas faixas de temperatura.

$\mathrm{Nb}$

$\longrightarrow \mathrm{D}=4,87 \times 10^{-2} \exp \left[\left(-166 \times 10^{3}\right) / \mathrm{RT}\right]$ para $\mathrm{T} 790-1103^{\circ} \mathrm{C}$ em U-y

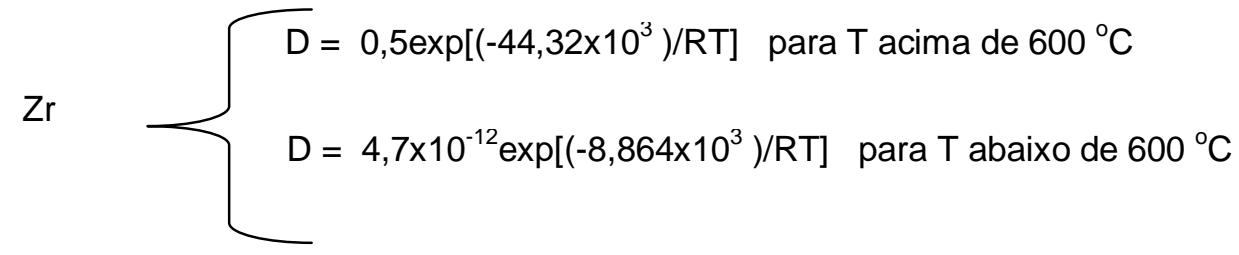


A mudança nos coeficientes de difusão para o zircônio ocorre devido ao fato de que abaixo da temperatura de $600{ }^{\circ} \mathrm{C}$ o mecanismo de difusão ocorre através de difusão no volume e para temperaturas superiores a $600{ }^{\circ} \mathrm{C}$ a difusão se dá através dos contornos de grãos.

A dissolução controlada por difusão do zircônio no urânio fundido é importante tanto para obtenção de ligas homogêneas como também para prever o comportamento do elemento combustível monolítico que possivelmente utilizará um revestimento de ligas de $\mathrm{Zr}-\mathrm{Nb}$. A energia de ativação $(\mathrm{E})$ e a constante de difusão (D), para o zircônio no urânio fundido em um dado tempo t, quando a temperatura é monotonicamente crescente são obtidos das seguintes expressões:

$$
D=\left(E d^{2} / N_{0} h\right) e^{-E / R T} \quad \text { e } \quad D[T(t)]=D_{0} e^{-\varepsilon / T(t)}
$$

Onde $\mathrm{E}$ é em cal $/ \mathrm{mol}, \mathrm{d}=$ distancia interatômica do urânio $=2,7 \times 10^{-8} \mathrm{~cm}, \mathrm{~h}=$ constante de Planck, $N_{o}$ é o numero de Avogadro, $\varepsilon=E / R$ onde $R$ é a constante dos gases, T é a temperaturas em graus Kelvin. Para temperatura de $1270{ }^{\circ} \mathrm{C}$ (1543 ${ }^{\circ} \mathrm{K}$ ) $\mathrm{D}=1,9 \times 10-4 \mathrm{~cm}^{2} / \mathrm{sec}, E=2,0764 \mathrm{cal} / \mathrm{mol}$ e $D_{0}=0,16596 \mathrm{~cm}^{2} / \mathrm{sec}$ (WILKINSON, Vol. II, 1962). Se uma coluna de $0,8 \mathrm{~cm}$ de urânio fundido for colocada em contato com uma barra de zircônio de $0,02 \mathrm{~cm}$ a uma temperatura de $1270 \stackrel{\circ}{\circ} \mathrm{C}$ é calculado que a dissolução total da barra de zircônio ocorrerá em 160 segundos.

Com relação à teoria descrita para a nucleação homogênea, toda a matemática desenvolvida também pode ser aplicada para casos onde ocorrem nucleações heterogêneas. 


\subsubsection{Transformação martensítica}

As transformações martensíticas ocorrem quando a difusão atômica de longo alcance não atua de forma significativa e, portanto, não estão associadas às mudanças de composição química, somente às mudanças de estrutura cristalina. Como tais transformações ocorrem quando os átomos possuem baixa mobilidade, acontece o movimento coordenado de átomos, o que faz com que estas transformações sejam denominadas de transformações "militares" (RIOS; PADILHA, 2007).

Para o sistema ternário U-Nb-Zr em estudo nesta dissertação tem-se as seguintes principais transformações martensíticas; $y \rightarrow \alpha^{\prime}, \beta \rightarrow \alpha^{\prime}$ e $\gamma \rightarrow \gamma^{\circ}$ (WILKINSON, Vol. II, 1962). Para as duas primeiras transformações o resultado é a geração de uma fase alfa modificada, podendo esta apresentar estrutura ortorrômbica com contração na direção cristalográfica b ou ainda uma mudança para estrutura cristalina para monoclínica (a qual em geral é identificada como a"), gerada pela ocorrência de solução sólida (ASM, Handbook Vol. 9). A transformação $\mathrm{Y} \rightarrow \mathrm{\gamma}^{\circ}$ apresenta uma leve alteração da estrutura cúbica de corpo centrado para tetragonal de corpo centrado, gerada pela presença preferencial de átomos de nióbio em alguns sítios, o que causa distorção na estrutura. As estruturas $\mathrm{y}$ e $\mathrm{y}^{0}$ exibem uma estrutura metalográfica praticamente idênticas o que causa dificuldade em distinção. Entretanto, $Y^{0}$ é anisotrópica respondendo a luz polarizada e ainda apresenta no difratograma um alargamento dos picos causado pela deformação inserida na rede (WILKINSON, Vol. II, 1962), sendo esses alguns fatores que podem ajudar na distinção de $\mathrm{y}$ e $\mathrm{Y}^{\circ}$. A transformação martensítica $\mathrm{Y} \rightarrow \mathrm{Y}^{0}$ é de especial interesse tecnológico, pois seu resultado é uma martensita dúctil, possibilitando a aplicação em conformação mecânica. A figura apresentada a seguir mostra as regiões onde essas transformações prevalecem para o sistema ternário U-Nb-Zr na temperatura de $900{ }^{\circ} \mathrm{C}$. 


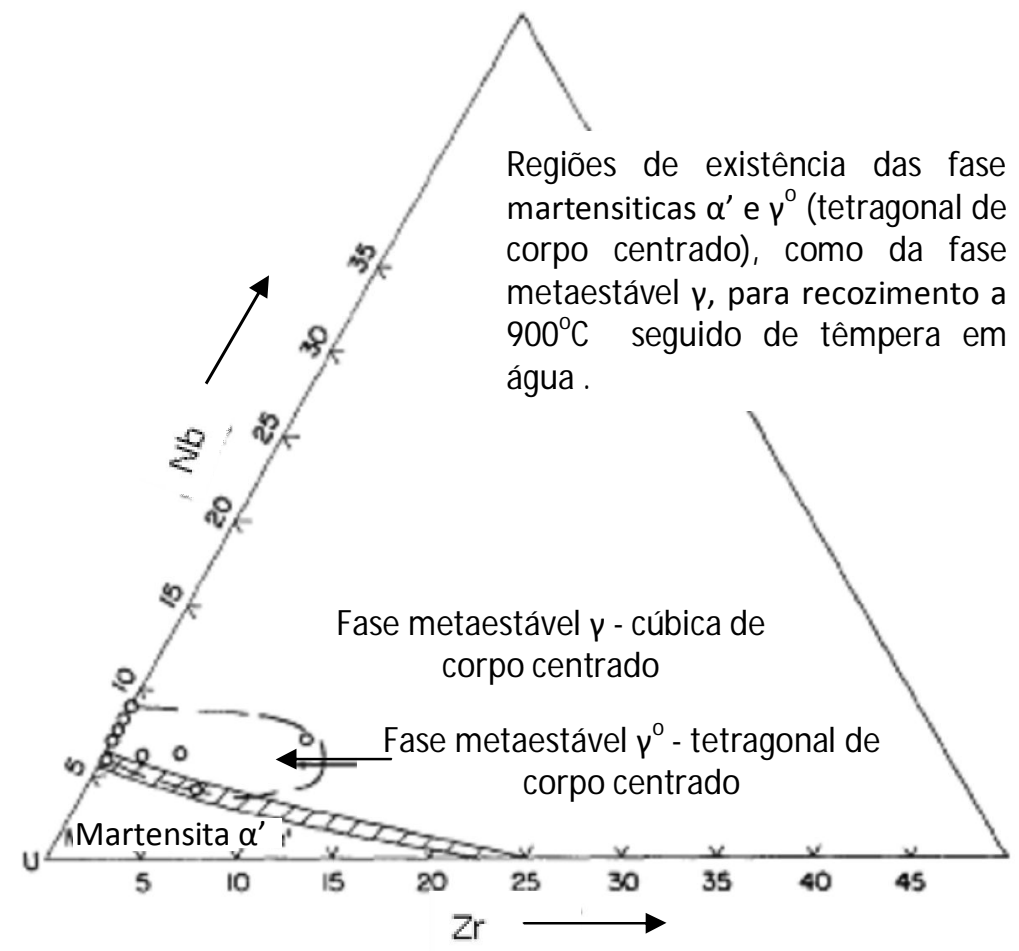

Figura 12: Regiões onde prevalecem transformações martensíticas para o sistema ternário U-Nb-Zr (\% massa) (DWIGHT; MUELLER ,1956).

O mecanismo da transformação martensítica $\beta \rightarrow \alpha$ ' é bem conhecido e se mostra o mesmo para todas as ligas ricas em urânio seguindo $\beta \rightarrow \alpha^{\prime}$ sem envolver nenhuma fase intermediária (HOLDEN, 1953).

O mecanismo de formação das fases matensítica $Y^{\circ}$, $\alpha$ " e $\alpha^{\prime}$ a partir da fase y é bem documentado na literatura para diferentes sistemas de liga à base de urânio (TANGRI; WILLIAMS, 1961; TANGRI, 1965; ANAGNOSTIDIS; BASCHWITZ; COLOMBIE, 1966). É suficiente mencionar aqui que cisalhamento progressivo na direção do sistema de escorregamento $\{112\}<111>$ da fase $\mathrm{Y}$ promove a sequência de transformações $\gamma \rightarrow \gamma^{0} \rightarrow \alpha^{\prime \prime} \rightarrow \alpha^{\prime}$.

Um aspecto importante apresentado pela fase martensítica a' é uma resistência à corrosão em água superior à da fase U- $\alpha$, devido, principalmente, à sua propriedade de absorver quantidades menores de hidrogênio, entretanto esta estrutura tende a 
apresentar uma excessiva instabilidade dimensional sob radiação (WILKINSON, Vol. II, 1962).

No que se refere à realização de têmpera para ligas que se apresentam em um campo bifásico $\beta+\gamma$, é relatada a supressão de reações isotérmicas (eutetóides e monotetóides) o que resulta em transformação de $\beta$ e $\gamma$ em fase alfa supersaturada. Um esquema da transformação martensítica vigente para campo bifásicos $\beta+\gamma$ é apresentado a seguir:

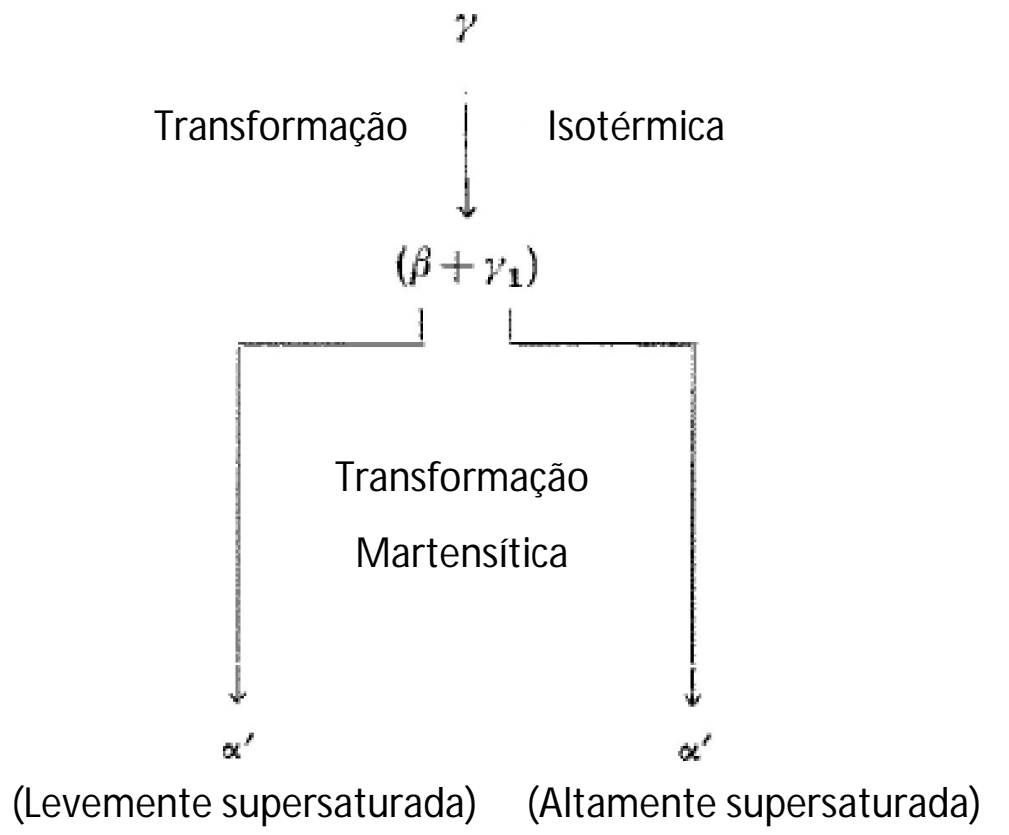

Figura 13: Esquema de transformação martensítica para tratamentos térmicos sobre campo $\beta+\gamma$ (D’AMATO; SARACENO; WILSON, 1964).

Do esquema apresentado na Figura 13 fica claro que há uma diferença de composição para a fase martensítica $\alpha$ ' conforme fase precedente, sendo que para transformação $\beta \rightarrow \alpha^{\prime}$ é esperada uma estrutura com um grau de saturação menor que a gerada pela transformação $\gamma \rightarrow \alpha$ '.

Os aspectos gerais fundamentais das transformações martensíticas, que a diferenciam das transformações controladas por difusão são: 
a) A composição química da martensita formada é a mesma da matriz que a originou.

b) A quantidade de martensita formada depende da temperatura atingida e não do tempo em que o material é mantido nesta temperatura (RIOS; PADILHA, 2007).

c) Em função da variação de volume associada à transformação, gera em um nível elevado de tensões residuais.

Este tipo de transformação ocorre para ligas de urânio resfriadas em baixas temperaturas a partir da região de fase $y$ e $y+\beta$, no qual a quantidade transformada depende da porcentagem de elemento de liga inserido (WILKINSON, Vol. II, 1962).

\subsection{Propriedades das Ligas U-Nb-Zr}

As propriedades físicas de maior interesse nas ligas de urânio, tendo em vista aplicação em reatores, são: condutividade térmica, coeficiente de expansão, estrutura cristalina, dureza, densidade, resistência à corrosão, comportamento sob ciclo térmico e, principalmente, estabilidade sob irradiação (WILKINSON, Vol. II, 1962).

O conhecimento do valor da condutividade térmica é necessário para que se possam ser estimados a temperatura e o fluxo de calor no centro e na superfície do elemento combustível. Já o coeficiente de expansão térmica, juntamente com outros parâmetros como módulo de Young, são necessários para que sejam calculadas a tensão e a deformação plástica que ocorrem no combustível sob ciclos térmicos. $\mathrm{O}$ conhecimento da resistência à corrosão ajuda a estimar as possíveis falhas na superfície do elemento combustível. Os valores de dureza são medidos a partir da resistência da liga a uma deformação plástica, sendo um bom indicativo para outras propriedades mecânicas (KULIN, 1954; KAUFAMANN, 1962; SMITH, 1967).

A adição de elementos de liga no urânio afeta essas propriedades de vários modos que serão abordados a seguir, incluindo uma breve revisão da literatura com 
propriedades térmicas, resistência a corrosão, dureza e influência do carbono nas ligas, já que este elemento é uma impureza sempre presente no urânio metálico fabricado pelo método de redução do $\mathrm{UF}_{4}$ por $\mathrm{Mg}$ metálico, como é o caso do urânio metálico utilizado neste trabalho (KOPELMAN, 1955).

\subsubsection{Propriedades térmicas}

A condutividade térmica das ligas de $\mathrm{U}-\mathrm{Nb}-\mathrm{Zr}$ é dependente de sua estrutura cristalina $(\alpha, \beta$ e $y)$. A condutividade térmica do urânio diminui com o aumento da quantidade de elementos de liga. Entretanto, ligas apresentam uma dependência com a temperatura, mais forte em relação ao urânio puro.

Os elementos de liga também reduzem consideravelmente a expansão térmica. Uma expansão térmica mais acentuada pode ser observada em faixas de temperaturas que ativam a transformação de fase (IAEA-TECDOC-2374, 2003). A Tabela 3 apresenta os valores da condutividade térmica e de expansão térmica para uma liga ternária U-5Zr-5Nb comparada com as propriedades do dióxido de urânio e do urânio puro. 
Tabela 3: Condutividade térmica e expansão térmica da liga U-5Zr-5Nb, $\cup_{2}$ e U (IAEA-TECDOC-2374, 2003).

\begin{tabular}{|l|c|c|c|}
\hline $\begin{array}{c}\text { Condutivida } \\
\text { de térmica } \\
(\mathbf{W} / \mathbf{m K})\end{array}$ & $\mathbf{U - 5 N b - 5 Z \mathbf { r }}$ & $\mathbf{U} \mathbf{O}_{2}$ & $\mathbf{U}$ \\
\hline $200{ }^{\circ} \mathrm{C}$ & 22,3 & - & 30,5 \\
\hline $500{ }^{\circ} \mathrm{C}$ & 41,2 & 4,0 & 36,6 \\
\hline $1000{ }^{\circ} \mathrm{C}$ & - & 2,1 & - \\
\hline $\begin{array}{l}\text { Coeficiente de } \\
\text { expansão linear } \\
\left(\mathrm{x} 10^{-6} \mathrm{k}^{-1}\right)\end{array}$ & 20 & 9 & 18 \\
\hline
\end{tabular}

\subsubsection{Resistência à corrosão}

Quando se adiciona elementos de liga altamente miscíveis na fase y ao urânio, como $\mathrm{Zr}$ e Nb, é possível a inserção em concentrações tais que a fase y é obtida à temperaturas ambientes. A liga resultante, em geral, apresenta boa resistência à corrosão em água (SMITH, 1967; TOTEMEIER, 1995).

A melhoria na resistência à corrosão da fase y está associada à melhor aderência de um filme de óxido sobre essa superfície, que atua de modo protetor, isolando a superfície da atmosfera oxidante. Esse filme é decorrência da mudança causada pelos elementos de liga em parâmetros como difusividade do íon de oxigênio e energia de formação do óxido (McWHIRTER; DRALEY, 1952).

A adição simultânea de nióbio e zircônio ao urânio torna possível a obtenção de uma resistência à corrosão similar à obtida para os sistemas U-Nb e U-Zr, com menores porcentagens de elementos de liga (YAKEL, 1969). Somente as ligas de 
urânio com microestrutura livre de fase a possuem uma resistência à corrosão em água suficientemente boa para o uso como combustível. Entretanto, a fase martensítica a' apresenta uma melhora na resistência à corrosão em água devido à baixa capacidade de absorver o hidrogênio em sua estrutura. A Tabela 4 apresenta propriedades de corrosão para algumas ligas ternárias U-Nb-Zr.

Tabela 4: Aspectos de resistência à corrosão ligas ternária U-Nb-Zr recozidas $1000^{\circ} \mathrm{C}$ e têmperadas em água (DRALEY, et al., 1957).

\begin{tabular}{|c|c|c|}
\hline \multicolumn{2}{|c|}{ Composição (\% massa) } & \multirow[t]{2}{*}{ Observações } \\
\hline $\mathrm{Nb}$ & $\mathrm{Zr}$ & \\
\hline 1,5 & 1,5 & $\begin{array}{c}\text { Desintegra em aproximadamente } 24 \mathrm{~h} \text {, em água } \\
\text { desmineralizada ou oxigenada a } 260{ }^{\circ} \mathrm{C} \text {. }\end{array}$ \\
\hline 2 & 4 & $\begin{array}{l}\text { Taxa de perda de metal: aproximadamente } 25 \\
\mathrm{mg} / \mathrm{cm}^{2} \mathrm{~h}\end{array}$ \\
\hline 1,5 & 5 & $\begin{array}{l}\text { Sem sinais de corrosão mesmo após } 237 \mathrm{~h} \text { em } \\
\text { água a } 350{ }^{\circ} \mathrm{C}\end{array}$ \\
\hline 0,51 & 4,90 & Desintegra após $72 \mathrm{~h}$ em água a $260{ }^{\circ} \mathrm{C}$ \\
\hline 1,06 & 4,85 & Desintegra após $72 \mathrm{~h}$ em água a $260^{\circ} \mathrm{C}$ \\
\hline 1,47 & 4,80 & $\begin{array}{l}\text { Taxa de perda de metal: aproximadamente } 14 \\
\mathrm{mg} / \mathrm{cm}^{2} \mathrm{~h} .\end{array}$ \\
\hline 2 & 4,80 & $\begin{array}{l}\text { Taxa de perda de metal: aproximadamente } 15 \\
\mathrm{mg} / \mathrm{cm}^{2} \mathrm{~h} .\end{array}$ \\
\hline
\end{tabular}

A Tabela 4 mostra que uma quantidade de $1,5 \%$ de nióbio é suficiente para atingir uma boa resistência à corrosão, e que a quantidade mínima necessária de zircônio é de $5 \%$.

\subsubsection{Dureza}

A adição de elementos de liga, gerando solução sólida substitucional, causa mudança na estrutura cristalina estável e assim modifica as propriedades de dureza. $\mathrm{O}$ conhecimento das propriedades de dureza da liga é de grande importância, pois sendo 
a medida de resistência mecânica a uma deformação plástica superficial, serve como indicativo de outras propriedades mecânicas, o que pode ajudar em uma possível definição de método de conformação do elemento combustível (KAUFMANN, 1962).

Das fases presentes nesse sistema, a fase $\gamma$, cúbica de corpo centrado, é a que apresenta a maior ductilidade. A propriedade de dureza no sistema U-Nb-Zr é dependente tanto da composição da liga, ou seja, da quantidade de elementos de liga como da temperatura onde ocorrem as transformações de fase. Na Figura 14, é apresentada a relação entre a dureza e a temperatura de transformação da liga U-1,5Nb-5Zr. Na figura, é possível observar que a curva possui um máximo para faixas de temperatura de estabilidade da fase $\alpha$. Essa dependência é reportada na literatura em diversos casos de composição (WILKINSON, Vol. II, 1962). Tendo em vista que a dureza é dependente desses dois fatores, a obtenção de um valor ótimo para dureza dependerá de uma ponderação entre a adição de elementos de liga e tratamentos térmicos, seja de têmpera ou envelhecimento.

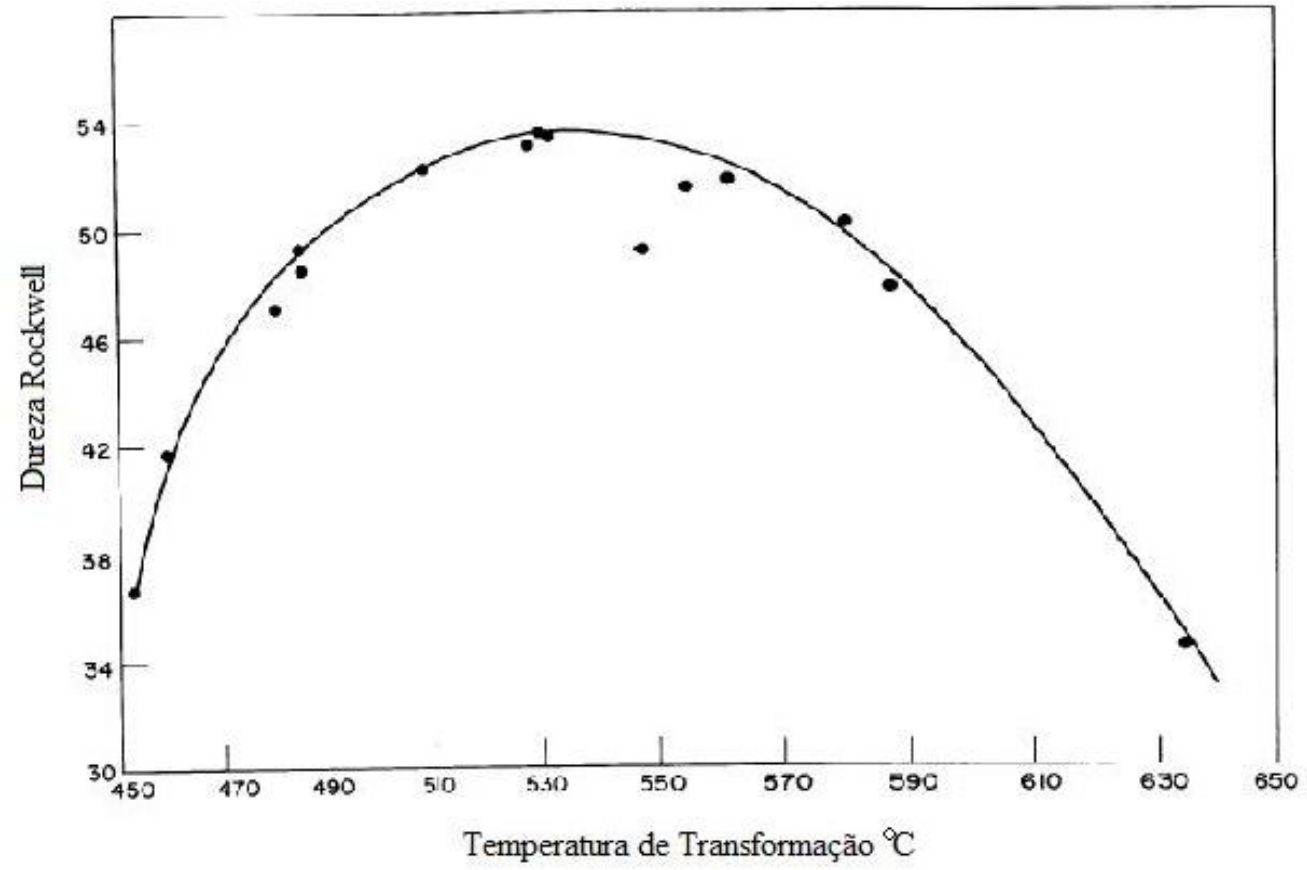

Figura 14: Dureza versus temperatura de transformação da liga U-1,5Nb-5Zr (DWIGHT; MUELLER, 1956). 


\subsubsection{Influência do carbono em ligas $\mathrm{U}-\mathrm{Nb}-\mathrm{Zr}$}

Neste item examina-se o efeito do carbono no sistema U-Nb-Zr, uma vez que este elemento é uma impureza normalmente encontrada no urânio, resultante das operações de redução e refusão de refino. A Figura 15 apresenta o diagrama de fases para o sistema U-C.

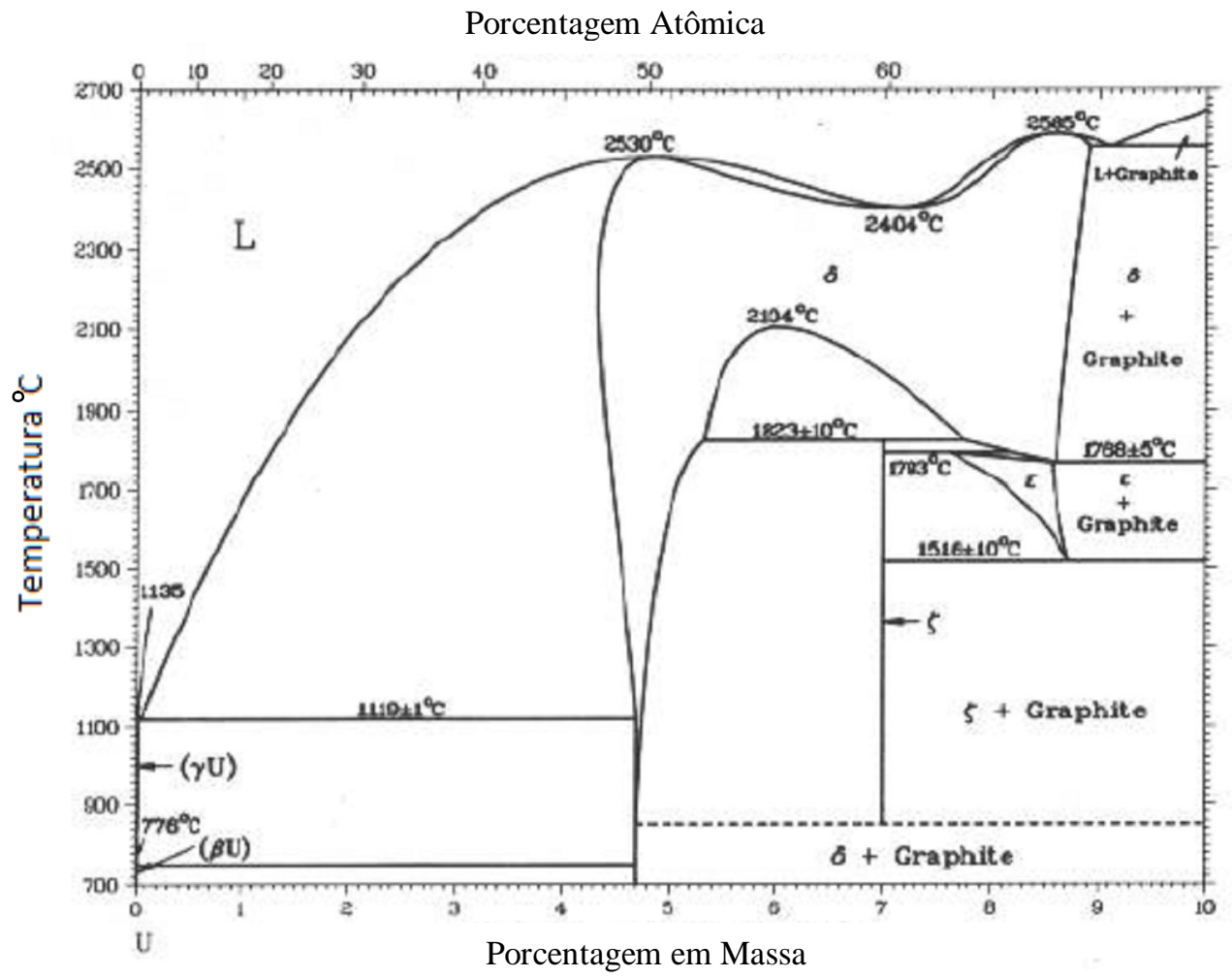

Figura 15: Diagrama de fases binário U-C (ASM Handbook ,vol. 3, 1992).

A solubilidade do carbono na fase $\alpha$ do urânio é inferior a 20 ppm, e menor que 150 ppm na fase $y$, a $1132^{\circ} \mathrm{C}$. Na fase y do urânio, a solubilidade do carbono é de 65 ppm a $800 \stackrel{\circ}{ } \mathrm{C}$ e de 115 ppm a $1050 \stackrel{\circ}{\circ}$ (BLUMENTHAL, 1959).

Estudos mostram a influência de carbono que está sempre presente como impureza no urânio metálico quando obtido pelas técnicas correntes, estando 
solubilizado no urânio líquido e praticamente não-solubilizado na fase sólida (MAGNIER, 1969). Os seguintes efeitos foram observados:

I. Para teores de carbono hipoeutéticos menores que 500 ppm, o carboneto deverá precipitar-se em uma matriz parcial ou totalmente solidificada, resultando assim, numa ação fraca com relação ao refino de grão;

II. Para teores hipereutéticos, os carbonetos precipitam antes que haja a solidificação da matriz, resultando assim núcleos heterogêneos de solidificação e consequente estrutura solidificada de grãos finos;

III. Para elevados teores de carbono, começa haver precipitação de carbonetos a temperaturas elevadas, resultando num coalescimento rápido desses precipitados. Em conseqüência, essas partículas vão tornar-se mais volumosas e menos numerosas, resultando numa diminuição de eficiência do papel de núcleo de solidificação.

Conclui-se que a presença do carbono no líquido diminui a velocidade de crescimento do sólido, ou melhor, dos grãos metálicos, podendo modificar as propriedades de interface (COLOMBIE, et al., 1968). Esta ação é proporcional ao teor de carbono e se superpõe à ação de nucleação heterogênea, para concentrações de ordem de 1000 ppm. A importância desse último fato está ligada à dispersão destas inclusões (COLOMBIE, et al., 1968).

Tem-se ainda que o aumento no teor de carbono diminui a instabilidade dimensional do urânio, quando este é submetido a ciclos térmicos (SHOBER; MARSH, 1954). Acima de $0,4 \%$ de carbono têm-se urânio muito estável. Quanto à microestrutura do urânio puro, a literatura (SHOBER; MARSH, 1954) relata que não há tendência de precipitação de carbonetos nos contornos de grão. Os carbonetos começam a se agrupar na liga para teores próximos a 0,22\% de carbono, e se coalescem para teores entre 0,34\% e 0,57\% (SHOBER; MARSH, 1954). 


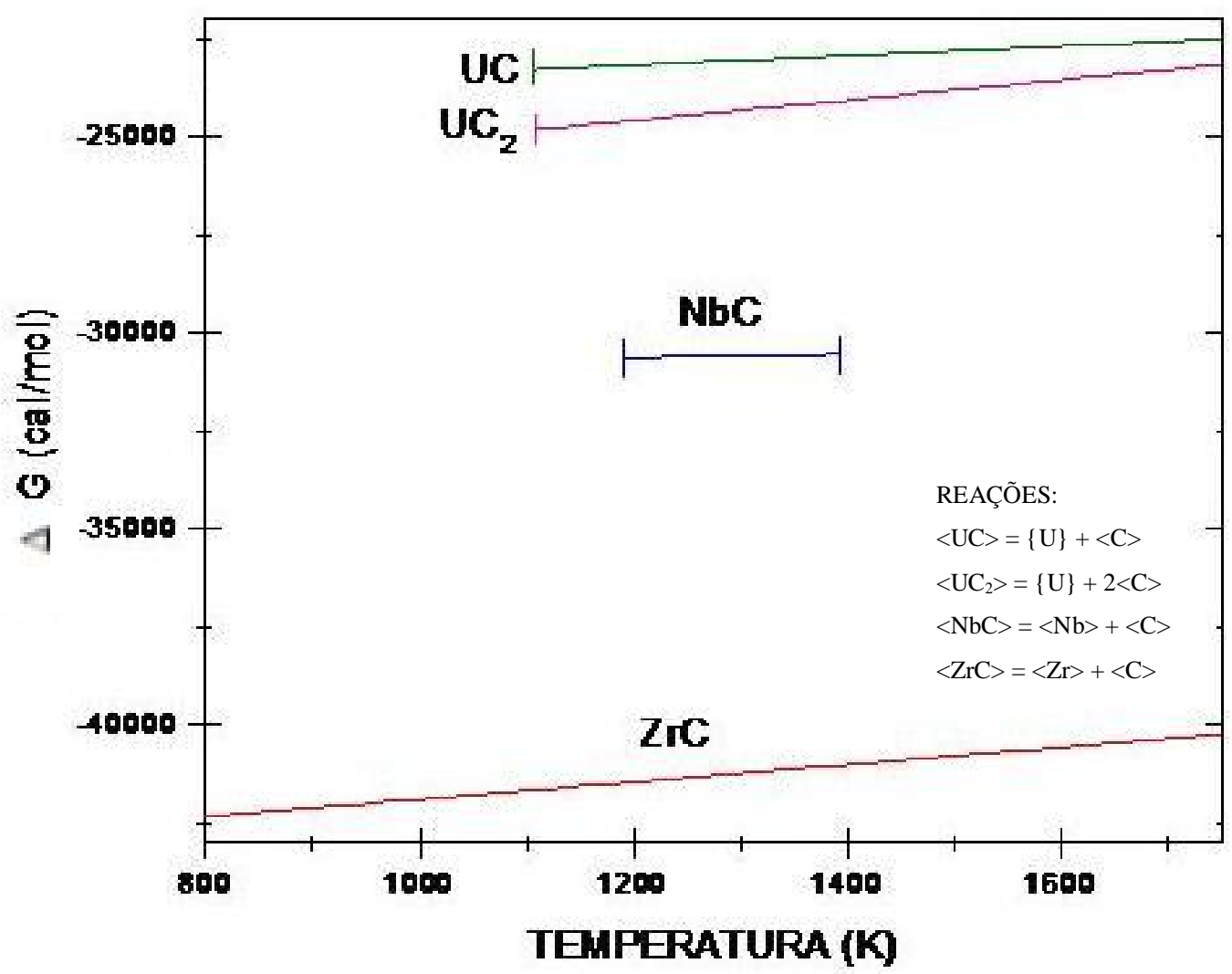

Figura 16: Energia livre de formação dos carbonetos para os elementos $\mathrm{U}, \mathrm{Nb}$ e Zr (KUBASCHEWSKI; ALCOCK, 1979).

A presença dos elementos $\mathrm{Nb}$ e $\mathrm{Zr}$ desloca o ponto eutético do sistema U-C, modificando a faixa de composição na qual se dá a precipitação, assim como a morfologia dos precipitados (WILKINSON, Vol. II, 1962).

A Figura 16 apresenta o gráfico da energia livre de Gibbs de formação dos carbonetos para os elementos $\mathrm{U}, \mathrm{Nb}$ e $\mathrm{Zr}$, obtidos a partir de cálculos termodinâmicos (KUBASCHEWSKI; ALCOCK, 1979). Analisando o gráfico, fica evidente a forte tendência de reação do carbono com o zircônio, sendo esperada a formação de carbonetos nas ligas fundidas do tipo ZrC.

A compreensão da influência do carbono no sistema U-Nb-Zr será essencial para a interpretação das estruturas obtidas nas peças fundidas, bem como na elaboração de tratamentos térmicos para refino dessa estrutura. 


\subsection{Aplicações nucleares das ligas U-Nb-Zr}

As ligas U-Nb-Zr encontram-se em um grupo que apresenta alta solubilidade na fase y do urânio. O sistema U-Nb-Zr é o que possui maior região de fase y estabilizada, dentre os sistemas ternários reportados para o urânio. Essa característica, juntamente com boa estabilidade sob irradiação e sob aplicação de ciclos térmicos e possível resistência à corrosão, fazem o sistema ternário $\mathrm{U}-\mathrm{Nb}-\mathrm{Zr}$ ser particularmente interessante para a fabricação de elementos combustíveis para reatores (MEYER, et al., 2001; WILLIAMS, 1979; YAKEL, 1969).

Uma liga de urânio deve ter vários pré-requisitos para poder ser utilizada como combustível nuclear. Em primeiro lugar, deve-se assegurar uma captura mínima de nêutrons, que permita uma redução do grau de enriquecimento do urânio. Para satisfazer esta exigência, é necessária a utilização de elementos de ligas com pequenas seções de choque de captura de nêutrons. A tabela seguinte apresenta a seção de choque para diversos elementos (ASM Handbook, vol. 2, 1992).

Tabela 5: Secção de choque (em barns) de diversos elementos, para nêutrons térmicos.

\begin{tabular}{|c|c|c|}
\hline Elemento & Número atômico & Secção de choque \\
\hline $\mathrm{Zr}$ & 40 & 0,184 \\
\hline $\mathrm{Nb}$ & 41 & 1,15 \\
\hline $\mathrm{Mo}$ & 42 & 2,6 \\
\hline $\mathrm{Hf}$ & 72 & 104 \\
\hline $\mathrm{Ta}$ & 73 & 20,6 \\
\hline $\mathrm{W}$ & 74 & 18,3 \\
\hline
\end{tabular}

Observa-se que o $\mathrm{Zr}$, juntamente com $\mathrm{Nb}$, apresenta as menores secções de choque, mesmo quando comparado com o Mo, que é outro elemento de alta miscibilidade com a fase $y$ do urânio.

Historicamente, o primeiro combustível utilizado em reatores rápidos refrigerados a metais líquidos (LMR's) (CAHN, et al., 1994) foi um combustível metálico 
devido à sua alta condutividade térmica e elevada densidade. No entanto, os combustíveis metálicos não foram escolhidos como a principal linha de desenvolvimento de reatores nucleares na década de 1960, pois não havia sido demonstrado o elevado potencial de queima destas ligas (alcançou-se um máximo de queima de $3 \%$ ) e não havia um revestimento adequado para operar a temperaturas muito elevadas (IAEA-TECDOC-2374, 2003). O primeiro combustível metálico testado foi constituído de varetas com pouco ou nenhum espaçamento entre o combustível e o revestimento e não havia, portanto, um sistema adequado para retenção dos gases de fissão (IAEA-TECDOC-2374, 2003). Quando o combustível inchava, devido à acumulação dos produtos de fissão, o revestimento deformava e falhava apresentando baixas queimas. Além disso, naquela época, as características básicas do comportamento do combustível metálico sob irradiação não eram conhecidas. Atualmente, estas desvantagens já foram equacionadas com um bom nível de superação (IAEA-TECDOC-2374, 2003). Como atualmente se procura diminuir o enriquecimento dos combustíveis para evitar a geração de $\mathrm{Pu}$ (resíduo do processo de fissão) e o uso desse elemento para fabricação de armas, tornou-se necessária a retomada de pesquisas sobre esses sistemas metálicos.

O sistema U-Nb-Zr pode ser aplicado como elemento combustível sob duas formas de montagem: monolítico tipo placa (KUMMERER, 1980) ou dispersa tipo placa (HOFMAN; SNELGROVE, 1997). A Figura 17 mostra desenhos esquemáticos da montagem desses elementos combustíveis. 


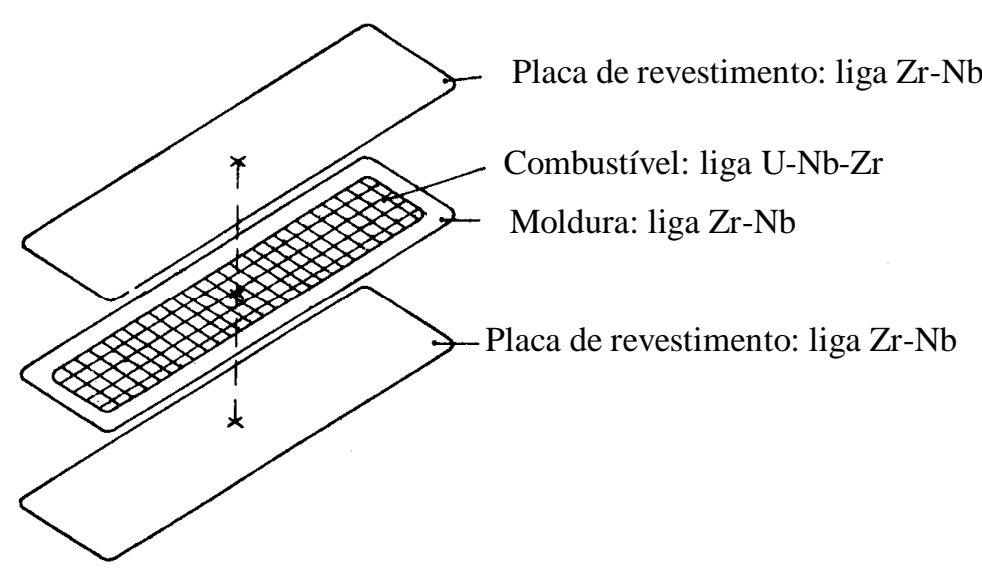

Combustível monolítico

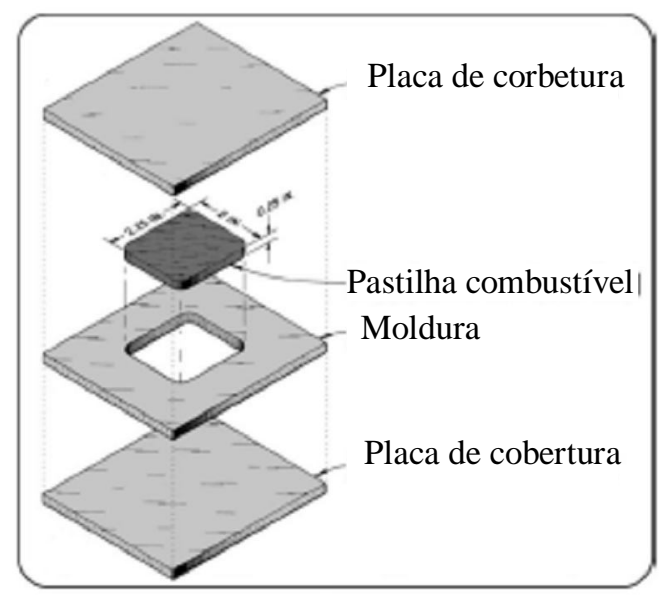

Combustível dispersivo

Figura 17: Desenho esquemático da montagem de um elemento combustível tipo placa; monolítico e dispersivo (HOFMAN; SNELGROVE, 1997; KUMMERER, 1980).

Essa versatilidade das ligas de U-Nb-Zr, torna o sistema uma linha de pesquisa promissora e necessária à evolução da tecnologia de reatores. 


\section{MATERIAIS E MÉTODOS}

Neste capítulo são descritos os materiais utilizados, os procedimentos adotados, os equipamentos usados na preparação das amostras, os tratamentos térmicos realizados e as técnicas de análise empregadas na presente dissertação.

\subsection{Materiais}

Foram preparadas amostras do sistema ternário U-Nb-Zr e dos sistemas binários U-Nb e U-Zr, no canto rico em urânio. Para a elaboração das ligas, os materiais de partidas foram os metais puros urânio, nióbio e zircônio.

O urânio metálico utilizado, procedente do Instituto de Pesquisas Energéticas e Nucleares (IPEN), foi fornecido em seu estado natural (99,275\% do isótopo $238,0,72 \%$ do isótopo 235 e 0,0058 do isótopo 233) na forma de um tarugo cilíndrico, com $33 \mathrm{~mm}$ de diâmetro. Sua composição química é apresentada na Tabela 6. O valor total de impurezas é da ordem de 5490 ppm.

Tabela 6: Composição química (ppm) do urânio metálico utilizado na preparação das ligas.

\begin{tabular}{ccccc}
\hline $\mathbf{B}$ & $\mathbf{M g}$ & $\mathrm{Al}$ & $\mathrm{Cr}$ & $\mathrm{Mn}$ \\
\hline$<0,09$ & $10,04 \pm 0,01$ & $4745,90 \pm 41,50$ & $13,76 \pm 0,39$ & $136,36 \pm 1,31$ \\
\hline $\mathbf{F e}$ & $\mathbf{C o}$ & $\mathrm{Ni}$ & $\mathbf{C u}$ & $\mathbf{Z n}$ \\
\hline $161,87 \pm 4,81$ & $<0,01$ & $12,50 \pm 0,38$ & $13,79 \pm 2,66$ & $5,40 \pm 0,72$ \\
\hline $\mathbf{A g}$ & $\mathbf{S i}$ & $\mathrm{Ti}$ & $\mathbf{V}$ & $\mathbf{M o}$ \\
\hline$<0,01$ & $20,97 \pm 0,12$ & $4,15 \pm 0,05$ & $<0,01$ & $<0,08$ \\
\hline $\mathbf{W}$ & $\mathbf{H}$ & $\mathbf{O}$ & $\mathbf{C}$ & $\mathbf{N}$ \\
\hline$<0,06$ & $1,42 \pm 0,18$ & $15 \pm 1$ & $350 \pm 10$ & $<0,0001$
\end{tabular}


O nióbio foi adquirido no mercado internacional na forma de pó, com pureza de $99,8 \%$. A sua composição química, em porcentagem em massa, é apresentada na Tabela 7.

Tabela 7: Composição química (ppm) do nióbio utilizado na preparação das ligas.

\begin{tabular}{ccccc}
\hline $\mathbf{B}$ & $\mathrm{Mg}$ & $\mathrm{Al}$ & $\mathrm{Cr}$ & $\mathrm{Mn}$ \\
\hline$<0,01$ & $34,70 \pm 0,29$ & $6,51 \pm 0,11$ & $<0,02$ & $1,84 \pm 0,05$ \\
\hline $\mathrm{Fe}$ & $\mathrm{Co}$ & $\mathrm{Ni}$ & $\mathrm{Cu}$ & $\mathrm{Zn}$ \\
\hline $183,3 \pm 0,68$ & $<0,02$ & $<0,02$ & $<0,01$ & $<0,01$ \\
\hline $\mathrm{Ag}$ & $\mathrm{Si}$ & $\mathrm{Ti}$ & $\mathbf{V}$ & $\mathrm{Mo}$ \\
\hline$<0,01$ & $637,21 \pm 0,92$ & $8,80 \pm 0,17$ & $27,86 \pm 0,87$ & $<0,03$ \\
\hline $\mathbf{W}$ & $\mathbf{H}$ & $\mathbf{O}$ & $\mathbf{C}$ & $\mathbf{N}$ \\
\hline$<0,03$ & $16,0 \pm 0,3$ & $1760 \pm 11$ & $70 \pm 10$ & $<0,01$ \\
\hline
\end{tabular}

O zircônio foi adquirido na forma de esponja, com grau nuclearmente puro e foi disponibilizado pelo Centro Tecnológico da Marinha em São Paulo (CTMSP). A sua composição química, em porcentagem em massa, é apresentada na Tabela 8.

Tabela 8: Composição química (\% massa) do zircônio utilizado na preparação das ligas.

\begin{tabular}{ccccc}
\hline Na & Mg & Al & Mn & Fe \\
\hline $0,053 \pm 0,001$ & $0,022 \pm 0,001$ & $0,051 \pm 0,001$ & $0,002 \pm 0,001$ & $0,166 \pm 0,002$ \\
\hline Ni & $\mathrm{Cu}$ & $\mathrm{Zn}$ & $\mathrm{Zr}$ & Hf \\
\hline $0,024 \pm 0,003$ & $0,004 \pm 0,001$ & $<0,001$ & $99,6 \pm 0,5$ & $<0,002$ \\
\hline
\end{tabular}

\subsection{Preparação das ligas}

A fusão das ligas foi realizada em um forno a plasma, modelo Discovery, fabricado pela empresa EDG Equipamentos e Controles Ltda, que se encontra 
instalado na Divisão de Desenvolvimento e Caracterização Física do Laboratório de Materiais Nucleares (LABMAT), no Centro Experimental Aramar do CTMSP.

Fornos a plasma utilizam o plasma como meio de transmissão de energia para promover o aquecimento e a fusão de metais e ligas metálicas, sendo o calor gerado pelo plasma suficiente para promover a fusão da maioria dos metais e ligas conhecidos (ASM Handbook, vol. 15, 1992). O gás utilizado foi o argônio que pertence ao grupo dos gases nobres, cuja característica principal é a inércia química.

O forno é composto externamente por um modulo único, havendo duas câmaras internas, uma de fusão e uma de fundição. A câmara de fusão é composta pelo suporte das amostras (um cadinho de cobre) e de um eletrodo de tungstênio. A câmara de fundição é composta por uma coquillha de alumínio, suportada por um elevador, onde o cadinho, com um movimento basculante, derrama o material líquido após o término da fusão, para obtenção da amostra fundida (ASM Handbook, vol. 15, 1992).

As massas foram inicialmente pesadas e em seguida, foram realizadas as fusões. Para se obter a homogeneidade desejada, foram realizadas entre 5 a 6 fusões para cada amostra. Os corpos de prova obtidos por esse processo possuem formato de botão com aproximadamente $20 \mathrm{~mm}$ de diâmetro e massa entre 30 e 40 gramas. A seguir, na Tabela 9, são apresentadas as composições das ligas produzidas:

Tabela 9: Composição nominal (\% massa) das ligas produzidas.

\begin{tabular}{|c|c|c|c|}
\hline Liga & $\mathbf{U}$ & $\mathbf{N b}$ & $\mathbf{Z r}$ \\
\hline $\mathrm{a}$ & 95 & 2,5 & 2,5 \\
\hline $\mathrm{b}$ & 90 & 5 & 5 \\
\hline $\mathrm{c}$ & 85 & 7,5 & 7,5 \\
\hline $\mathrm{d}$ & 80 & 10 & 10 \\
\hline $\mathrm{e}$ & 90 & 10 & 0 \\
\hline $\mathrm{f}$ & 90 & 0 & 10 \\
\hline $\mathrm{g}$ & 85 & 15 & 0 \\
\hline $\mathrm{h}$ & 85 & 0 & 15 \\
\hline $\mathrm{i}$ & 80 & 20 & 0 \\
\hline $\mathrm{j}$ & 80 & 0 & 20 \\
\hline
\end{tabular}

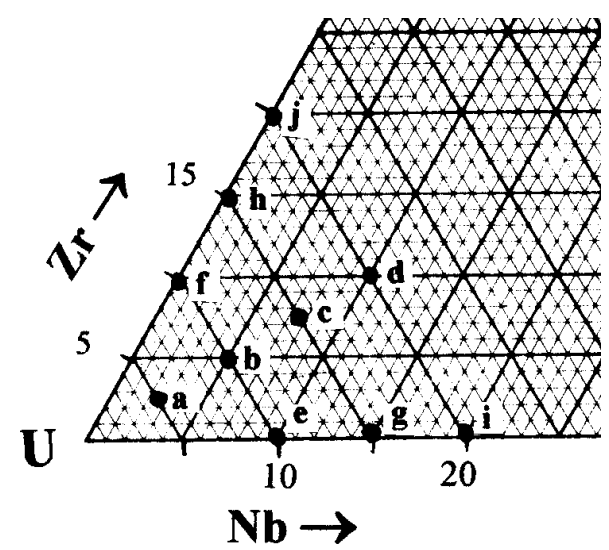


Para a fusão das ligas ternárias foi produzida inicialmente uma pré-liga binária de $\mathrm{Nb}: Z r$ na razão de 1:1, de modo a propiciar uma distribuição de carga que facilitasse a homogeneidade da liga e também a formação do arco de plasma.

\subsection{Tratamentos térmicos}

Os tratamentos térmicos foram realizados em forno resistivo, fabricado pela empresa EDG, composto por um tubo de alumina isolado nas suas duas extremidades. Em uma das extremidades existem três orifícios, um para a entrada de argônio, outro para a fixação de um termopar e outro para entrada da haste que empurra a amostra para realização da têmpera (NOVIKOV, 1994). A Figura 18 ilustra o sistema utilizado para realização dos tratamentos térmicos.

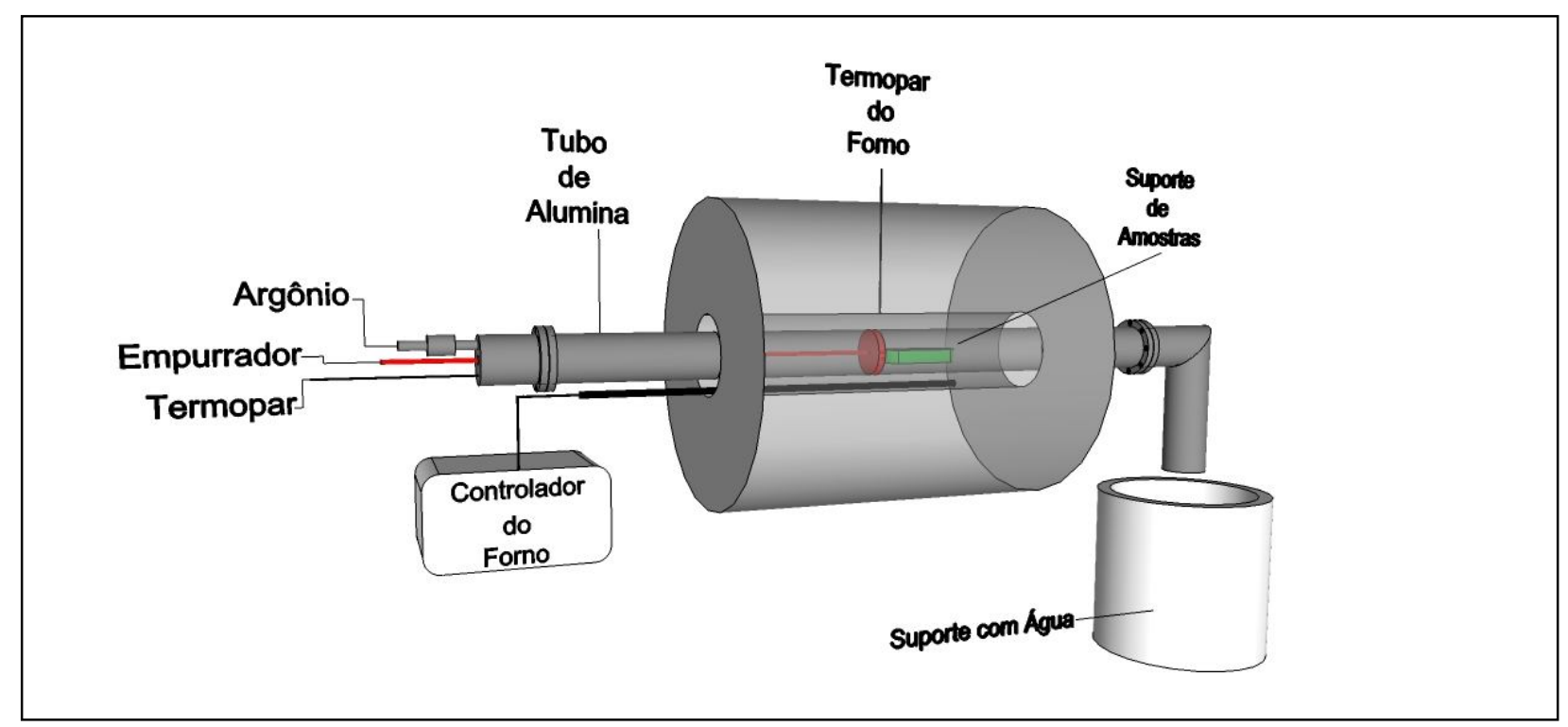

Figura 18: Esquema de montagem do equipamento para realização dos tratamentos térmicos.

Os dois principais objetivos dos tratamentos térmicos foram: eliminar ou minimizar a micro-segregação (solubilização) proveniente da solidificação e em seguida obter as microestruturas de equilíbrio nas temperaturas desejadas (estabilização).

As amostras foram tratadas inicialmente a $1000 \stackrel{\circ}{\circ}$ e resfriadas em água, com o objetivo de homogeneização química. Em seguida foram feitos tratamentos isotérmicos 
para precipitação de fases nas temperaturas de interesse, ou seja, nas secções isotérmicas do diagrama de fases (700 ํㅡ e $\left.500^{\circ} \mathrm{C}\right)$, seguidos de resfriamento em água. Nos ciclos acima descritos, de solubilização e precipitação de fases, as amostras foram mantidas respectivamente por períodos de 96 h e 20 h cada, sendo utilizada uma taxa de aquecimento de $15^{\circ} \mathrm{C} / \mathrm{min}$. A Figura 19 ilustra os ciclos térmicos realizados nas ligas estudadas.

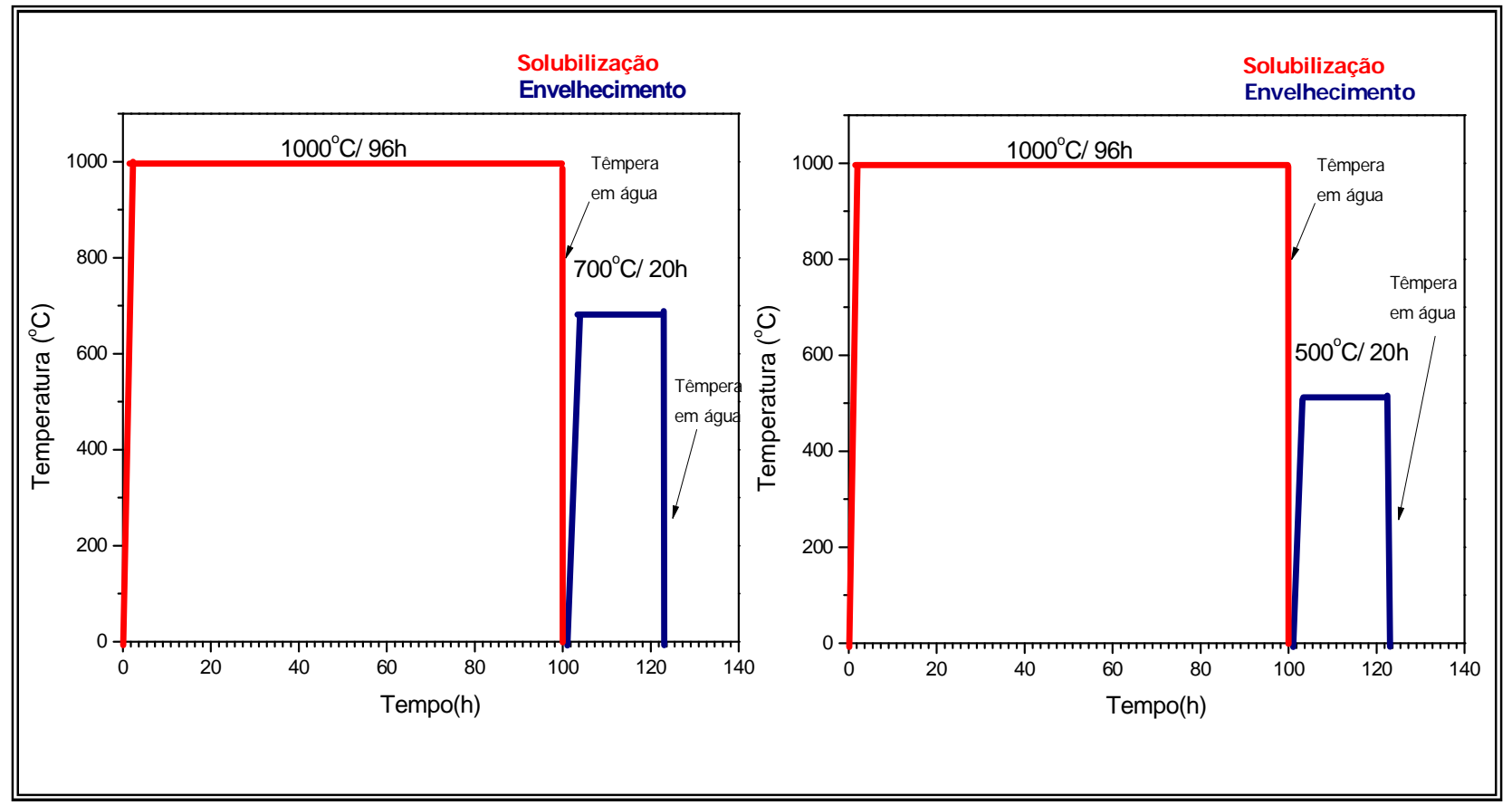

Figura 19: Esquema ilustrativo dos ciclos térmicos utilizados no presente trabalho.

\subsection{Técnicas de caracterização microestrutural}

A caracterização microestrutural das amostras foi realizada com auxílio de diversas técnicas complementares, tais como microscopia óptica (MO), microscopia eletrônica de varredura (MEV) com microanálise química (EDS; Energy Dispesive Spectroscopy), difração de raios X e microdureza Vickers. 


\subsubsection{Preparação metalográfica}

As amostras para a análise metalográfica foram preparadas mecanicamente. Inicialmente, amostras foram cortadas e em seguida embutidas a quente em resina acrílica, lixadas e polidas com pasta de diamante. O lixamento foi realizado com lixas de granulometria \#100, \#320, \#400, \#600, \#1200 e \#2400. O polimento mecânico final foi realizado com pasta de diamante de $6 \mu \mathrm{m}, 3 \mu \mathrm{m}$ e $1 \mu \mathrm{m}$.

Para revelar as fases presentes na microestrutura, foram utilizados os seguintes ataques metalográficos por imersão em solução:

$40 \mathrm{~mL}$ ácido nítrico $\left(\mathrm{HNO}_{3}\right), 40 \mathrm{~mL}$ glicerina $\left(\mathrm{C}_{3} \mathrm{H}_{8} \mathrm{O}_{3}\right)$ e $10 \mathrm{~mL}$ de ácido fluorídrico (HF), de 5 - 20 segundos.

$20 \mathrm{~mL}$ água oxigenada $\left(\mathrm{H}_{2} \mathrm{O}_{2}\right), 5 \mathrm{~mL}$ de ácido sulfúrico e uma gota do reagente extran, de 5 - 20 segundos.

> Solução l: $40 \mathrm{~mL} \mathrm{HNO}$, $40 \mathrm{~mL}$ glicerina e $10 \mathrm{~mL} \mathrm{HF}$, por 5 segundos.

Solução II: $70 \mathrm{~mL} \mathrm{H} \mathrm{H}_{3} \mathrm{PO}, 25 \mathrm{~mL} \mathrm{H} \mathrm{SO}_{4}, 5 \mathrm{~mL} \mathrm{HNO} \mathrm{HN}_{3}$ por 5 minutos.

Foi utilizado ainda ataque eletrolítico com o seguinte eletrólito:

> Ácido perclórico 20\%

> Álcool etílico $70 \%$

$>$ Etileno glicol $10 \%$

Com cátodo de aço inoxidável e uma diferença de potencial aplicada da ordem de $20 \mathrm{~V}$. Os ataques escolhidos variaram de acordo com as composições e tratamentos térmicos das ligas. 


\subsubsection{Microscopia óptica (MO)}

Após a preparação metalográfica, muitos aspectos da microestrutura se tornam visíveis no microscópio óptico. A microscopia óptica, cujos elementos básicos são o sistema óptico e a iluminação, podem ser utilizados para observar alguns defeitos cristalinos, tais como contornos de grão e contornos de macla, e fases maiores que 0,5 $\mu \mathrm{m}$. Além disto, esta técnica possibilita a observação e análise de grandes áreas e propicia uma visão geral da microestrutura (PADILHA; AMBROZIO FILHO, 2004).

As amostras deste trabalho foram observadas no microscópio óptico, após preparação metalográfica. Utilizou-se um microscópio óptico da marca Zeiss, com analisador de imagem acoplado, disponível na Divisão de Caracterização Física do LABMAT.

\subsubsection{Microscopia eletrônica de varredura (MEV)}

O MEV é basicamente composto pelos seguintes componentes: coluna ópticoelêtronica, câmara para amostras, sistema de vácuo e um sistema de imagem. As imagens no MEV são construídas ponto a ponto de modo semelhante à formação de imagem de uma televisão. $O$ feixe de elétrons de alta energia é focalizado num ponto da amostra, onde por interações elásticas e inelásticas são emitidos respectivamente elétrons retroespalhados e secundários, que serão coletados e amplificados para a obtenção de um sinal elétrico.

A imagem observada em um MEV é dada pela variação de contraste, o qual é condicionado a diversas variáveis dentre as quais se destaca, pela forte dependência, o contraste topográfico (uma vez que a geração de elétrons é fortemente dependente do ângulo de coleta dos elétrons emitidos) e contraste de número atômico. Quanto maior for o número atômico, menor é o volume de interação gerado pelo feixe, relação quantizada pela equação de Kanaya-Okayama (GOLDSTEIN, 2003), e 
consequentemente há uma alteração na energia dos elétrons emitidos e assim do sinal gerado.

No MEV são geralmente utilizadas ampliações entre 10 e mais de 50.000 vezes (valores dependentes do tipo de filamento utilizado), ou seja, uma ordem de grandeza maior que do microscópio óptico, além de proporcionar imagem com profundidade de foco. Para análise no MEV, a superfície pode ou não estar polida e atacada quimicamente, porém ela deve ser condutora de eletricidade.

As amostras deste trabalho foram observadas no microscópio eletrônico de varredura (MEV) após preparação metalográfica. Para observação das microestruturas foram utilizadas predominantemente imagens de elétrons retroespalhados, devido às diferenças de número atômico entre os elementos urânio, nióbio e zircônio. Utilizou-se um MEV da marca Philips, modelo PE1418, disponível na Divisão de Caracterização Física do LABMAT.

\subsubsection{Análise por dispersão de energia (EDS)}

Para análise química de microrregiões das amostras foi utilizada análise por dispersão de energia (EDS), acoplada ao MEV.

Ao incidir sobre a amostra, os elétrons de alta energia podem remover um elétron de seu orbital por colisões inelásticas e ejetá-lo do átomo, fazendo com que este passe a um estado excitado. Para que ocorra a estabilização do átomo, um elétron de uma órbita de maior energia deve preencher o vazio criado pela ejeção do elétron e o excesso de energia é emitido como um fóton de raios $X$. A energia desses raios $X$ é característica de cada átomo, o que torna possível a identificação de elementos presentes na amostra (CHANDLER, 1977).

A possibilidade de realização da análise química resulta da existência de uma relação entre o comprimento de onda dos raios $X$ característicos e o número atômico do elemento, expressão obtida por Moseley em 1914 (CHANDLER, 1977), expressa da seguinte forma: 
$I=B /(Z-C)^{2}$

Onde:

I é o comprimento de onda; B, C são constantes diferentes para camadas K, L, M; e Z é o número atômico.

Com auxílio da equação da energia do fóton, uma energia específica é definida para cada comprimento de onda, caracterizando a amostra (CHANDLER, 1977).

$O$ detector de um espectrômetro de energia dispersiva consiste de um cristal de silício, sobre o qual é aplicada uma tensão elétrica. Uma camada de lítio é parcialmente difundida no cristal de silício, formando uma camada extrínseca $p$ sobre o qual serão incididos os raios $X$ característicos, gerando um sinal elétrico. $O$ detector é mantido na temperatura do nitrogênio líquido para minimizar qualquer evento termicamente induzido (CHANDLER, 1977).

O urânio possui emissões características nas camadas $L$ e $M$, já o nióbio e zircônio apresentam emissões da camada L. Para que se entendam melhor os espectros obtidos para as ligas é apresentado aqui as energias referentes a emissões das camadas $L$ e $M$ do urânio e $L$ do nióbio e zircônio: 
Tabela 10: Linhas características de emissão de raios X dos elementos U, Nb e Zr (GOLDSTEIN, 2003; OHNO, 1986).

\begin{tabular}{|c|c|c|c|}
\hline \multicolumn{5}{|c|}{ Linhas características de emissão de raios X dos elementos U, Nb e Zr } \\
\hline Camada & U (Energia keV) & Nb (Energia keV) & $\mathbf{Z r}$ (Energia keV) \\
\hline $\mathrm{L}_{\mathrm{II} \alpha \beta}$ & 17,16 & 2,37 & 2,22 \\
\hline $\mathrm{L}_{\mathrm{II} \alpha \beta}$ & 20,94 & 2,46 & 2,31 \\
\hline $\mathrm{L}_{\mathrm{I} \alpha \beta}$ & 21,77 & 2,71 & 2,54 \\
\hline $\mathrm{L}_{\alpha}$ & 13,61 & 2,17 & 2,04 \\
\hline $\mathrm{L}_{\beta 1}$ & 17,22 & 2,26 & 2,12 \\
\hline $\mathrm{L}_{\beta 2}$ & 16,43 & - & - \\
\hline $\mathrm{L}_{\gamma}$ & 20,16 & - & - \\
\hline $\mathrm{M}_{\zeta 1}$ & 2,51 & - & - \\
\hline $\mathrm{M}_{\alpha 1}$ & 3,17 & - & - \\
\hline $\mathrm{M}_{\alpha 2}$ & 3,16 & - & - \\
\hline $\mathrm{M}_{\beta}$ & 3,34 & - & - \\
\hline $\mathrm{M}_{\gamma}$ & 3,57 & & - \\
\hline
\end{tabular}

\subsubsection{Difração de raios $X$}

Os raios X são uma forma de onda eletromagnética cujo comprimento é da ordem do espaçamento interatômico. Quando um feixe de raios $X$ incide sobre um cristal, uma fração desse feixe será dispersa em todas as direções pelos elétrons associados a cada átomo (CULLITY, 1978). A lei de Bragg exprime as condições geométricas necessárias para que seja produzida interferência construtiva produzindo um feixe difratado, e é expressa pela seguinte equação:

$$
\mathrm{n} \lambda=2 \mathrm{~d} \operatorname{sen} \theta
$$


onde:

n é o numero da ordem da franja de interferência;

$\lambda$ é o comprimento de onda da radiação característica utilizada;

$\theta$ é o ângulo de incidência; $\mathrm{e}$

d é o espaçamento entre planos cristalinos.

A análise da posição (20) dos feixes difratados leva à identificação da fase presente na amostra, ao tamanho, forma e orientação da célula unitária. A intensidade e a forma dos máximos (picos) de difração também propiciam informações importantes sobre as fases presentes (CULLITY, 1978) como a identificação de fases por meio de suas estruturas cristalinas e a determinação de suas quantidades. A difração de raios $X$ é uma técnica muito precisa, capaz de medir variações de nanômetros. Por outro lado, ela apresenta limite de detecção pobre, pois é incapaz de detectar a presença de uma fase cuja quantidade seja inferior à 1\% em volume (CULLITY, 1978).

As amostras deste trabalho foram analisadas, após polimento, em um difratômetro de raios $X$ da marca Shimatzu, com tubo de CuKa e monocromador de radiação, instalado na Divisão de Caracterização Física do LABMAT.

\subsubsection{O método Rietveld}

O método de refinamento estrutural Rietveld baseia-se na construção de um padrão de difração calculado (ou como também é chamado, um padrão de difração simulado) de acordo com um modelo para uma estrutura cristalina, obtido pela introdução das grandezas pertinentes para descrevê-lo. O seu refinamento ou ajuste é feito visando obter uma mínima diferença em comparação com o padrão de difração experimental. Se toma, sob determinados critérios, os parâmetros do padrão simulado e refinado como sendo suficientemente próximos aos dos parâmetros da estrutura real de nossa amostra (YOUNG, 1995). 
Por meio das informações cristalográficas do grupo espacial, parâmetros de rede e posição atômica com valores próximos aos valores reais da estrutura do material em estudo, um padrão de difração pode ser simulado com o uso de uma equação ou modelo, que fornece a intensidade de cada reflexão sugerida por Rietveld (YOUNG, 1995) na forma:

$$
y_{c i}=s \Sigma L_{k}\left[F_{k}\right]^{2} \Phi\left(2 \theta_{i}-2 \theta_{k}\right) P_{k} A+y_{b i}
$$

\section{Sendo:}

$s$ é o fator escala.

k representa os índices de Miller, h k I, para a reflexão de Bragg.

$L_{k}$ este fator contém os fatores de Lorentz, polarização, e multiplicidade.

$F_{k}$ é o fator de estrutura da k-ésima reflexão de Bragg.

$\Phi$ é a função perfil de reflexão.

$2 \theta_{i}$ é o ângulo do i-ésimo ponto no padrão.

$2 \theta_{\mathrm{k}}$ é o ângulo de Bragg calculado.

$P_{k}$ é a função orientação preferencial

A é o fator de absorção.

$y_{b i}$ é a intensidade da linha de base no i-ésimo passo.

Esta equação dá a intensidade simulada para definir um padrão de difração simulado que pode se ajustar de forma mais satisfatória a um padrão de difração experimental (YOUNG, 1995). O método Rietveld baseia-se no refinamento ou ajuste dos parâmetros do padrão simulado de difração, de modo a este apresentar uma diferença mínima em relação ao padrão experimental. Isto é feito através do método de ajuste por mínimos quadrados (RUGGIERO; LOPES, 1997).

Todos os ajustes realizados foram feitos usando o programa livre GSAS com interface para Windows EXPIGUI (LARSON; VON DREELE, 2004) sendo inseridos no modelo apenas átomos de urânio nas referentes estruturas; cúbicas de corpo centrado de grupo espacial Im-3m e ortorrômbica de grupo espacial $\mathrm{Cmcm}$. Durante o refinamento as variáveis estruturais ficaram livres de modo a justar-se com o perfil 
experimental e essas mudanças na estrutura são então associadas à solução sólida com os elementos $\mathrm{Nb}$ e $\mathrm{Zr}$.

\subsubsection{Medidas de dureza}

Dureza é considerada uma medida da resistência mecânica de um material à deformação plástica localizada (SOUZA, 1982). Os ensaios de dureza são ensaios de fácil execução e de grande utilidade para avaliação da microestrutura de material metálico. O método conhecido como dureza Vickers utiliza um penetrador de diamante em forma de pirâmide de base quadrada, com ângulo de $136^{\circ}$ entre as faces opostas (SOUZA, 1982). Para cada ensaio, o penetrador é forçado por uma força $\mathbf{F}$ sobre a superfície de uma amostra plana e polida. A impressão resultante da aplicação de uma carga $\mathbf{F}$ é observada sob um microscópio e é feita a medida das diagonais (d) da impressão. A dureza Vickers (HV) é obtida com auxílio da fórmula (SOUZA, 1982):

$$
H V=1,8544 F / d^{2}
$$

As cargas aplicadas podem variar em uma ampla faixa. Nas análises realizadas no presente trabalho foram utilizadas cargas de $0,5 \mathrm{~kg}$ e foram feitas dez medidas por amostra. Os ensaios foram realizados em um durômetro marca Leco, modelo LV700AT, disponível na Divisão de Caracterização Física do LABMAT. 


\section{RESULTADOS}

Os resultados foram subdivididos e serão apresentados na seguinte sequência: caracterização microestrutural das ligas no estado bruto de fundição, após tratamento térmico de solubilização e após os tratamentos térmicos de envelhecimento a $700{ }^{\circ} \mathrm{C} \mathrm{e}$ a $500{ }^{\circ} \mathrm{C}$.

\subsection{Caracterização microestrutural das ligas}

Neste item serão apresentados os resultados de caracterização microestrutural das ligas no estado bruto de fundição e tratados termicamente, obtidos com as seguintes técnicas de análise: microscopia óptica, microscopia eletrônica de varredura acompanhada de análise química de microregiões por dispersão de energia (EDS), difração de raios $\mathrm{X}$ e dureza Vickers.

\subsubsection{Estado bruto de fundição}

Em seguida serão apresentados resultados referentes às ligas U-2,5Nb-2,5Zr (A), U-5Nb-5Zr (B), U-7,5Nb-7,5Zr (C), U-10Nb-10Zr (D), U-10Nb (E), U-10Zr (F), U$15 \mathrm{Nb}(\mathrm{G}), \mathrm{U}-15 \mathrm{Zr}(\mathrm{H}), \mathrm{U}-20 \mathrm{Nb}(\mathrm{I})$ e U-20Zr (J) no estado bruto de fundição.

\subsubsection{Microscopia óptica (MO)}

A Figura 20 apresenta a microestrutura das ligas fundidas via plasma; as peças foram analisadas após realização de ataque metalográfico. No experimento de fusão a plasma, os resfriamentos foram realizados no próprio forno e acontecem apenas por 
condução térmica, mantendo a amostra em contato com uma base de cobre e a parte superior em contato com um fluxo de argônio. Como o gás é pior condutor de calor, espera-se que o resfriamento na parte superior ocorra mais lentamente que na parte em contado com a base de cobre. Esta diferença, aliada à geometria da carga, levou à formação das microestruturas observadas na Figura 20.

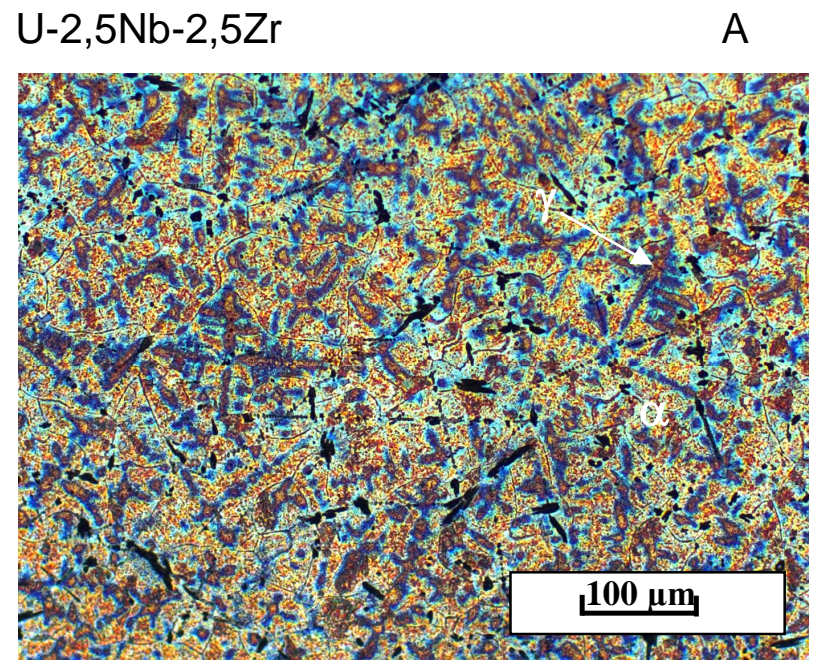

$\alpha+\gamma$
$\mathrm{U}-5 \mathrm{Nb}-5 \mathrm{Zr} \quad \mathrm{B}$

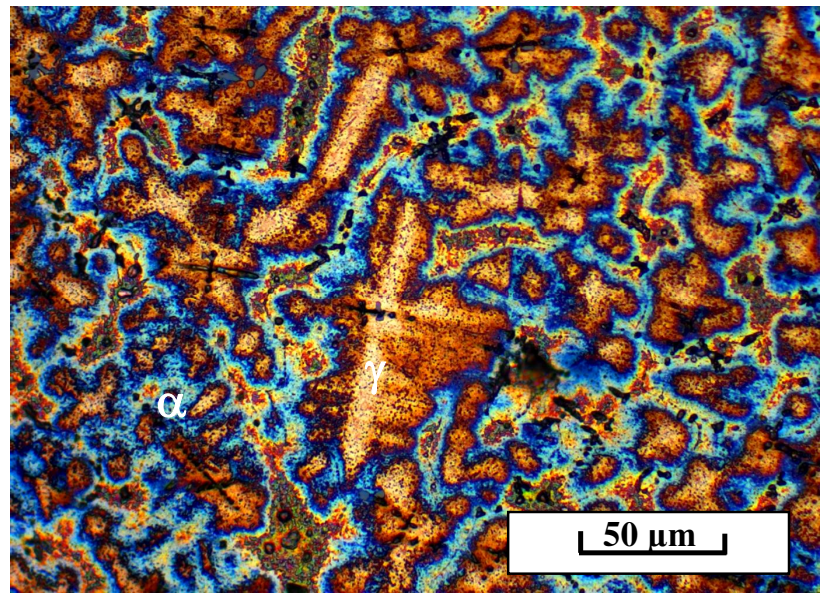

$\alpha+\gamma$

$\mathrm{U}-7,5 \mathrm{Nb}-7,5 \mathrm{Zr}$

C U-10Nb-10Zr

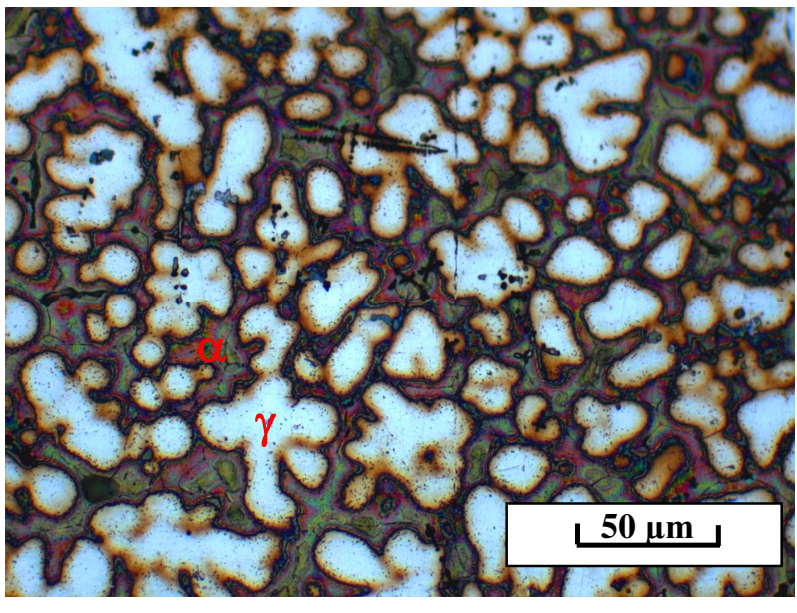

$\alpha+\gamma$

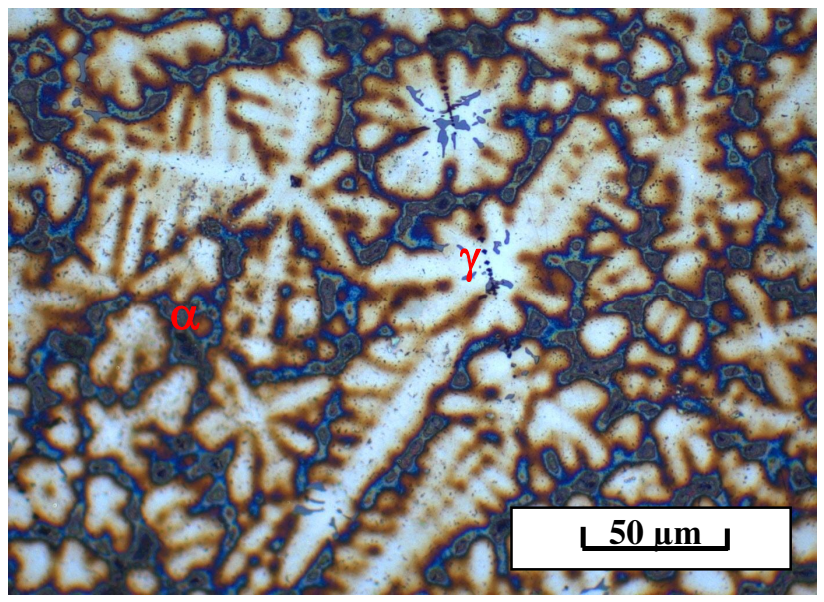

$\alpha+\gamma$

Figura 20: Micrografias óticas das ligas em estado bruto de fundição, fusão a plasma. Ataque imersão solução glicerina, $\mathrm{HNO}_{3}$ e HF, 5-15 s. 


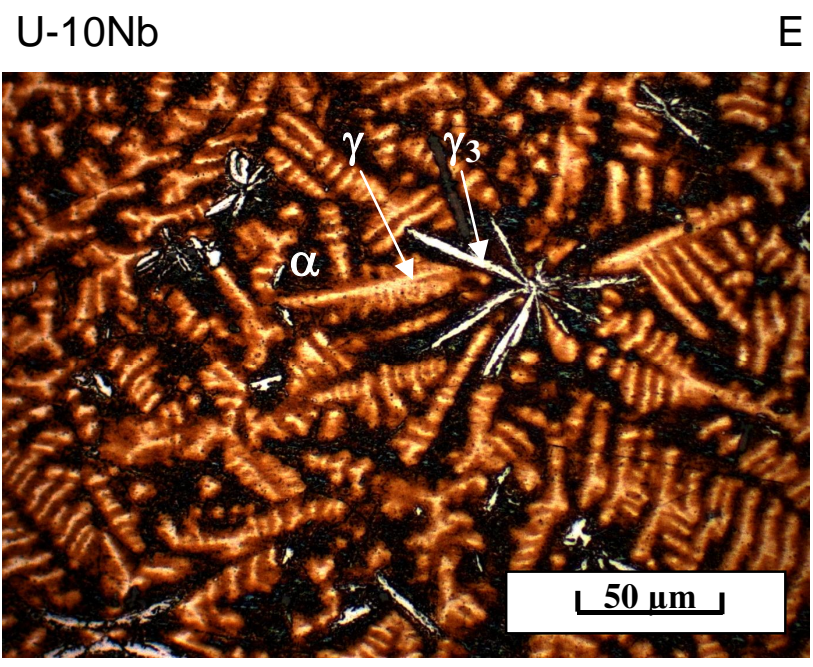

$\alpha+\gamma_{1}+\gamma_{3}$
E U-10Zr

$\mathrm{F}$

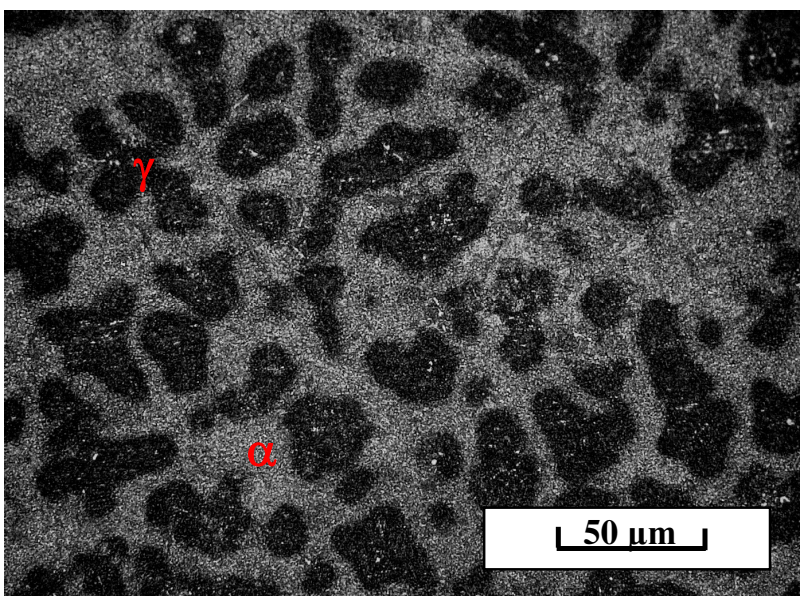

$\alpha+\gamma$
$\mathrm{U}-15 \mathrm{Nb}$

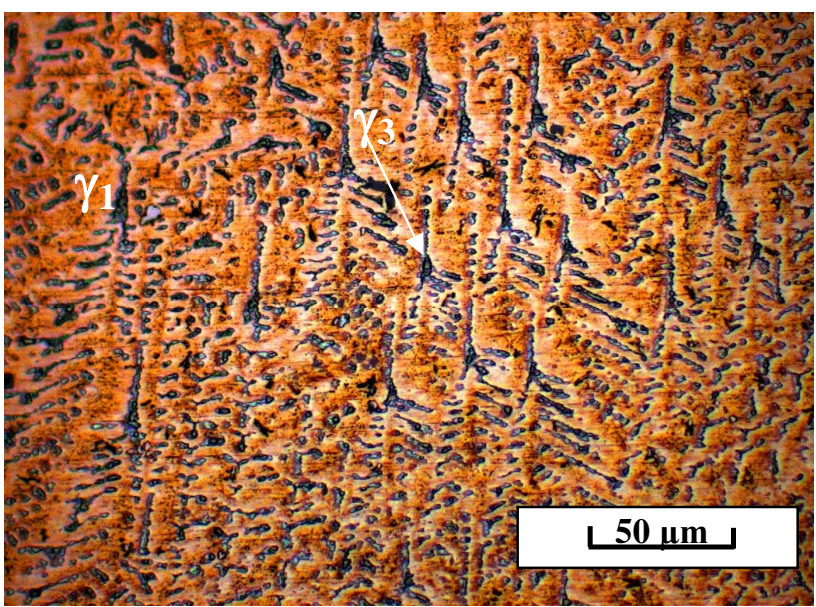

$\mathrm{r}_{1}+\mathrm{y}_{3}$
G U-15Zr

$\mathrm{H}$

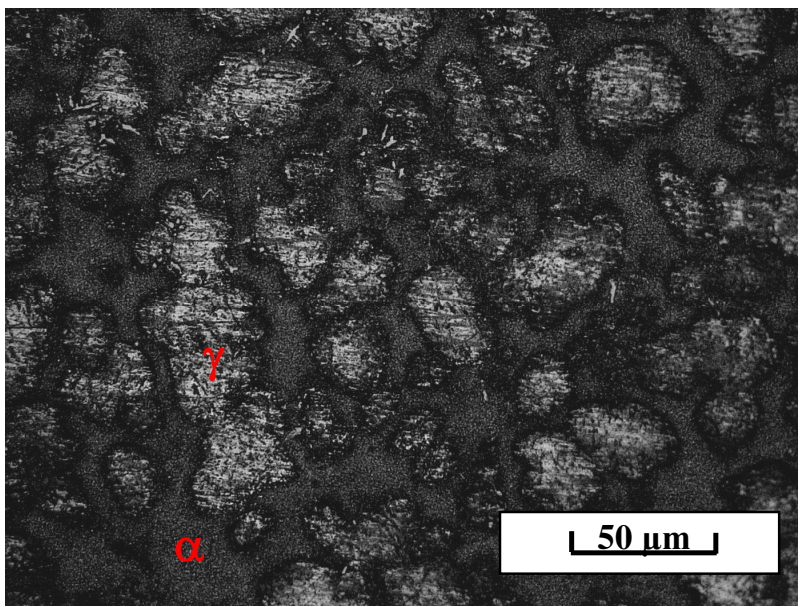

$\alpha+\gamma$

Figura 20 continuação: Micrografias óticas das ligas em estado bruto de fundição, fusão a plasma. Ataque imersão solução glicerina, $\mathrm{HNO}_{3}$ e $\mathrm{HF}, 5-15 \mathrm{~s}$. 

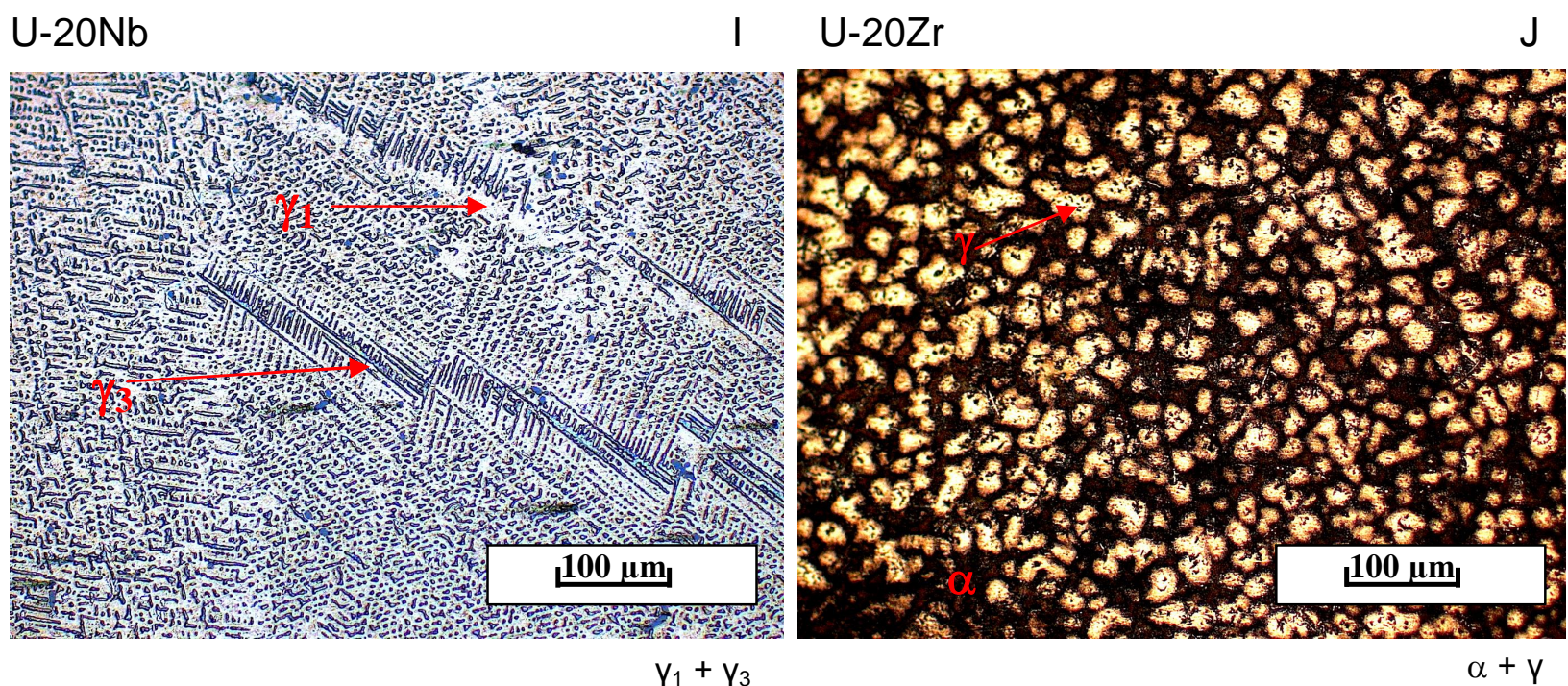

Figura 20 continuação: Micrografias óticas das ligas em estado bruto de fundição, fusão a plasma. Ataque imersão solução glicerina, $\mathrm{HNO}_{3}$ e HF, 5-15 s.

Observa-se para as ligas ternárias que o ataque metalográfico revelou a presença de duas fases cristalinas do urânio, dendritas de urânio gama (U-y) e fase alfa (U- $\alpha)$ interdendrítica. É observado um progressivo aumento no alargamento das dendritas da fase $\mathrm{U}-\mathrm{y}$ conforme aumento na quantidade de elemento de ligas inserido, revelando a forte influência dos elementos $\mathrm{Nb}$ e $\mathrm{Zr}$ na estabilização desta fase.

Um aspecto similar é observado para as ligas binárias do sistema $\mathrm{U}-\mathrm{Zr}$, as quais após ataque metalográfico revelaram presença de dendritas da fase gama e fase alfa interdendrítica. Durante a solidificação, o líquido remanescente segue, em termos de composição, a curva líquidus que para o caso do sistema ternário U-Nb-Zr tem caráter isomórfico (líquido e fase gama), descendente para o canto do urânio, sendo assim, isto explica a morfologia encontrada, que sugere solidificação primária da fase gama, e a fase alfa solidificando por último (sendo ela muito pobre em composição dos elementos de liga). 
Para as ligas binárias do sistema U-Nb, produzidas com carga de nióbio em pó utilizado sobre a forma de pastilha após prensagem, destaca-se a morfologia observada para a liga $\mathrm{U}-10 \mathrm{Nb}(\mathrm{E})$, que apresentou uma matriz composta por duas fases (U- $\alpha$ e U- $-\gamma$ ) e ainda precipitação da fase $\gamma_{3}$ em forma de plaquetas com visível crescimento preferencial evidenciando a ocorrência do domo de imicibilidade no diagrama de fases. As demais ligas U-15Nb e U-20Nb, apresentaram-se compostas por duas fase $\gamma_{1}$ e $\gamma_{3}$ com morfologia de monotetóide irregular. Este fato evidencia a forte inclinação da linha que divide o campo y e $\gamma_{1}+\gamma_{3}$.

Um importante fato a ser relatado é que a utilização de carga em pó para a realização da fusão via plasma, apesar de aparentemente causar uma maior facilidade na dispersão pelo urânio metálico fundido, ocasionou em uma relativa dificuldade para fechamento do arco possivelmente causada pela formação de pequenas camadas de óxido que podem envolver as partículas de nióbio.

\subsubsection{Microscopia eletrônica de varredura (MEV)}

As imagens de microscopia eletrônica de varredura podem ser observadas na figura a seguir, onde as microestruturas das ligas foram analisadas com elétrons retroespalhados. $\mathrm{Na}$ imagem com elétrons retroespalhados, as regiões mais escuras são mais ricas nos elementos químicos de numero atômico mais baixo ( $\mathrm{Nb}$ e $\mathrm{Zr}$ ), enquanto que as regiões mais claras são mais ricas em urânio. Em análise visual fica claro que a liga apresentou problemas de homogeneidade onde é possível visualizar a presença de precipitados, igualmente distribuídos ao longo da extensão das amostras, de composição distinta a da matriz. 

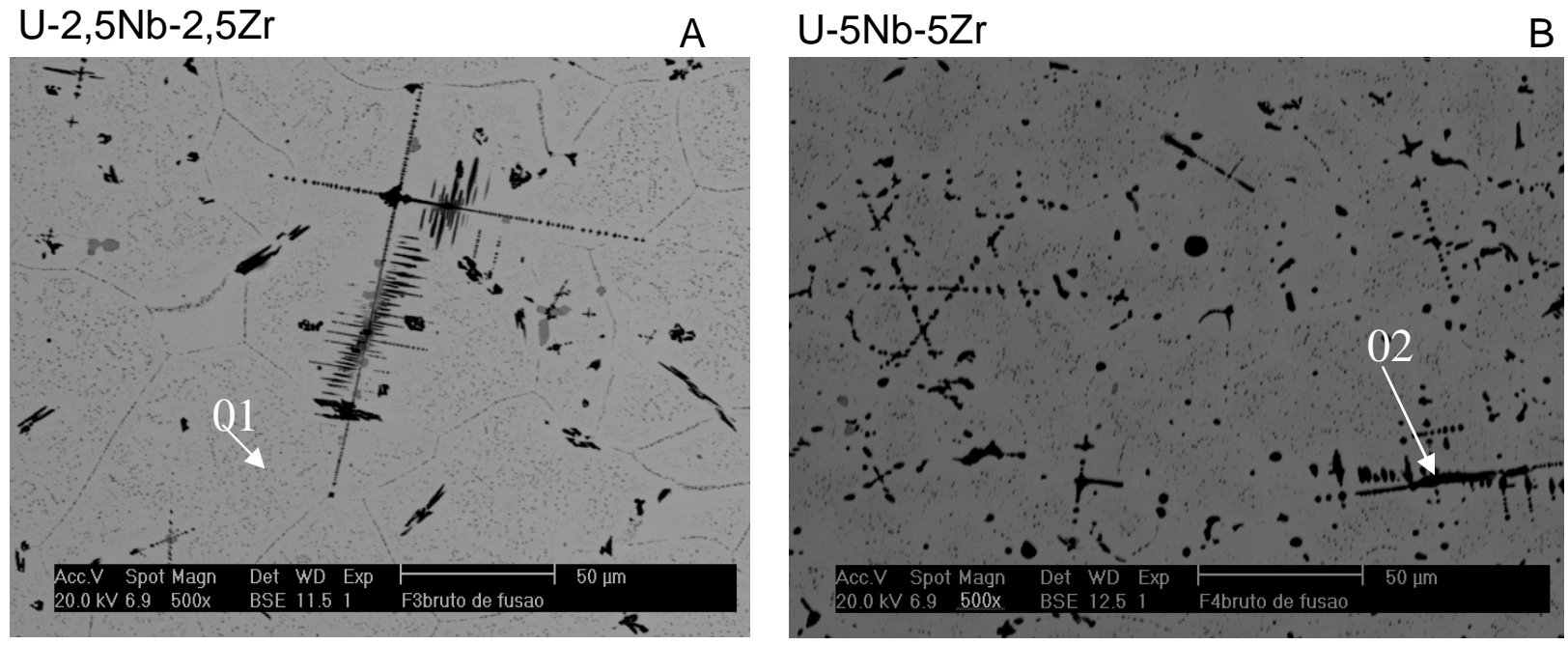

\section{$\mathrm{U}-7,5 \mathrm{Nb}-7,5 \mathrm{Zr}$}

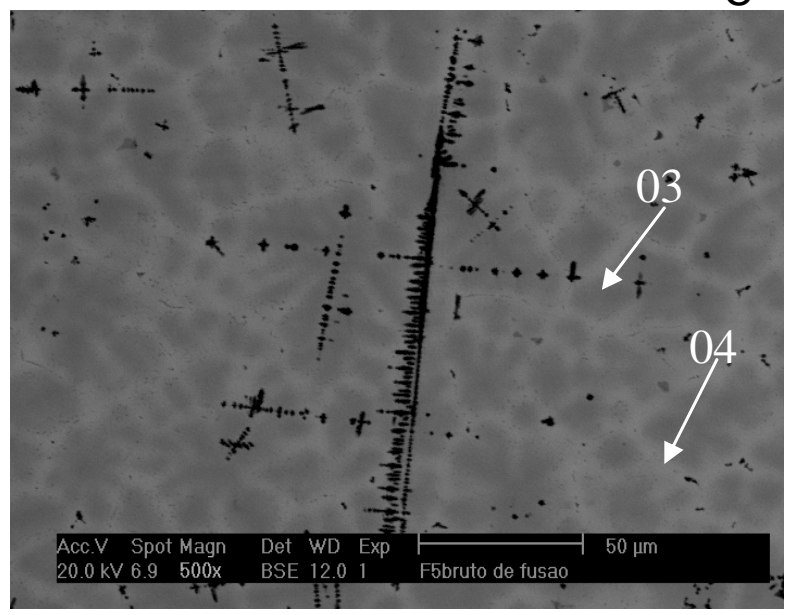

C U-10Nb-10Zr

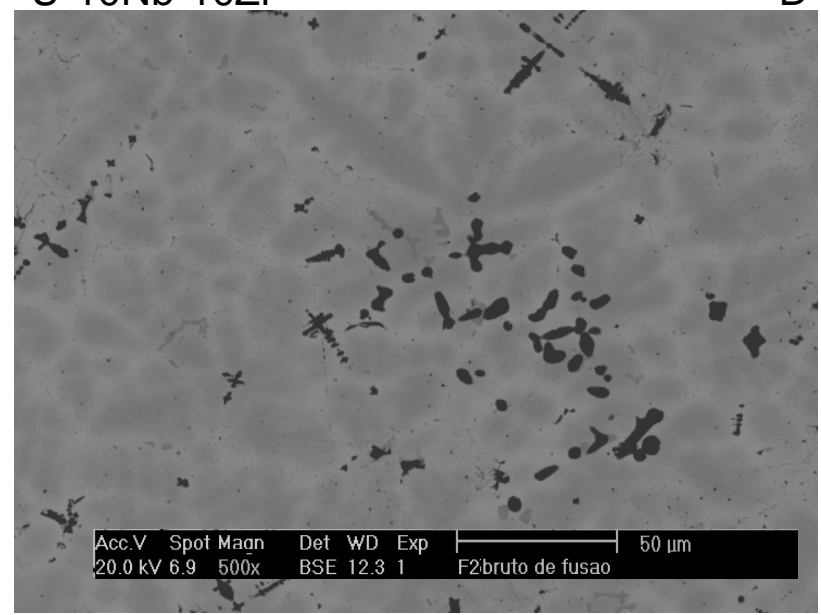

Figura 21: Micrografias eletrônicas das ligas em estado bruto de fundição. Regiões numeradas áreas de análise por EDS. MEV com elétrons retroespalhados. Amostras analisadas após polimento mecânico. 


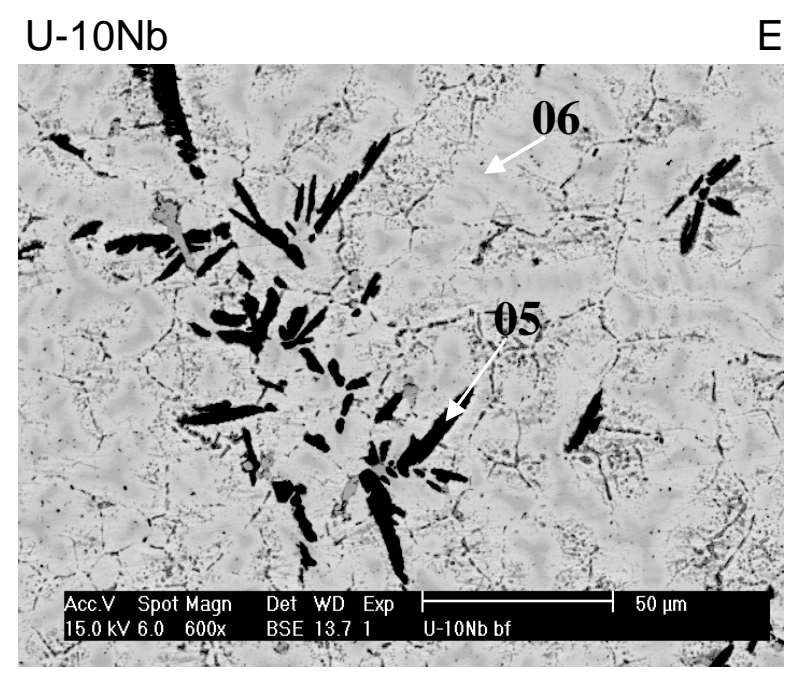

E U-10Zr

F
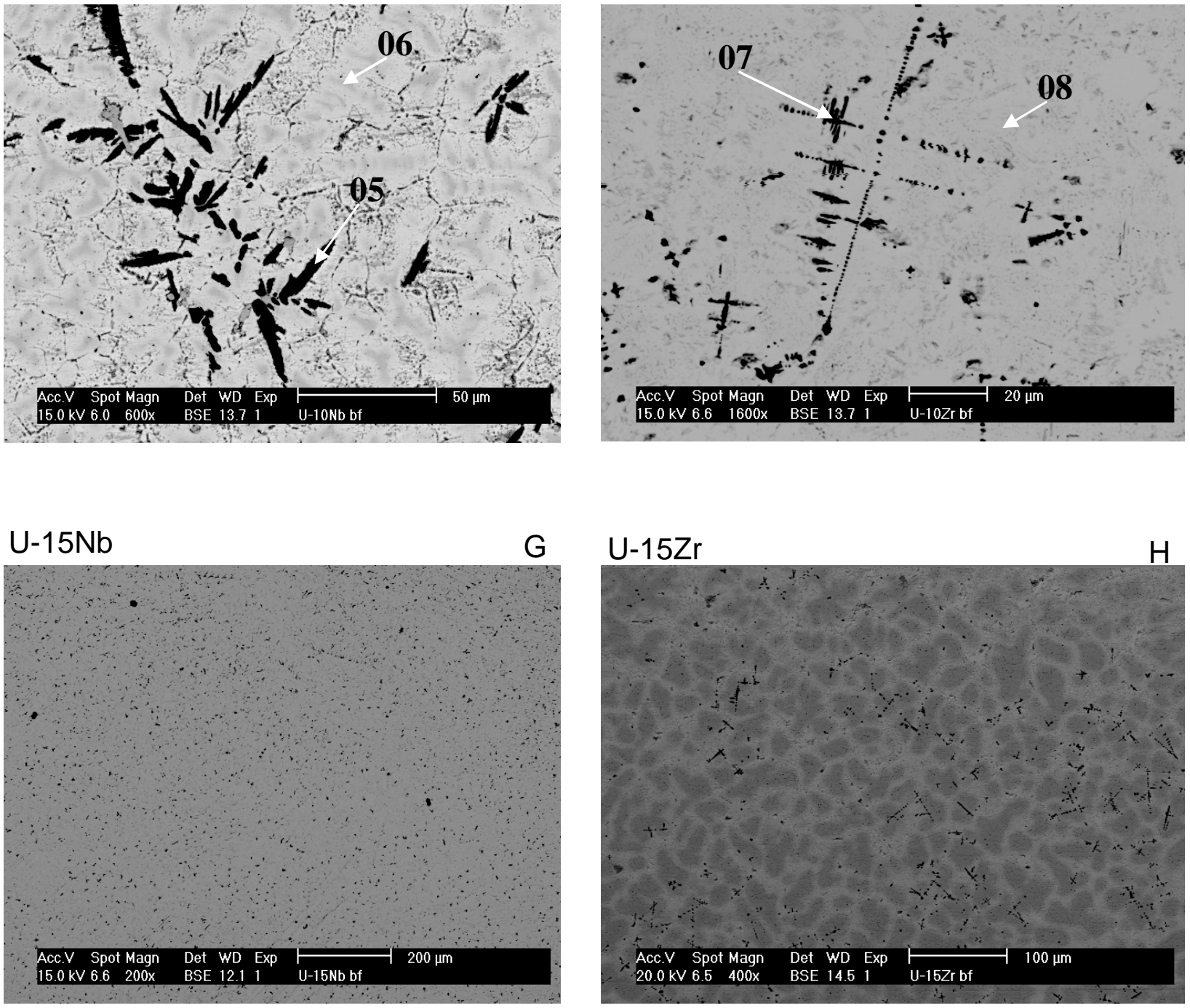

Figura 21 continuação: Micrografias eletrônicas das ligas em estado bruto de fundição. Regiões numeradas áreas de análise por EDS. MEV com elétrons retroespalhados. Amostras analisadas após polimento mecânico. 
$\mathrm{U}-20 \mathrm{Nb}$

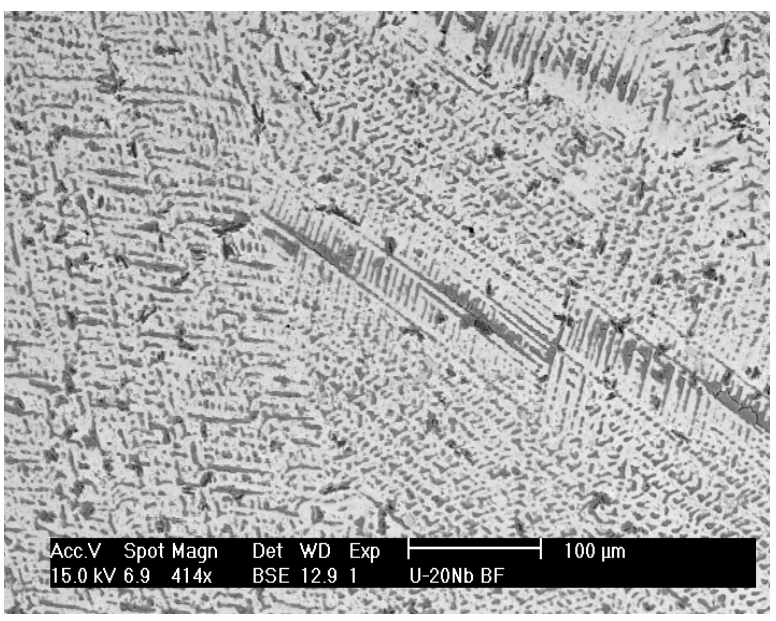

$\mathrm{U}-20 \mathrm{Zr}$

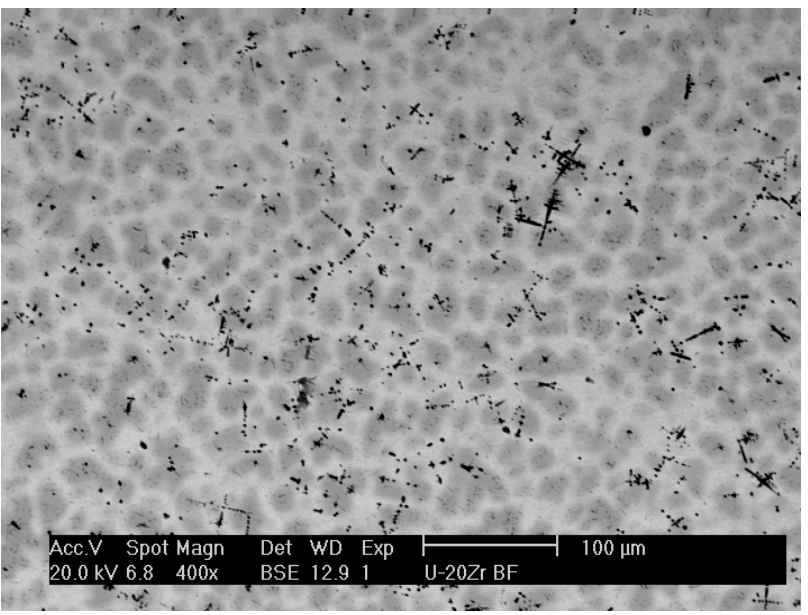

Figura 21 continuação: Micrografias eletrônicas das ligas em estado bruto de fundição. Regiões numeradas áreas de análise por EDS. MEV com elétrons retroespalhados. Amostras analisadas após polimento mecânico.

Observação microestrutural revela para as ligas ternárias e binárias do sistema U-Zr a presença de precipitados de morfologia similar, dendrítica de solidificação primária. A não ocorrência destes precipitados nas ligas do sistema binário U-Nb, sugere que esta fase possui composição independente do elemento $\mathrm{Nb}$.

Observa-se nesta primeira visão das microestruturas brutas de fundição que, em geral, o fator carregamento dos elementos de liga foi determinante na obtenção da microestrutura observada, sendo que as cargas de nióbio em pó apresentaram maior facilidade na dissolução pelo urânio metálico fundido, apesar da maior dificuldade de fechamento do arco. Talvez a distribuição de uma carga com geometria menor e mais uniformemente distribuída, se dissolva mais facilmente no urânio liquido, minimizando a necessidade de se elaborar dispositivos para melhor controle de resfriamento. 


\subsubsection{Análise por dispersão de energia (EDS)}

A Figura 22 apresenta os espectros de raios $X$ da análise química por dispersão de energia obtidos para as ligas. Os espectros foram tomados em diversas partes das ligas, especialmente onde foi verificada a possível segregação dos principais elementos $(\mathrm{U}, \mathrm{Nb}, \mathrm{Zr})$, o que geraria um contraste de imagem diferente. Os espectros estão identificados com relação a regiões demarcadas nas micrográfias obtidas por microscopia eletrônica de varredura apresentadas na seção anterior. Nos espectros obtidos é possível observar as emissões da camada $M$ do urânio, assim como as emissões das camadas $L$ do nióbio e zircônio.

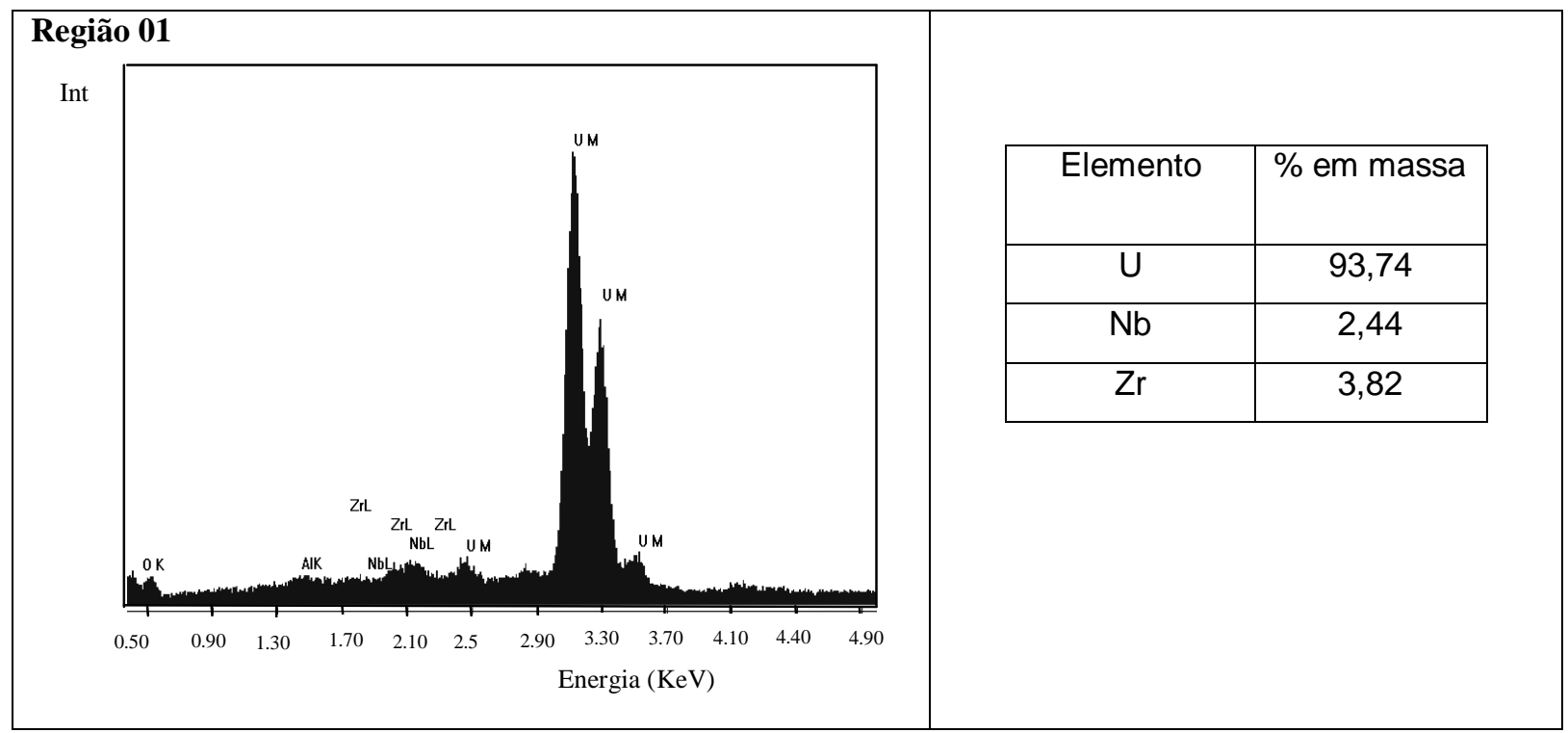

Figura 22: Análise por dispersão de energia (EDS) das ligas no estado bruto de fundição, regiões de análise referente às micrografias apresentadas em seção precedente na Figura 21. 


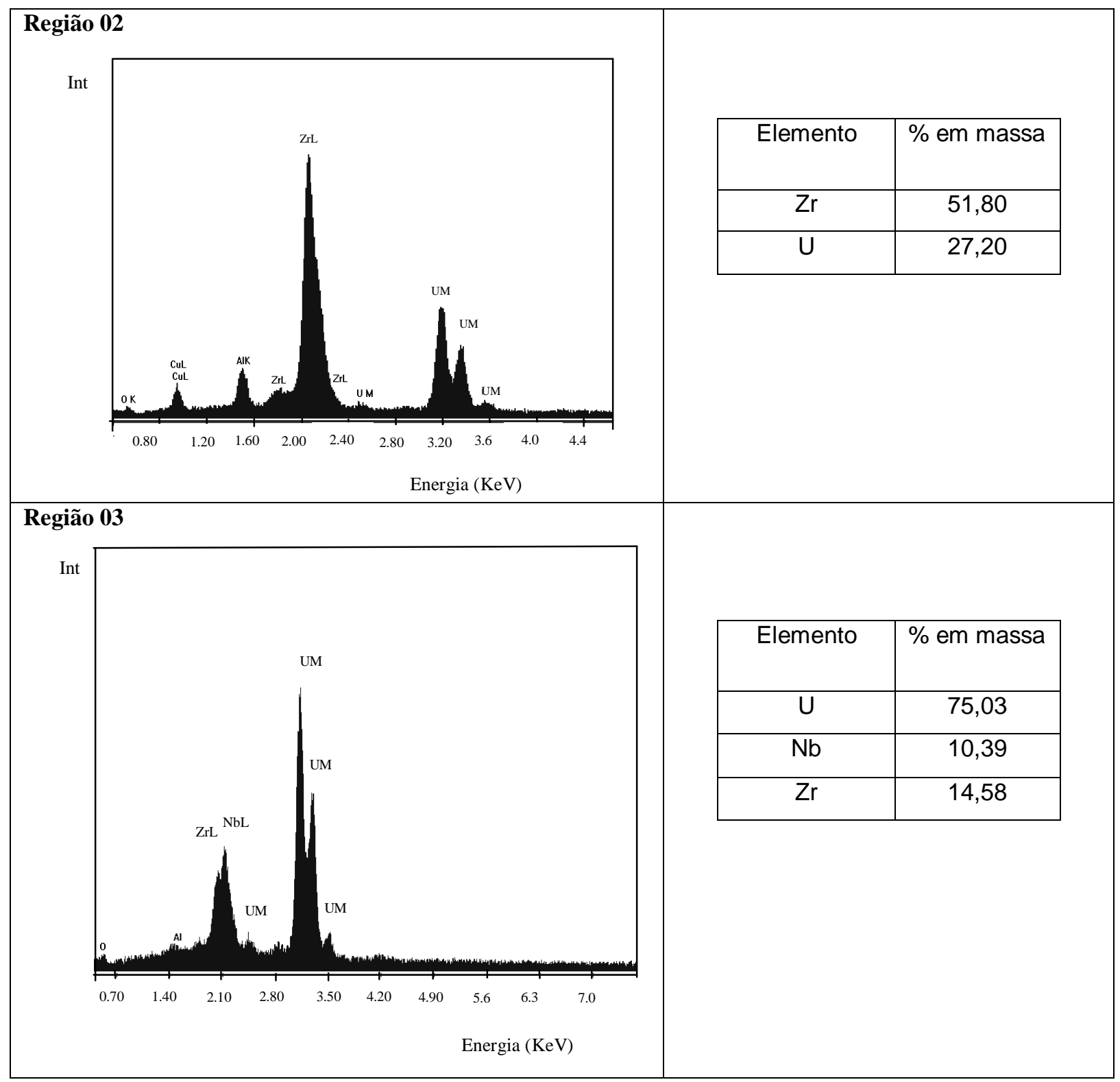

Figura 22 continuação: Análise por dispersão de energia (EDS) das ligas no estado bruto de fundição, regiões de análise referente às micrografias apresentadas em seção precedente na Figura 21. 


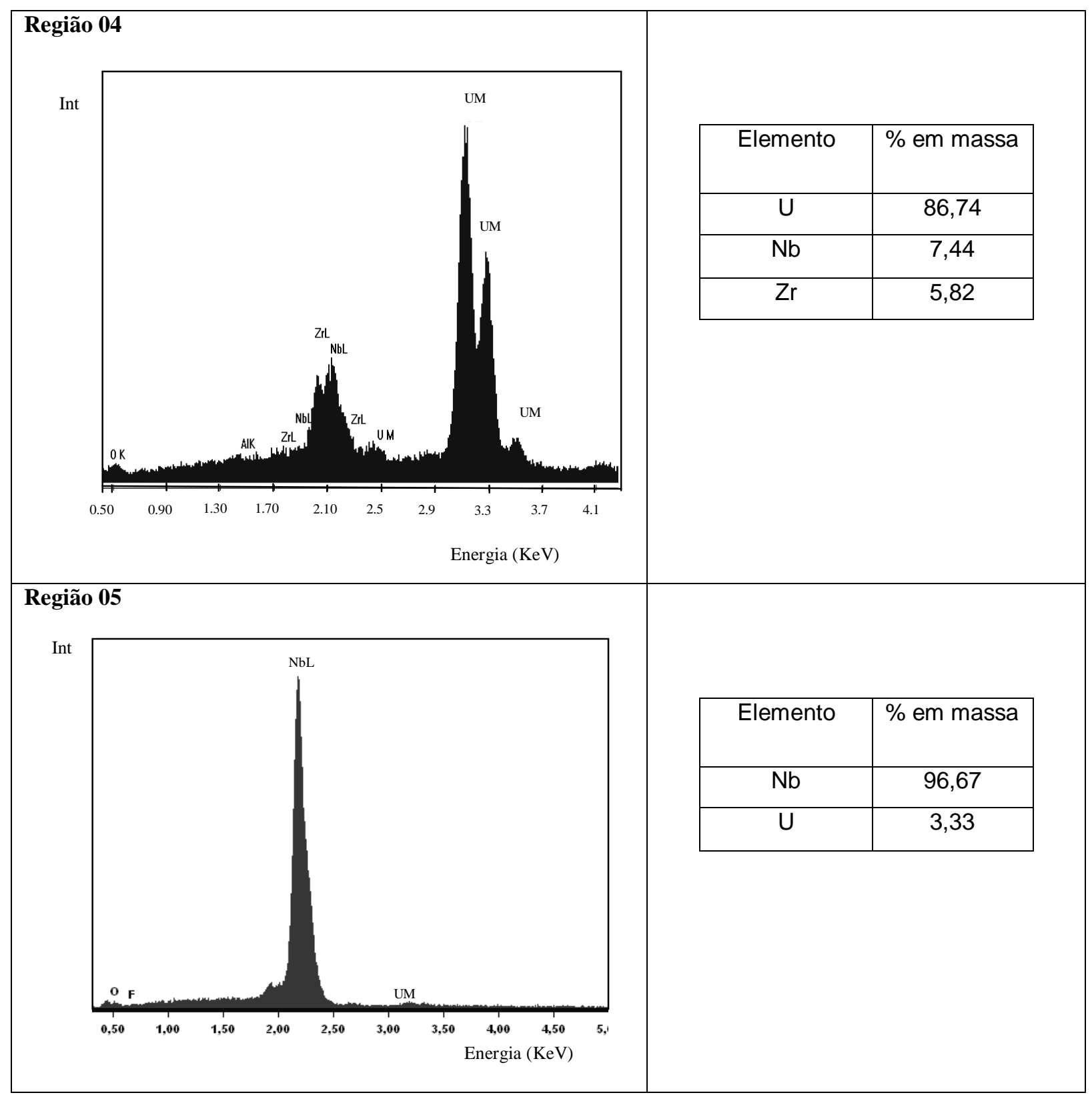

Figura 22 continuação: Análise por dispersão de energia (EDS) das ligas no estado bruto de fundição, regiões de análise referente às micrografias apresentadas em seção precedente na Figura 21. 


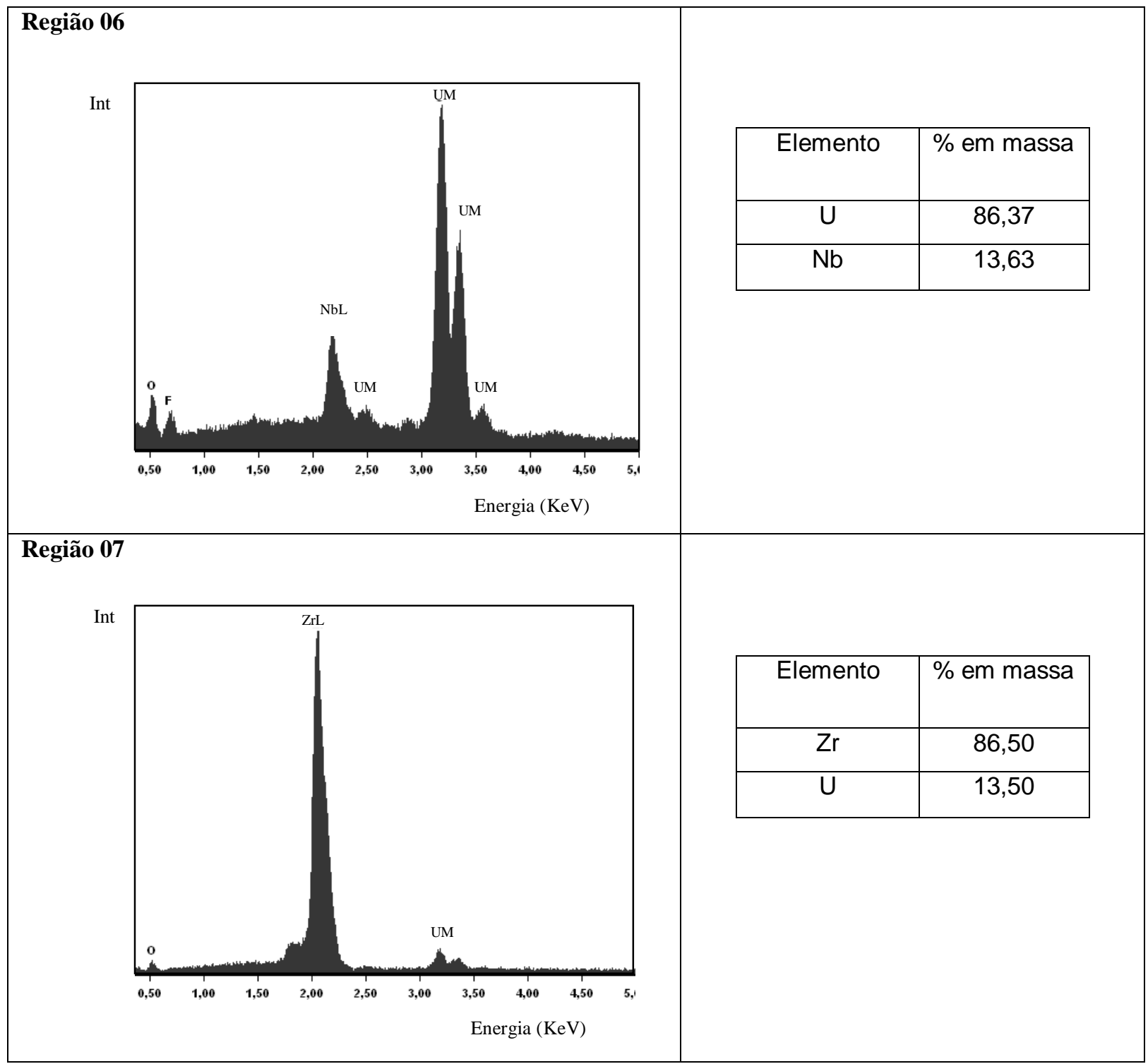

Figura 22 continuação: Análise por dispersão de energia (EDS) das ligas no estado bruto de fundição, regiões de análise referente às micrografias apresentadas em seção precedente na Figura 21 


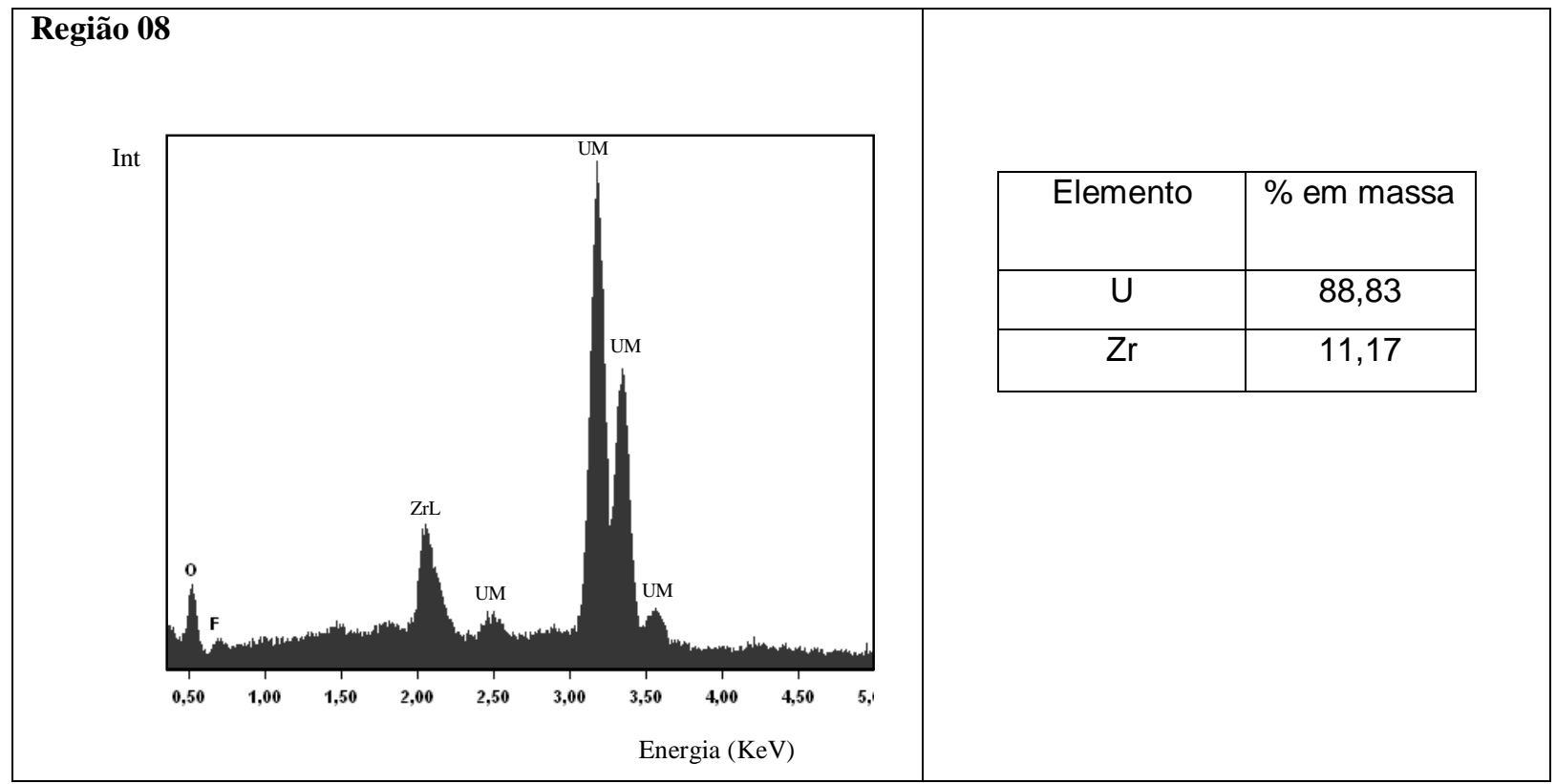

Figura 22 continuação: Análise por dispersão de energia (EDS) das ligas no estado bruto de fundição, regiões de análise referente às micrografias apresentadas em seção precedente na Figura 21 .

Observou-se nas amostras, que independentemente da realização dos tratamentos térmicos, houve mistura muito próxima a da composição nominal para região da matriz. As regiões mais escuras, pretas, nas ligas ternárias e binárias do sistema U-Zr apresentaram baixa concentração de urânio e mostraram-se extremamente ricas em zircônio. A morfologia destes precipitados indica que sua precipitação ocorreu em alta temperatura, antes que houvesse solidificação da matriz.

Para as ligas binárias do sistema U-Nb fica visível a precipitação da fase $\mathrm{Y}_{3}$, muito rica em nióbio. Composições mais próximas das nominais foram obtidas sempre nas regiões mais escuras da matriz, indicando a ocorrência desta fase como U- $\gamma$, em concordância com o observado na microscopia óptica. 


\subsubsection{Estado solubilizado}

Em seguida serão apresentados resultados referentes às ligas $\mathrm{U}-2,5 \mathrm{Nb}-2,5 \mathrm{Zr}$ (A), U-5Nb-5Zr (B), U-7,5Nb-7,5Zr (C), U-10Nb-10Zr (D), U-10Nb (E), U-10Zr (F), U$15 \mathrm{Nb}(\mathrm{G}), \mathrm{U}-15 \mathrm{Zr}(\mathrm{H}), \mathrm{U}-20 \mathrm{Nb}$ (I) e U-20Zr (J) no estado solubilizado.

\subsubsection{Microscopia eletrônica de varredura (MEV)}

Na Figura 23 pode-se observar a o aspecto geral das ligas após tratamento térmico de solubilização a $1000{ }^{\circ} \mathrm{C}$ por 96 horas, seguido de têmpera em água. As amostras foram analisadas ao microscópio eletrônico de varredura com elétrons retroespalhados. Nas micrografias é possível verificar que não houve solubilização total dos precipitados, possivelmente formados em alta temperatura, mas fica evidente a progressiva dissolução dos mesmos. Entretanto o tratamento térmico mostrou-se eficiente para eliminação da estrutura dendrítica das fases na matriz, conseqüente da solidificação. Foi ainda verificada uma forte mudança na morfologia dos precipitados para as ligas binárias do sistema $\mathrm{U}-\mathrm{Zr}$, que apresentou agora um morfologia agulhada. O fato desta transição não ter ocorrido para as ligas ternárias indica influência do nióbio na inibição desta transformação. 

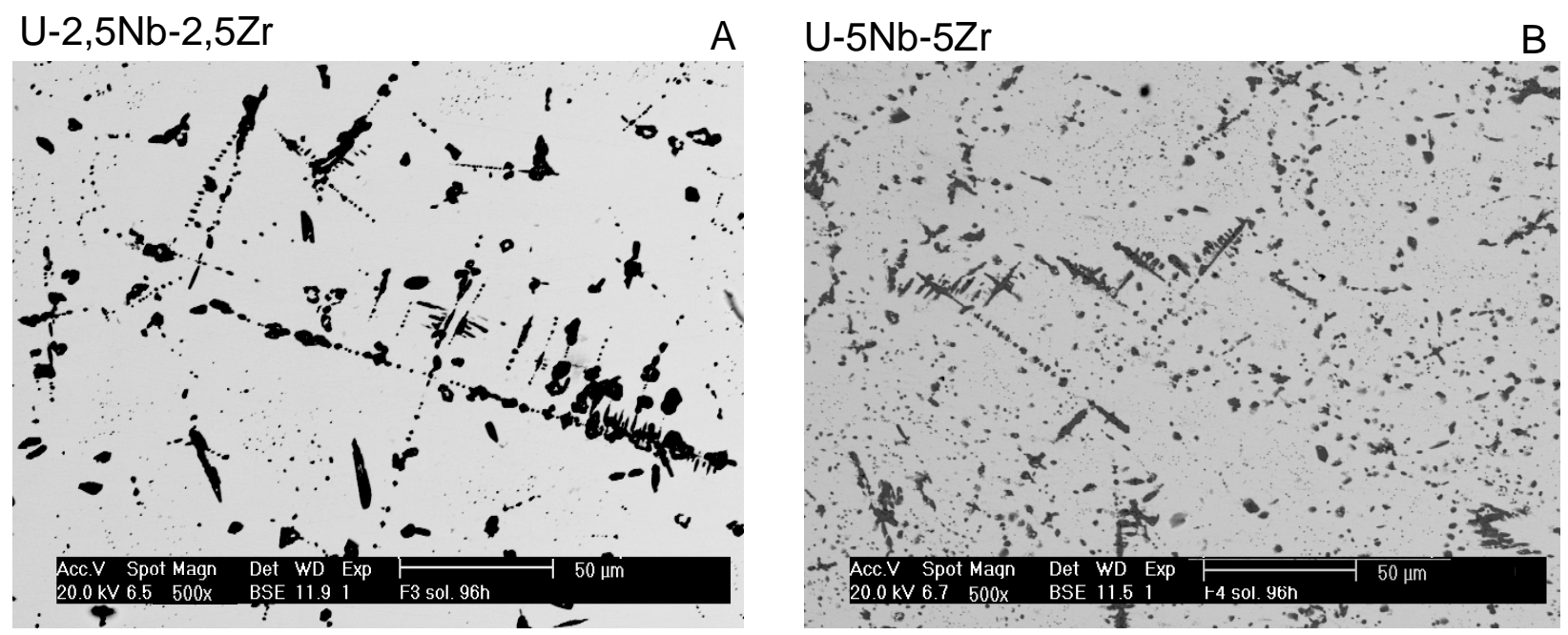

\section{U-7,5Nb-7,5Zr}

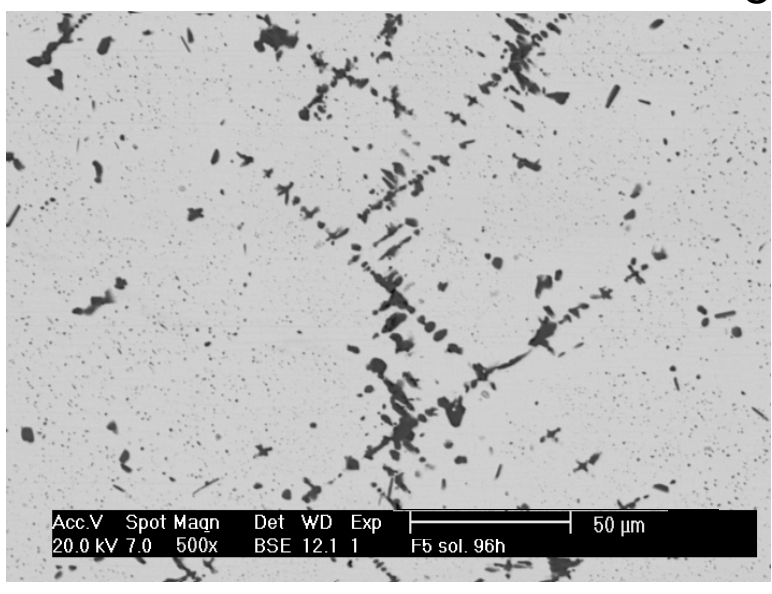

$\mathrm{U}-10 \mathrm{Nb}-10 \mathrm{Zr}$
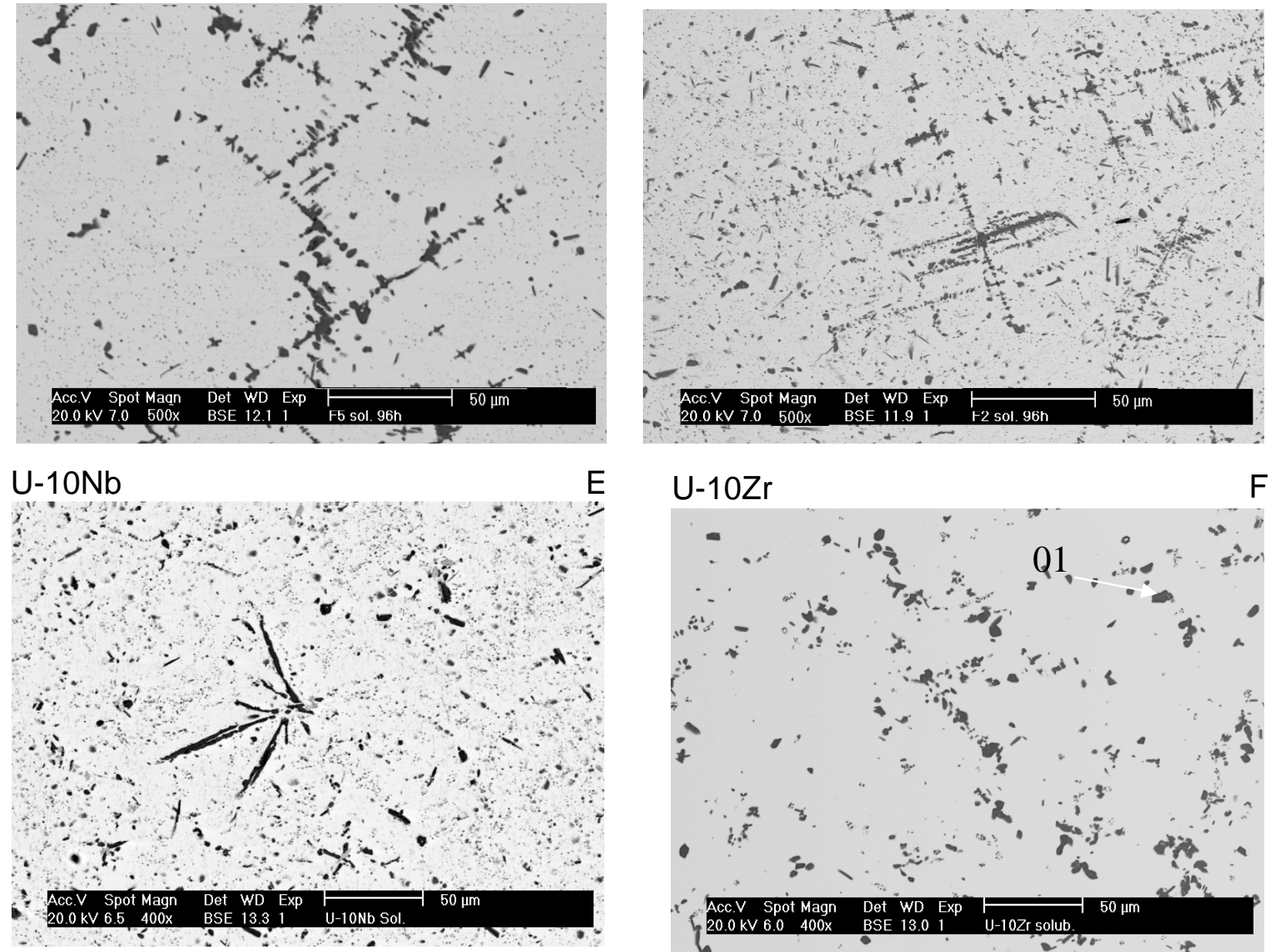

Figura 23: Micrografias eletrônicas das ligas em estado solubilizado a $1000 \stackrel{\circ}{\circ}$ por 96 horas. Regiões numeradas áreas de análise por EDS. MEV com elétrons retroespalhados. Amostras analisadas após polimento mecânico. 

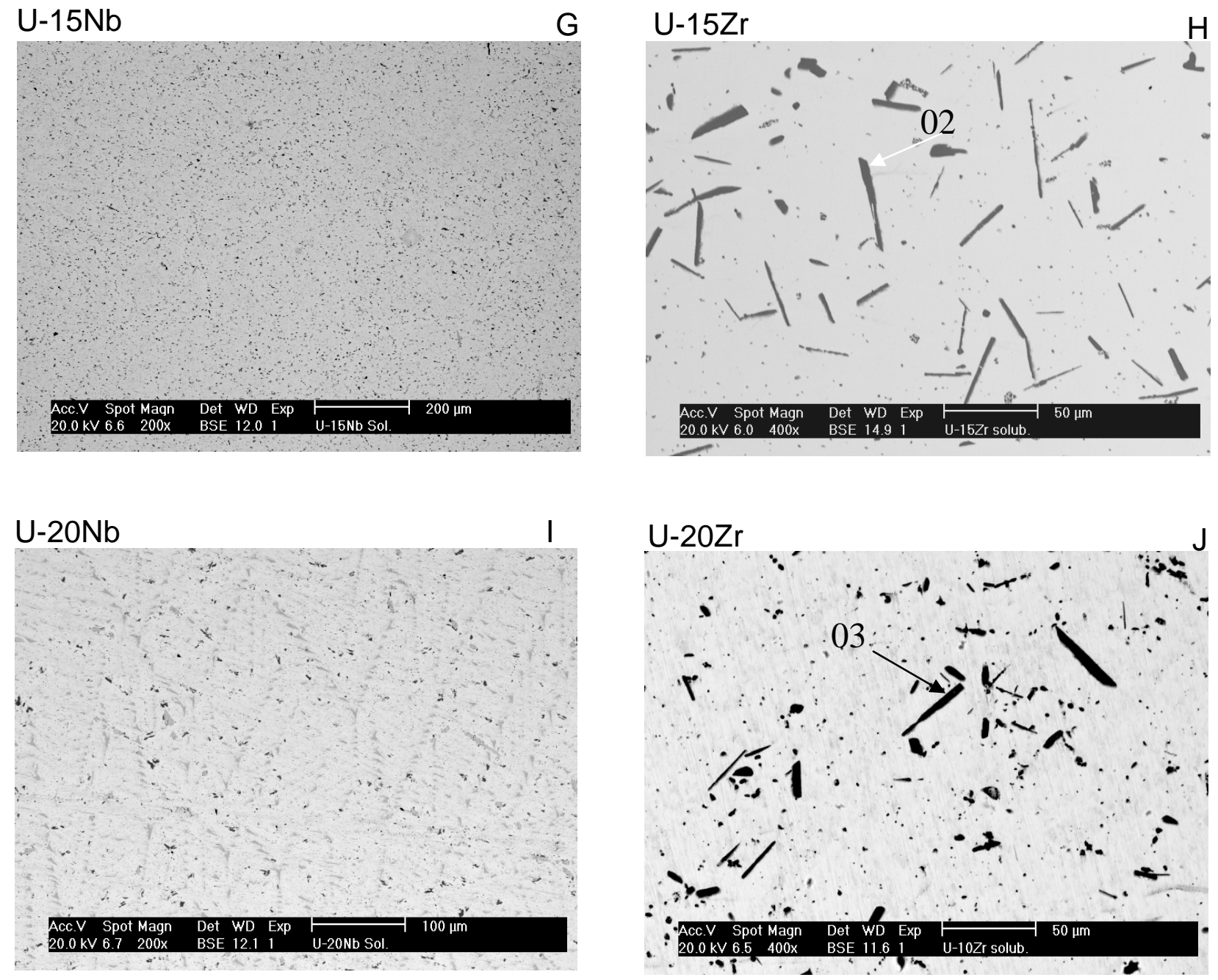

Figura 23 continuação: Micrografias eletrônicas das ligas em estado solubilizado a $1000 \stackrel{\circ}{\circ}$ por 96 horas. Regiões numeradas áreas de análise por EDS. MEV com elétrons retroespalhados. Amostras analisadas após polimento mecânico.

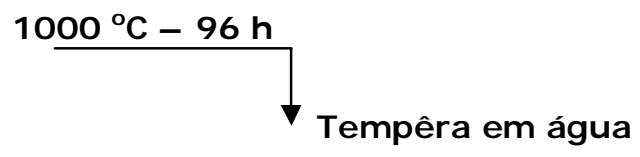

Como ainda é possível observar a presença de precipitados, conclui-se que os precipitados formaram-se em altas temperaturas, não sendo a temperatura do tratamento térmico suficiente para sua solubilização. Entretanto observar-se uma 
progressiva dissolução dos precipitados evidenciando o estado de não equilíbrio dos mesmos. A diminuição do tamanho médio dos precipitados após a solubilização é um resultado interessante tendo em vista futuras aplicações de deformação mecânica sobre a amostra, pois os precipitados são possivelmente menos dúcteis que a matriz, geram indesejáveis pontos de início de trincas no interior da peça.

\subsubsection{Análise por dispersão de energia (EDS)}

A Figura 24 apresenta os espectros de raios $X$ da análise química por dispersão de energia obtidos para as ligas. Os espectros foram tirados em diversas partes das ligas, de modo a avaliar o real efeito do tratamento térmico de solubilização. Os espectros estão identificados com relação a regiões demarcadas nas micrografias obtidas por microscopia eletrônica de varredura apresentadas na seção anterior. Em geral, o que se observou foi uma maior aproximação da composição nominal para a matriz, e para os precipitados das ligas binárias U-Zr, que mostraram uma mudança drástica na morfologia. Foi detectada a presença de alumínio nos precipitados.

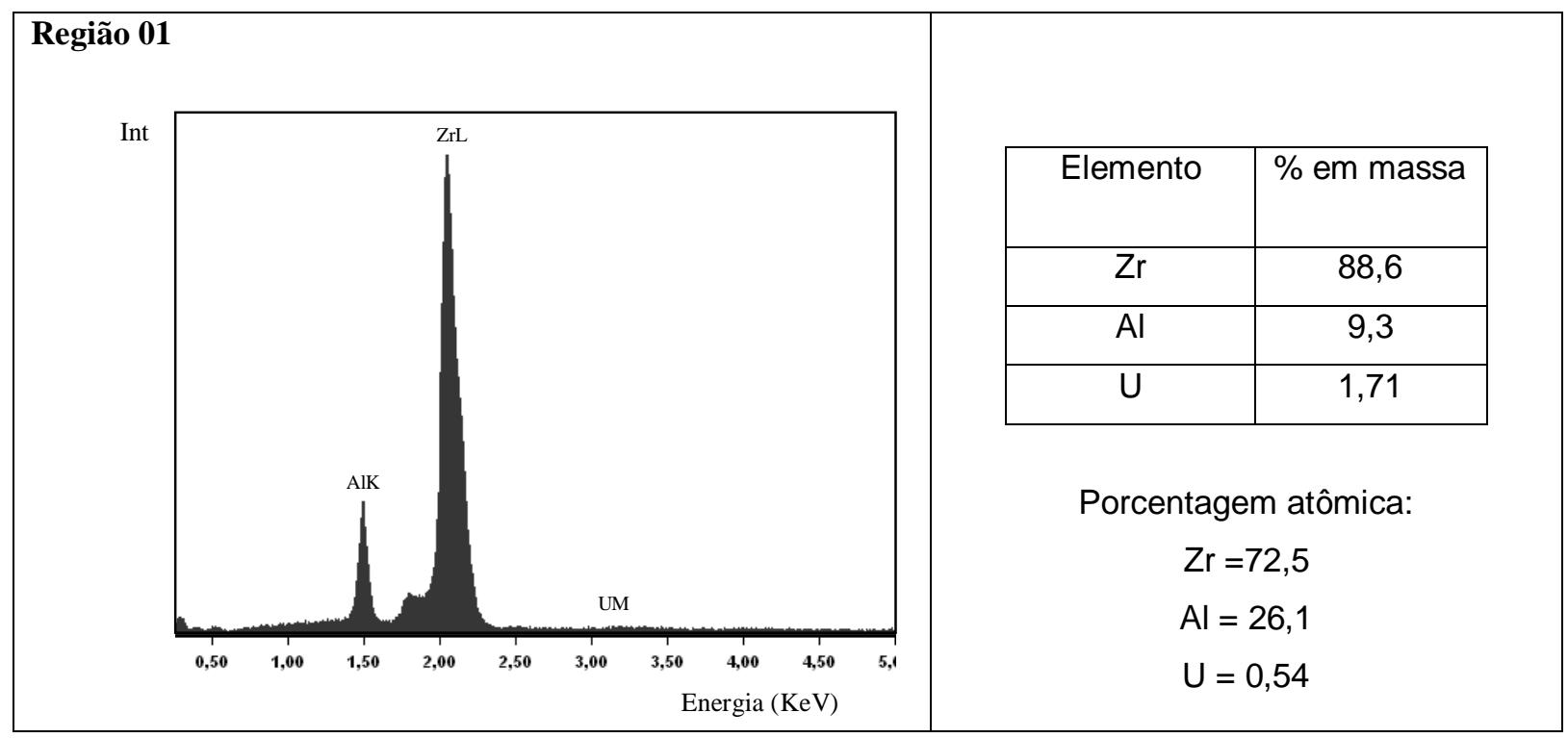

Figura 24: Análise por dispersão de energia (EDS) das ligas no solubilizado, regiões de análise referente às micrografias apresentadas em seção precedente na Figura 23. 


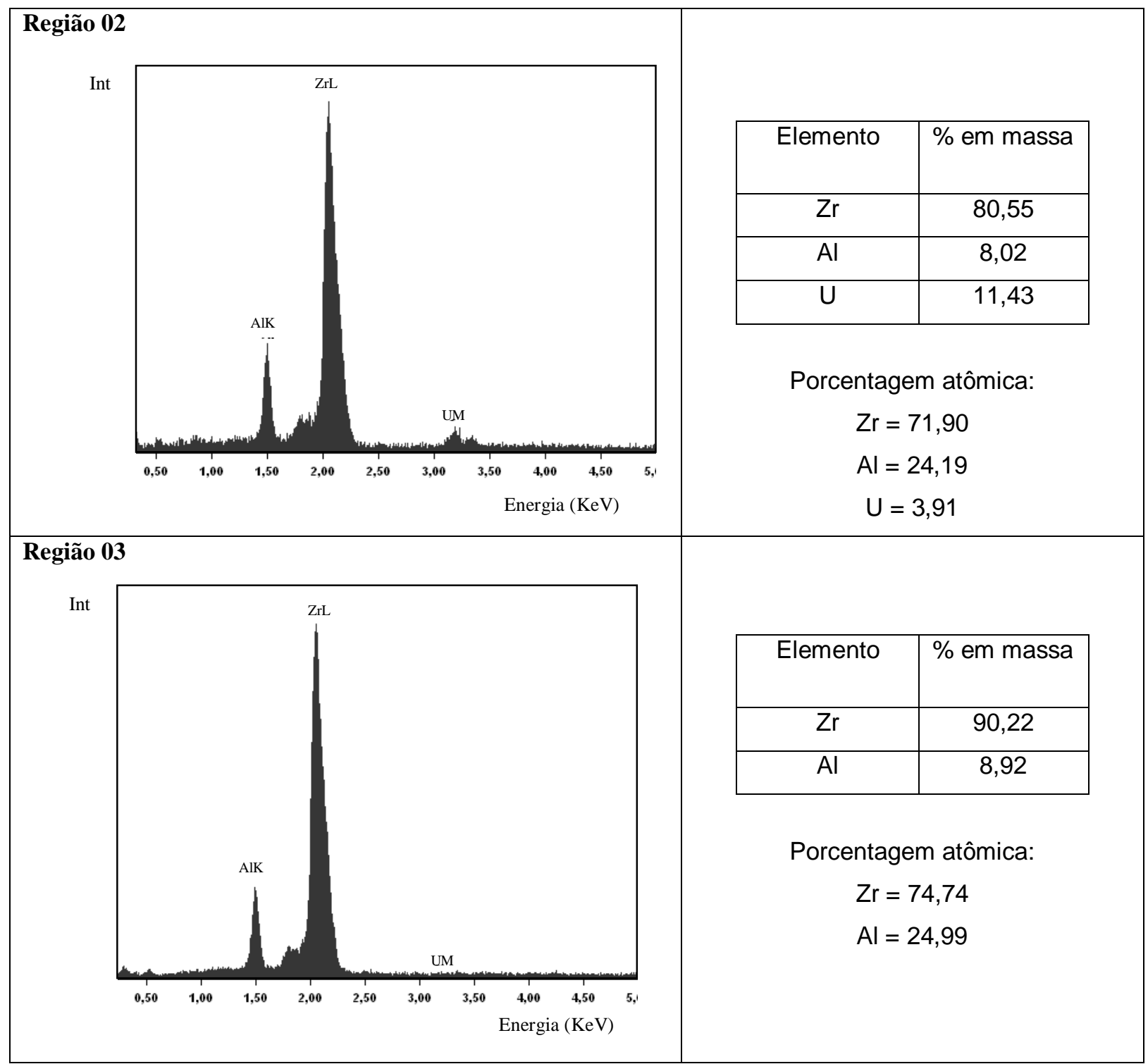

Figura 24 continuação: Análise por dispersão de energia (EDS) das ligas no solubilizado, regiões de análise referente às micrografias apresentadas em seção precedente na Figura 23.

$1000{ }^{\circ} \mathrm{C}-96 \mathrm{~h}$

\section{Tempêra em água}




\subsubsection{Difração de raios $X(D R X)$}

São apresentados a seguir alguns dos difratogramas obtidos para as ligas após realização de tratamento térmico de solubilização a $1000 \stackrel{\circ}{\circ} \mathrm{C}$ por 96 horas, seguido têmpera em água. Optou-se por expor aqui somente os difratogramas que apresentaram estrutura referente à fase martensítica $\alpha$ '. Assim os difratogramas não expostos apresentaram somente picos ou reflexões dos planos (110), (200), (211), (220), (310), (222) e (321) característicos de uma estrutura cúbica de corpo centrado, em coerência com campo monofásico de $\gamma$.

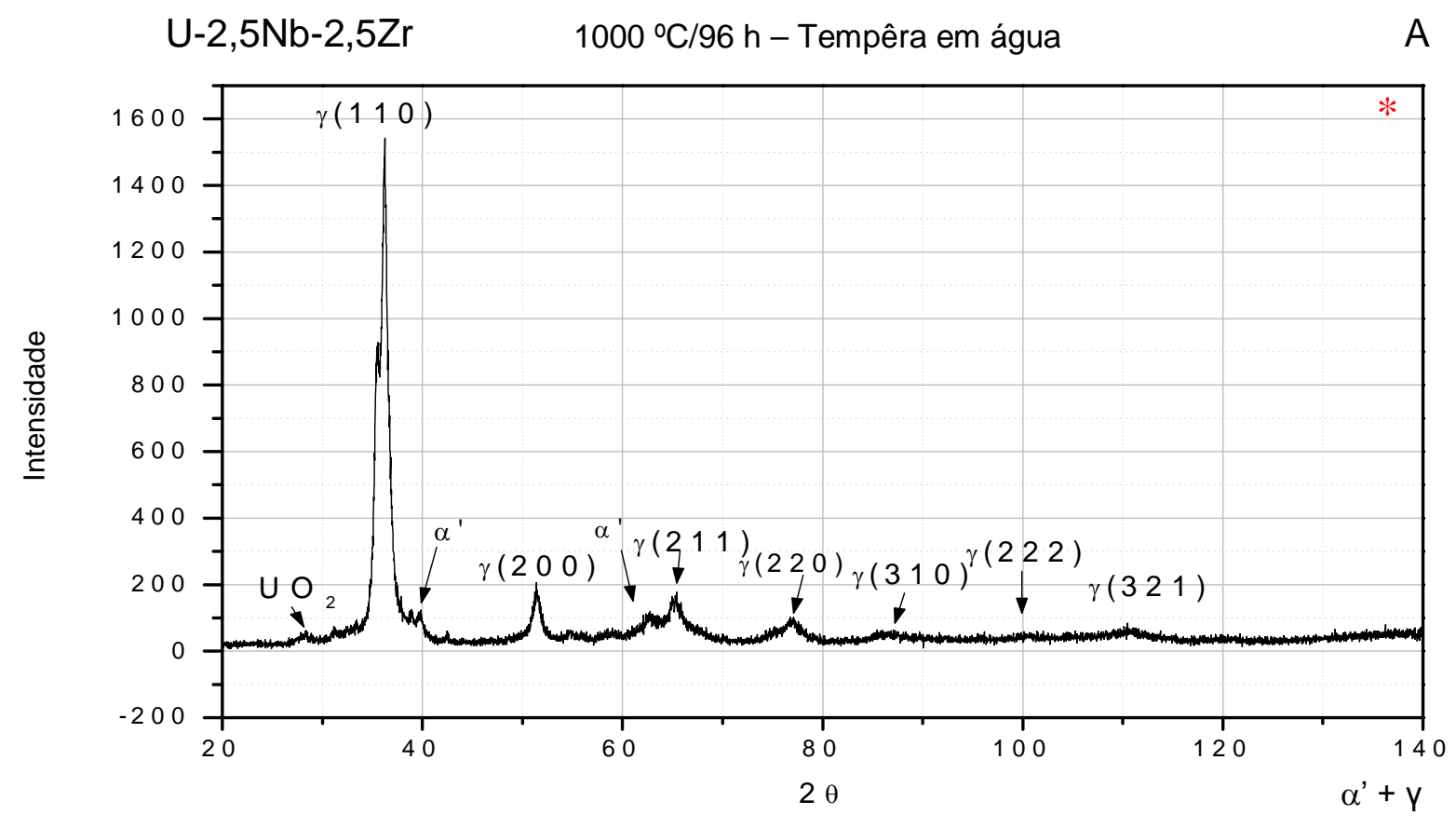

*Não se obteve um padrão simulado (método Rietveld) com proximidade aceitável ao padrão observado.

Figura 25: Difratogramas de raios $X$ das ligas que apresentaram formação da fase matensítica $\alpha$ ' após tratamento térmico a $1000 \stackrel{\circ}{ } \mathrm{C}$ por 96 horas seguidas de têmpera em água. 


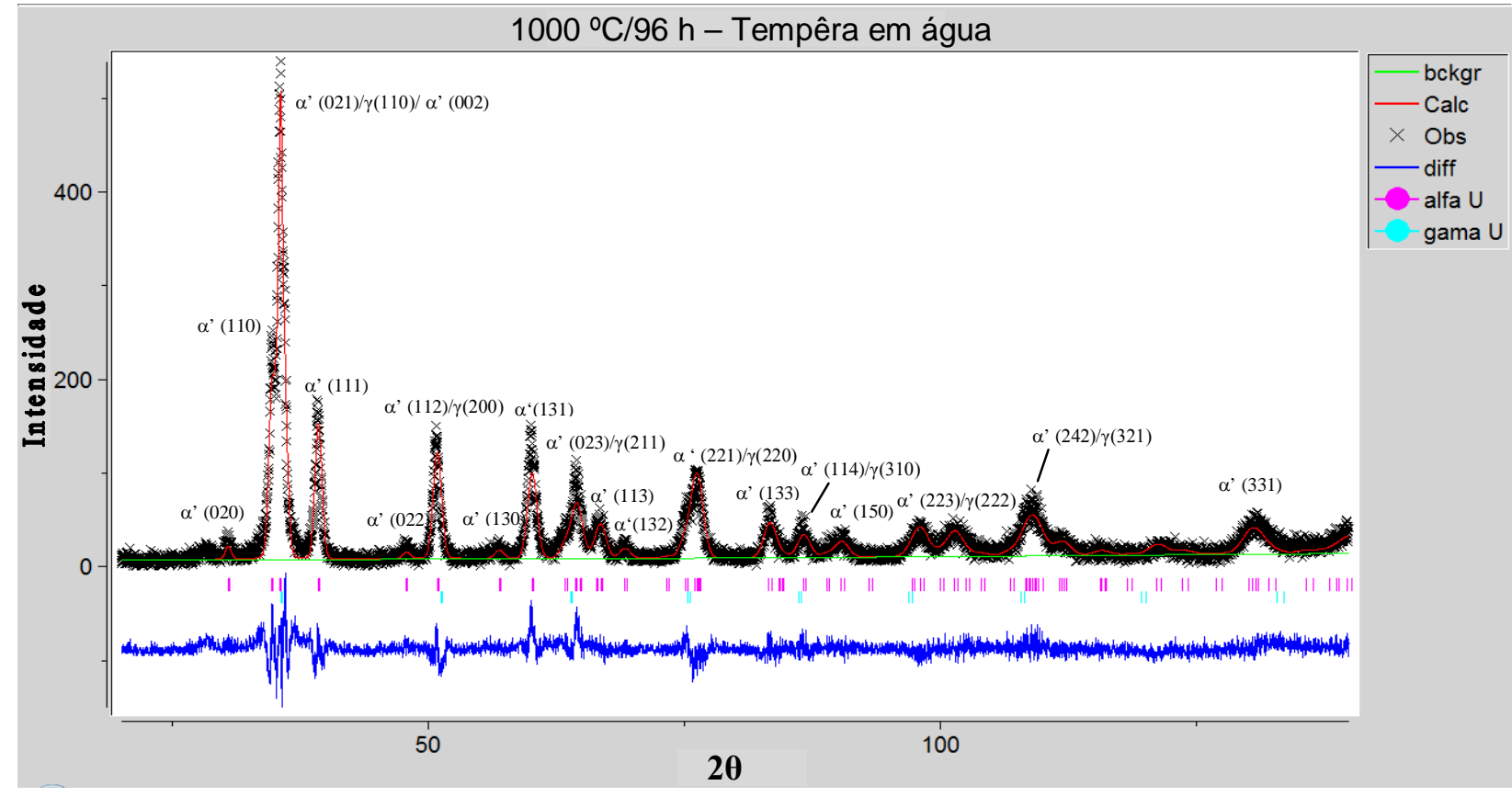

$\alpha^{\prime}+y$

$\mathrm{U}-15 \mathrm{Zr}$

$\mathrm{H}$

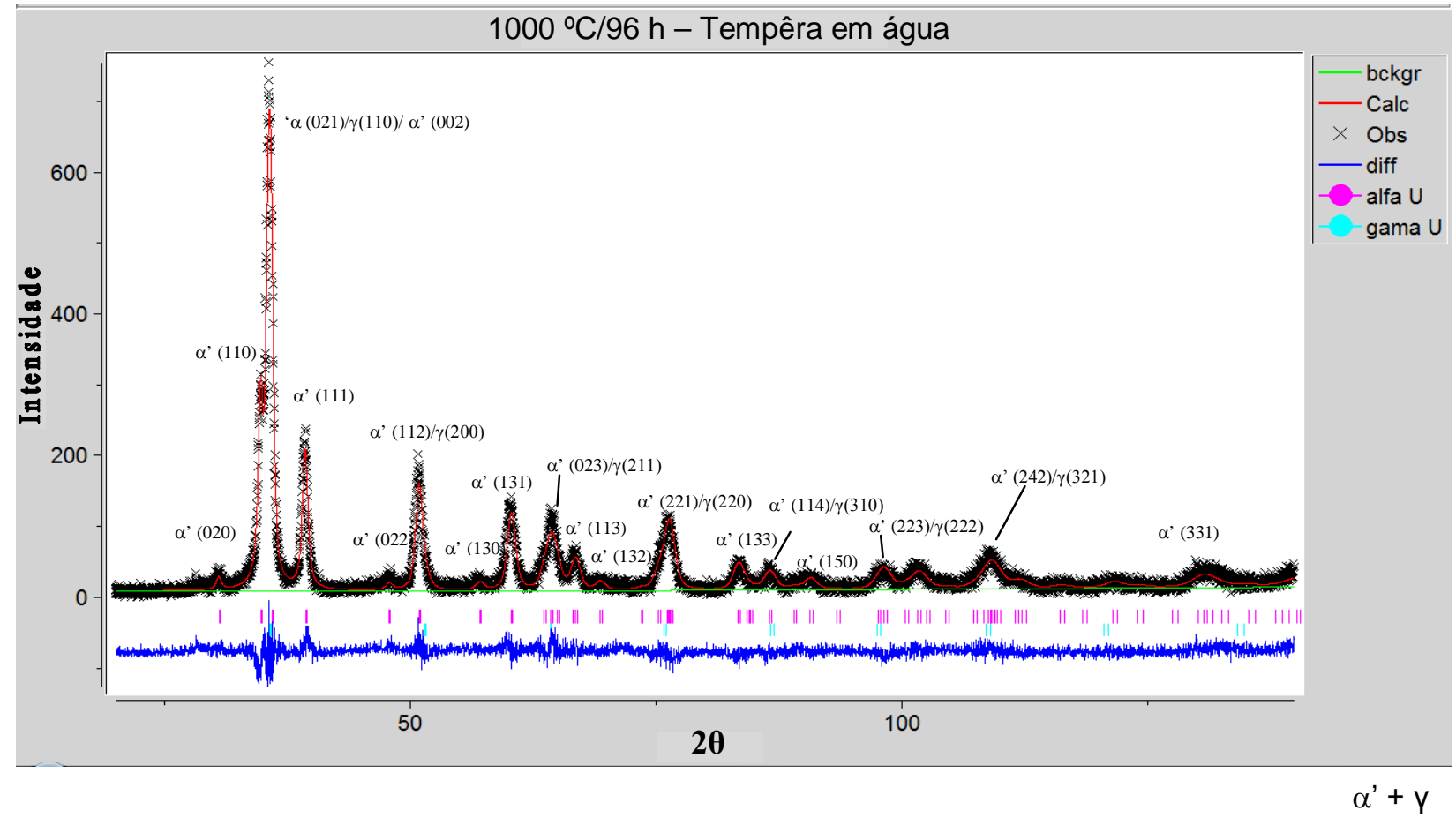

Figura 25 continuação: Difratogramas de raios $X$ das ligas que apresentaram formação da fase matensítica $\alpha$ após tratamento térmico a $1000^{\circ} \mathrm{C}$ por 96 horas seguidas de têmpera em água. 
$\mathrm{U}-20 \mathrm{Zr}$

$J$

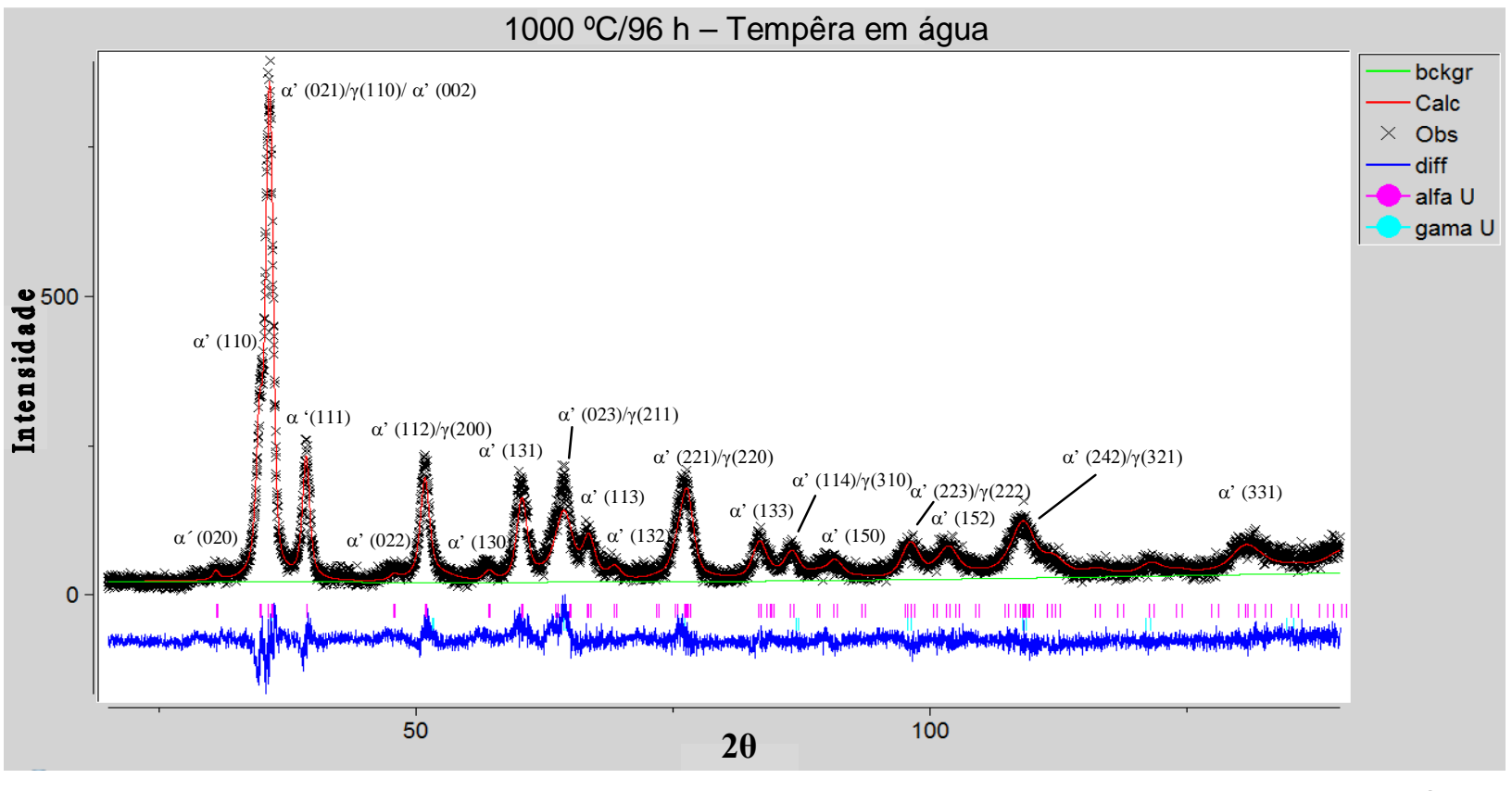

$\alpha^{\prime}+y$

Figura 25 continuação: Difratogramas de raios $X$ das ligas que apresentaram formação da fase matensítica $\alpha$ após tratamento térmico a $1000 \stackrel{\circ}{C}$ por 96 horas seguidas de têmpera em água.

De maneira geral, observou-se a presença da fase martensítica $\alpha^{\prime}$ de forma mais acentuada para as ligas binárias do sistema U-Zr. Este fato indica a atuação conjunta dos elementos $\mathrm{Nb}$ e Zr na inibição da formação desta fase e na estabilização da fase U-y, que prevaleceu para as ligas ternárias de composição U-5Nb-5Zr, U7,5Nb-7,5Zr e U-10Nb-10Zr, e nas ligas binárias do sistema U-Nb.

$\mathrm{Na}$ tabela a seguir são apresentados os parâmetros de rede das estruturas cristalinas das fases presentes nos difratogramas das ligas após aplicação de tratamento isotérmico a $1000 \stackrel{\circ}{\circ}$. 
Tabela 11: Parâmetros de rede das fases encontradas para as ligas após aplicação de tratamento isotérmico a $1000 \stackrel{\circ}{\circ}$.

\begin{tabular}{ccccccc}
\hline Liga & Fase & $\mathbf{a}(\mathbf{)}$ & $\mathbf{b}(\mathbf{)}$ & $\mathbf{c}(\mathbf{)}$ & Fase & $\mathbf{a = b = c ( ~})$ \\
\hline $\mathrm{U}-2,5 \mathrm{Nb}-2,5 \mathrm{Zr}(\mathrm{A})$ & $\alpha$ & $\approx 2,85$ & $\approx 5,87$ & $\approx 4,96$ & $\gamma$ & $\approx 3,54$ \\
\hline $\mathrm{U}-5 \mathrm{Nb}-5 \mathrm{Zr}(\mathrm{B})$ & - & - & - & - & $\gamma$ & 3,5031 \\
\hline $\mathrm{U}-7,5 \mathrm{Nb}-7,5 \mathrm{Nb}(\mathrm{C})$ & - & - & - & - & $\gamma$ & 3,4801 \\
\hline $\mathrm{U}-10 \mathrm{Nb}-10 \mathrm{Zr}(\mathrm{D})$ & - & - & - & - & $\gamma$ & 3,4881 \\
\hline $\mathrm{U}-10 \mathrm{Nb}(\mathrm{E})$ & - & - & - & - & $\gamma$ & 3,4777 \\
\hline $\mathrm{U}-10 \mathrm{Zr}(\mathrm{F})$ & $\alpha$ & 2,8760 & 5,8664 & 4,9880 & $\gamma$ & 3,5621 \\
\hline $\mathrm{U}-15 \mathrm{Nb}(\mathrm{G})$ & - & - & & - & $\gamma$ & 3,4585 \\
\hline $\mathrm{U}-15 \mathrm{Zr}(\mathrm{H})$ & $\alpha$ & 2,8692 & 5,8470 & 4,9969 & $\gamma$ & 3,5482 \\
\hline $\mathrm{U}-20 \mathrm{Nb}(\mathrm{I})$ & - & - & - & - & $\gamma$ & 3,4467 \\
\hline $\mathrm{U}-20 \mathrm{Zr}(\mathrm{J})$ & $\alpha$ & 2,8705 & 5,8452 & 4,9985 & $\gamma$ & 3,5398 \\
\hline
\end{tabular}

\subsubsection{Medidas de dureza}

Os resultados dos ensaios de dureza para as ligas obtidas via fusão a plasma, após aplicação de tratamento térmico de solubilização a $1000{ }^{\circ} \mathrm{C}$ seguido de têmpera em água são mostrados na Tabela 12. Escolheu-se este tipo de ensaio mecânico pela facilidade na tomada das medidas, que podem ser feitas sobre as próprias amostras embutidas, não havendo necessidade de confecção de amostras em geometrias especiais. Na Tabela 12, HV representam o valor médio da dureza Vickers medidas $\mathrm{N}$ vezes ao longo da amostra e Sd é o desvio padrão. 
Tabela 12: Dureza Vickers, ligas fundidas a plasma tratadas termicamente a $1000 \stackrel{\circ}{C}$ e temperadas em água.

\begin{tabular}{clll}
\hline Liga & HV & N & Sd \\
\hline $\mathrm{U}-2,5 N b-2,5 Z r(A)$ & 269 & 10 & 35 \\
\hline $\mathrm{U}-5 \mathrm{Nb}-5 \mathrm{Zr}(\mathrm{B})$ & 245 & 10 & 45 \\
\hline $\mathrm{U}-7,5 \mathrm{Nb}-7,5 \mathrm{Zr}(\mathrm{C})$ & 288 & 10 & 16 \\
\hline $\mathrm{U}-10 \mathrm{Nb}-10 \mathrm{Zr}(\mathrm{D})$ & 189 & 10 & 17 \\
\hline $\mathrm{U}-10 \mathrm{Nb}(\mathrm{E})$ & 187 & 10 & 35 \\
\hline $\mathrm{U}-10 \mathrm{Zr}(\mathrm{F})$ & 487 & 10 & 42 \\
\hline $\mathrm{U}-15 \mathrm{Nb}(\mathrm{G})$ & 242 & 10 & 10 \\
\hline $\mathrm{U}-15 \mathrm{Zr}(\mathrm{H})$ & 373 & 10 & 14 \\
\hline $\mathrm{U}-20 \mathrm{Nb}(\mathrm{I})$ & 255 & 10 & 15 \\
\hline $\mathrm{U}-20 \mathrm{Zr}(\mathrm{J})$ & 298 & 10 & 27
\end{tabular}

A fase $\mathrm{y}$ tem um comportamento plástico superior ao da fase $\alpha$, por apresentar uma estrutura mais comum aos metais, apresentando um elevado numero de sistemas cristalográficos onde pode ocorrer deformação por escorregamento. Os menores valores de dureza foram obtidos para ligas que apresentaram total retenção da fase metaestável Y. A presença da fase martensítica $\alpha$ ' foi acompanhada de valores maiores de dureza. Os valores encontrados mostram-se em concordância com os relatados para ligas ternárias U-Nb-Zr tratadas a 1000 ํ e temperadas em água (IVANOV; BADAJA, 1958) onde são apresentadas projeções de curvas isohardness sobre o diagrama ternário. 


\subsubsection{Estado envelhecido a $700^{\circ} \mathrm{C}$}

Em seguida serão apresentados resultados referentes às ligas $\mathrm{U}-2,5 \mathrm{Nb}-2,5 \mathrm{Zr}$ (A), U-5Nb-5Zr (B), U-7,5Nb-7,5Zr (C), U-10Nb-10Zr (D), U-10Nb (E), U-10Zr (F), U$15 \mathrm{Nb}(\mathrm{G}), \mathrm{U}-15 \mathrm{Zr}(\mathrm{H}), \mathrm{U}-20 \mathrm{Nb}(\mathrm{I})$ e U-20Zr (J) no estado envelhecido a $700 \stackrel{\circ}{\mathrm{C}}$.

\subsubsection{Microscopia óptica}

A Figura 26 apresenta a microestrutura das ligas fundidas via a plasma e submetidas a tratamento térmico de envelhecimento a $700 \stackrel{\circ}{\mathrm{C}}$ por 20 horas seguido de têmpera em água; as peças foram analisadas após realização de ataque metalográfico. Nas imagens é possível verificar o modo como as fases estão distribuídas, assim como suas morfologias, auxiliando no estudo das fases e seus mecanismos de formação.

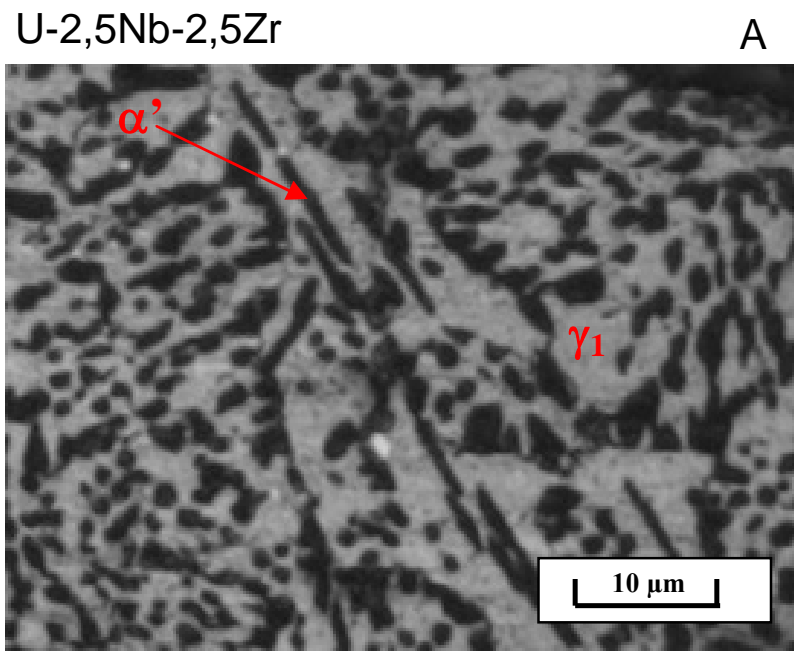

$\alpha^{\prime}+\gamma_{1}$
U-5Nb-5Zr

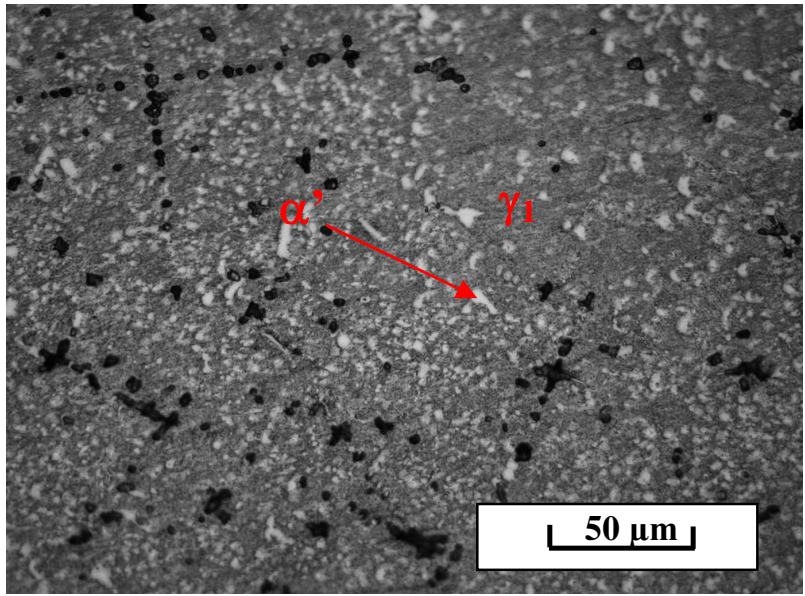

$\alpha^{\prime}+\gamma_{1}$

Figura 26: Micrografias óticas das ligas após tratamento isotérmico a $700 \stackrel{\circ}{\mathrm{C}}$ por 20 horas seguidas de têmpera em água, MO. 
$\mathrm{U}-7,5 \mathrm{Nb}-7,5 \mathrm{Zr}$

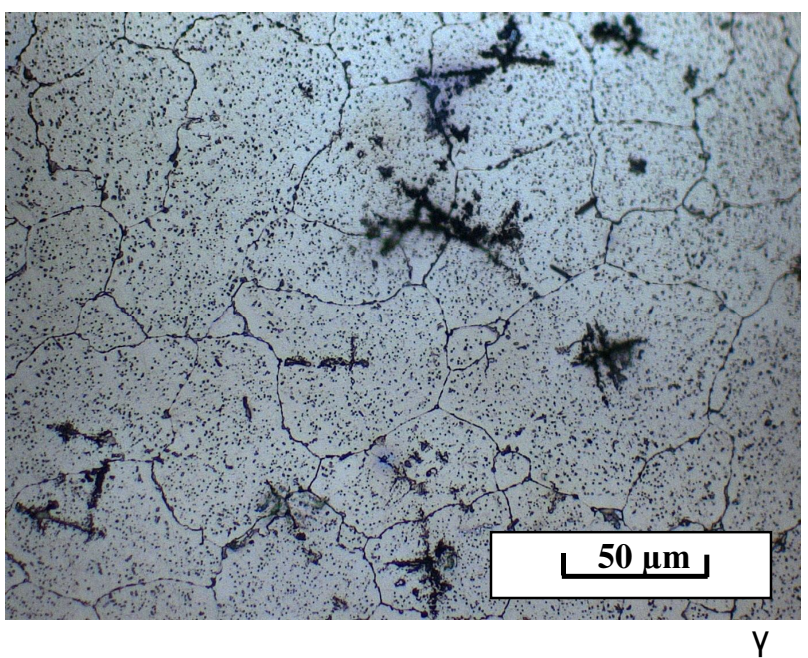

C U-10Nb-10Zr

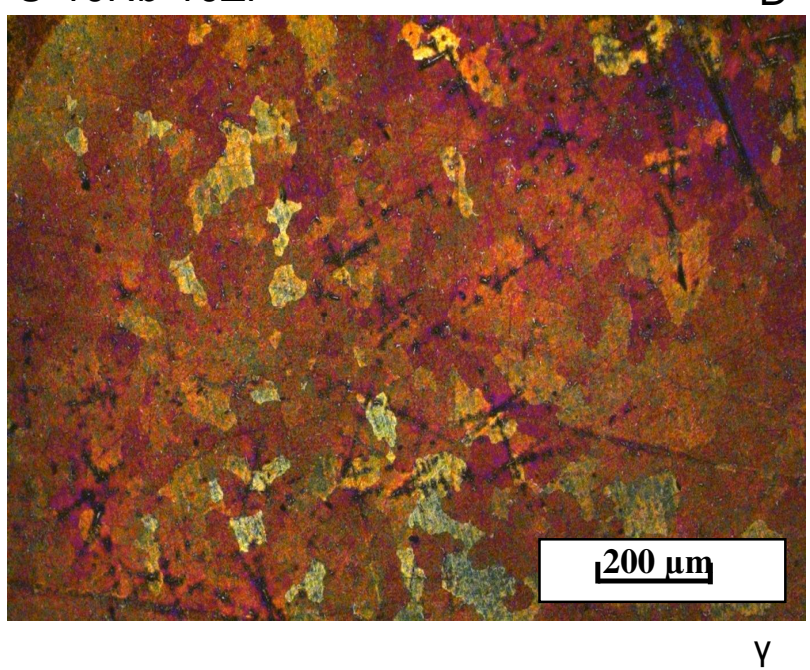

$\mathrm{U}-10 \mathrm{Nb}$

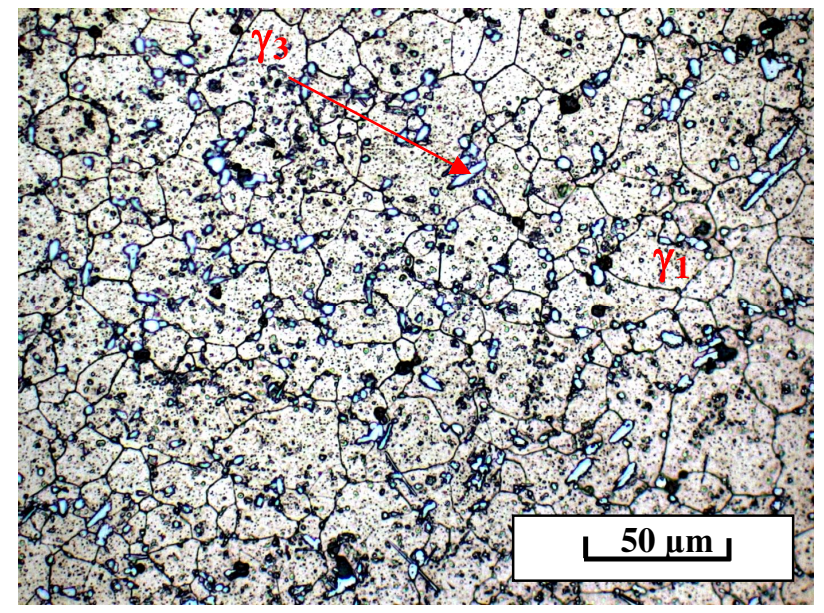

$\mathrm{y}_{1}+\mathrm{y}_{3}$
E U-10Zr

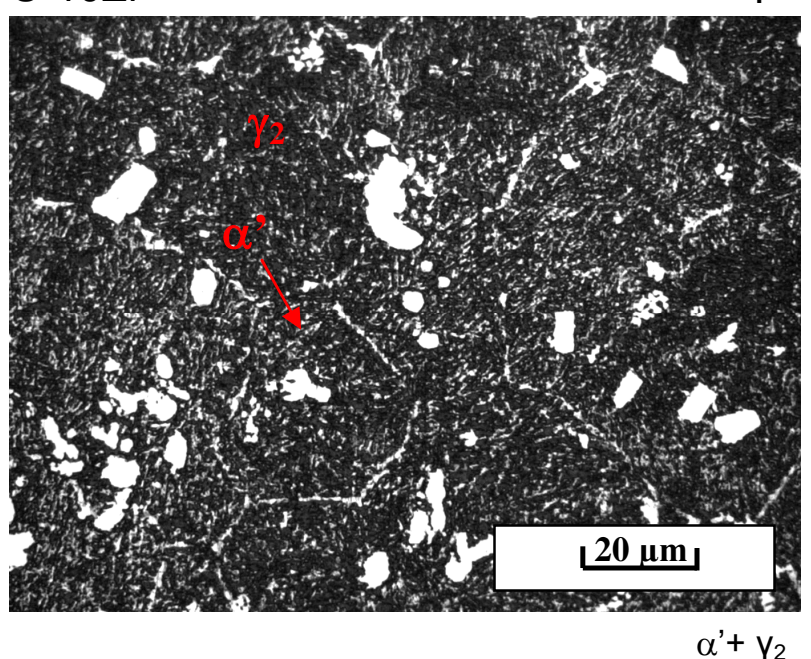

Figura 26 continuação: Micrografias óticas das ligas após tratamento isotérmico a $700 \stackrel{\circ}{C}$ por 20 horas seguidas de têmpera em água, MO. 
$\mathrm{U}-15 \mathrm{Nb}$

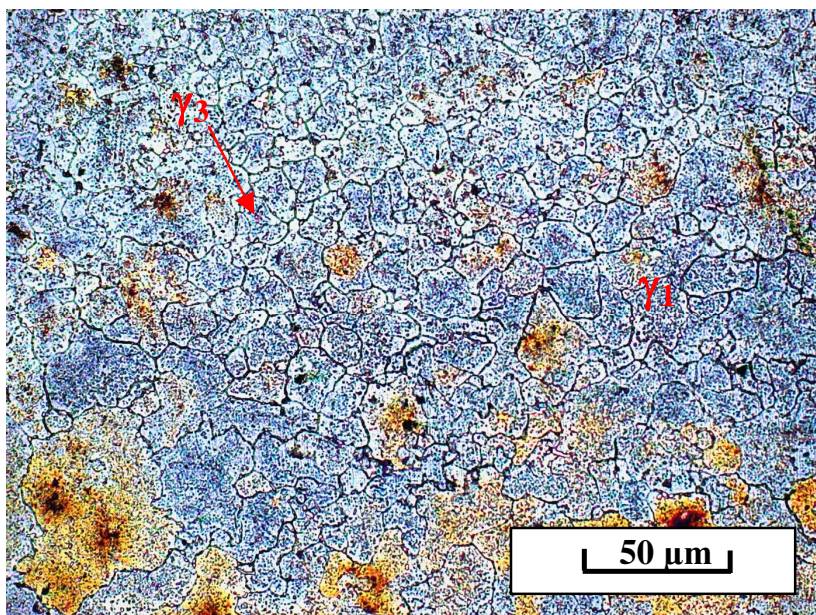

$\mathrm{Y}_{1}+\mathrm{Y}_{3}$
$\mathrm{H}$

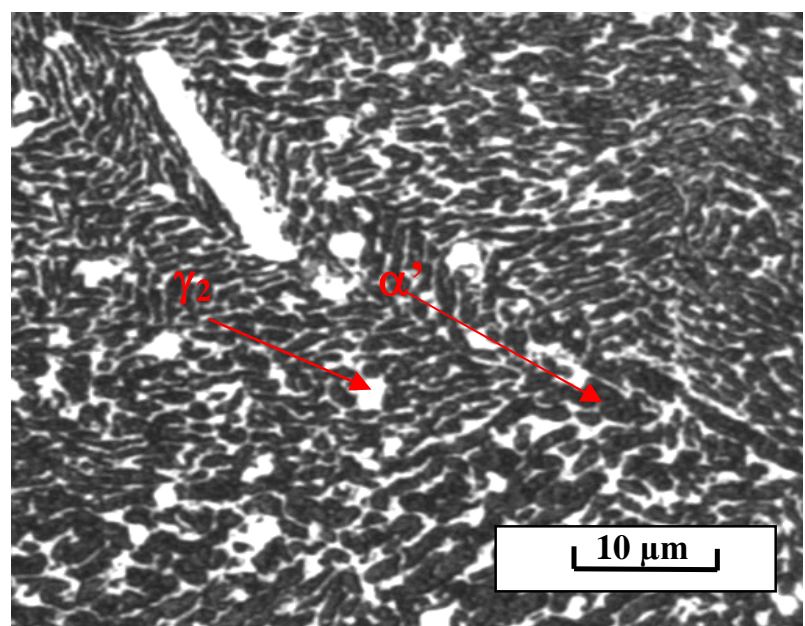

$\alpha^{\prime}+\gamma_{2}$

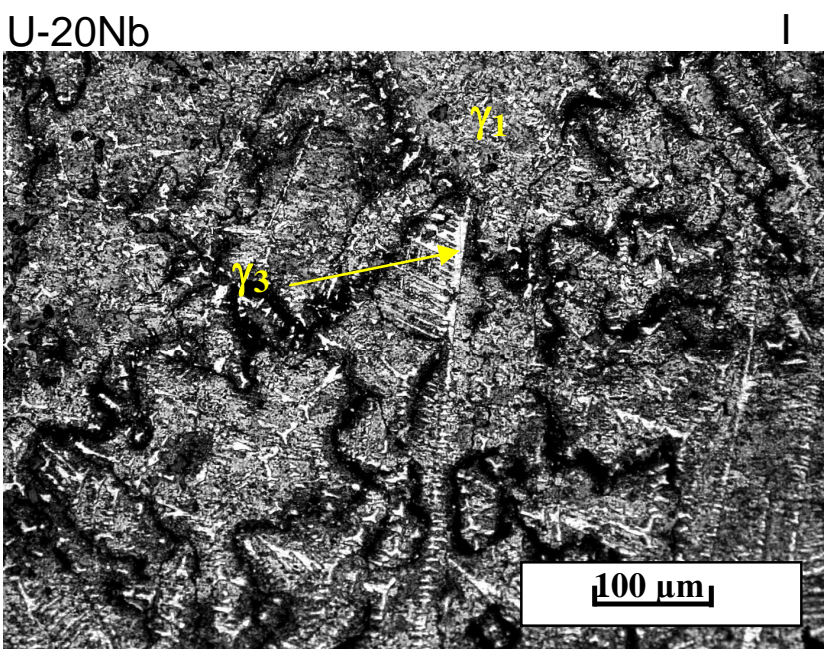

$\mathrm{Y}_{1}+\mathrm{Y}_{3}$

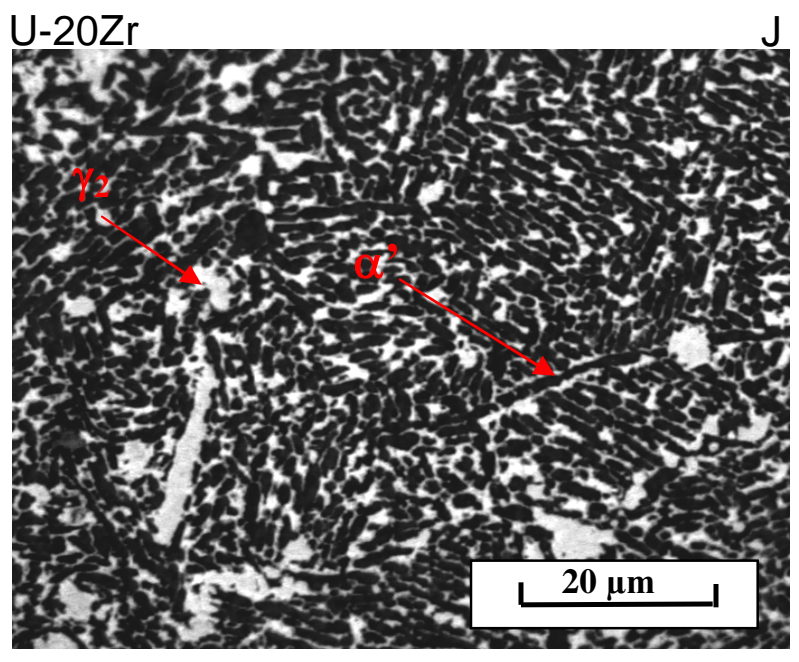

$\alpha^{\prime}+\gamma_{2}$

Figura 26 continuação: Micrografias óticas das ligas após tratamento isotérmico a $700 \stackrel{\circ}{C}$ por 20 horas seguidas de têmpera em água, MO.

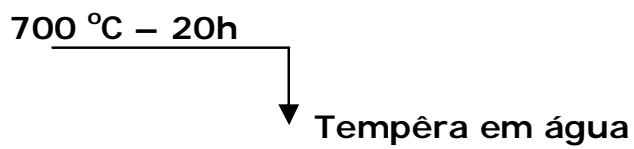

De maneira geral observa-se uma morfologia acicular para a fase martensítica $\alpha^{\prime}$, evidenciando mecanismo de formação por cisalhamento. A liga U-5Nb-5Zr mostra relativa diferença na morfologia para esta fase (com aspecto mais arredondado), além de ter se mostrado muito resistente ao ataque químico, o que pode indicar uma 
alteração no mecanismo de formação desta fase. Para as ligas com total retenção da fase $\mathrm{Y}$, o ataque metalográfico apresentou dificuldades de revelar os grãos das amostras, em decorrência da fase U-ү ser muito resistente à oxidação (TOTEMEIER, 1995). Para as ligas do sistema binário U-Nb, a presença da fase $\gamma_{3}$ é evidente para as composições U-10Nb e U-20Nb.

\subsubsection{Difração de raios $X$}

As fases presentes nas ligas após realização de tratamento isotérmico a $700{ }^{\circ} \mathrm{C}$ por 20 horas seguido de resfriamento em água foram analisadas por difração de raios $\mathrm{X}$, de modo a complementar a análise metalográfica. Os difratogramas obtidos são apresentados nas figuras a seguir.

\section{$\mathrm{U}-2,5 \mathrm{Nb}-2,5 \mathrm{Zr}$}

A

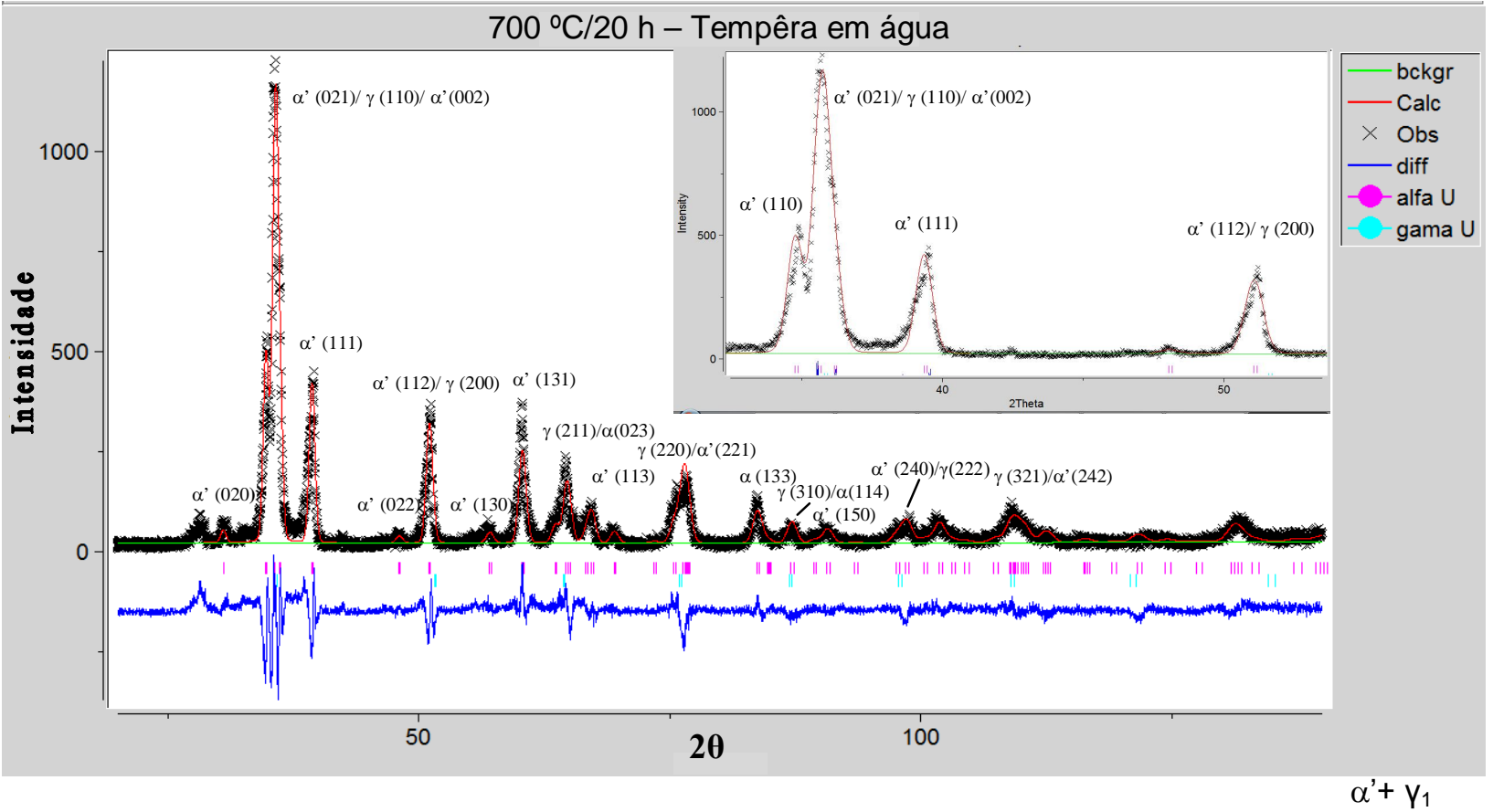

Figura 27: Difratogramas de raios $X$ das ligas após tratamento isotérmico a $700 \stackrel{\circ}{C}$ por 20 horas seguidas de têmpera em água. 
$\mathrm{U}-5 \mathrm{Nb}-5 \mathrm{Zr}$

B

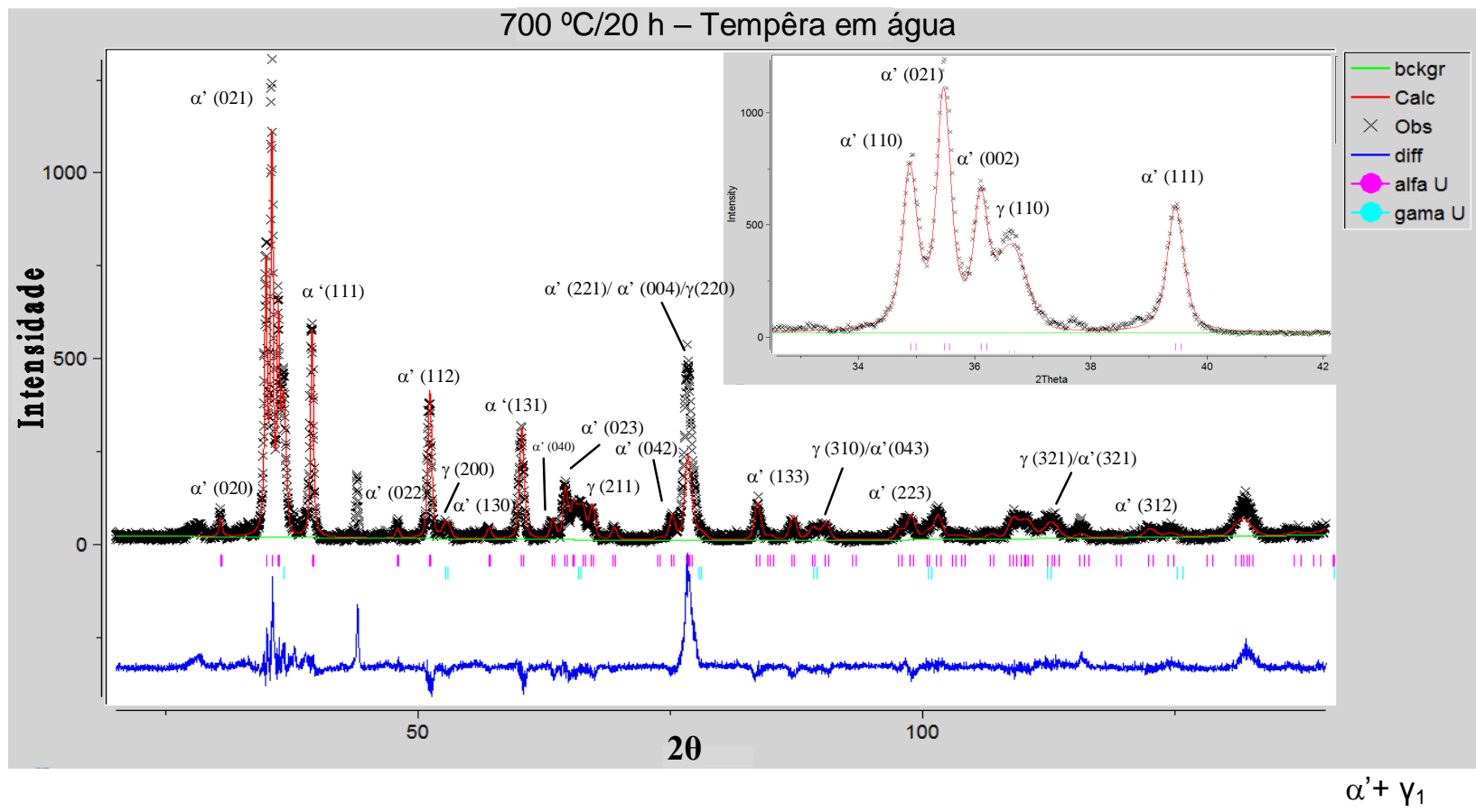

$\mathrm{U}-7,5 \mathrm{Nb}-7,5 \mathrm{Zr}$

C

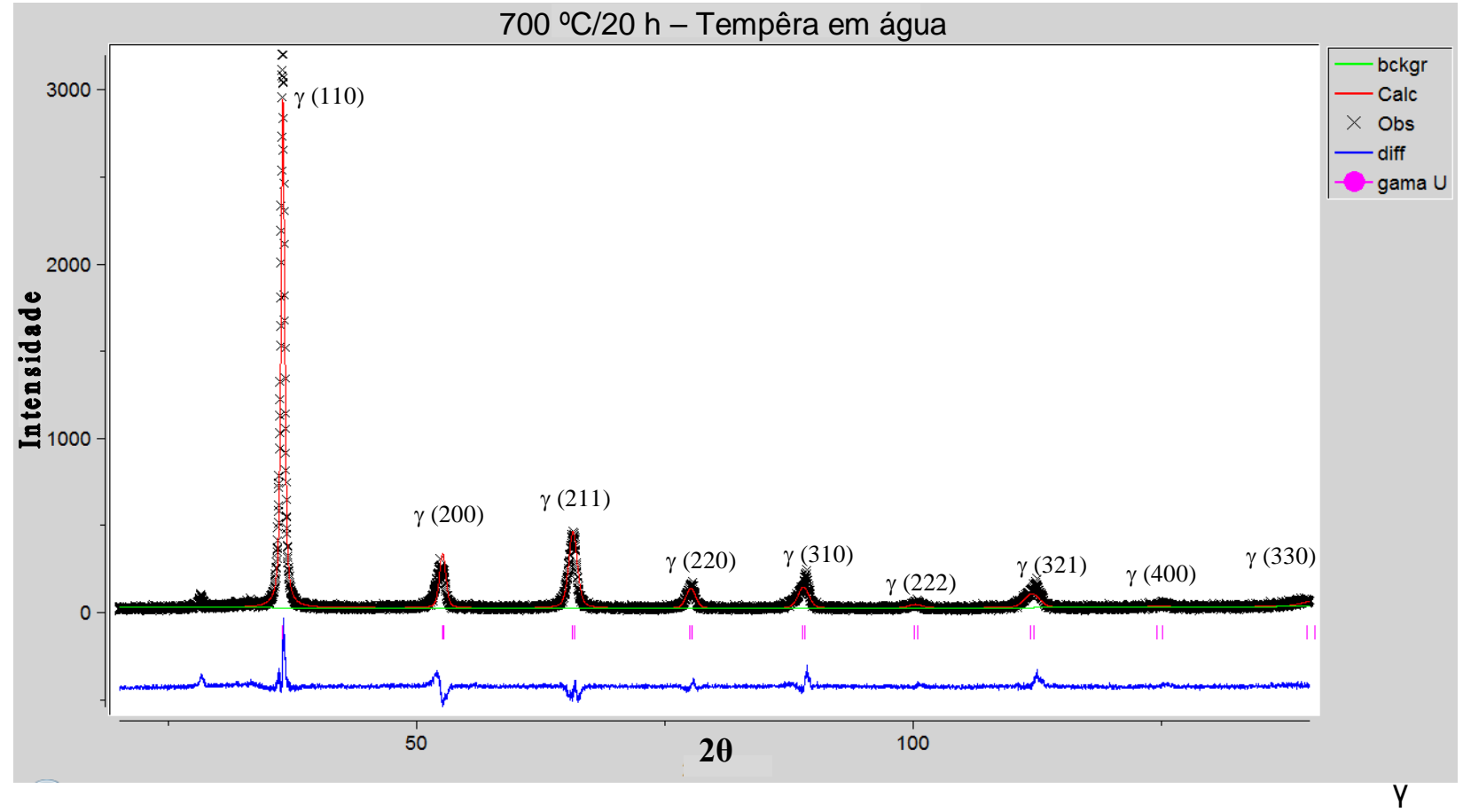

Figura 27 continuação: Difratogramas de raios $X$ das ligas após tratamento isotérmico a $700 \stackrel{\circ}{ } \mathrm{C}$ por 20 horas seguidas de têmpera em água. 
U-10Nb-10Zr

D

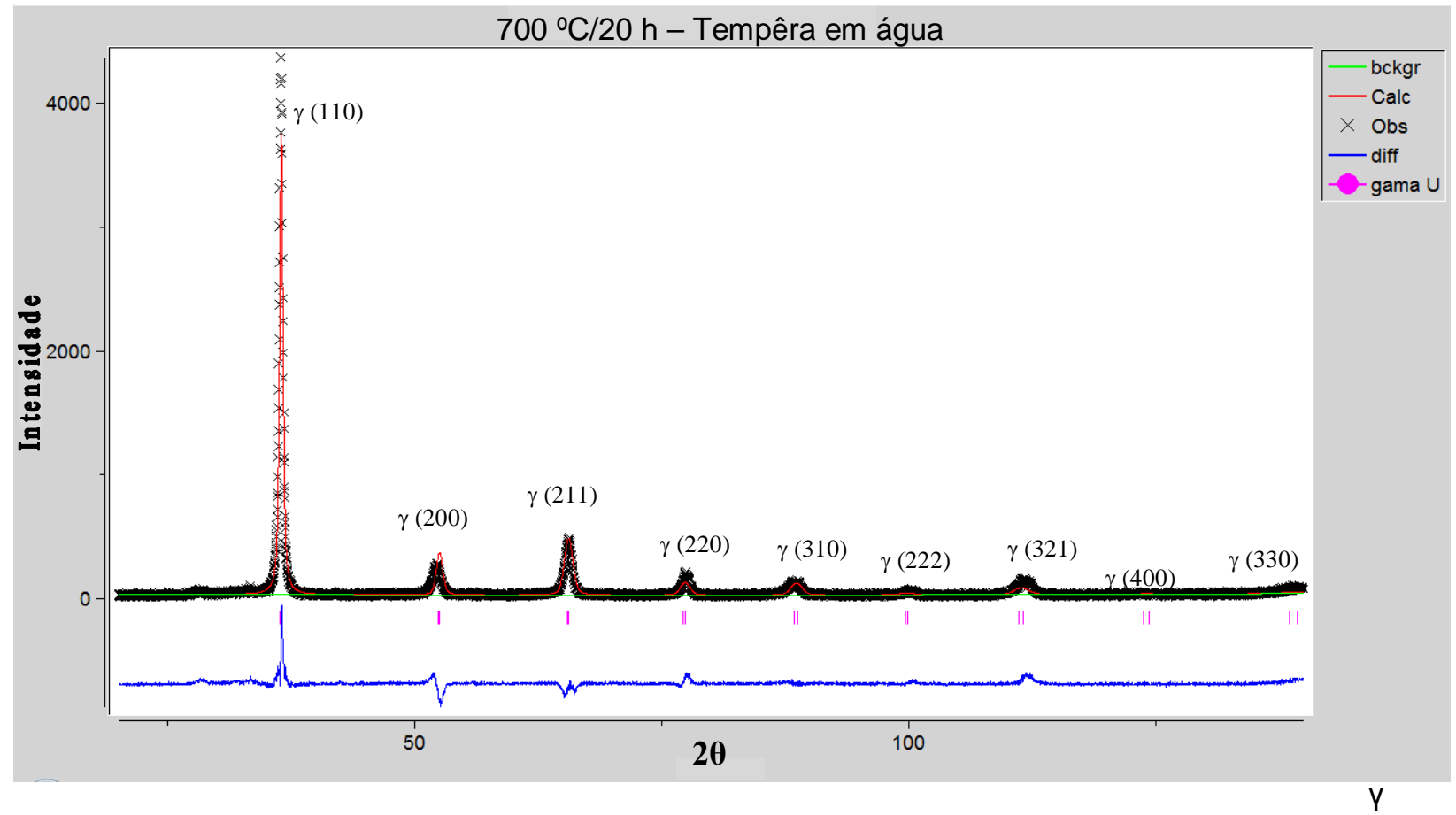

$\mathrm{U}-10 \mathrm{Nb}$

E

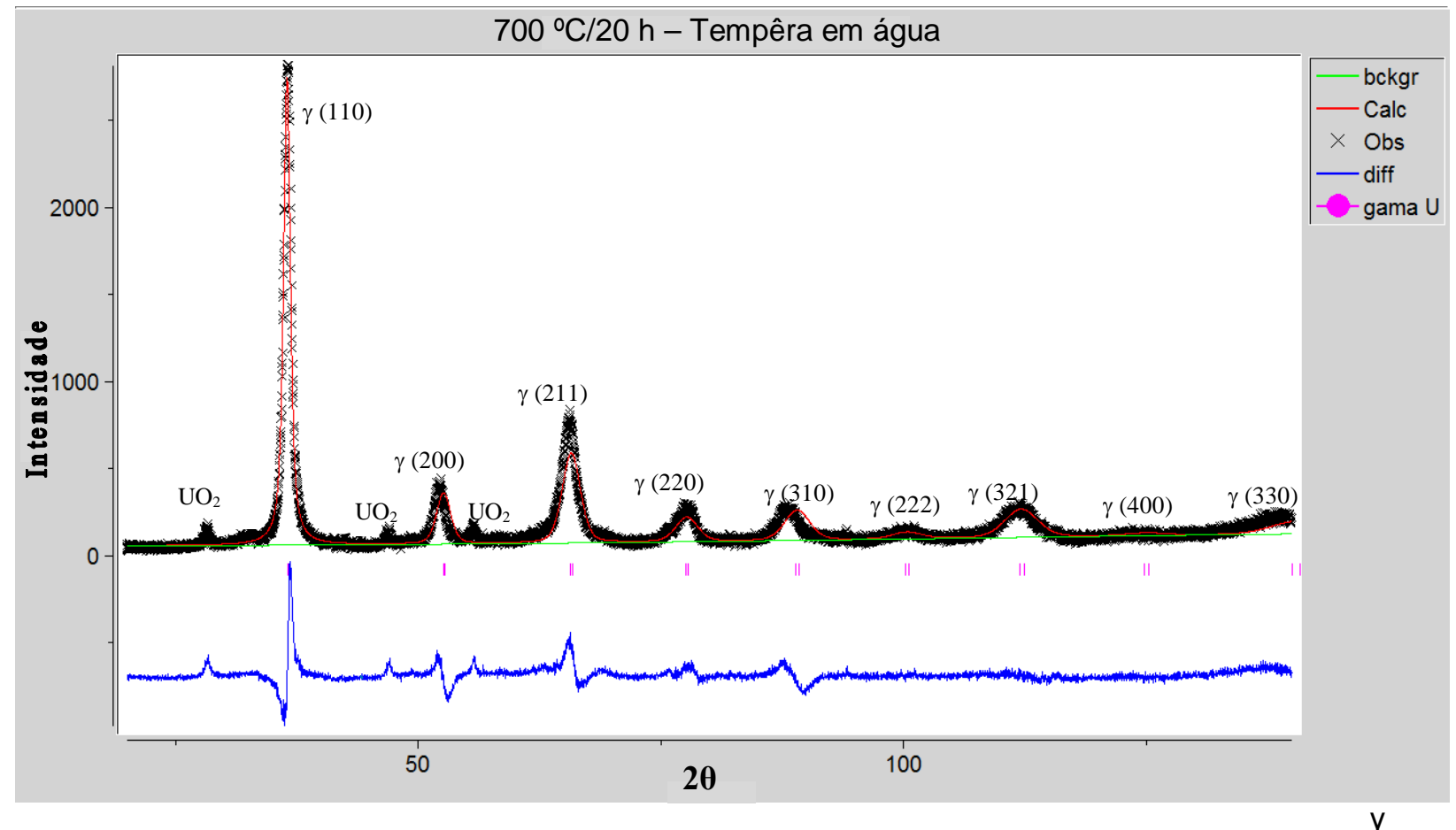

Figura 27 continuação: Difratogramas de raios $X$ das ligas após tratamento isotérmico a $700{ }^{\circ} \mathrm{C}$ por 20 horas seguidas de têmpera em água. 

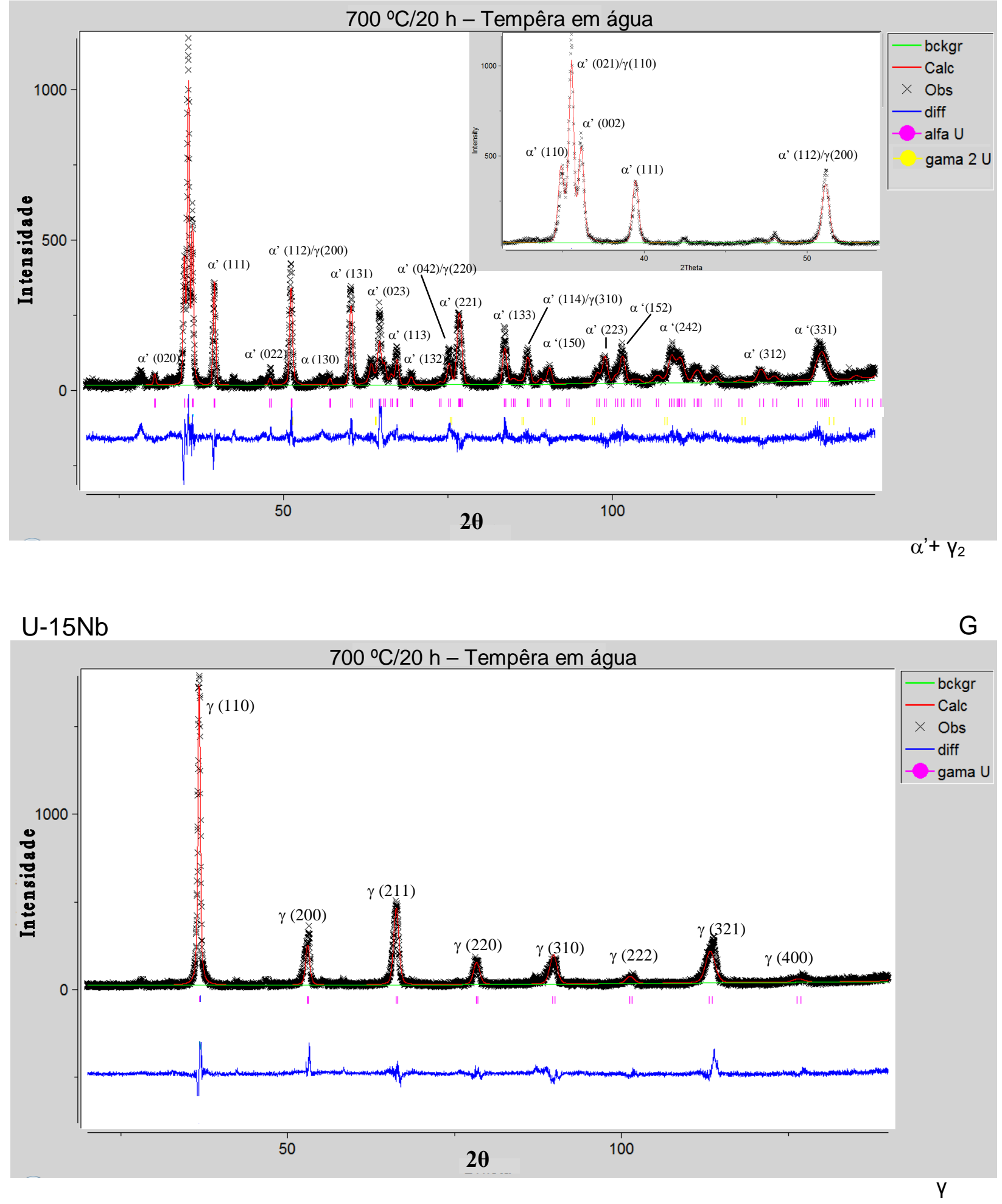

Figura 27 continuação: Difratogramas de raios $X$ das ligas após tratamento isotérmico a $700 \stackrel{\circ}{ } \mathrm{C}$ por 20 horas seguidas de têmpera em água. 


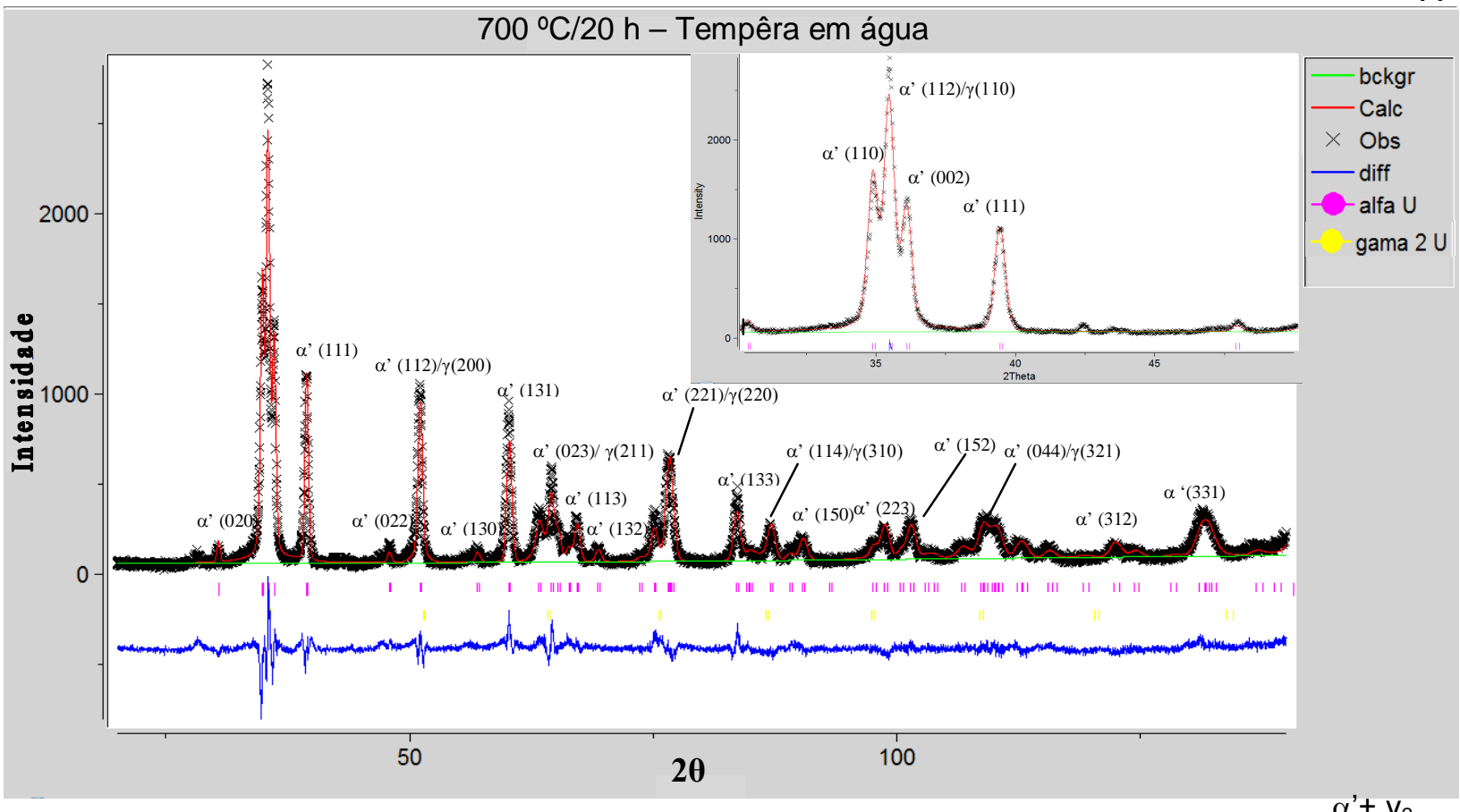

U-20Nb $\quad 700 \stackrel{\circ}{C} / 20 \mathrm{~h}-$ Tempêra em água

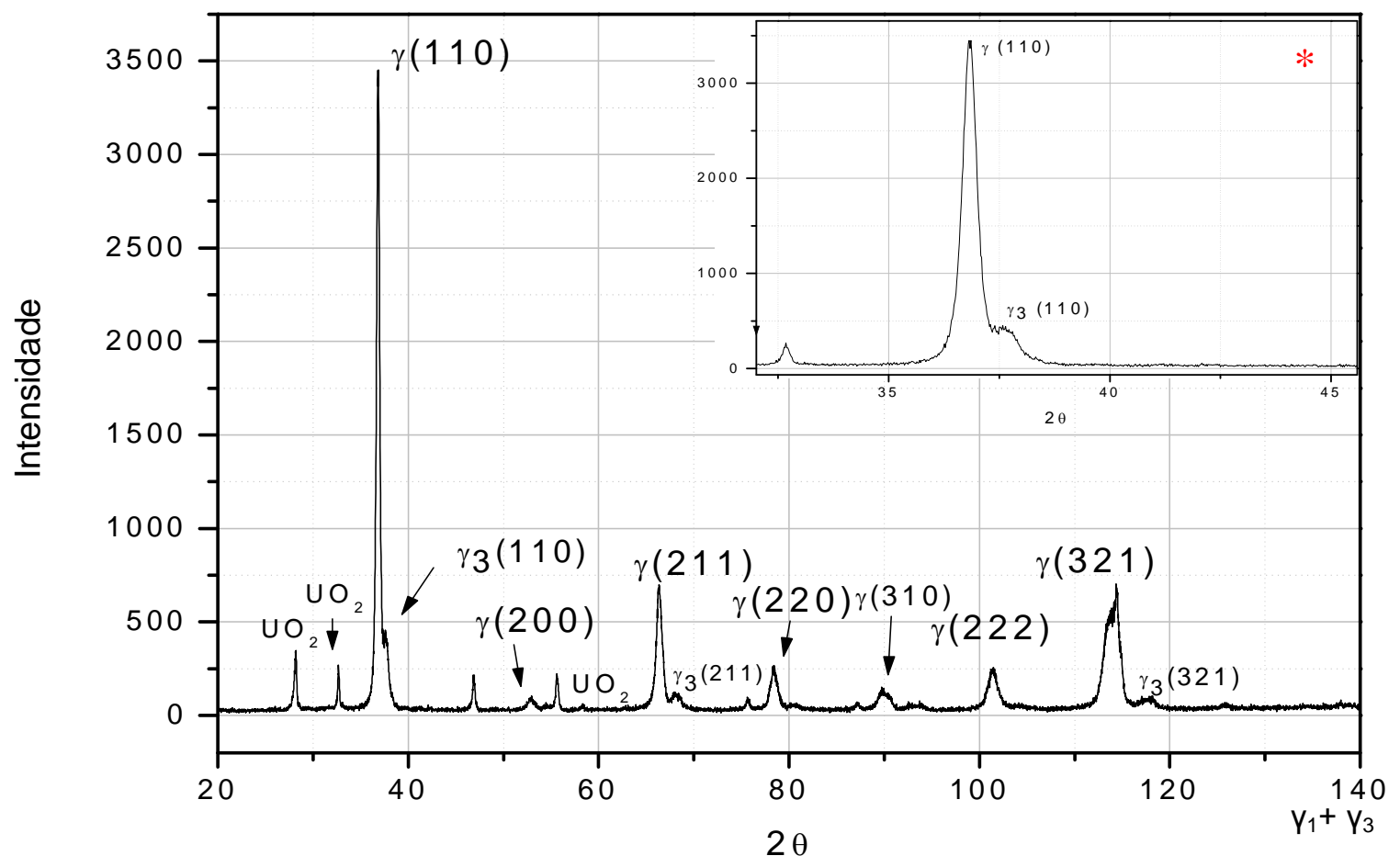

* Não se obteve um padrão simulado (método Rietveld) com proximidade aceitável ao padrão

observado.

Figura 27 continuação: Difratogramas de raios $X$ das ligas após tratamento isotérmico a $700 \stackrel{\circ}{ } \mathrm{C}$ por 20 horas seguidas de têmpera em água. 


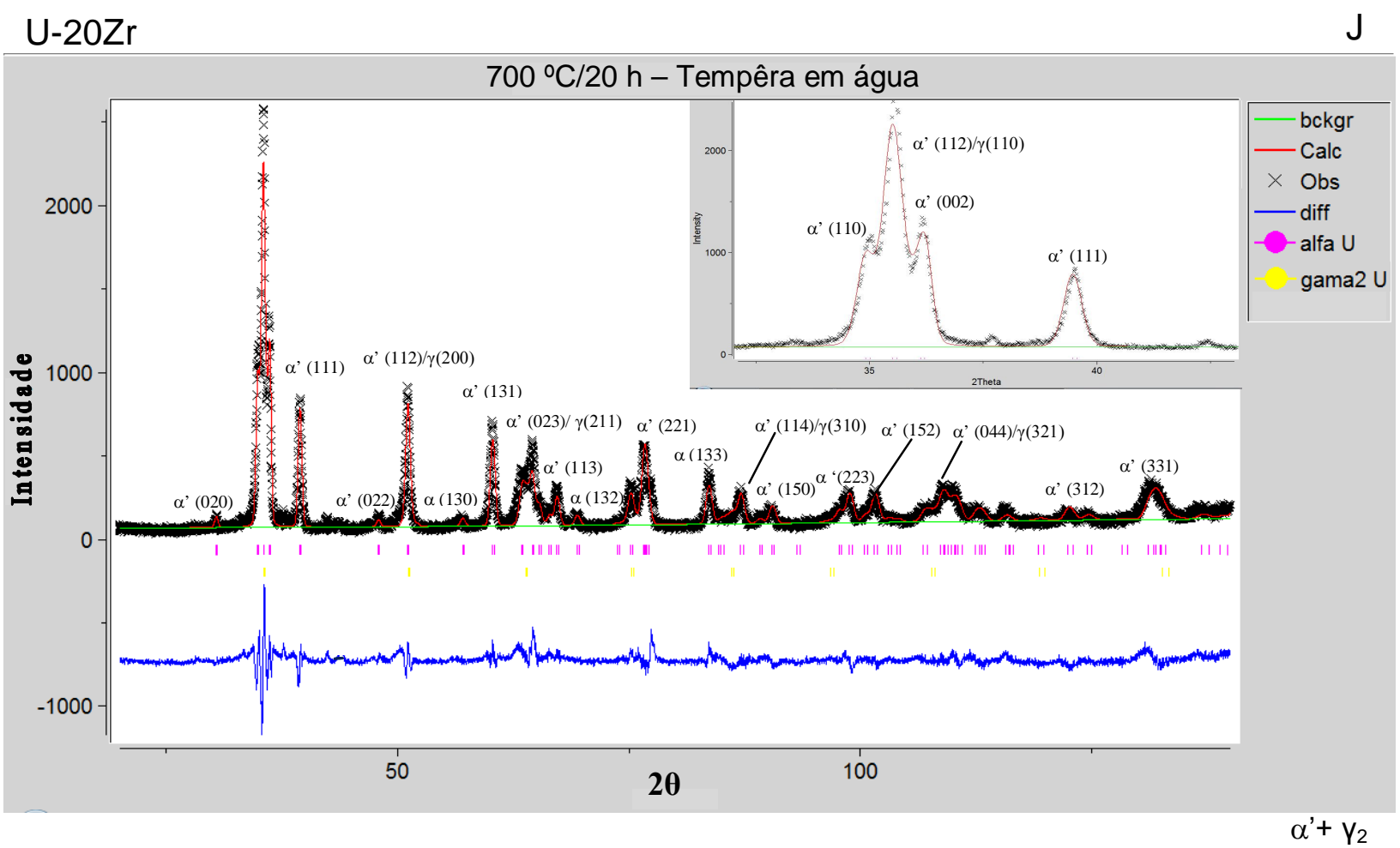

Figura 27 continuação: Difratogramas de raios $X$ das ligas após tratamento isotérmico a $700 \stackrel{\circ}{ } \mathrm{C}$ por 20 horas seguidas de têmpera em água.

Pelos difratogramas obtidos, é possível verificar que as ligas ternárias U-2,5Nb-2,5Zr e U-5Nb-5Zr e binárias do sistema U-Zr são essencialmente formadas pela fase martensítica $\alpha$ ' e uma estrutura y modificada. A distorção nos parâmetros de rede da estrutura ortorrômbica assim como o deslocamento dos planos de reflexão indica formação desta fase por mecanismo de cisalhamento. Para as demais ligas são observadas somente reflexões referentes a uma estrutura cúbica de corpo centrado, em concordância com resultados da microscopia óptica. Picos de óxido também podem ser observados, mas são devidos à exposição da amostra ao ar durante preparo e manuseio já que metalograficamente não foi observado nenhuma inclusão não metálica. Observou-se para o difratograma obtido para a liga ternária U-5Nb-5Zr

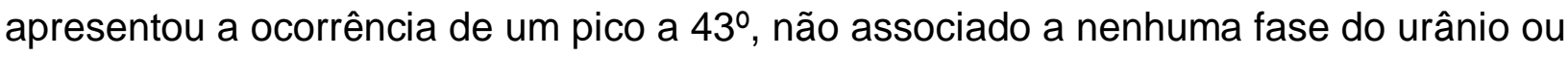
dos elementos de liga, além de um aumento na intensidade da reflexão próxima do 
ângulo 76,6ํㅜㄹ, resultando em uma grande diferença entre o difratograma observado e o calculado. Este fato pode estar ligado à presença dos precipitados de solidificação.

$\mathrm{Na}$ tabela a seguir são apresentados os parâmetros de rede das estruturas cristalinas presentes nos difratogramas das ligas após aplicação de tratamento isotérmico a $700{ }^{\circ} \mathrm{C}$ por 20 horas seguidas de têmpera em água.

Tabela 13: Parâmetros de rede das fases encontradas para as ligas após aplicação de tratamento isotérmico a $700 \stackrel{\circ}{ } \mathrm{C}$ por 20 horas seguidas de têmpera em água.

\begin{tabular}{ccccccc}
\hline Liga & Fase & a ( ) & b ( ) & c ( ) & Fase & a=b=c ( ) \\
\hline $\mathrm{U}-2,5 \mathrm{Nb}-2,5 \mathrm{Zr}(\mathrm{A})$ & $\alpha$ & 2,8701 & 5,8435 & 4,9798 & $\gamma_{1}$ & 3,5429 \\
\hline $\mathrm{U}-5 \mathrm{Nb}-5 \mathrm{Zr}(\mathrm{B})$ & $\alpha$ & 2,8568 & 5,8725 & 4,9705 & $\gamma_{1}$ & 3,4693 \\
\hline $\mathrm{U}-7,5 \mathrm{Nb}-7,5 \mathrm{Nb}(\mathrm{C})$ & - & - & - & - & $\gamma$ & 3,4812 \\
\hline $\mathrm{U}-10 \mathrm{Nb}-10 \mathrm{Zr}(\mathrm{D})$ & - & - & - & - & $\gamma$ & 3,4937 \\
\hline $\mathrm{U}-10 \mathrm{Nb}(\mathrm{E})$ & - & - & - & - & $\gamma$ & 3,4777 \\
\hline $\mathrm{U}-10 \mathrm{Zr}(\mathrm{F})$ & $\alpha$ & 2,8554 & 5,8712 & 4,9686 & $\gamma$ & 3,5637 \\
\hline $\mathrm{U}-15 \mathrm{Nb}(\mathrm{G})$ & - & - & & - & $\gamma$ & 3,4537 \\
\hline $\mathrm{U}-15 \mathrm{Zr}(\mathrm{H})$ & $\alpha$ & 2,8578 & 5,8731 & 4,9701 & $\gamma$ & 3,5623 \\
\hline $\mathrm{U}-20 \mathrm{Nb}(\mathrm{I})$ & - & - & - & - & $\gamma ; \gamma_{3}$ & $\approx 3,44 ; \approx 3,38$ \\
\hline $\mathrm{U}-20 \mathrm{Zr}(\mathrm{J})$ & $\alpha$ & 2,8558 & 5,8669 & 4,9693 & $\gamma$ & 3,5688 \\
\hline
\end{tabular}

A análise do parâmetro de rede da fase y sugere que o $\mathrm{Nb}$ e $\circ \mathrm{Zr}$ tenham efeitos opostos. Fica evidente a tendência de contração do parâmetro de rede para adição de nióbio e expansão para o zircônio. Para as ligas ternárias observa-se um valor do parâmetro de rede mais próximo ao da fase $U$-y do urânio puro, evidenciando que a distorção inserida por um elemento tende a ser compensada pelo outro.

\subsubsection{Medidas de dureza}

Os resultados dos ensaios de dureza para as ligas após aplicação de tratamento isotérmico a $700{ }^{\circ} \mathrm{C}$ por 20 horas seguidas de têmpera em água são mostrados na 
Tabela 14. Realizou-se este ensaio no intuito de averiguar a influência das fases presentes e seus mecanismos de formação nesta propriedade mecânica.

Tabela 14: Dureza Vickers das ligas fundidas a plasma e tratadas termicamente a $700 \stackrel{\circ}{\mathrm{C}}$ por 20 horas seguidas de têmpera em água.

\begin{tabular}{cccc}
\hline Liga & HV & N & Sd \\
\hline U-2,5Nb-2,5Zr (A) & 281 & 10 & 14 \\
\hline U-5Nb-5Zr (B) & 391 & 10 & 34 \\
\hline U-7,5Nb-7,5Zr (C) & 290 & 10 & 14 \\
\hline U-10Nb-10Zr (D) & 183 & 10 & 7 \\
\hline U-10Nb (E) & 190 & 10 & 13 \\
\hline U-10Zr (F) & 294 & 10 & 8 \\
\hline U-15Nb (G) & 340 & 10 & 13 \\
\hline U-15Zr (H) & 278 & 10 & 45 \\
\hline U-20Nb (I) & 357 & 10 & 12 \\
\hline U-20Zr (J) & 269 & 10 & \\
\hline
\end{tabular}

Foram observados os menores valores de dureza para as ligas com retenção da fase metaestável y. Observa-se também que o aumento no teor do elemento nióbio tende a causar um aumento na dureza, possivelmente causado pela distorção gerada na estrutura da fase $\mathrm{y}$. O comportamento inverso é observado para adição de $\mathrm{Zr}$, mostrando-se este elemento mais eficiente na redução dos valores de dureza. Outra observação importante é o valor obtido para a liga U-5Nb-5Zr que se mostrou expressivamente maior ao obtido para a liga U-2,5Nb-2,5Zr. A explicação deste fato vem da ocorrência da formação da fase a' por mecanismo de cisalhamento ("shear") relacionado a um aumento de dureza, relatado na literatura (ASM, Handbook Vol. 9). 


\subsubsection{Estado envelhecido a $500^{\circ} \mathrm{C}$}

Em seguida serão apresentados resultados referentes às ligas $\mathrm{U}-2,5 \mathrm{Nb}-2,5 \mathrm{Zr}$ (A), U-5Nb-5Zr (B), U-7,5Nb-7,5Zr (C), U-10Nb-10Zr (D), U-10Nb (E), U-10Zr (F), U$15 \mathrm{Nb}(\mathrm{G}), \mathrm{U}-15 \mathrm{Zr}(\mathrm{H}), \mathrm{U}-20 \mathrm{Nb}(\mathrm{I})$ e U-20Zr (J) no estado envelhecido a $500 \stackrel{\circ}{\mathrm{C}}$.

\subsubsection{Microscopia óptica}

A Figura 28 apresenta a microestrutura das ligas fundidas a plasma e submetidas a tratamento térmico de envelhecimento a $500 \stackrel{\circ}{\mathrm{C}}$ por 20 horas seguido de têmpera em água, as peças foram analisadas após realização de ataque metalográfico. Nas imagens é possível verificar o modo como as fases estão distribuídas assim como suas morfologias, auxiliando no estudo das fases e seus mecanismos de formação.
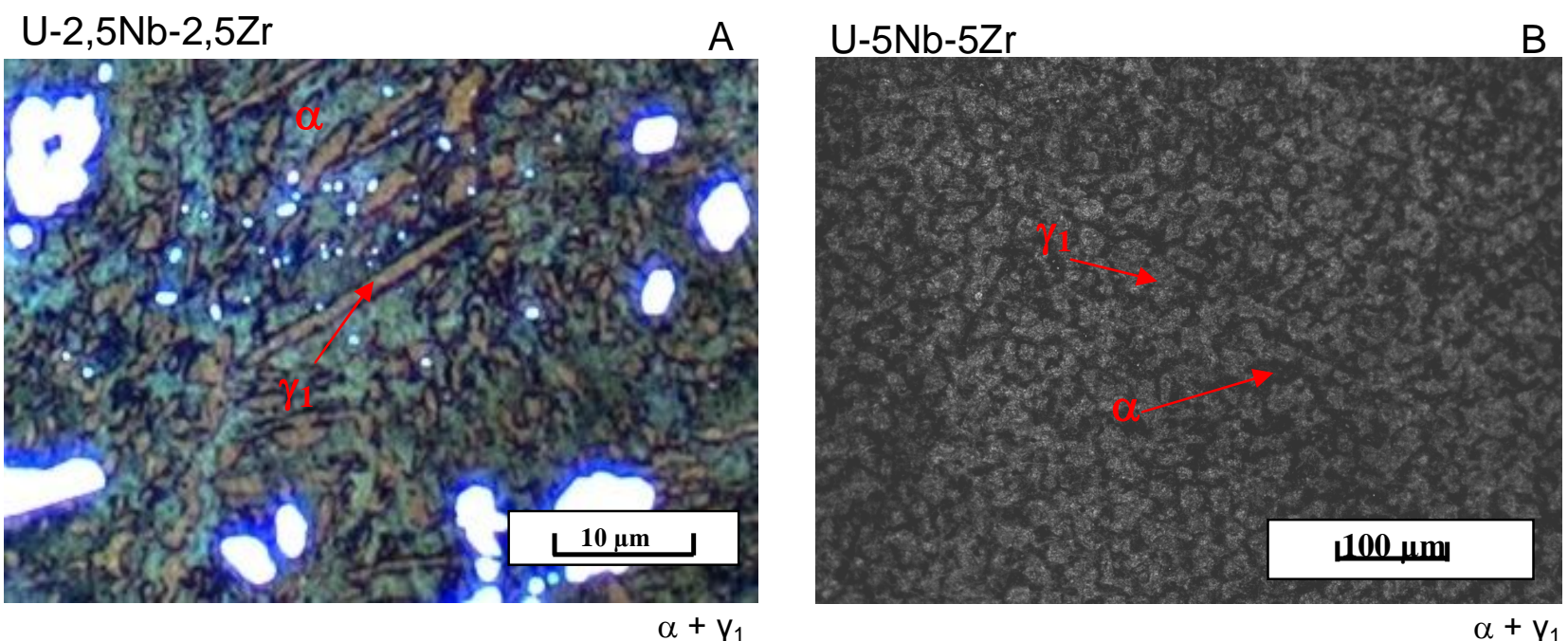

B

Figura 28: Micrografias ópticas das ligas no após tratamento isotérmico a $500{ }^{\circ} \mathrm{C}$ por 20 horas seguidas de têmpera em água, MO. 


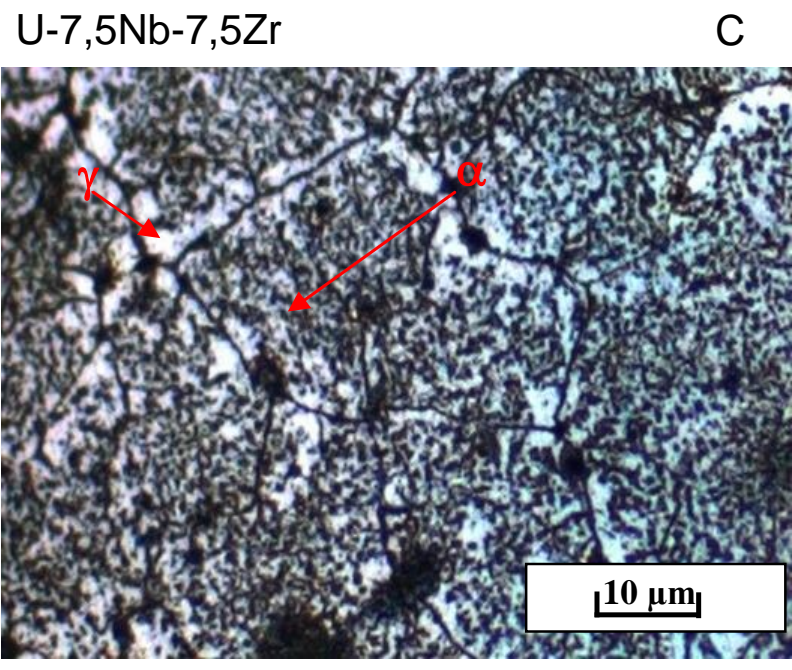

$\alpha+\gamma$
D

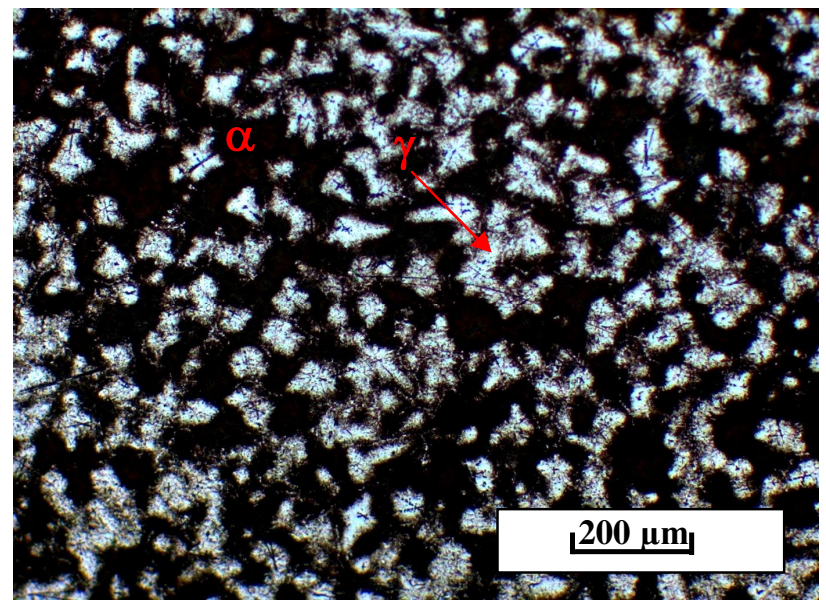

$\alpha+\gamma$

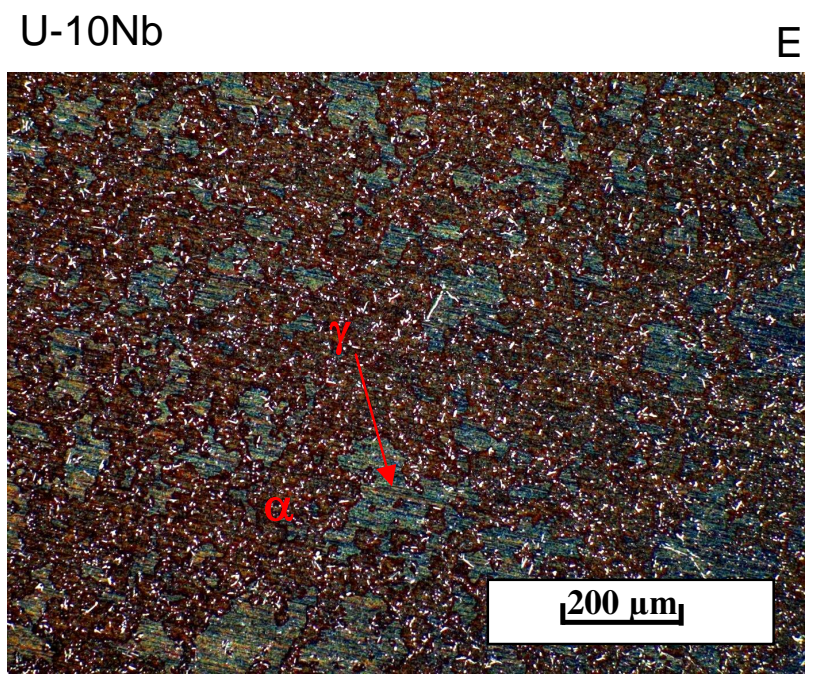

E U-10Zr

F

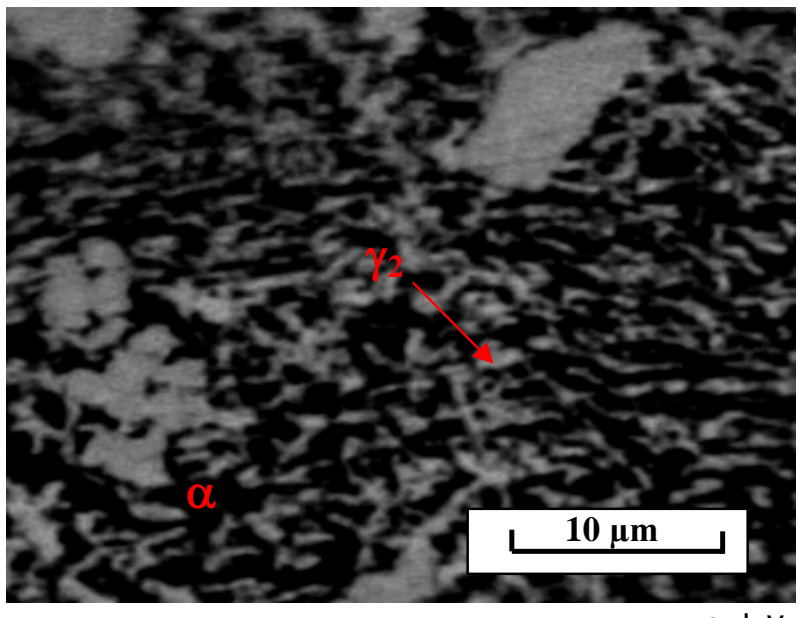

$\alpha+\gamma$

$\alpha+\gamma_{2}$

Figura 28 continuação: Micrografias ópticas das ligas no após tratamento isotérmico a $500 \stackrel{\circ}{\circ}$ por 20 horas seguidas de têmpera em água, MO. 


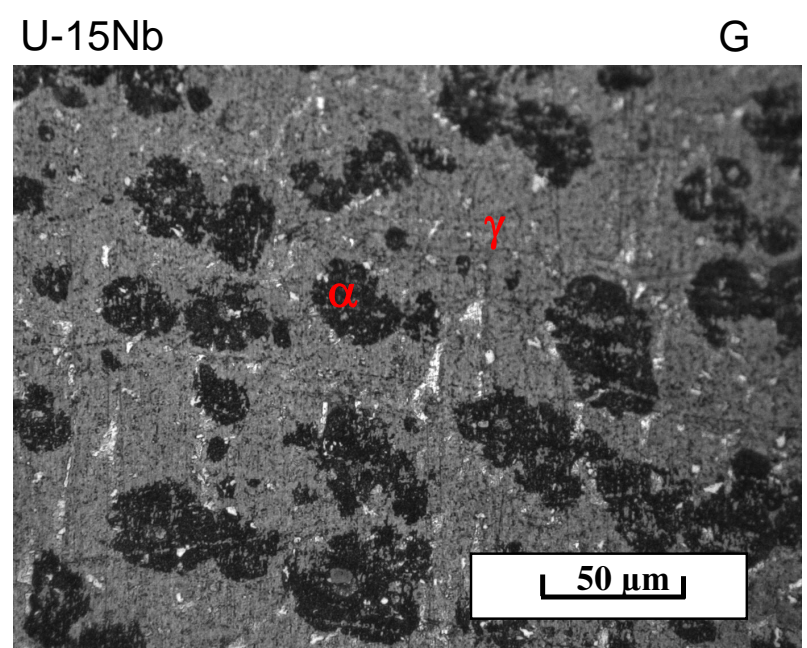

$\alpha+\gamma$

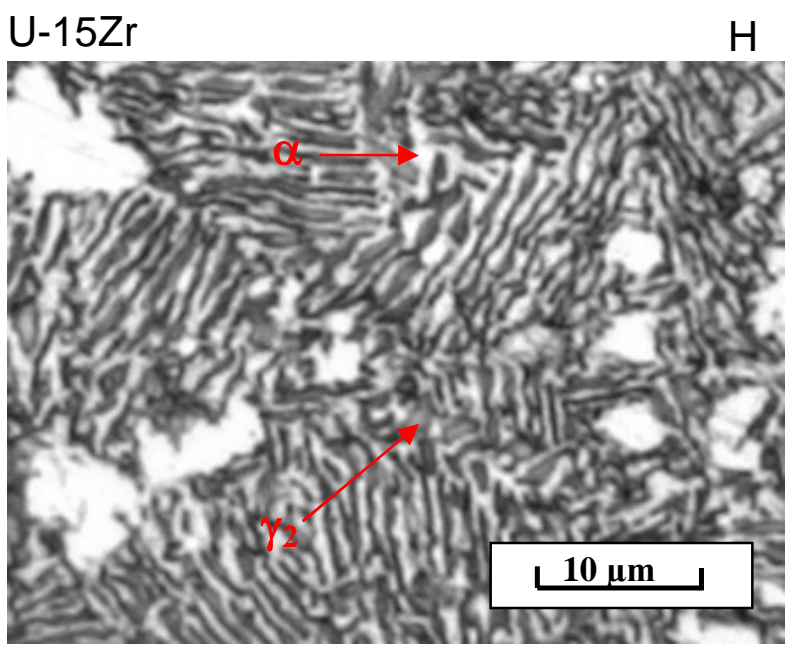

$\alpha+\gamma_{2}$
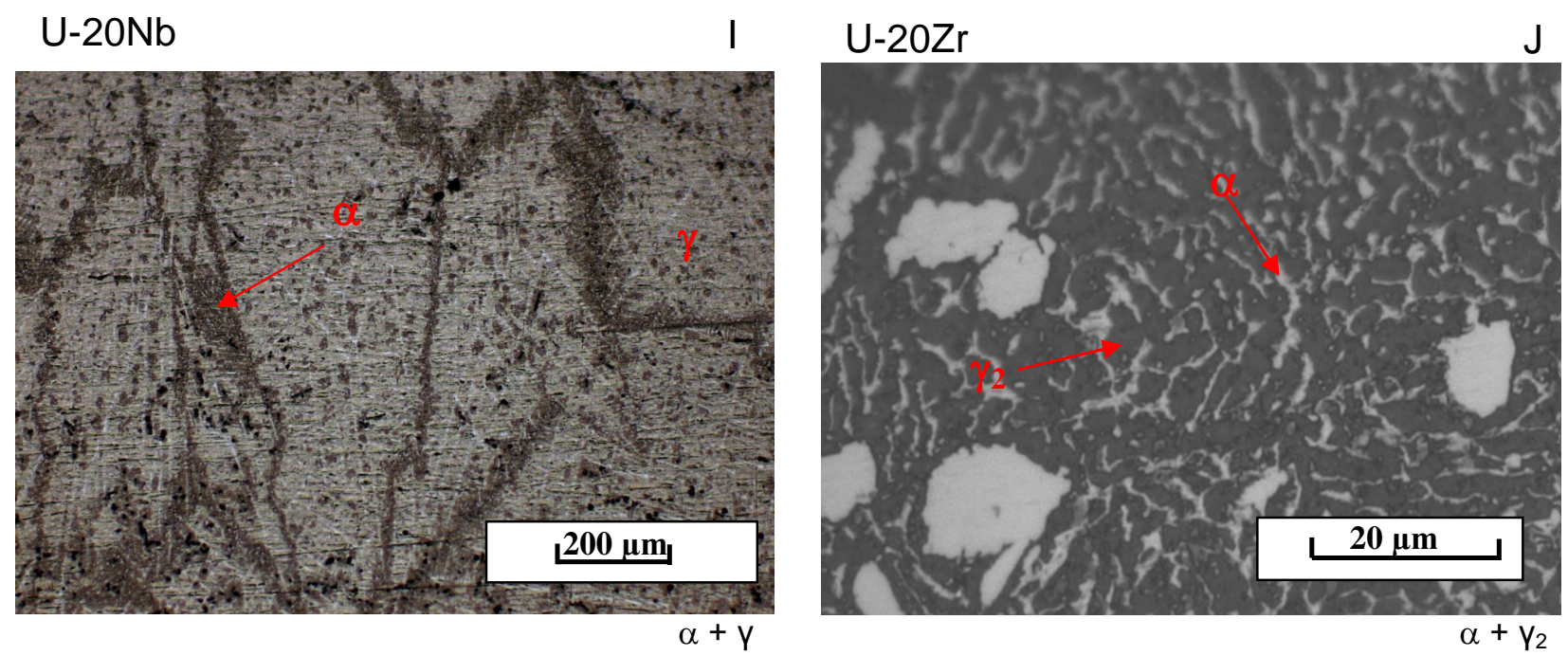

Figura 28 continuação: Micrografias ópticas das ligas no após tratamento isotérmico a $500{ }^{\circ} \mathrm{C}$ por 20 horas seguidas de têmpera em água, MO.

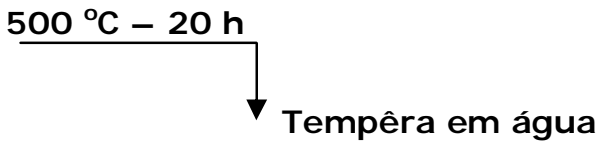


Observa-se nesta primeira visão, que em geral as ligas apresentaram distribuição homogênea de fase $\alpha$ e $\gamma$. Ve-se que as fases deixaram a distribuição dendítrica observada nas peças no estado bruto de fundição, passando a se distribuir de forma homogenia ao redor dos grãos. Este fato indica que os tratamentos térmicos foram bem sucedidos.

\subsubsection{Difração de raios $X$}

As fases presentes nas ligas após realização de tratamento isotérmico $500{ }^{\circ} \mathrm{C}$ por 20 horas, seguido de resfriamento em água foram analisadas por difração de raios $X$ de modo a complementar a análise metalográfica. Os difratogramas obtidos são apresentados na figura a seguir.

$\mathrm{U}-2,5 \mathrm{Nb}-2,5 \mathrm{Zr}$

A

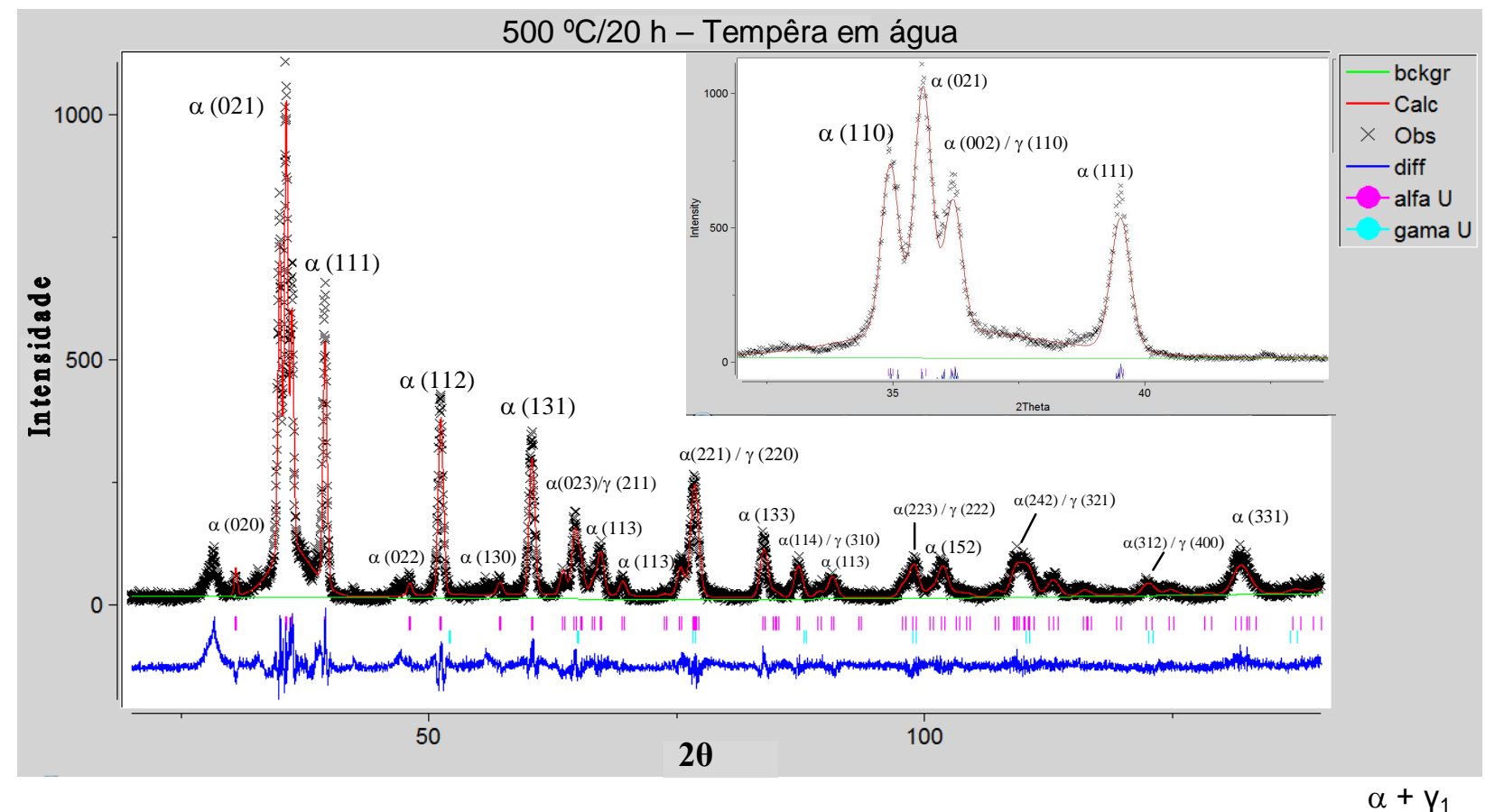

Figura 29: Difratogramas de raios $X$ das ligas após tratamento isotérmico a $500{ }^{\circ} \mathrm{C}$ por 20 horas seguidas de têmpera em água. 


\section{$U-5 \mathrm{Nb}-5 \mathrm{Zr}$}

B

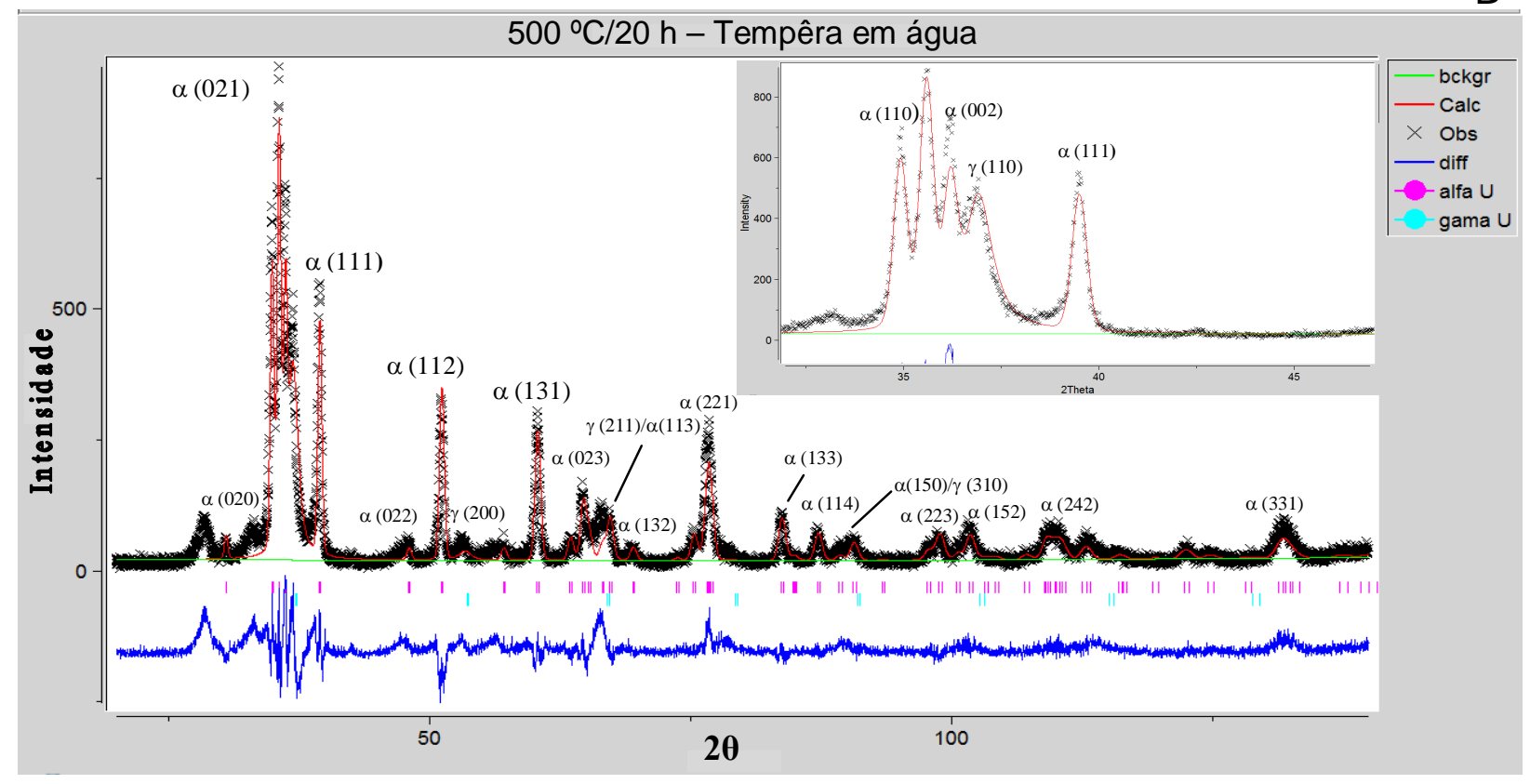

$\alpha+\gamma_{1}$
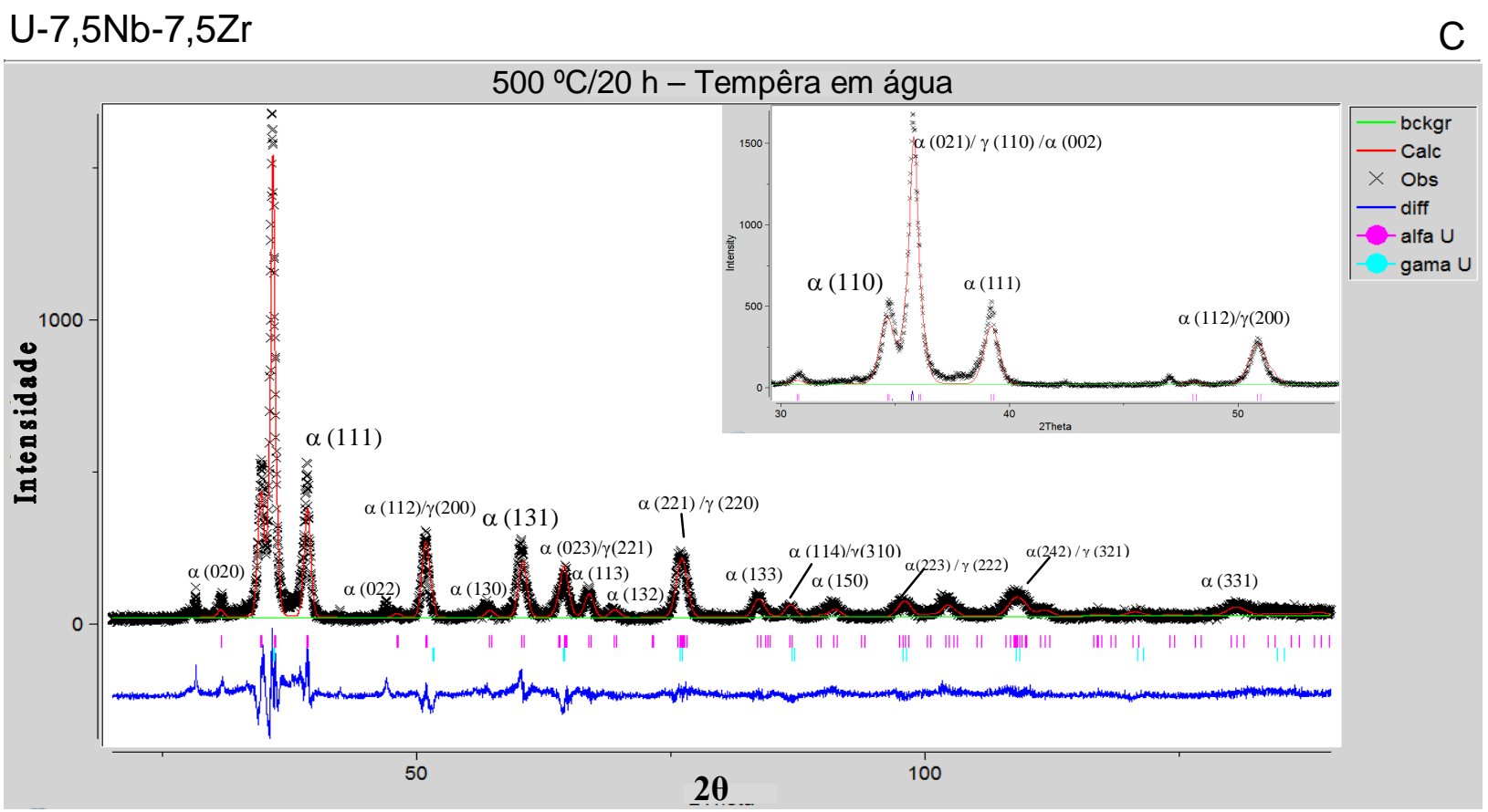

$\alpha+\gamma$

Figura 29 continuação: Difratogramas de raios $X$ das ligas após tratamento isotérmico a $500 \stackrel{\circ}{\mathrm{C}}$ por 20 horas seguidas de têmpera em água. 
$\mathrm{D}$

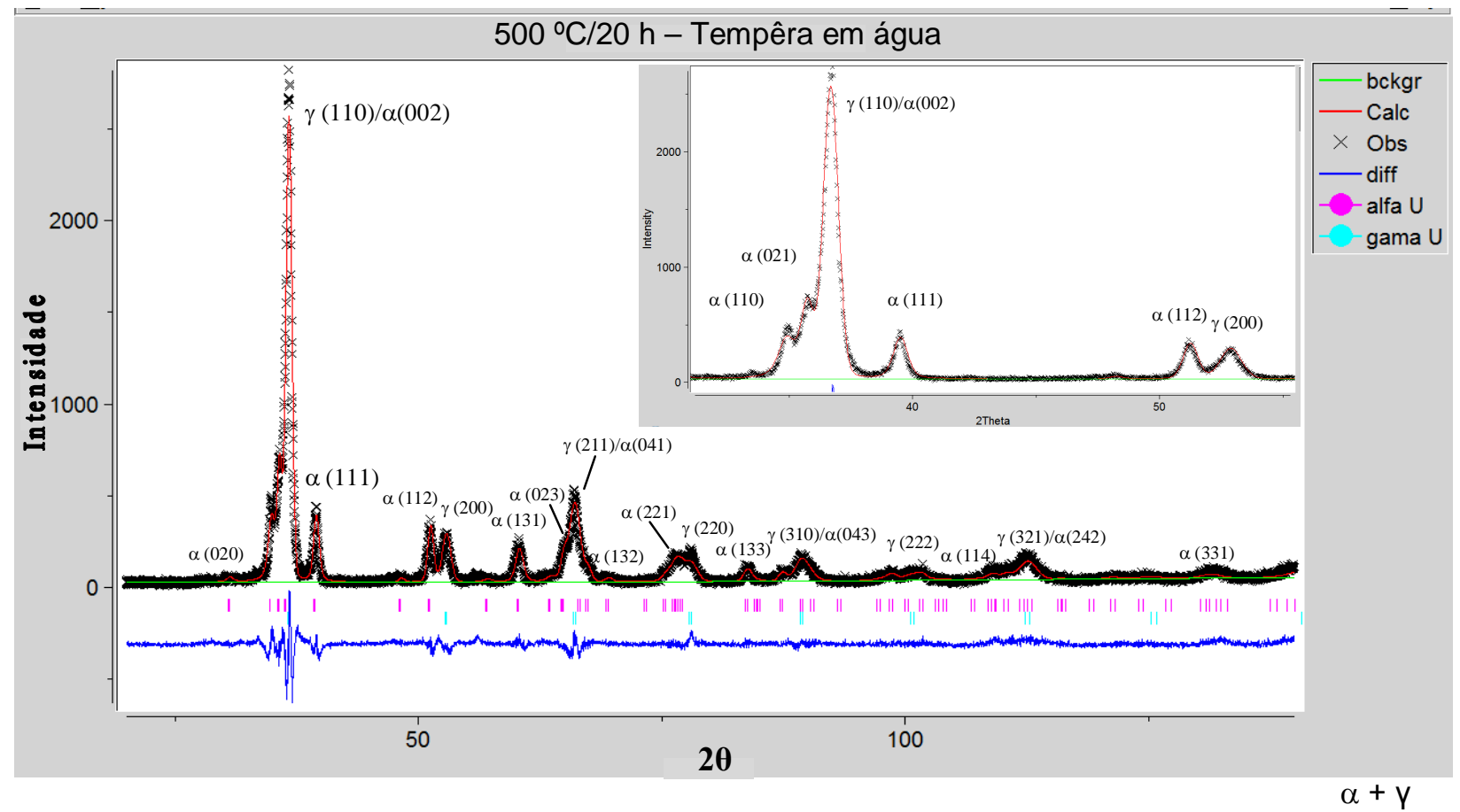

$\mathrm{U}-10 \mathrm{Nb}$

$\mathrm{E}$

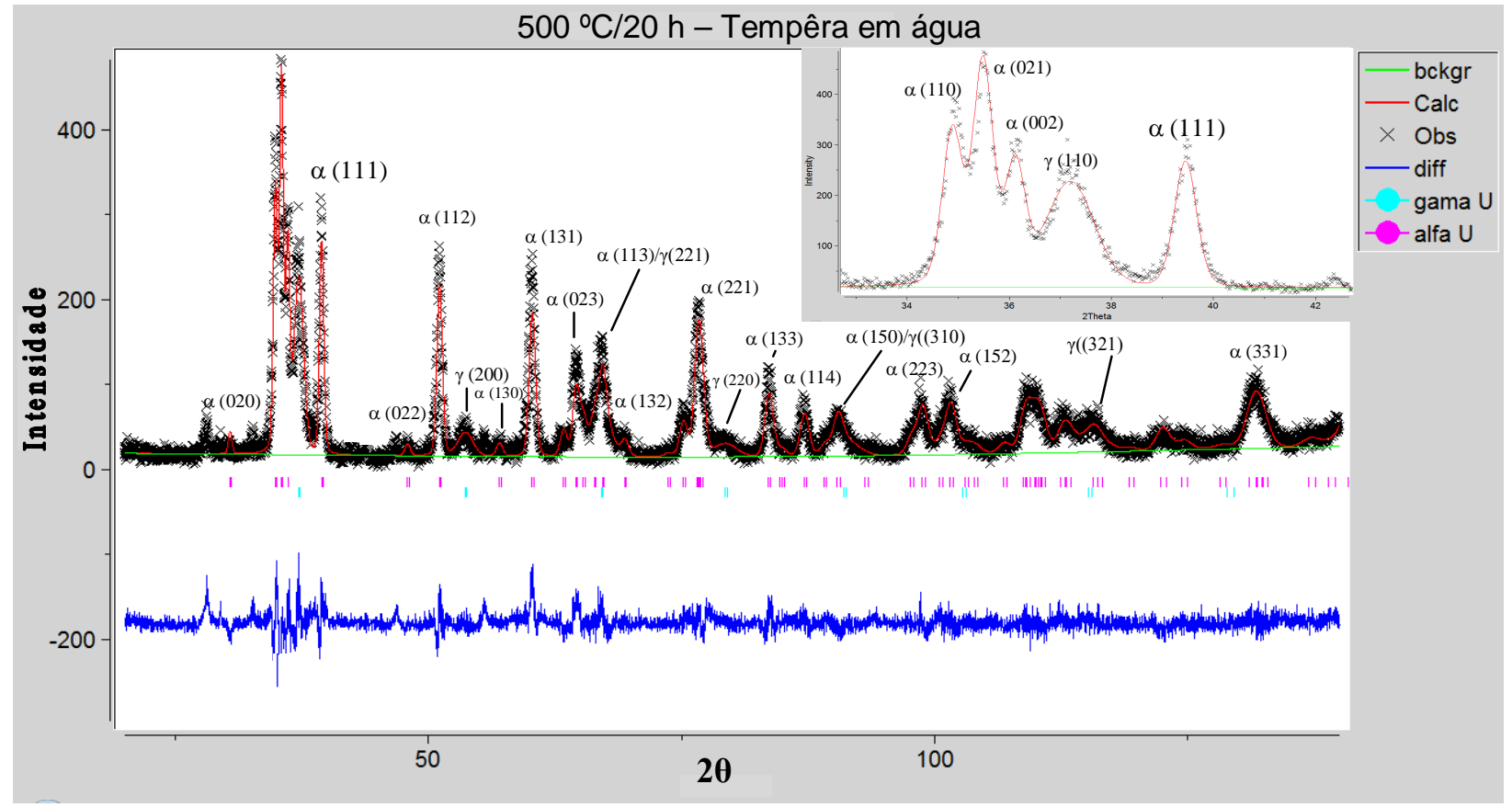

$\alpha+\gamma$

Figura 29 continuação: Difratogramas de raios $X$ das ligas após tratamento isotérmico a $500{ }^{\circ} \mathrm{C}$ por 20 horas seguidas de têmpera em água. 


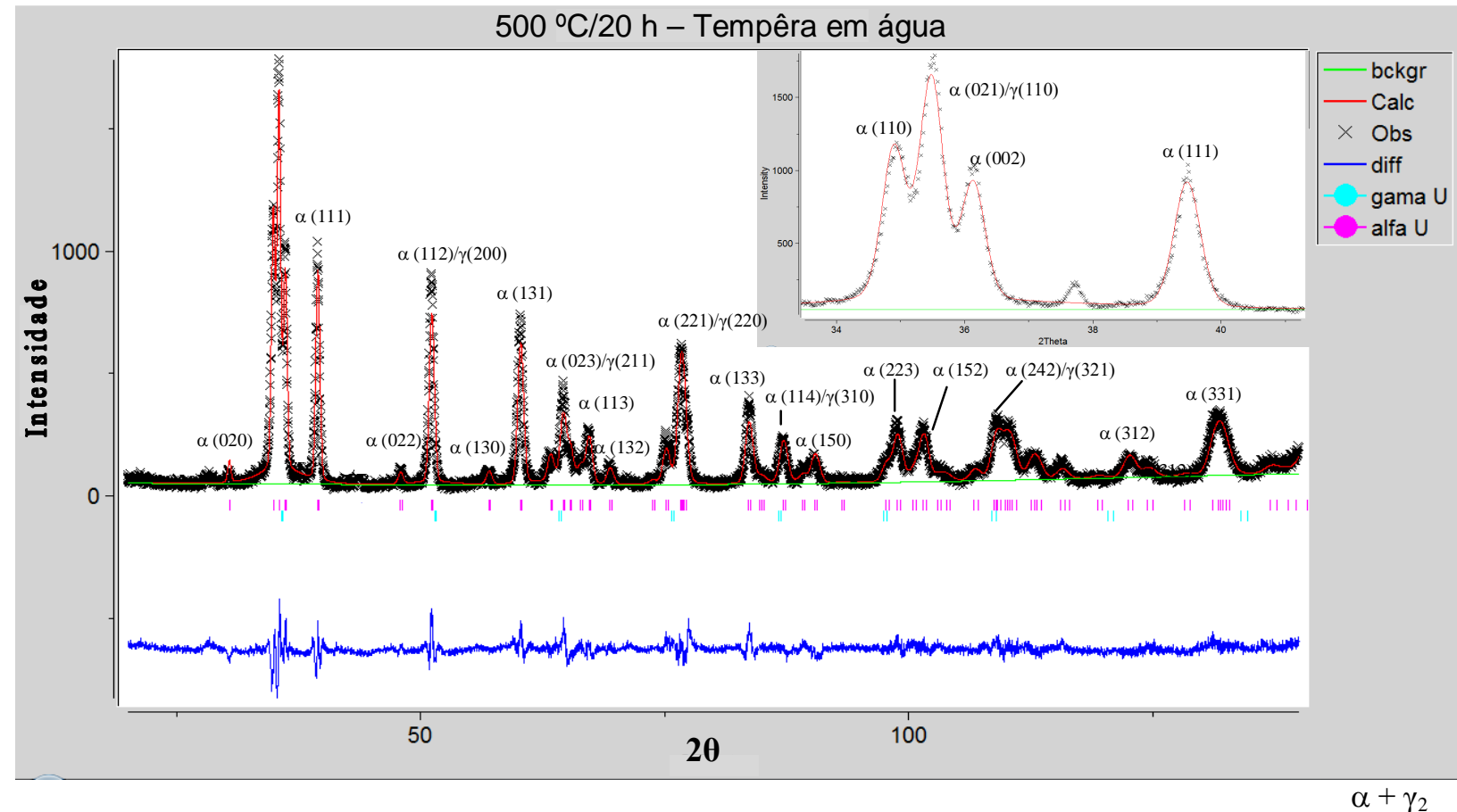

\section{$\mathrm{U}-15 \mathrm{Nb}$}

G

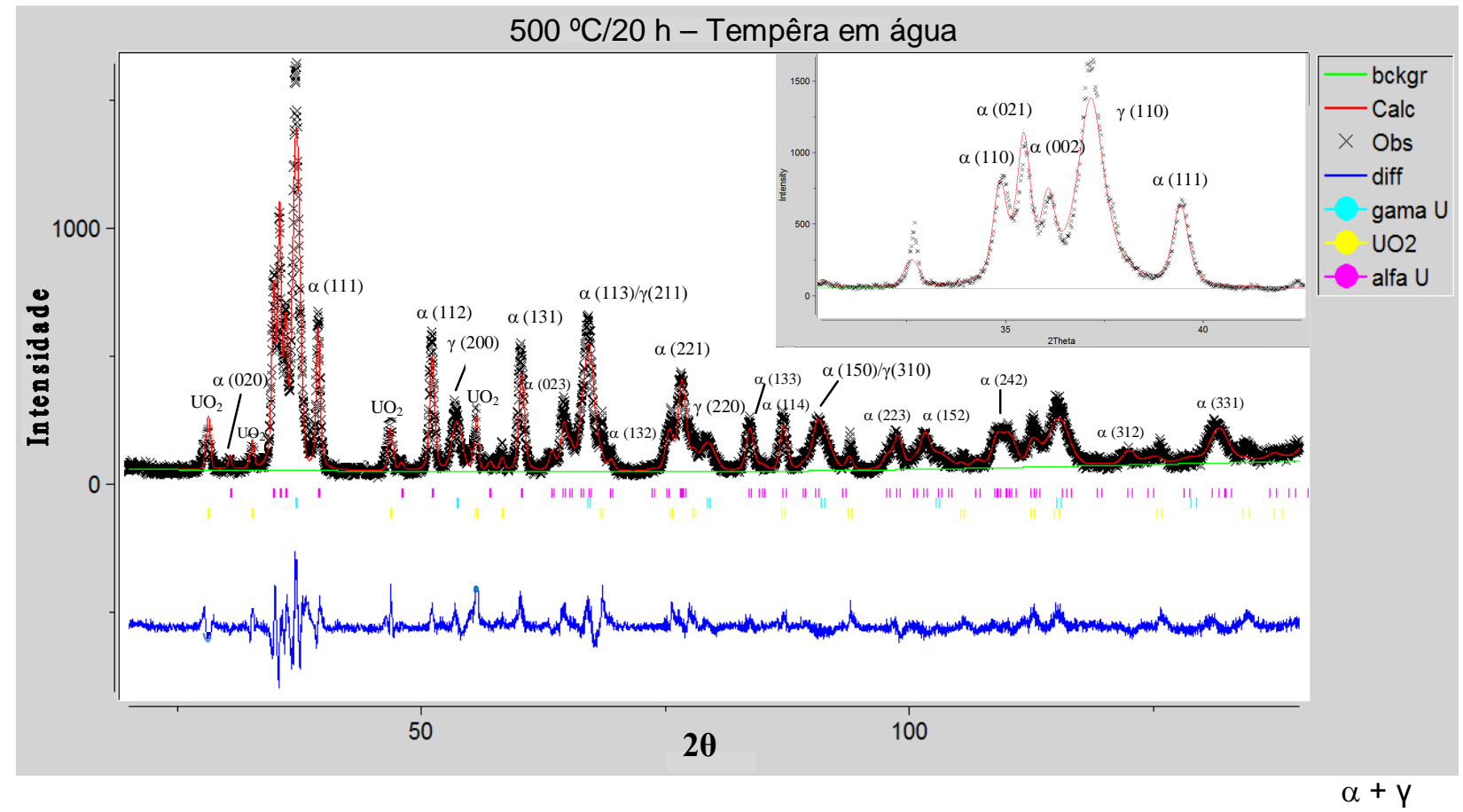

Figura 29 continuação: Difratogramas de raios $\mathrm{X}$ das ligas após tratamento isotérmico a $500{ }^{\circ} \mathrm{C}$ por 20 horas seguidas de têmpera em água. 

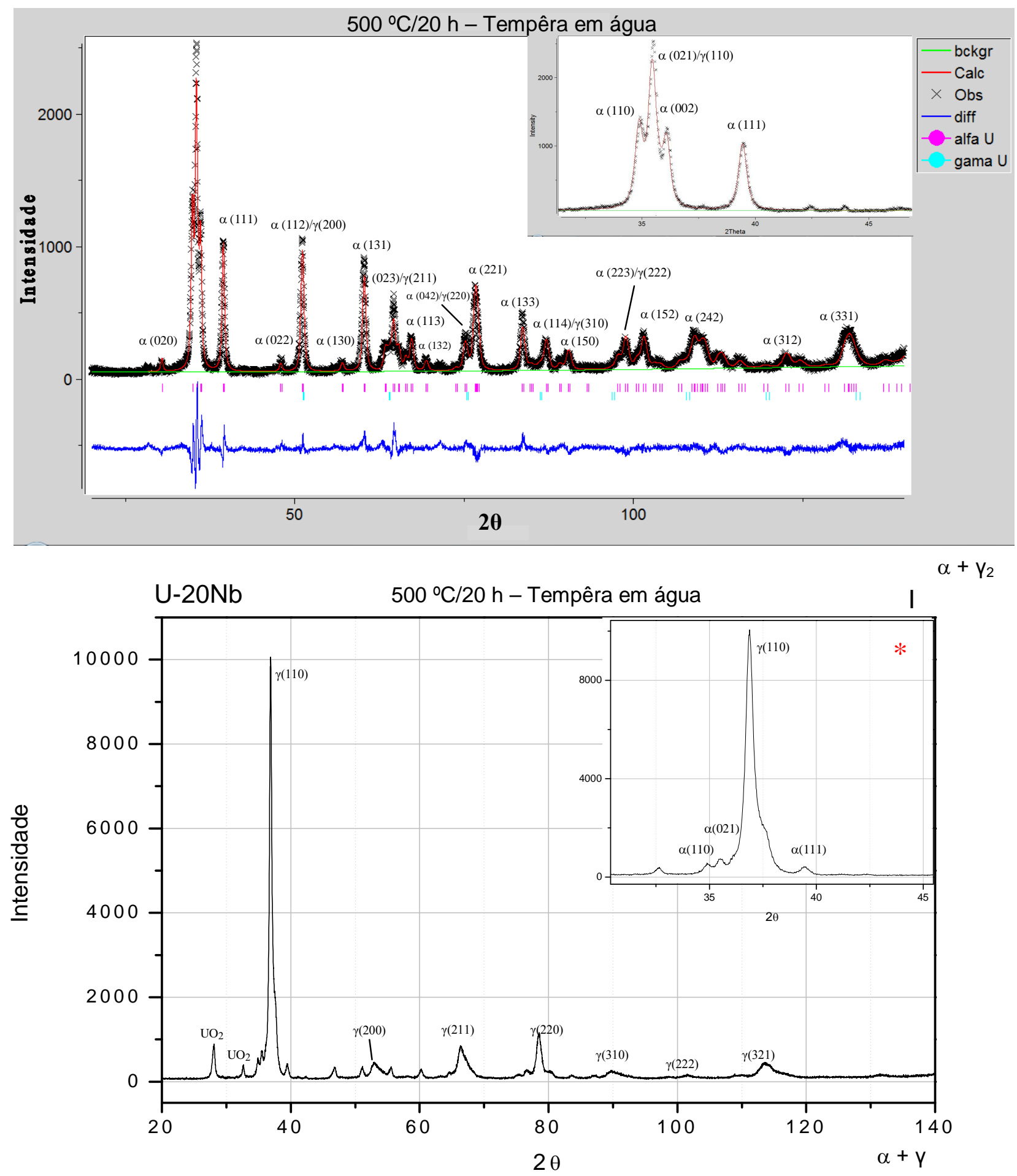

* Não se obteve um padrão simulado (método Rietveld) com proximidade aceitável ao padrão observado.

Figura 29 continuação: Difratogramas de raios $X$ das ligas após tratamento isotérmico a $500{ }^{\circ} \mathrm{C}$ por 20 horas seguidas de têmpera em água. 


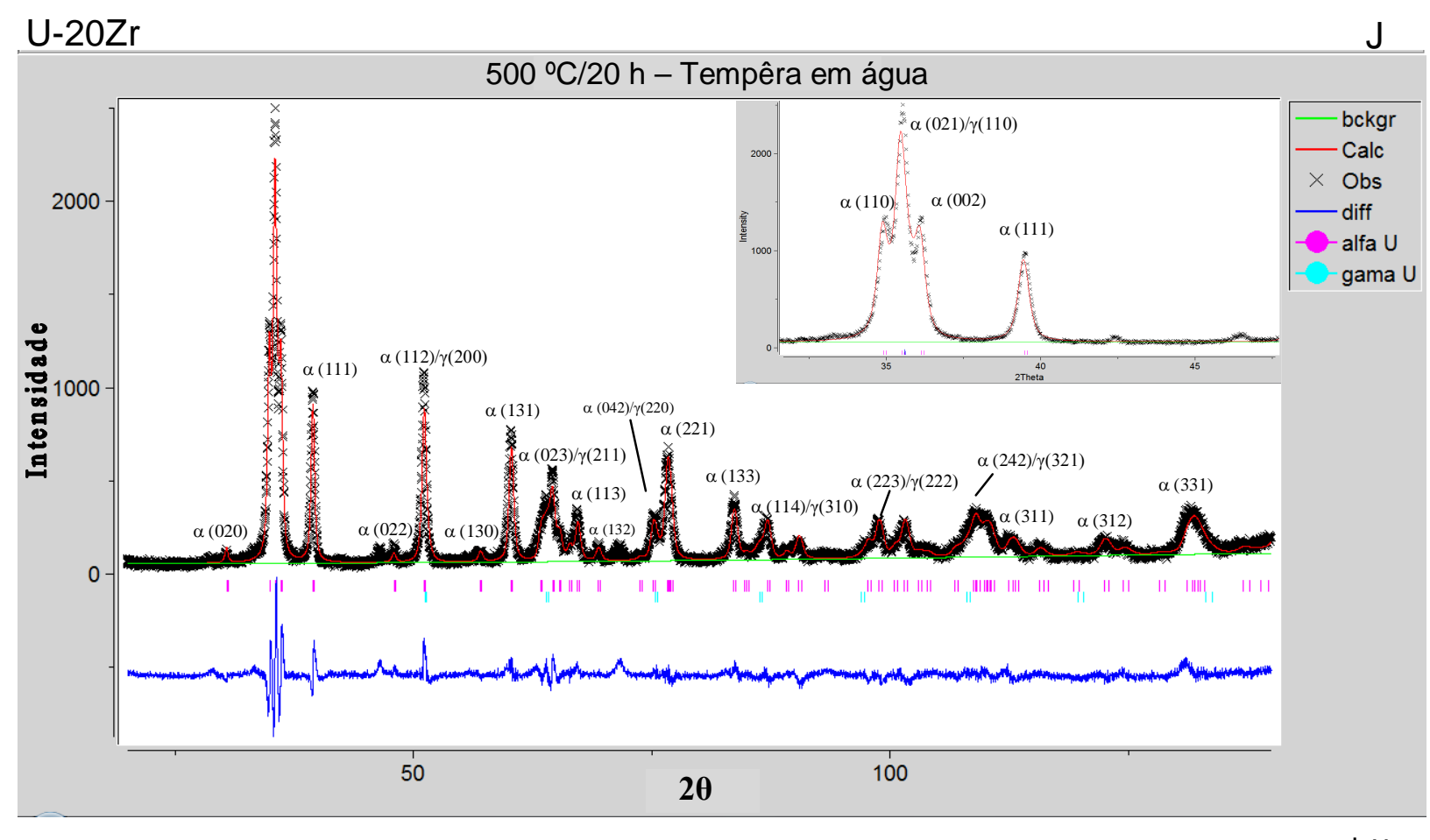

Figura 29 continuação: Difratogramas de raios $X$ das ligas após tratamento isotérmico a $500 \stackrel{\circ}{\circ}$ por 20 horas seguidas de têmpera em água.

Todas as ligas apresentaram no difratograma picos referentes à fase alfa e gama do urânio. Picos de óxido também podem ser observados, mas são devidos a exposição da amostra ao ar durante preparo e manuseio, uma consequência direta da grande quantidade de fase a retida.

Na Tabela 15 a seguir são apresentados os parâmetros de rede das estruturas cristalinas presentes nos difratogramas das ligas, após aplicação de tratamento isotérmico a $500^{\circ} \mathrm{C}$. 
Tabela 15: Parâmetros de rede das fases encontradas para as ligas após aplicação de tratamento isotérmico a $500^{\circ} \mathrm{C} 20$ horas seguidas de têmpera em água.

\begin{tabular}{ccccccc}
\hline Liga & Fase & $\mathbf{a}(\mathbf{)}$ & $\mathbf{b}(\mathbf{)}$ & $\mathbf{c}(\mathbf{)}$ & Fase & $\mathbf{a = b = c ( ~ ) ~}$ \\
\hline $\mathrm{U}-2,5 \mathrm{Nb}-2,5 \mathrm{Zr}(\mathrm{A})$ & $\alpha$ & 2,8572 & 5,8568 & 4,9645 & $\gamma_{1}$ & 3,5139 \\
\hline $\mathrm{U}-5 \mathrm{Nb}-5 \mathrm{Zr}(\mathrm{B})$ & $\alpha$ & 2,8587 & 5,8574 & 4,9635 & $\gamma_{1}$ & 3,4150 \\
\hline $\mathrm{U}-7,5 \mathrm{Nb}-7,5 \mathrm{Nb}(\mathrm{C})$ & $\alpha$ & 2,8772 & 5,8703 & 4,9632 & $\gamma$ & 3,4812 \\
\hline $\mathrm{U}-10 \mathrm{Nb}-10 \mathrm{Zr}(\mathrm{D})$ & $\alpha$ & 2,8795 & 5,8685 & 4,9596 & $\gamma$ & 3,4795 \\
\hline $\mathrm{U}-10 \mathrm{Nb}(\mathrm{E})$ & $\alpha$ & 2,8571 & 5,8688 & 4,9691 & $\gamma$ & 3,4150 \\
\hline $\mathrm{U}-10 \mathrm{Zr}(\mathrm{F})$ & $\alpha$ & 2,8556 & 5,8718 & 4,9671 & $\gamma_{2}$ & 3,5504 \\
\hline $\mathrm{U}-15 \mathrm{Nb}(\mathrm{G})$ & $\alpha$ & 2,8579 & 5,8676 & 4,9795 & $\gamma$ & 3,4162 \\
\hline $\mathrm{U}-15 \mathrm{Zr}(\mathrm{H})$ & $\alpha$ & 2,8578 & 5,8731 & 4,9701 & $\gamma_{2}$ & 3,5623 \\
\hline $\mathrm{U}-20 \mathrm{Nb}(\mathrm{I})$ & $\alpha$ & $\approx 2,85$ & $\approx 5,87$ & $\approx 4,97$ & $\gamma$ & $\approx 3,45$ \\
\hline $\mathrm{U}-20 \mathrm{Zr}(\mathrm{J})$ & $\alpha$ & 2,8560 & 5,8692 & 4,9678 & $\gamma_{2}$ & 3,5627 \\
\hline
\end{tabular}

\subsubsection{Medidas de dureza}

Os resultados dos ensaios de dureza para as ligas após aplicação de tratamento isotérmico $500^{\circ} \mathrm{C}$ seguido de têmpera em água são mostrados na Tabela 16. Realizouse este ensaio com o aspecto de averiguar a influência das fases presentes e seus mecanismos de formação nesta propriedade mecânica. 
Tabela 16: Dureza Vickers, ligas fundidas a plasma tratadas termicamente a $500 \stackrel{\circ}{\mathrm{C}}$ por 20 horas e temperadas em água.

\begin{tabular}{|c|c|c|c|}
\hline Liga & HV & $\mathbf{N}$ & Sd \\
\hline U-2,5Nb-2,5Zr (A) & 438 & 10 & 29 \\
\hline U-5Nb-5Zr (B) & 381 & 10 & 24 \\
\hline $\mathrm{U}-7,5 \mathrm{Nb}-7,5 \mathrm{Zr}(\mathrm{C})$ & 397 & 10 & 23 \\
\hline U-10Nb-10Zr (D) & 430 & 10 & 50 \\
\hline $\mathrm{U}-10 \mathrm{Nb}(\mathrm{E})$ & 465 & 10 & 32 \\
\hline U-10Zr (F) & 377 & 10 & 22 \\
\hline U-15Nb (G) & 340 & 10 & 21 \\
\hline U-15Zr (H) & 347 & 10 & 19 \\
\hline U-20Nb (I) & 320 & 10 & 21 \\
\hline U-20Zr (J) & 343 & 10 & 32 \\
\hline
\end{tabular}

São observados para este patamar os maiores valores de dureza, juntamente com as amostras que apresentaram a fase martensítica $\alpha$ '. Os valores encontrados ressaltam a alta quantidade de fase U- $\alpha$ retida, causando um pico nos valores de dureza. A proximidade dos valores de dureza para as ligas com estabilidade da fase $\alpha$ e a fase martensítica $\alpha$ ', revelam a forte influência que os mecanismos de formação de fases possuem sobre as propriedades mecânicas. 


\subsection{Caracterização química das ligas}

A seguir é apresentada a composição química das ligas obtidas através de análise química quantitativa por espectroscopia de emissão óptica com fonte de plasma acoplado (ICP), realizada na Divisão de Caracterização Química do LABMAT.

Tabela 17: Análise quantitativa dos elementos de liga (\% massa).

\begin{tabular}{cccc}
\hline Liga & $\boldsymbol{U}$ & $\boldsymbol{N} \boldsymbol{b}$ & $\boldsymbol{Z r}$ \\
\hline $\mathrm{U}-2,5 \mathrm{Nb}-2,5 \mathrm{Zr}(\mathrm{A})$ & $95,5 \pm 0,6$ & $2,6 \pm 0,1$ & $2,4 \pm 0,1$ \\
\hline $\mathrm{U}-5 \mathrm{Nb}-5 \mathrm{Zr}(\mathrm{B})$ & $90,3 \pm 0,2$ & $4,6 \pm 0,1$ & $4,6 \pm 0,1$ \\
\hline $\mathrm{U}-7,5 \mathrm{Nb}-7,5 \mathrm{Zr}(\mathrm{C})$ & $83,9 \pm 0,4$ & $6,5 \pm 0,1$ & $9,6 \pm 0,1$ \\
\hline $\mathrm{U}-10 \mathrm{Nb}-10 \mathrm{Zr}(\mathrm{D})$ & $79,4 \pm 0,8$ & $8,8 \pm 0,1$ & $11,3 \pm 0,1$ \\
\hline $\mathrm{U}-10 \mathrm{Nb}(\mathrm{E})$ & $91,9 \pm 0,1$ & $10,0 \pm 0,1$ & - \\
\hline $\mathrm{U}-10 \mathrm{Zr}(\mathrm{F})$ & $90,7 \pm 0,1$ & - & $9,8 \pm 0,02$ \\
\hline $\mathrm{U}-15 \mathrm{Nb}(\mathrm{G})$ & $86,5 \pm 0,3$ & $13,9 \pm 0,1$ & - \\
\hline $\mathrm{U}-15 \mathrm{Zr}(\mathrm{H})$ & $84,3 \pm 0,1$ & - & $15,1 \pm 0,6$ \\
\hline $\mathrm{U}-20 \mathrm{Nb}(\mathrm{I})$ & $80,7 \pm 0,1$ & $19,9 \pm 0,1$ & - \\
\hline $\mathrm{U}-20 \mathrm{Zr}(\mathrm{J})$ & $78,9 \pm 0,5$ & - & $19,2 \pm 0,3$ \\
\hline
\end{tabular}


A tabela a seguir apresenta a análise química de impureza das ligas.

Tabela 18: Análise quantitativa de impurezas (ppm).

\begin{tabular}{|c|c|c|c|c|}
\hline Elementos & U-2,5Nb-2,5Zr & U-5Nb-5Zr & U-7,5Nb-7,5Zr & U-10Nb-10Zr \\
\hline $\mathbf{B}$ & $<0,01$ & $<0,01$ & $<0,01$ & $<0,1$ \\
\hline $\mathbf{M g}$ & $23,5 \pm 0,3$ & $61,2 \pm 1,3$ & $67,7 \pm 0,1$ & $4,6 \pm 0,1$ \\
\hline $\mathbf{A l}$ & $2146,3 \pm 9,2$ & $2355,4 \pm 43,8$ & $2207,4 \pm 11,9$ & $2060 \pm 4$ \\
\hline $\mathbf{C r}$ & $21,2 \pm 0,1$ & $39,0 \pm 3,4$ & $30,6 \pm 1,3$ & $1020 \pm 1$ \\
\hline $\mathbf{M n}$ & $93,9 \pm 0,9$ & $97,4 \pm 3,7$ & $87,7 \pm 0,3$ & $195,6 \pm 1,5$ \\
\hline $\mathbf{F e}$ & $562,8 \pm 3,9$ & $824,0 \pm 13,2$ & $1150,3 \pm 3,4$ & $204,2 \pm 6,5$ \\
\hline $\mathbf{C o}$ & $<0,01$ & $<0,01$ & $<0,01$ & $<0,02$ \\
\hline $\mathbf{N i}$ & $13,2 \pm 0,3$ & $20,6 \pm 0,8$ & $20,0 \pm 1,1$ & $15,0 \pm 0,5$ \\
\hline $\mathbf{C u}$ & $1042,0 \pm 20,4$ & $3567,4 \pm 79,3$ & $398,06 \pm 5,2$ & $1180 \pm 10$ \\
\hline $\mathbf{Z n}$ & $6,2 \pm 0,4$ & $16,2 \pm 2,2$ & $28,7 \pm 2,3$ & $<0,02$ \\
\hline $\mathbf{A g}$ & $<0,01$ & $<0,01$ & $<0,01$ & $504,6 \pm 8,9$ \\
\hline $\mathbf{S i}$ & $53,2 \pm 1,1$ & $99,2 \pm 0,6$ & $125,8 \pm 1,1$ & $1880 \pm 100$ \\
\hline $\mathbf{T i}$ & $61,7 \pm 0,9$ & $129,2 \pm 2,3$ & $143,3 \pm 2,4$ & $342,4 \pm 4,2$ \\
\hline $\mathbf{V}$ & $<0,01$ & $<0,01$ & $<0,01$ & $<0,01$ \\
\hline $\mathbf{M o}$ & $<0,01$ & $<0,01$ & $<0,01$ & $<0,01$ \\
\hline $\mathbf{W}$ & $<0,02$ & $<0,02$ & $<0,02$ & $<0,01$ \\
\hline
\end{tabular}


Tabela 18 continuação: Análise quantitativa de impurezas (ppm).

\begin{tabular}{|c|c|c|c|c|c|c|}
\hline Elementos & $\mathrm{U}-10 \mathrm{Nb}$ & $\mathrm{U}-10 \mathrm{Zr}$ & $\mathrm{U}-15 \mathrm{Nb}$ & $\mathrm{U}-15 \mathrm{Zr}$ & $\mathrm{U}-20 \mathrm{Nb}$ & $\mathrm{U}-20 \mathrm{Zr}$ \\
\hline $\mathbf{B}$ & $<0,01$ & $3,8 \pm 0,1$ & $<0,01$ & $<0,01$ & $<0,01$ & $<0,01$ \\
\hline $\mathbf{M g}$ & $21,4 \pm 0,4$ & $37,50 \pm 0,7$ & $52,8 \pm 0,1$ & $25,3 \pm 0,6$ & $28,2 \pm 0,1$ & $21,6 \pm 0,2$ \\
\hline $\mathbf{A l}$ & $3114 \pm 62$ & $2217 \pm 30$ & $1639 \pm 50$ & $1244 \pm 22$ & $1268 \pm 23$ & $2437 \pm 86$ \\
\hline $\mathbf{C r}$ & $14,5 \pm 0,3$ & $12,3 \pm 0,5$ & $23,6 \pm 0,5$ & $12,7 \pm 0,5$ & $13,6 \pm 0,3$ & $16,6 \pm 0,3$ \\
\hline $\mathbf{M n}$ & $114,9 \pm 0,6$ & $112,3 \pm 0,8$ & $107,0 \pm 2,4$ & $109,1 \pm 0,1$ & $77,6 \pm 0,4$ & $99,8 \pm 0,3$ \\
\hline $\mathbf{F e}$ & $211,1 \pm 0,1$ & $294,4 \pm 3,6$ & $214,3 \pm 2,0$ & $278,6 \pm 1,0$ & $213,8 \pm 0,5$ & $294,7 \pm 1,5$ \\
\hline $\mathbf{C o}$ & $<0,02$ & $<0,02$ & $<0,02$ & $<0,02$ & $<0,02$ & $<0,02$ \\
\hline $\mathbf{N i}$ & $<0,03$ & $<0,03$ & $<0,03$ & $<0,03$ & $<0,03$ & $<0,03$ \\
\hline $\mathbf{C u}$ & $558,8 \pm 2,8$ & $39,7 \pm 0,3$ & $616,1 \pm 8,5$ & $74,3 \pm 2,2$ & $424,9 \pm 3,7$ & $83,3 \pm 1,1$ \\
\hline $\mathbf{Z n}$ & $8,5 \pm 0,4$ & $10,4 \pm 0,3$ & $18,3 \pm 0,4$ & $5,5 \pm 0,8$ & $9,9 \pm 0,3$ & $5,1 \pm 0,3$ \\
\hline $\mathbf{A g}$ & $<0,03$ & $<0,03$ & $<0,03$ & $<0,03$ & $<0,03$ & $<0,03$ \\
\hline $\mathbf{S i}$ & $8,0 \pm 0,2$ & $31,0 \pm 0,8$ & $45,6 \pm 0,6$ & $17,8 \pm 0,4$ & $11,2 \pm 0,1$ & $33,4 \pm 0,3$ \\
\hline $\mathbf{T i}$ & $*$ & $19,0 \pm 0,2$ & $*$ & $14,0 \pm 0,2$ & $*$ & $10,3 \pm 0,3$ \\
\hline $\mathbf{V}$ & $2,0 \pm 0,1$ & $1,6 \pm 0,1$ & $2,5 \pm 0,1$ & $0,9 \pm 0,1$ & $2,1 \pm 0,1$ & $0,8 \pm 0,1$ \\
\hline $\mathbf{M o}$ & $<0,06$ & $<0,06$ & $<0,06$ & $<0,06$ & $<0,06$ & $<0,06$ \\
\hline $\mathbf{W}$ & $<0,08$ & $<0,08$ & $<0,08$ & $<0,08$ & $<0,08$ & $<0,08$ \\
\hline
\end{tabular}

* O teor do elemento Titânio não foi determinado nas ligas U-Nb devido à interferência espectral sofrida pelo elemento nióbio. 


\section{DISCUSSÃO DOS RESULTADOS}

A presente dissertação ve por objetivo precípuo um estudo experimental do diagrama de fases U-Nb-Zr no canto rico em urânio, e posterior obtenção de ligas que apresentem retenção de fase metaestável $U-\gamma$ na temperatura ambiente. As ligas podem ser aplicadas como combustível nuclear de alta densidade e baixo enriquecimento.

Procurou-se para tanto avaliar as ligas obtidas via fusão a plasma em todos os estados, de brutos de fundição a tratadas termicamente, para avaliar a influência das variáveis composição e temperatura na evolução da quantidade de fases e em suas morfologias.

Para as ligas ternárias no estado bruto de fundição em análise ao microscópio óptico (vide Figura 20) é possível observar uma progressiva retenção da fase $U-\gamma$, revelando a forte influência dos elementos de liga ( $\mathrm{Nb}$ e $\mathrm{Zr}$ ) na estabilização desta fase. A microestrutura observada para a liga é típica de solidificação (FLEMINGS, 1973). Na solidificação de metais puros, os grãos colunares podem crescer até o centro do molde. No caso de ligas metálicas, há formação de grãos equiaxiais na zona central, cujo crescimento é limitado por grãos vizinhos semelhantes, nucleados simultaneamente (FLEMINGS, 1973). Além disso, pelo fato de tratar-se de sistema ternário, deve-se considerar além do mecanismo térmico de solidificação, a ocorrência do superresfriamento constitucional. Este ocorre quando o líquido apresenta composição diferente da composição do sólido formado, podendo gerar a morfologias nas quais as fases encontram-se distribuídas (FLEMINGS, 1973). Ressalta-se que esta dissertação evidencia um fato importante relativo à técnica de fabricação das ligas. As ligas sempre apresentam estruturas dendríticas, onde as regiões interdendríticas se apresentaram com baixa composição de $\mathrm{Nb}$ e $\mathrm{Zr}$, sendo esta fase necessariamente fase $\mathrm{U}-\alpha$. Isso conduz, necessariamente, à aplicação de tratamento térmico de homogeneização.

Para as ligas ternárias e binárias do sistema U-Zr, nos resultados obtidos por microscopia eletrônica de varredura (vide Figura 21), observa-se a presença de precipitados primários formados durante solidificação também de morfologia dendrítica, 
possivelmente formados em alta temperatura. Não houve dissolução destes precipitados mesmo após aplicação de tratamento térmico de solubilização. Através de micro análise química por dispersão de energia foi verificada a composição destes precipitados (vide Figura 22), ricos em zircônio com presença mais definida de picos referentes à camada $\mathrm{K}$ do alumínio, que se apresenta em quantidade expressiva no urânio metálico utilizado. Deve-se ressaltar a possível ocorrência desses precipitados devido à esta alta concentração de alumínio, formando assim um sistema quaternário na qual esta fase ocorreria em equilíbrio. Em estudo recente, EWH et al. (2010) realizou uma análise microestrutural de ligas ternárias U-Nb-Zr, U-Mo-Nb e U-Mo-Ti, obtidas via processo de fusão a arco. Nestas ligas é reportada a existência de uma pequena fração volumétrica de precipitados. Através de difração de elétrons, os precipitados encontrados no sistema U-Nb-Zr foram identificados como uma solução sólida de $\mathrm{Nb}$ e $\mathrm{Zr}$ com uma estrutura cúbica de corpo centrado, com parâmetro de rede de 3,51 Å. É reportado ainda que os precipitados persistiram mesmo após tratamento térmico de solubilização a $950{ }^{\circ} \mathrm{C}$ por 96 horas. Entretanto, os precipitados relatados no trabalho de EWH et al. (2010) apresentaram morfologia esférica, (diferentemente dos encontrados na presente dissertação) principalmente após aplicação de tratamentos térmicos. Além disso, o fato do sistema $\mathrm{Nb}-\mathrm{Zr}$ possuir um domo de imiscibilidade elevado fez com que o autor sugerisse a ocorrência dessa fase como de equilíbrio para o patamar de solubilização. No que se refere à presença do elemento Nb nos precipitados, na presente dissertação não foi possível sua averiguação. Seria esperada pouca quantidade deste elemento nos precipitados quando comparada com $\mathrm{Zr}$, e esses elementos possuem emissões da camada $L$ muito próximos. A distinção destas camadas foge a resolução da técnica utilizada para micro analise química (EDS).

Os difratogramas obtidos para as ligas ternárias no estado bruto de fundição confirmaram a influência dos elementos $\mathrm{Nb}$ e $\mathrm{Zr}$ na estabilização da fase metaestável U-y atuando de modo a atrasar sua cinética de decomposição, onde para a liga de menor quantidade de elementos de liga U-2,5Nb-2,5Zr observa-se a pouca definição dos picos referentes a esta fase e a sua total definição para as ligas U-7,5Nb-7,5Zr e $\mathrm{U}-10 \mathrm{Nb}-10 \mathrm{Zr}$. Os difratogramas não apresentaram contagens de alta intensidade em 
ângulos referentes aos elementos de liga, indicando que o número de refusões foi suficiente para que se atingisse um considerável grau de homogeneidade.

No que se refere à influência individual de cada um dos elementos ( $\mathrm{Nb}$ e $\mathrm{Zr}$ ) na estabilidade da fase metaestável gama, os resultados obtidos para as ligas binárias confirmam atuação com intensidades diferentes. Tanto na análise em microscópio óptico quanto nos resultados dos ensaios de difração de raios $\mathrm{X}$, é possível observar que a estabilidade foi obtida mais facilmente para o sistema U-Nb, confirmando o relatado previamente em literatura (HARRINGTON; RUEHLE, 1959). O elemento $\mathrm{Zr}$ deve ser inserido em teores muito mais elevados para promover mesma estabilização promovida pelo elemento Nb (HARRINGTON; RUEHLE, 1959). Contudo, os sistemas binários mostraram-se inferiores ao ternário U-Nb-Zr, confirmando a teoria de atuação conjunta desses elementos na estabilidade da fase metaestável U-ү.

Para as ligas binárias do sistema U-Nb, no estado bruto de fundição, é possível observar a ocorrência da fase $\gamma_{3}$ rica em nióbio (vide Figura 20), evidenciando a ocorrência do domo de imiscibilidades no diagrama de fases. Além disso, a existência de fase alfa somente na liga $\mathrm{U}-10 \mathrm{Nb}$ indica a forte inclinação da linha que divide os campos $\mathrm{y}_{\mathrm{e}} \mathrm{Y}_{1}+\mathrm{Y}_{3}$. Durante o resfriamento no forno, as ligas $\mathrm{U}-15 \mathrm{Nb}$ e $\mathrm{U}-20 \mathrm{Nb}$ permanecem no campo $Y_{1}+Y_{3}$, apresentando somente essas fases.

Nos resultados da análise por difração de raios $X$ para as ligas binárias no estado bruto de fundição, pode-se inferir que eles se mostraram coerentes com o observado metalograficamente. Também se confirma o comportamento relatado na literatura (DWIGHT; MUELLER, 1956) de que o $\mathrm{Nb}$ causa uma diminuição no parâmetro de rede (da fase cúbica de corpo centrado do urânio) enquanto o $\mathrm{Zr}$ causa um ligeiro aumento. Este comportamento persiste mesmo após aplicação de tratamento térmico e explica a obtenção de parâmetros de rede, similar ao da fase U-y do urânio puro, obtido para as ligas ternárias com considerável acréscimo de elementos de liga (U-7,5Nb-7,5Zr e U-10Nb-10Zr). Cada elemento tenderia a compensar a distorção inserida pelo outro.

Com os resultados obtidos para as ligas analisadas após tratamento térmico de solubilização seguido de têmpera observou-se para as ligas U-2,5Nb-2,5Zr, U-10Zr, U$15 Z r$ e U-20Zr a ocorrência da transformação martensítica do tipo $\gamma \rightarrow \alpha^{\prime}$ (vide Figura 
25 e Tabela 11, conclui-se que a região onde essa transformação prevalece é prolongada para a face $\mathrm{U}-\mathrm{Zr}$, sendo então este sistema muito mais suscetível à esta transformação. Diversos trabalhos (TANGRI; WILLIAMS, 1961; HOLDEN 1953; TANGRI, 1965; ANAGNOSTIDIS; BASCHWITZ; COLOMBIE, 1966, ASM, Handbook Vol. 9) relatam a ocorrência de estruturas a modificada, resultante de uma transformação independente de difusão, para sistema como U-Ti, U-Mo, U-Nb e U-Zr . Essas estruturas são em geral supersaturadas, diferenciando-se pelo modo como foram obtidas. Os tipos básicos de estruturas supersaturadas alfa são: $\alpha_{n}^{\prime} \alpha_{s}^{\prime}, \alpha_{b}^{\prime}, \alpha_{a}^{\prime}$, $\alpha$ "b, $\alpha$ "s. O símbolo subscrito 's' indica mecanismo cisalhamento ("shear") referenciando o mecanismo de formação da fase, 'n' indica formação por mecanismo de "nucleação e crescimento", 'a' indica mecanismo "needles" e 'b' indica uma "banded structure". Os termos sobrescritos simples são referentes à uma relativa contração na direção cristalográfica b, e o símbolo sobrescrito duplo denota uma relativa contração na direção cristalográfica $b$, adicionado a uma mudança para uma estrutura monoclínica (WILKINSON, Vol. II, 1962). Também é observado que as ligas binárias U-Zr mostraram uma mudança expressiva na morfologia dos precipitados, que agora apresentam uma morfologia agulhada (vide Figura 23). Ocorreu também um aumento da composição de Al neste precipitados, verificada via EDS (vide Figura 24), fato que evidencia a ocorrência desta fase como não pertencente ao sistema U-Nb-Zr, sendo ela uma consequência do elevado teor de alumínio presente no urânio metálico utilizado.

Para o sistema binário $\mathrm{U}-\mathrm{Nb}$, após a realização de tratamento térmico de solubilização, observou-se a retenção da fase metaestável U- $\gamma$, para todas as composições estudadas. Isto revela a forte influência deste elemento na cinética de transformação desta fase. Este comportamento foi observado também para as ligas ternárias U-5Nb-5Zr, U-7,5Zr-7,5Nb e U-10Nb-10Zr, que possuem quantidade de soluto suficiente para reter a fase $\mathrm{U}$-y para a isoterma à $1000^{\circ} \mathrm{C}$.

Com relação aos resultados obtidos para a seção isotérmica a $700{ }^{\circ} \mathrm{C}$, sobressaem-se os fatos a seguir:

- As ligas ternárias U-2,5Nb-2,5Zr e U-5Nb-5Zr se apresentaram compostas por duas fases ( $\alpha$ ' e $y_{1}$ ) (vide Figuras 26 e 27 e Tabela 13), revelando que para 
esta região, na temperatura de $700{ }^{\circ} \mathrm{C}$, ainda prevalece transformação martensítica. A ocorrência da fase a' para a liga ternária U-5Nb-5Zr (a qual não ocorreu para a isoterma a $1000^{\circ} \mathrm{C}$ ) somada à maior presença da fase $\alpha$ ' na liga U-2,5Nb-2,5Zr, sugere uma possível contribuição para a formação da fase martensítica $\alpha$ ' pela transformação $\beta \rightarrow \alpha^{\prime}$. Assim, a evidência da existência do campo $\beta+\gamma$ é indireta, já que ambas as fases após aplicação de têmpera sofrem transformação martensítica e se apresentam na temperatura ambiente como $\alpha$ '.

- A transformação martensítica em estrutura alfa modificada prevalece para todas as composições estudadas para o sistema binário U-Zr (vide Figuras 26 e 27 e Tabela 13). As ligas do sistema binário apresentaram as fase $\alpha^{\prime}+\gamma_{2}$, onde provavelmente a fase $\gamma_{1}$ sofreu transformação martensítica convertendo-se em a'. Este resultado confirma que o campo de formação desta fase é de maior extensão para a face U-Zr do sistema ternário U-Nb-Zr. Isto mostra-se coerente com o relatado na literatura, na qual é citado uma quantidade mínima de $25 \%$ em massa de Zr necessária para inibir a formação da fase martensítica a', e obter total retenção da fase metaestável y (HILLS; BUTCHER; HOWLETT, 1965).

Vários elementos que possuem alta solubilidade no urânio (como Mo, Ti, $\mathrm{Nb}$ e Zr), em baixa e média concentração, podem resultar na liga em retenção de uma fase alfa supersaturada de grãos irregulares ou microestrutura martensítica acicular. Ambas as morfologias apresentam uma estrutura ortorrômbica, sendo esta uma variação da estrutura da fase alfa (ASM, Handbook Vol. 9). Tais microestruturas tendem a apresentar um aumento da dureza proporcional à concentração de elementos de liga, devido à ocorrência de solução sólida (ASM, Handbook Vol. 9). Para concentrações de ligas intermediárias há uma transição termoelástica, ou bandas, martensítica. A dureza de tais microestruturas tende a decrescer com o aumento de elementos de liga, aparentemente devido ao aumento da mobilidade dos planos de deslizamento durante a transformação. Isto pode acarretar uma mudança na estrutura de ortorrômbica para monoclínica, apresentando uma pequena distorção em um dos ângulos (ASM, Handbook Vol. 9). A Figura $\mathbf{3 0}$ apresentada a seguir mostra esquematicamente o efeito 
dos elementos de liga na morfologia das fases, nas estruturas e na dureza, para ligas temperadas.

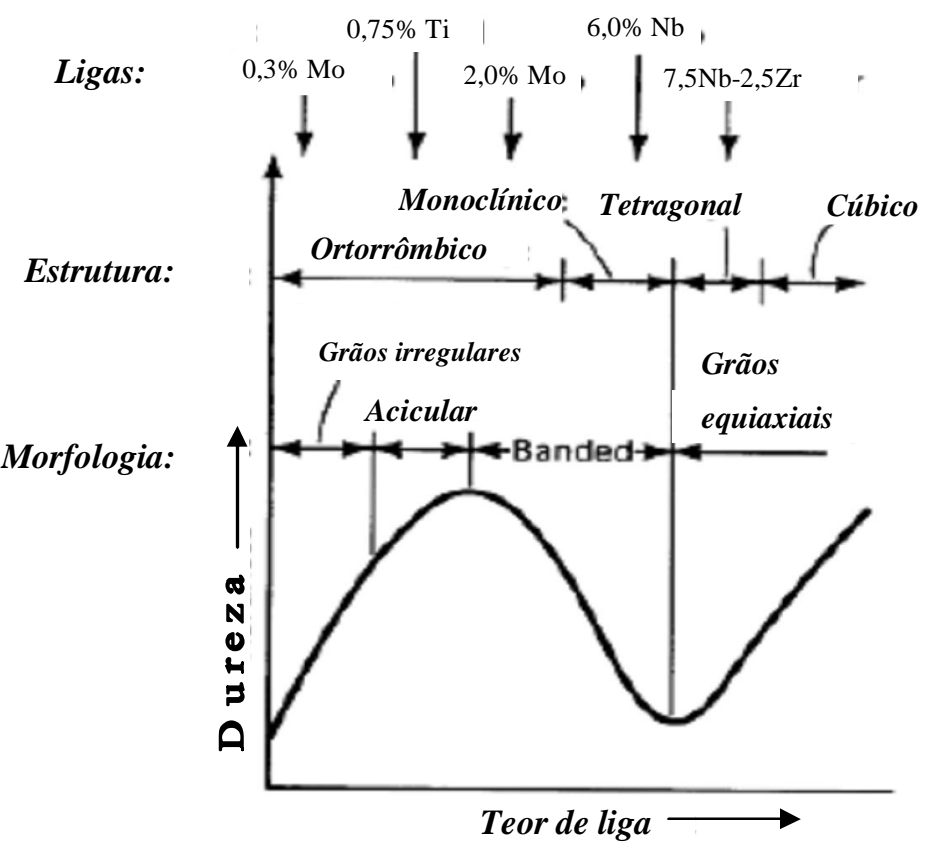

Figura 30: Efeitos da concentração de elementos de liga na morfologia, estrutura e propriedades para algumas ligas temperadas (ASM, Handbook Vol. 9).

Entretanto, sabe-se que a estrutura formada após têmpera é dependente da taxa de resfriamento. Com a técnica de difração de raios $X$ foi possível verificar a influência da taxa de resfriamento na estrutura martesítica $\alpha$ ' formada para ligas estudas na presente dissertação. O comportamento observado para as ligas que apresentaram esta fase pode ser observado na figura a seguir, na qual é apresentada a variação nos parâmetros de rede da fase $\alpha$ ' para a liga U-10Zr. 


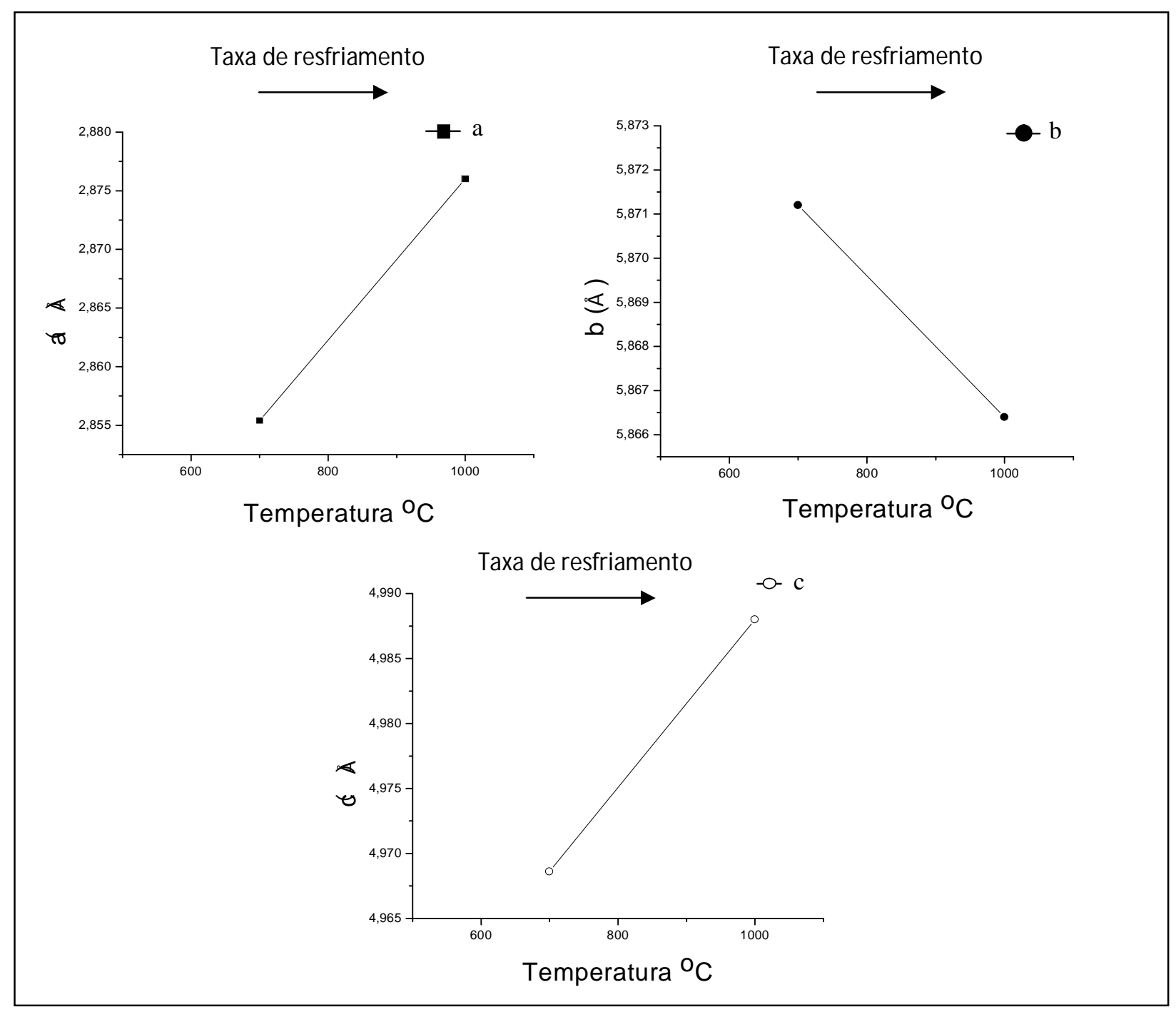

Figura 31: Variação dos parâmetros de rede da fase martensítica $\alpha^{\prime}$ com a taxa de resfriamento da liga U-10Zr.

Pode-se observar na Figura 31 que o aumento na taxa de resfriamento causa um aumento nos parâmetros a e c e uma contração no parâmetro b, e ainda foi observado um progressivo aumento no volume da célula unitária (para o caso da transformação $\mathrm{Y} \rightarrow \alpha^{\prime}$ ) com 0 aumento na taxa de resfriamento. Para o caso da liga $\mathrm{U}-10 \mathrm{Zr}$ foi obtido os seguintes valores; 83,2967 $\dot{A}^{3}$ para resfriamentos a partir $700 \stackrel{\circ}{ } \mathrm{C}$ e $84,1563 \dot{A}^{3}$ para resfriamento a partir de $1000 \stackrel{\circ}{\circ}$. A estrutura $\alpha$ pode ser 
razoavelmente descrita através empilhamento de planos atômicos ao longo da direção [010]. A introdução de metais de transição com tendência a solução sólida do tipo substitucional pode causar uma diferença no ângulo de empilhamento causando

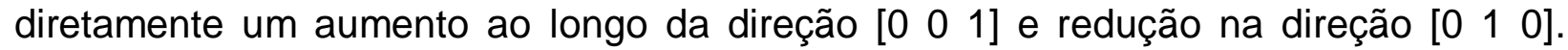
Essas mudanças causam aumento no espaçamento interatômico gerando aumento no parâmetro a (BASAK et al., 2009), este comportamento está fortemente ligado à natureza anisotrópica da estrutura alfa, na qual as ligações químicas ocorrem de modo direcional. Verificou-se que transição $\beta \rightarrow \alpha$ ' apresenta comportamento semelhante quanto aos parâmetros de rede, entretanto esta transformação apresentou uma maior expansão da célula unitária $\alpha$ '. Este comportamento pode auxiliar na distinção da fase $\alpha^{\prime}$ proveniente das fases distintas $\beta$ e $\gamma$. Na Figura 32 pode ser observado 0 comportamento descrito acima.

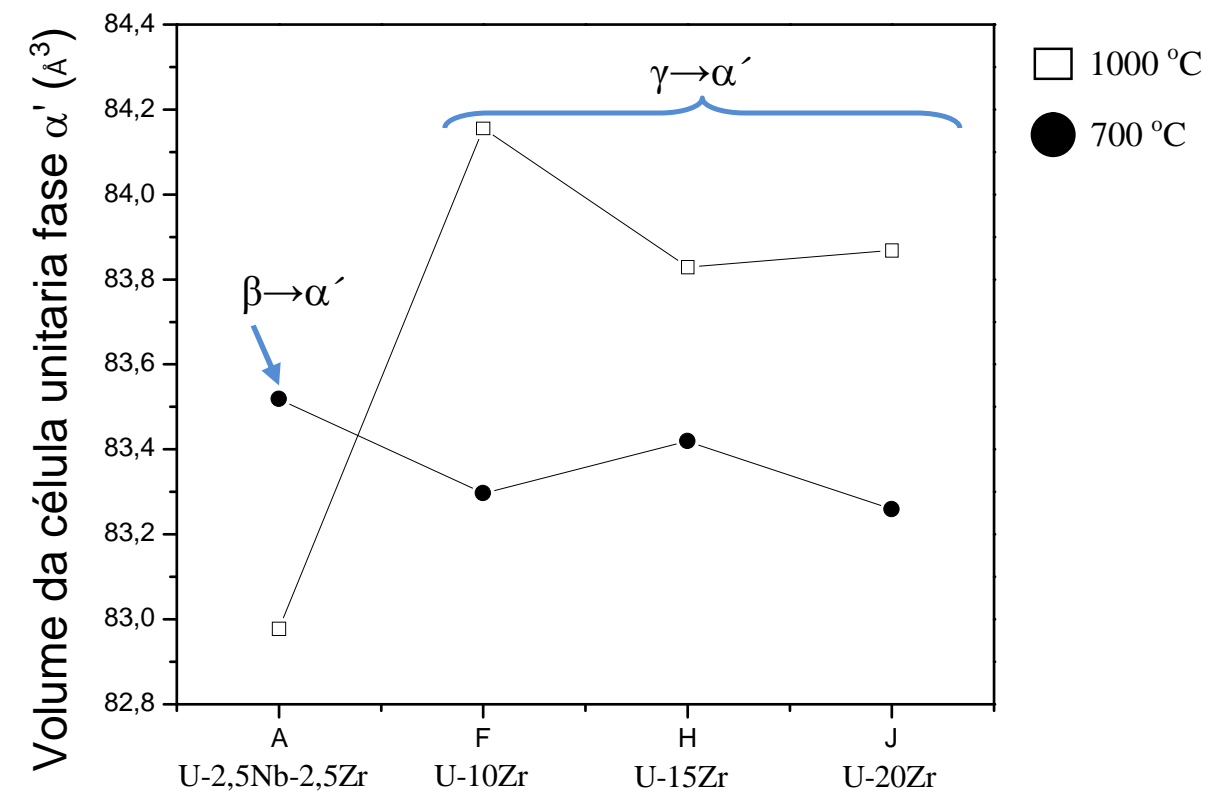

Figura 32: Cálculo volume da célula unitária fase $\alpha^{\prime}$ para os patamares $1000^{\circ} \mathrm{C}$ e $700^{\circ} \mathrm{C}$.

- Nas ligas do sistema binário U-Nb, para seção isotérmica $700 \stackrel{\circ}{\circ}$, as composições estudadas mostram-se sobre um campo bifásico de estabilidade das fases $\gamma_{1}$ e $\gamma_{3}$ (vide Figura 26). $O$ resultado ressalta a forte influência deste 
elemento na cinética de transformação da fase U-y. Além disso, é verificada uma progressiva contração do parâmetro de rede da fase U-y com o aumento da porcentagem de nióbio (vide Tabela 13). Isto sugere a ocupação de sítios preferenciais pelo elemento $\mathrm{Nb}$ nesta estrutura. Destaca-se ainda nos resultados deste sistema binário o difratograma obtido para a liga U-10Nb (vide Figura 27), que apresentou uma elevado alargamento dos picos. Este alargamento indica uma possível retenção da fase $\gamma^{\circ}$, que é tetragonal. Aqui faz-se necessária análise com microscópio de luz polarizada para distinção de fase retida.

- Para as ligas ternárias de composição U-7,5Nb-7,5Zr e U-10Nb-10Zr verificou-se para a temperatura $700{ }^{\circ} \mathrm{C}$ a presença somente de fase metaestável $\gamma$. Este resultado destaca a forte influência conjunta desses elementos na estabilidade da fase metaestável U- $\mathrm{\gamma}$, como também a influência dos elementos $\mathrm{Nb}$ e $\mathrm{Zr}$ na redução da extensão dos domos de imiscibilidades presentes nos respectivos sistemas U-Zr e U-Nb.

Os resultados obtidos deixam evidente que a temperatura de transformação martensítica $M_{s}$ da fase $\alpha$ ' para ligas do sistema U-Nb-Zr no canto rico em urânio diminui com o a aumento de porcentagem de elemento inserido. Esta temperatura intercepta a temperatura ambiente entre as composições U-5Nb-5Zr e U-7,5Nb-7,5Zr, em concordância com trabalhos anteriores (D'AMATO; SARACENO; WILSON, 1964; DWIGHT; MUELLER 1956).

A ocorrência da fase martensítica $\alpha$ ' para as ligas binárias do sistema U-Zr, para as quais é célebre a ocorrência de campo $\gamma_{1}+\gamma_{2}$ possibilita a conclusão de que ambas as fase $y$ e $\beta$ tendem a sofrer transformação martensítica gerando $\alpha$ '.

Como a formação de $\alpha$ ' a partir da fase $\mathrm{y}$ ocorre por meio da formação de fases intermediárias seguindo a sequência $\gamma \rightarrow \gamma^{\circ} \rightarrow \alpha$ "' $\rightarrow \alpha$, sendo que a fase $\alpha$ " pode se transformar em $\alpha$ ' através de pequena deformação (devido à semelhança estrutural) é esperado para esta transformação uma variação volumétrica da célula unitária menor do que a gerada pela transformação $\beta \rightarrow \alpha^{\prime}$ (BASAK et al., 2009). Este fato aliado à diferença no nível de saturação da fase a' gerada pode servir para identificação da fase precedente a $\alpha$ '. No presente trabalho esta distinção é facilitada pelo fato de ter-se 
trabalhado com composições no sistema U-Zr muito distantes da região de estabilidade da fase $\beta$, sendo somente possível a transformação $\beta \rightarrow \alpha^{\prime}$ para as ligas ternárias de composição U-2,5Nb-2,5Zr e U-5Nb-5Zr.

Com relação aos resultados obtidos para a seção isotérmica a $500{ }^{\circ} \mathrm{C}$ sobressaem-se os fatos discutidos em seguida:

Todas as composições de ligas ternárias estudadas se apresentaram sobre um campo bifásico de $\alpha+\gamma$ na secção isoterma $500{ }^{\circ} \mathrm{C}$ (vide Figuras 28 e 29 e Tabela 15). Foi obtido o seguinte percentual de fases para a liga ternária de maior composição U-10Nb-10Zr: $50,1 \%$ de fase $U$ - $\alpha$ e $49,9 \%$ de fase $U-y$. A morfologia observada para a fase $\alpha$ foi em geral uma distribuição homogênea ao redor dos grãos. Isto evidencia a ocorrência de mecanismo de nucleação e crescimento, para a formação desta fase. Essa configuração é de especial interesse para a questão da instabilidade do urânio sob alternância térmica, já que é relatado na literatura, que amostras de urânio com rede contínua de segunda fase não apresentaram enrugamento (GENTILE, 1971). Esse resultado sugere que o mecanismo de crescimento sob alternância térmica é dependente da interação entre grãos.

- Para a liga ternária U-7,5Nb-7,5Zr (vide Figura 28), a morfologia observada da fase $\alpha$ apresentou uma distribuição fina sobre a matriz. Este fato pode ser uma consequência da existência de vales monotetóides no sistema ternário U-Nb-Zr. O que se pode afirmar é que esta liga encontra-se dentro da região de crescimento conjunto. São dois os principais tipos de região de crescimento conjunto, no primeiro a região não inclui a composição monotetóides. Já no segundo, tem-se incluída essa composição. Ambas diferenciam-se pela inclinação da linha de separação das fases com relação à isoterma monotetóides, sendo o primeiro notado principalmente para grandes diferenças. Um estudo mais profundo sobre o sistema U-Nb-Zr será necessário para averiguar em qual dos casos o sistema se enquadra, possibilitando a localização mais exata deste vale monotetóides.

- As ligas binárias do sistema U-Nb apresentaram-se compostas principalmente de fase $\alpha+\gamma$. Para a liga $U-20 N b$ foi observada uma distribuição não 
homogênea (vide Figura 28), apresentando forte tendência à precipitação ao redor dos grãos colunares.

- Todas as ligas do sistema binário U-Zr estudadas apresentaram as fases $\alpha+\gamma_{2}$ (vide Figuras 28, 29 e Tabela 15), não sendo observada a presença da fase intermetálica $\delta$. Esta fase, de composição nominal $U Z_{2}$, é resultante da reação peritetóide $\alpha+\gamma_{2} \rightarrow \delta$ no canto rico em urânio, sendo esperada segundo o diagrama de fases. Este resultado indica que a reação de estado sólido $\alpha+\gamma_{2} \rightarrow \delta$, ocorre de modo muito lento na natureza, não sendo obtida para $o$ tempo de recozimento utilizado, em concordância com trabalhos recentes (BASAK et al., 2009).

Considerando somente os resultados obtidos, é apresentado aqui um resumo esquemático para as fases encontradas para as secções isotérmicas $700 \stackrel{\circ}{\circ}$ e $500 \stackrel{\circ}{C}$ para o sistema ternário U-Nb-Zr no canto rico em urânio.

A partir dos resultados é possível especificar uma região de possíveis composições para combustível nuclear de alta densidade tipo placa. Fica evidente que uma quantidade mínima de $7,5 \%$ de nióbio é necessária para retenção da fase metaestável $\gamma$. Mostra-se também que a estabilidade da fase gama é mais facilmente obtida para regiões próximas à face $\mathrm{U}-\mathrm{Nb}$, daí concluiu- se que as ligas do sistema U-Nb-Zr, no canto rico em urânio para aplicação como combustível, devem possuir maior quantidade do elemento $\mathrm{Nb}$ que $\mathrm{Zr}$. 


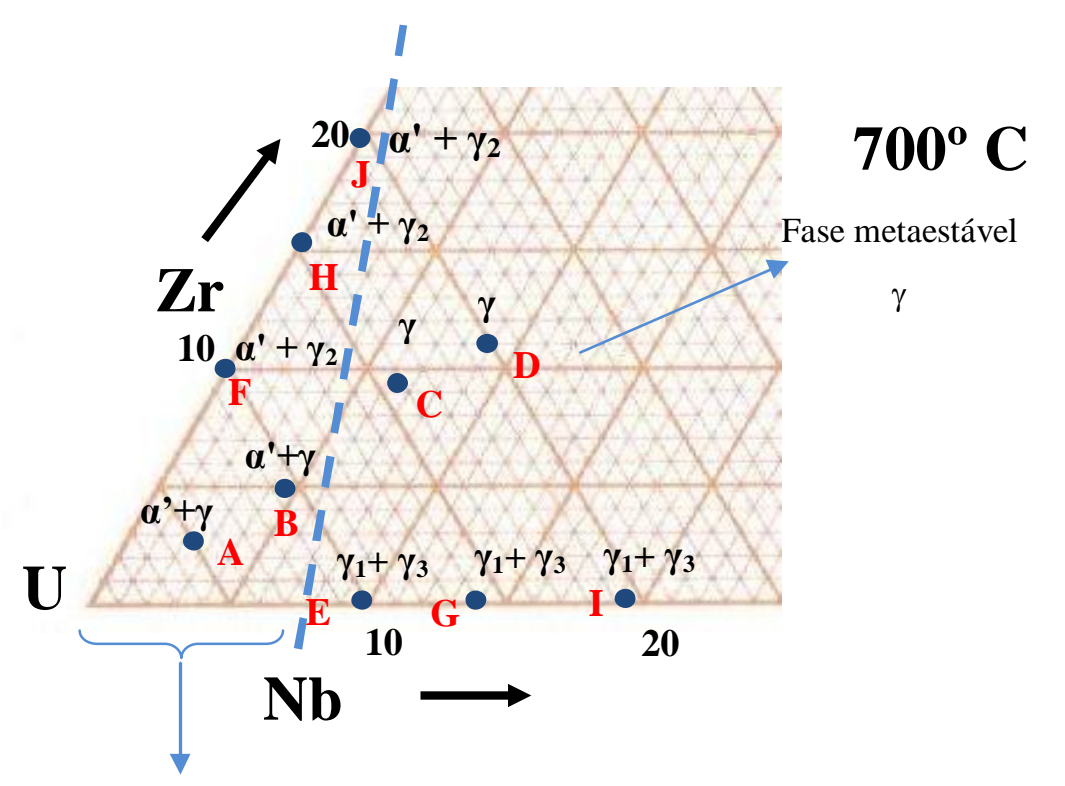

A - Liga nominal U-2,5Nb-2,5Zr

B - Liga nominal U-5Nb-5Zr

C - Liga nominal U-7,5Nb-7,5Zr

D - Liga nominal U-10Nb-10Zr

$\mathrm{E}$ - Liga nominal U-10Nb

$\mathrm{F}$ - Liga nominal U-10Zr

$\mathrm{G}$ - Liga nominal U-15Nb

$\mathrm{H}$ - Liga nominal U-15Zr

I - Liga nominal U-20Nb

$\mathrm{J}$ - Liga nominal U-20Zr

Martensita $\alpha^{\prime}$

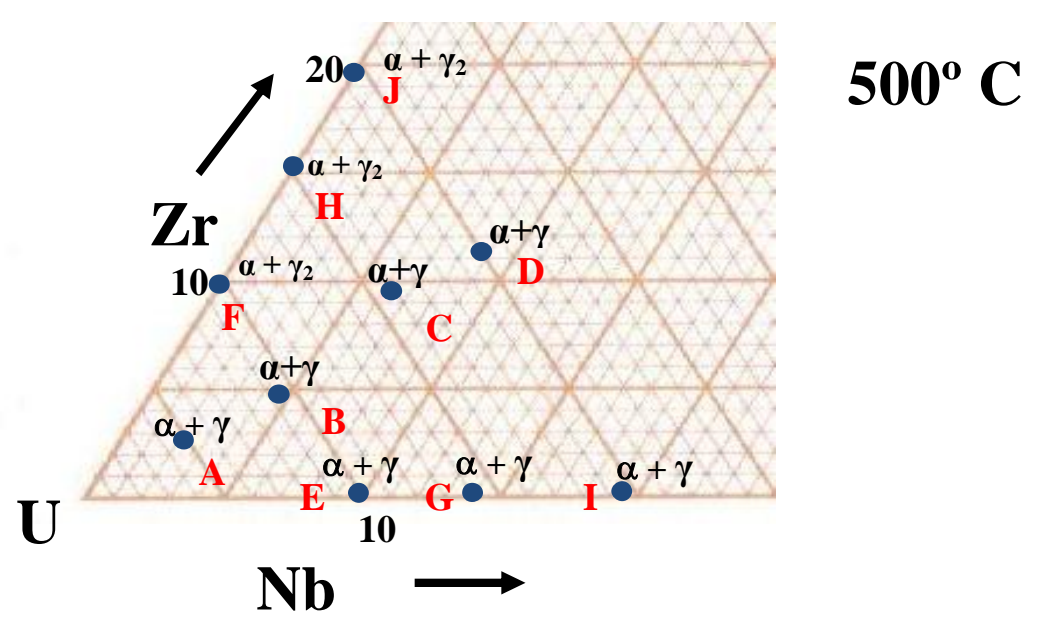

Figura 33: Posicionamento das ligas com base na análise química sobre um canto do triângulo de Gibbs, juntamente com resumo esquemático das fases encontradas nos respectivos cortes isotérmicos $700 \stackrel{\circ}{\mathrm{C}}$ e $500 \stackrel{\circ}{ } \mathrm{C}$.

A seguir são apresentados gráficos de contorno de superfícies dos valores de dureza. Os gráficos foram obtidos utilizando-se os valores medidos via ensaio de dureza Vickers. É feita uma prospecção para as temperaturas e composições intermediárias às estudadas nesta dissertação. Nos gráficos, é possível visualizar o efeito da temperatura de envelhecimento e da estrutura formada na propriedade de dureza. 


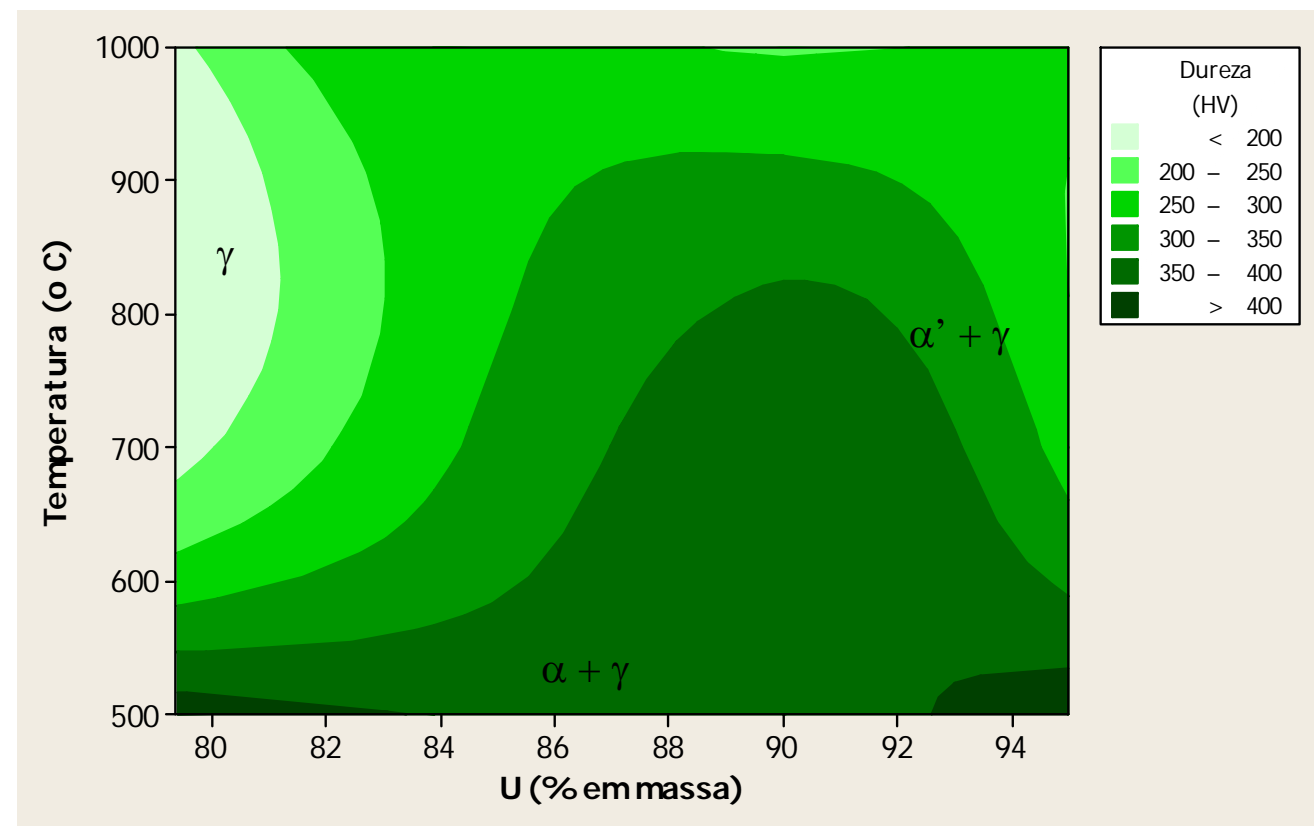

Figura 34: Gráfico contorno de superfície dos valores de dureza para as ligas ternárias.

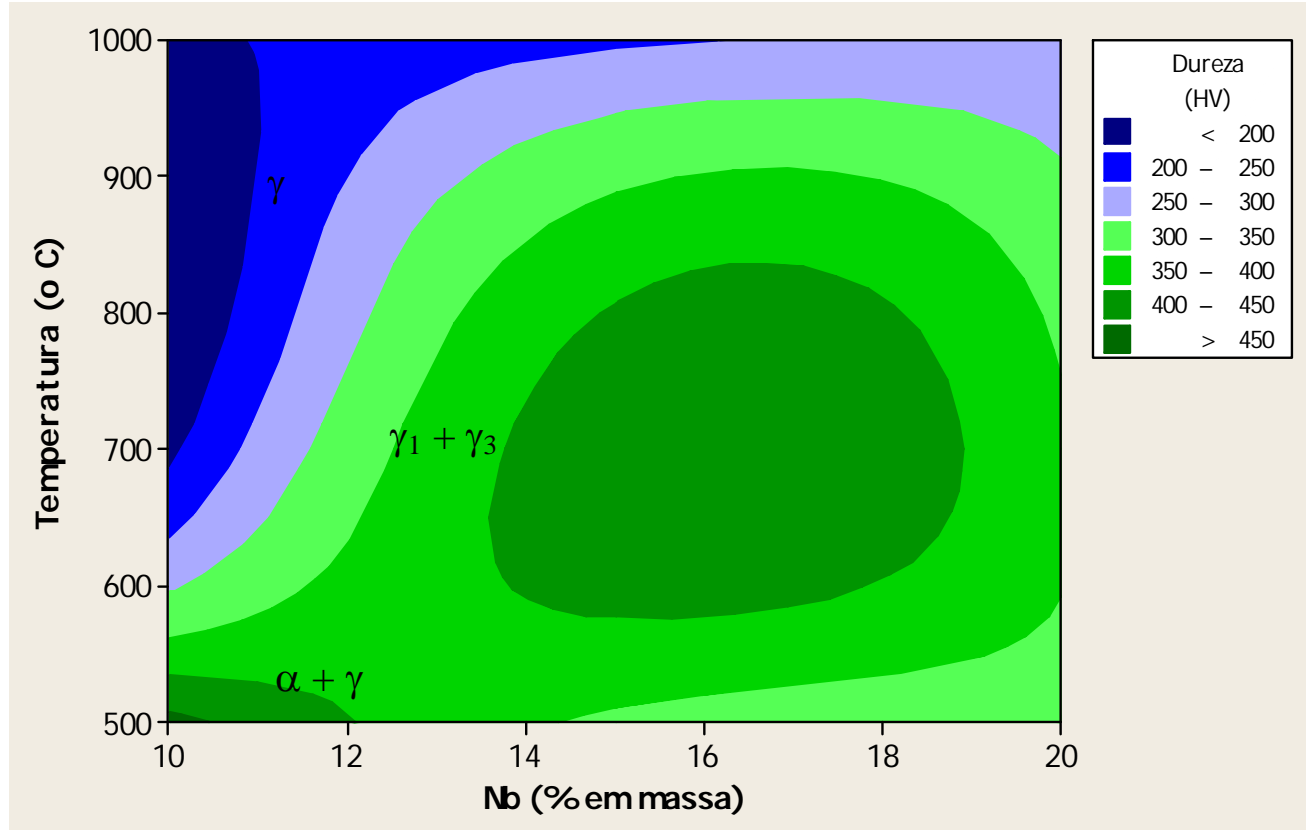

Figura 35: Gráfico contorno de superfície dos valores de dureza para as ligas binárias do sistema U-Nb. 


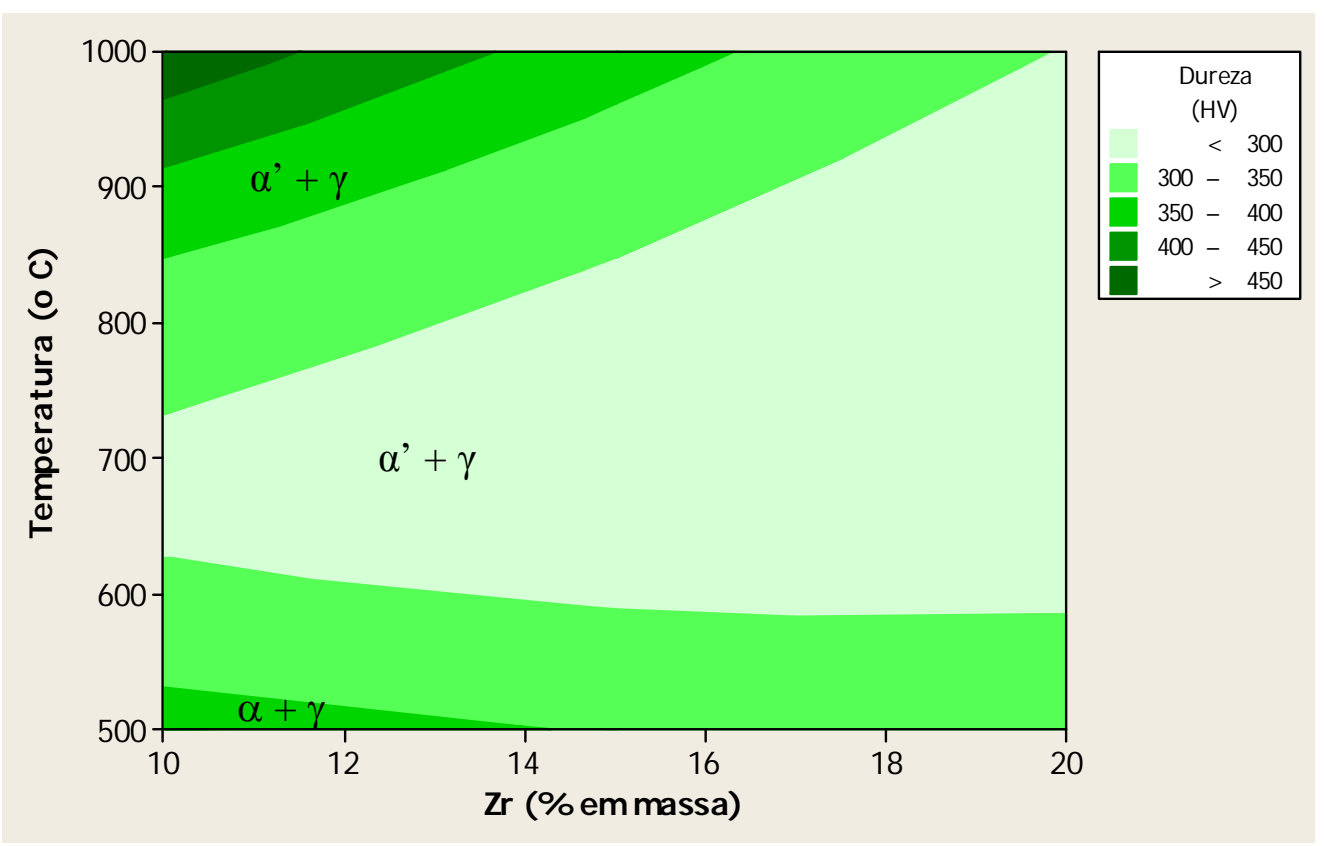

Figura 36: Gráfico contorno de superfície dos valores de dureza para as ligas binárias do sistema U-Zr.

Pode-se observar que para as faixas de estabilidade da fase alotrópica U- $a$ do urânio e nas regiões de ocorrência da fase martensítica $\alpha^{\prime}$, ocorrem os máximos valores de dureza.

Nas ligas ternárias, observa-se um pico nos valores de dureza para a isoterma $700{ }^{\circ} \mathrm{C}$ na faixa de composição entre U-2,5Nb-2,5Zr e U-5Nb-5Zr. Prevalece nesta faixa a ocorrência da fase martensitica $\alpha^{\prime}$ (vide Figura 34). Entretanto, para as ligas que apresentaram retenção da fase metaestável U- $\gamma$, obteve-se valores de dureza inferiores a $200 \mathrm{HV}$.

No que se refere aos valores observados para as ligas do sistema binário U-Nb destaca-se dois fatos importantes: a) nas isotermas $700{ }^{\circ} \mathrm{C}$ e $1000{ }^{\circ} \mathrm{C}$ (onde ocorre predominância da fase metaestável y) é possível observar somente a influência do elemento $\mathrm{Nb}$ na dureza, o que se observa é que a adição deste causa um aumento nesta propriedade. A possível causa é a grande contração que este elemento gera na estrutura y do urânio, oriunda da ocupação ordenada nesta estrutura. b) na isoterma de $500 \stackrel{\circ}{ }{ }^{\circ}$ (onde ocorre à estabilidade da fase $\alpha$ ) é possível verificar a redução dos valores de dureza com o aumento na porcentagem de $\mathrm{Nb}$. Este fato está associado à maior 
quantidade de fase gama retida. Conclui-se que a presença da fase a influi mais fortemente no valor desta propriedade mecânica que a distorção causada pela adição do elemento $\mathrm{Nb}$ (vide Figura 35).

O gráfico (vide Figura 36) observado para as ligas do sistema U-Zr mostra que a adição deste elemento diminui os valores de dureza, com valores mínimos para a região de $700 \stackrel{\circ}{\circ}$ (vide Figura 36 ). Este comportamento não se difere muito de trabalhos anteriores (FOOTE, 1955). Entretanto, a diferença observada no parâmetro de dureza para as temperaturas $1000{ }^{\circ} \mathrm{C}$ e $700{ }^{\circ} \mathrm{C}$ (já que ambas apresentam fase martensítica $\alpha^{\prime}$ ) pode estar associada à mudança na estrutura $\alpha$ ' conforme a taxa de resfriamento. Para taxas mais rápidas é esperado um progressivo aumento no volume da célula unitária e consequentemente, a obtenção de uma célula com uma maior quantidade de tensões inseridas. Ainda é relatado na literatura, que para teores mais altos de zircônio (na faixa de composições de estabilidade da fase $\delta$ ), ocorre um segundo máximo deste parâmetro (WILKINSON, Vol II, 1962). A não ocorrência deste segundo pico está em concordância com as análises metalográficas e de difração de raios $X$, pois não foi verificada a presença da fase intermetálica $\delta$.

Os resultados evidenciam a maior eficácia do uso conjunto dos elementos $\mathrm{Nb}$ e Zr para obtenção de menores valores de dureza, ressaltando assim potencialidade do sistema ternário U-Nb-Zr para aplicação como combustível nuclear tipo placa. Ressalta-se ainda que é necessária muita atenção à porcentagem de elementos de liga inseridas, quando se tem por objetivo melhores propriedades mecânicas, já que este comportamento não é dependente apenas da composição, mas também de tratamentos térmicos aplicados posteriormente à peça fundida (WILKINSON, Vol. II, 1962). Do ponto de vista das propriedades mecânicas, a adição de elementos de liga mostra-se muito eficiente. Porém, do ponto de vista neutrônico, deve-se lembrar que existe um empecilho referente à secção de choque dos elementos de liga para reatores térmicos (LAMASH, 1982), pois o fluxo de nêutrons é relativamente pequeno e qualquer perda, que não a intrínseca ao projeto do reator, ocasiona uma diminuição do rendimento do mesmo. 


\section{CONCLUSÕES}

A presente dissertação teve como objetivo principal o estudo experimental do diagrama ternário U-Nb-Zr no canto rico em urânio, assim como também a obtenção de ligas que apresentem retenção da fase metaestável U- $\gamma$ na temperatura ambiente, para aplicação como combustível nuclear de alta densidade e baixo enriquecimento.

Conforme os objetivos propostos, as conclusões principais desta dissertação são apresentadas a seguir:

Ambas as fases $\beta$ e y sofrem transformação martensítica se apresentando como $\alpha$, a temperatura ambiente. Os resultados mostram que a temperatura de transformação martensítica $M_{s}$ da fase a' diminui com adição dos elementos de liga, sendo que ela intercepta a temperatura ambiente entre as composições U-5Nb-5Zr e U-7,5Nb-7,5Zr.

Verificou-se com a técnica de difração de raios $X$, que para o canto rico em urânio, sob as condições estudadas nesta dissertação, que a estrutura cristalina registrada para a fase martensítica $\alpha$ ' é basicamente estrutura da fase $U$ - $\alpha$ distorcida, com o mesmo grupo espacial $\mathrm{Cmcm}$. Foi verificado ainda que para as transições $Y \rightarrow \gamma^{0} \rightarrow \alpha^{\prime \prime} \rightarrow \alpha^{\prime}$ e $\quad \beta \rightarrow \alpha^{\prime}$ a estrutura formada apresenta variações conforme taxa de resfriamento. Não foram observadas para nenhuma composição aqui estudada, reflexões referentes à estrutura monoclínica que poderia indicar formação da fase martensítica $\alpha$ ". Aparentemente, esta fase é instável para o canto rico em urânio.

As ligas ternárias $\mathrm{U}-7,5 \mathrm{Nb}-7,5 \mathrm{Zr}$ e U-10Nb-10Zr, e binárias do sistema U-Nb, possuem quantidades suficientes de soluto para total retenção da fase metaestável $y$ nos patamares de $1000 \stackrel{\circ}{\circ}$ e $700 \stackrel{\circ}{\circ}$. Como decorrência deste fato, essas ligas definem uma região de possíveis composições para combustíveis nuclear de alta densidade tipo placa.

A partir dos resultados das ligas binárias pode-se verificar a influência distinta dos elementos de liga na cinética de decomposição de fases, sendo que o elemento $\mathrm{Nb}$ mostrou-se mais eficiente no retardo da decomposição da fase $U-\gamma$, apresentando total retenção desta fase já para a liga $\mathrm{U}-10 \mathrm{Nb}$. Por sua vez, o sistema binário U-Zr apresentou ainda a formação de fase martensítica a' para a liga de maior porcentagem 
em massa estudada (U-20Zr) confirmando o relatado na literatura, de que são necessários teores muito elevados de $\mathrm{Zr}$ para promover a mesma estabilidade obtida pelo elemento $\mathrm{Nb}$. A precipitação da fase $\mathrm{\gamma}_{3}$ nas amostras binárias do sistema U-Nb no estado bruto de fundição indica a maior extensão do domo de imicibilidade do sistema $\mathrm{U}-\mathrm{Nb}$ que do sistema U-Zr.

Outra conclusão a ser relatada aqui com relação ao sistema binário U-Zr é o fato de a reação do estado sólido $\alpha+\gamma_{2} \rightarrow \delta$, que gera a fase $\delta$, aparentemente ocorre de modo muito lento, não sendo obtida para os tempos de recozimento realizados neste trabalho.

No que tange aos resultados dos ensaios de dureza, observou-se valores máximos para as faixas de estabilidade da fase alotrópica do urânio $U$ - $\alpha$ e regiões de ocorrência da fase martensítica $\alpha$ '. As ligas que apresentaram total retenção da fase metaestável y apresentaram valores relativamente baixos deste parâmetro, sendo obtidos os menores valores para as ligas ternárias, que mostram-se promissoras para aplicações que exigem conformação mecânica. 


\section{REFERÊNCIAS}

ANAGNOSTIDIS, M., BASCHWITZ, R., COLOMBIE, M. Metastable phases in uraniumtitanium alloys. M. Mem. Sci. Rev. Metall. v. 63, p.163-168, 1966.

ASM Handbook, Volume 2: Properties and selction: Nonferrous alloys and specialpurpose materials, Ohio, USA, 1992.

ASM Handbook Volume 3: Alloy Phase Diagrams. Ohio, USA, 1992

ASM Handbook Volume 9: Metallography and Microestructure: Uranium and uranium alloys: Techniques and microestructure. Ohio, USA, 1992.

ASM Handbook Volume 15: Casting. Ohio, USA, 1992.

BASAK, C., KESWANI, R., PRASAD, G. J., KAMATH, H. S., PRABHU, N., GANARJEE, S. Phase transformation in U-2\%wtZr alloy. Jounal of Nuclear Materials, v. 471, p.544-552, 2009.

BLUMENTHAI, B. Constitution of low carbon U-C Alloys. ANL-5958, 1959.

BROPHY, J. H., ROSE, R. M., WULLFF, J. The structure and properties of materials - V. II -Thermodynamics of Structure. John Willey \& Sons. New York, 1964.

CAHN, R. W., hAASEN, P., KRAMER, E. J., FROST, B. Materials science and technology - a comprehensive treatment. Editora: $\mathrm{VCH}$ VerlagsgesellschaftGmBH, Weinheim, v. 10A, p.1-40, 1994.

CHANDLER, J. A. X-ray microanalysis in the electron microscope. Editora: NorthHolland Publishing Company, New York, USA, p. 327-365, 1977. 
CHRISTIAN, J. W. The theory of transformation in metals and alloys. Pergamon Press, $1^{\text {a }}$ edição, New York, 1965.

COLOMBIE, M., DECOURS, J., FOURE, M. e MAGNIER, P. Observations complementaires sur l'affinage du grain de coulee d'alliages d'uranium. Influence de Faibles Additions - CEA-R-3529, 1968.

COLPAERT $\mathrm{H}$. Metalografia dos produtos siderúrgicos comuns. $4^{\mathrm{a}}$ Ed., Blucher, São Paulo, p. 180-206, 2008.

CTMSP. Conclusões sobre os estudos sobre combustível $\mathrm{U}_{2}$-aço inoxidável no workshop sobre combustíveis tipo placa. Relatório interno, 2000.

CTMSP. Internos do reator do laboratório de geração núcleo-elétrica. Boletim Interno, 4. São Paulo, 2005.

CULLITY B. D. Elements of X-ray diffraction. Addison-Wesley, Editora: Prentice Hall Ltda., $2^{a}$ edição, New Jersey, p. 1-96,1978.

D'AMATO, C. SARACENO, F. S., WILSON, T.B. Phase transformation and equibrium structure in uranium-rich niobium alloys. Journal Nuclear Materials, v. 12 , p. 291-304, 1964.

DRALEY, J.E., GREENBERG, S., RUTHER, W. E. The hight-temperature aqueous corrosion of uranium alloys containing minor amounts of Niobium and Zirconium. ANL-5530, 1957.

DWIGHT, A. E., MUELLER, M. H. Constituition of the uranium-rich U-Nb and U-NbZr systems. ANL-5581. Illinois. 1956. 
EG\&G. Health physics manual of good practice for uranium facilities. UC-41, NTIS DE88-013620, 1988.

EWH, A., PEREZ, E., KEISER, D.D., SOHN, Y. H. Microstructural characterization of U$\mathrm{Nb}-\mathrm{Zr}$, U-Mo-Nb and U-Mo-Ti Alloys via Electron Microscopy. Jounal of Phase Equilibria and Diffusion, v. 31, p. 216-222, 2010.

FLEMINGS, M. C. Solidification processing. New York: McGraw-Hill, 1973.

FOOTE, F. G. Physical metallurgy of uranium. Proc. Intern. Conf., 9, v. 33, p. 555, 1955.

FROST B. R. T. Nuclear fuels elements. Editora: Reinhold Publishing Corporation, $1^{\text {a }}$ edição, New York, p. 01-75, 1959.

FROST, B. R. T. Nuclear fuels elements - Design, frabrication and performance, $1^{\mathrm{a}}$ Edição, Pergamon Press Inc., Oxford, GB, p. 1-49, 1982.

GALE W. F., TOTEMEIER, T.C. Smithells metals reference book. Editora: Butterworth-Heinemann, 8 a edição, USA, 2004. (ISBN 0-7506-7509-8).

GENTILE, E. F. Estudo sobre a instabilidade dimensional do urânio metálico sujeito a alternância térmica. Dissertação (Mestrado em Engenharia) São Paulo: Escola Politécnica da Universidade de São Paulo, 1971.

GOLDSTEIN, J. Scanning electron microscopy and x-ray microanalysis . Editora: Springer-Verlag, $3^{\mathrm{a}}$ edição, 2003.

HARRINGTON, C. D., RUEHLE, A. E. Uranium production technology. Editora: D. Van Nostrand Co. Inc, $1^{\text {a }}$ edição, New York, p. 245-381 294-349, 1959. 
HENDERSON, M. D. Evaluation of radiation in metal preparation depleted uranium process areas, Y/DQ-5, Martin Marietta Energy Systems, Inc., 1989.

HILLS, R.F., BUTCHER, B.R., HOWLETT, B. W. The effect of cooling rate on the decomposition of the $\mathrm{Y}$-phase in uranium-zirconium alloys. Journal of Nuclear Materials, v.16, p. 25-38, 1965.

hOFMAN, G. L., SNELGROVE, J. L. Dispersion fuels. In: R. W. Cahn; P. Haasen. Materials science and technology - a comprehensive treatment. New York: B.R.T. FROST. v. 10A, Nuclear Materials, Part I. 1997.

HOLDEN, A. N. The isothermal transformation of metastable beta-uranium single crystals,. Acta Matallurgica v.1 p. 617-623, 1953.

HOLDEN, A. N. Physical metallurgy of uranium. Addison-Wesley Publishing Co. Capitulo 3, p. 27-29, 1958.

IAEA-TECDOC-2374. Development status of metallic. dispersion and non-oxide advanced and alternative fuels for power and research reactors. Vienna, Austria: International Atomic Energy Agency, 2003.

IVANOV, O. S., BADAJA, T. A. Phase diagrams of certain ternary systems of uranium and thorium. Proc. 2nd Intern. Conf., 6, p. 2043, v. 139, 1958.

KAUFMANN, ALBERT R. Nuclear reactor fuel elements - Metallurgy and fabriation, Capitulo 3, Klein, J.L., Uranium and Its Alloys, editora John Wiley \& Sons, New York, 1962.

KOPELMAN, B. Fundamental considerations in the reduction processes of thorium and uranium. Proc. Intern. Conf., 8 p. 531, v. 175, 1955. 
KOPELMAN, B. Materials for nuclear reactors. London: McGraw-Hill Book Company, Inc, 1959.

KUBASCHEWSKI, O., ALCOCK, C. B. Metallurgical thermochemistry. Editora: Pergamon Press, $5^{a}$ edição, 1979.

KULIN, P. A., J. De Avellar, and R. Jekins. The preparation of uranium alloys of high density and high hardness, AD-44620, 1954.

KUMMERER, K. Werkstoffe der kerntechnik, G. Braun, Karlsruhe, 1980.

LAMARSH, J. R. Introduction to Nuclear Engineering. $2^{\circ}$ edição. Editora: AddisonWesley Publishing Co., New York, p. 45-48, 102-103, 103-110, 111, 117, 118, 125, 275, 1982.

LARSON, A. C., VON DREELE, R. B. General structure analysis system (GSAS). Los Alamos National Laboratory Report, 2004.

LEHMANN, W., HILLS, R. F. Proposed nomeclature for phase in uranium alloys. Journal Nuclear Material, v. 2, p. 261-268, 1960.

MAGNIER, P. Affinage de grain a et etude metallurgique de i'alliage d'uranium, sicral F 1. pour Elements Combustibles. CEA Ft 3905, p. 4, 1969.

MASH, D. R., DISSELHORST J. F. Uranium-Zirconium diffusion studies. AECD-3701, 1955.

McWHIRTE, J. W. e DRALEY, J. E. Aqueous corrosion of uranium and alloys: Survey of project lierature, ANL-4862, 1952. 
MEYER, M. K., HOFMAN, G. L., WIENCEK, T. C., HAYES, S. L., SNELGROVE, J. L. Irradiation behavior of $\mathrm{U}-\mathrm{Nb}-\mathrm{Zr}$ alloy dispersed in aluminum. Journal of Nuclear Materials, v. 299, p. 175-179, 2001.

NOVIKOV, ILIA. Teoria dos tratamentos térmicos dos metais. Editora UFRJ, 1994.

OHNO M. High Resolution M X-Ray Emission Spectrum of MetallicUranium ( $Z=92$ ). Physica Scripta. v. 34, p.146-150, 1986.

OKAMOTO, H. Phase Diagram Updates. Jounal Phase Equilibria. v. 13, 1992.

PADILHA, A. F., AMBROZIO FILHO, F. Técnicas de análise microestrutural. São Paulo, Hemus Livraria, Distribuidora e Editora, Reimpressão, 2004.

Radiological Health Handbook, U.S. Department of Health, Education, and Welfare, Public Health Service, Food and Drug Administration, Bureau of Radiological Health, Rockville, MD, 1970.

RIOS, P. R.; PADILHA, A. F. Transformações de fases. Editora: Artliber, 1ª edição, São Paulo, 2007.

RUGGIERO, M. A. G., LOPES, V. L. R. Cálculo numérico, aspectos teóricos e computacionais. Editora: McGraw-Hill, Campinas, 1997.

SHOBER, F. R., MARSH, L. L., MUEHLENKAMP. Development of dimensionally stable uranium alloys. BMI-961, p. 12-21, Ohio, 1954.

SMITH, C. O. Nuclear reactor materials. Editora: Addison-Wesley, London, 1967.

SNelgrove, J., hOFMAN, G. L., MeYer, TRYBU, C. L. E WIENCENK, T. C. Proceedings of the $18^{\text {th }}$ International Meeting on RERTR. Seoul, Korea, 1996. 
SOUZA, S. A de. Ensaios mecânicos de materiais metálicos. Editora: Edgard Blücher Ltda., 5ª edição, São Paulo, p. 103-137, 1982.

TANGRI, K., CHAUDHURI, D. K. Metastable phase in uranium alloys with high solute solubility in the BBC gamma phase. Part I - The system U-Nb. Journal of Nuclear Materials, v. $15 n^{\circ} 4$, p. 278-287, 1965.

TANGRI, K., WILLIAMS, G. I. Metastable phase in the uranium - Molybdenum system and their origin. Journal of Nuclear Materials, v.2, p.226-233, 1961.

TOTEMEIER, T. C. A Review of the corrosion and pyrophoricity behavior of uranium and plutonium. Argonne National Laboratory. 1995.

VON HIPPEL, FRANK; CHUNYAN MA, Ending the production fo highly enriched uranium for naval reactors. The Non Proliferation Review / Spring, p. 86-101, 2001.

WILKINSON W. D. Uranium metallurgy Vol. I. Editora: Interscience Publishers, $1^{a}$ edição, New York, p. 02-217, 1962.

WILKINSON, W. D. Uranium metallurgy Vol. II. Editora: Interscience Publishers, $1^{\mathrm{a}}$ edição, New York, USA, p. 867-1261, 1962.

WILLIAMS, R. O. Stability of the body-centered cubic gamma phase in the uraniumzirconium-niobium system. Journal of Nuclear Materials, v.82, p. 184-192, 1979.

YAKEL, H. L. Cristal structure of transition phases formed in $\mathrm{U} / 16$ at $\% \mathrm{Nb} / 5.64 \mathrm{at} \% \mathrm{Zr}$ alloys. Journal of Nuclear Materials, v. 33, p. 286-295, 1969.

YEMELYANOV V. S., YEVSTYUKHIN, A. I. The metallurgy of nuclear fuel. Editora: Pergamon Press, London, 1969. 
YOUNG, R. A. The rietveld method. Editora: Oxford University Press, New York, 1995. 